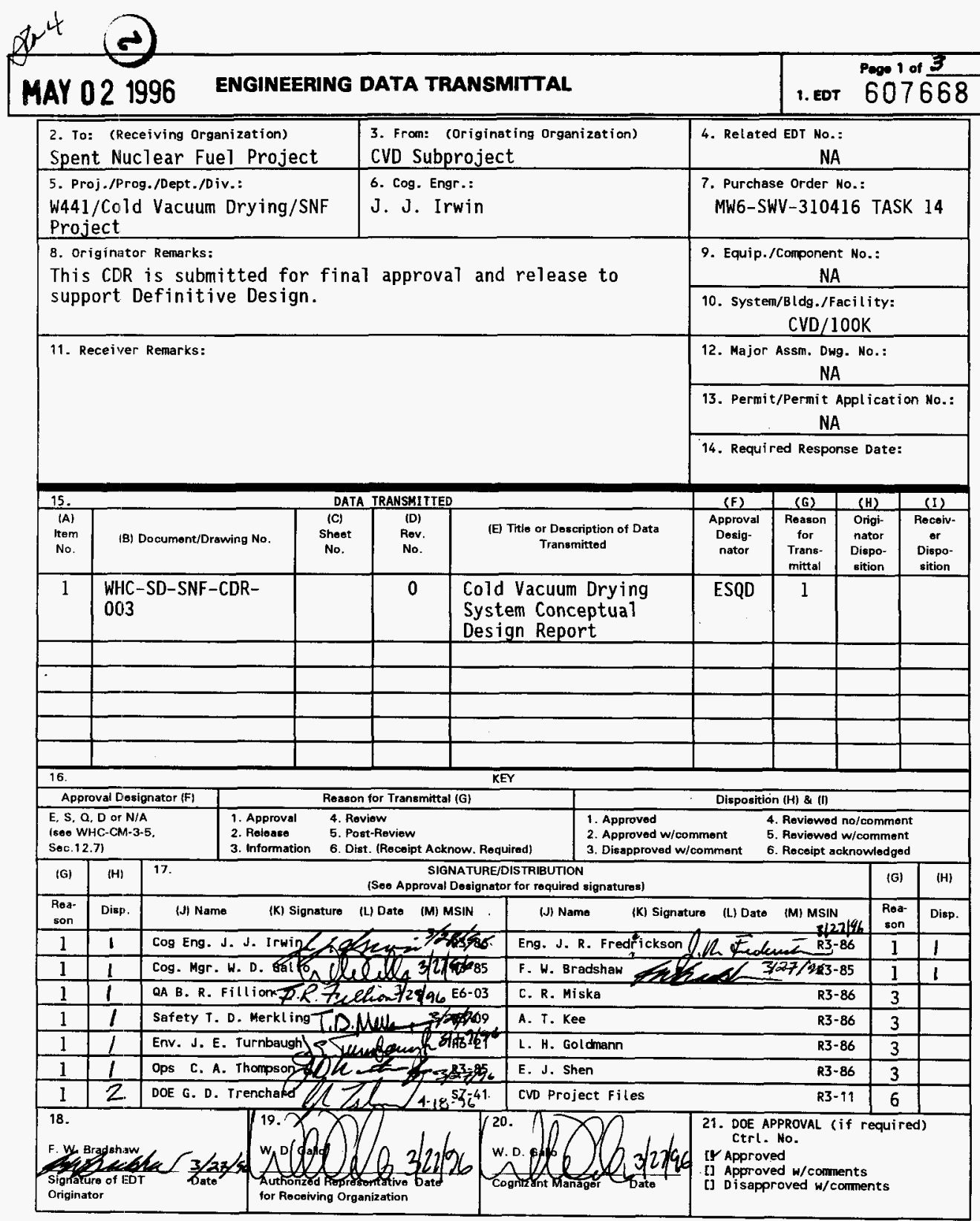

BD-7400-172-2 (04/94) GEF097 
DOE Comments to Cold Vacuum Drying System Conceptual Design Report, WHC-SD-SNF-CDR-003

1. This facility should be as simple, temporary, and inexpensive as possible. Any function that could be provided outside of the facility and could be used somewhere else after the two year design life of this building is desirable. If the office space, conference room, bathrooms, change rooms, etc. were in trailers or other transportable modules, they could be used again el sewhere. This creates some salvage value, while minimizing decommissioning costs. This would save money as well as work to address stakeholder concerns?

2. The construction labor costs seem low. Workers at Hanford can not be obtained this inexpensively. Are these construction industry standard numbers?

3. The weld location issue must be solved and its impacts factored in as soon as possible.

4. Although it is proper to use $500 \mathrm{mR} / \mathrm{yr}$ as an exposure limit for the CDR, WHC should consider extending this for actual operation.

5. Deactivation and Decommissioning should be addressed in a CDR. That feature is not addressed adequately here. At least, cost estimates should be provided.

6. Intro, page 3 - This discusses that Cat 3 is assumed based on the fuel being contained in the cask and MCO. It will not be contained in the cask while in the CVD facility and may not even be contained within the MCO (if welding is not yet done).

7. Sect 1, page 3 - It is stated that CVD cannot have a credible offsite release $>25$ rem even if unmitigated. Is this statement true if the river is considered the site boundary? Since the definition of the site boundary is under debate, this should be addressed.

8. Sect 2, page 8 , item 69 - This assumes that any leak is caused by quick connection problems and iterates back through replacing them. Is this not a check of the weld al so? How do you know the leak is not through a weld, and if it is what would be done - certainly not just replace quick connections?

9. Sect 2, page 11 - The reasoning given does not seem to add up to as many as six bays. This number should be closely looked at for optimization.

10. Sect 2, page 18 and drawing SK-1-80140 - Will the ion exchange column be able to handle water at 75 degrees $C$ ? Since we' re allowing water up to $75 \mathrm{C}$, this must be considered.

11. Sect 2, page 23 - What does MO mean when describing backup drive for the PC system? 
12. Sect 2 , page 26 - This discusses a table of interfaces with other subprojects. This table could not be found anywhere in the package.

13. Sect 3, page 1 - It seems like it would make more sense logistically to modify the fence so construction occurs outside the fence and then the fence would be moved around the facility for operation. This minimizes security impacts on construction crews.

14. Sect 3, page 5 - As discussed previously, the need for an administrative area for a two year facility appears to be unwarranted.

15. Sect 3 , page 8 - Are any other natural phenomena hazards (flood, wind, etc.) considered in the CDR?

16. Sect 3, page 19 - Section 3.4.1.2.17 is the first place QA is mentioned. Under 10 CFR 830.120, CVD must have a QA plan approved by DOE. Has this been prepared? What is the schedule if not?

17. Attach 2, pages 2 through 7 - The cask will not be DoT certified. This is an incorrect assumption.

18. Attach 2, page 20, item 16 - QAP per 10CFR 830.120 is sti11 required, even if we take our pedigree from $5700.6 \mathrm{C}$.

19. Attach 7 , section 6.0 - Hopefully the ORR will be subsumed into a SNF ORR being planned.

20. The cost estimate package provided with the CDR does not include any escalation. Is any planned? 


\title{
Cold Vacuum Drying System Conceptual Design Report
}

\author{
F. W. Bradshaw
}

Westinghouse Hanford Company, Richland, WA 99352

U.S. Department of Energy Contract DE-AC06-87RL10930
EDT/ECN: 607668
UC: 2000
Org Code: 5B400
B\&R Code: EW3135040
Charge Code: 1 H030
Total Pages: 379348
Fink.

Key Words: Cold Vacuum Drying, CVD, SNF Project, CSB, SNF

Abstract:

TRADEMARK DISCLAIMER. Reference herein to any specific commercial product, process, or service by trade name, trademark, manufacturer, or otherwise, does not necessarily constitute or imply its endorsement, recommendation, or favoring by the United States Government or any agency thereof or its contractors or subcontractors.

Printed in the United States of America. To obtain copies of this document, contact: WHC/BCS

Document Control Services, P.O. Box 1970, Mailstop H6-08, Richland wA 99352, Phone (509) 372-2420;

Fax (509) 376-4989.
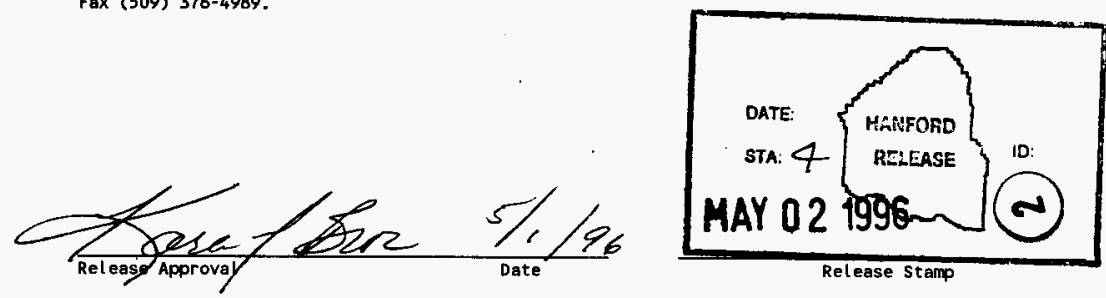

Approved for Public Release 
WHC-SD-SNF-CDR-003, Revision 0

TABLE OF CONTENTS

\subsection{INTRODUCTION}
1.1
Background
1.2
Overview of the Cold Vacuum Drying System

\subsection{PROCESS DESIGN}

2.1 Overall Process Sequence Description

2.1.1 Overall Block Flow Diagram Description

2.1.2 Time and Motion Model Description

2.2 Vacuum/Gas Purge System Design Description

2.2.1 System Function

2.2.2 System Design Requirements

2.2 .3

2.2.4

2.2 .5

2.2.5.1

2.2.5.2

Equipment Arrangement and Design Description

2.2.5.3

2.2.5.4

2.2.5.5

System Limitations, Accident Scenarios, and Response to Accidents Operation

Water Drainage

Evacuation

Once Through Gas Flow

Circulated Gas Flow

Maintenance

MCO Temperature Control

Heat Transfer Estimates

System Design Description

2.3.2.3.1

2.3.2.3.2

System Function

System Design Requirements

2.3.2.3.3

Equipment Arrangement and Design Description

Water Heater

Water Cooler

2.3.2.3.4

Ion Exchange Column

2.3.2.4

2.3.2.4.1

2.3.2.4.2

2.3.2.4.3

2.3.2.5

Pumps

Operation

MCO Heating

MCO Cooling

lon Exchange

Maintenance 
WHC-SD-SNF-CDR-003, Revision 0

TABLE OF CONTENTS

$\begin{array}{ll}2.4 .4 & \text { Operation } \\ 2.4 .4 .1 & \text { MCO Bulk Liquid Draining } \\ 2.4 .4 .2 & \text { Other Liquids } \\ 2.4 .5 & \text { Maintenance } \\ 2.5 & \text { Solid Waste Disposal } \\ 2.6 & \text { Process Control SDD } \\ 2.6 .1 & \text { Control System Design } \\ 2.6 .2 & \text { Visual Monitoring } \\ 2.6 .3 & \text { Programmable Logic Controllers } \\ 2.7 & \text { System Design Description } \\ 2.7 .1 & \text { System Function } \\ 2.7 .2 & \text { System Design Requirements } \\ 2.7 .3 & \text { Equipment Arrangement and Design Description } \\ 2.8 & \text { Process Interfaces }\end{array}$

\subsection{FACILITY DESIGN}

3.1 Site Description

3.1.1

Site Development

3.1.1.1

3.1.1.2

3.1 .1 .3

3.1.2

3.1.2.1

3.1 .2 .2

3.1.2.3

Site Area and Access

Site Grading

Landscaping

Site Utilities

Sanitary Water

3.1.2.3.1

Fire Protection Water

Liquid Systems

3.1.2.3.2

Basin Water

3.1.2.3.3

Fire Water Collection

Sanitary Sewage Collection

3.2

3.2 .1

3.2 .2

3.2.2.1

3.2.2.2

3.2 .2 .3

3.2.2.4

Building System SDD

General

Process Bays

Process Bay Space Requirements

Process Bay Support Areas

Decontamination Room

3.2.2.5

Swipe/Count Room

Process Water Tank Room 
WHC-SD-SNF-CDR-003, Revision 0

TABLE OF CONTENTS

3.2.2.6 Miscellaneous Materials Storage Room

3.2.2.7 Equipment Storage Room

3.2 .3

3.2.3.1

3.2.3.2

3.2.3.3

3.2.3.4

3.2.3.5

3.2.3.6

3.2.3.7

3.2.3.8

3.2.3.9

3.3

3.4

3.4 .1

3.4.1.1

3.4 .1 .2

3.4.1.2.1

3.4.1.2.2

3.4.1.2.3

3.4.1.2.4

3.4 .1 .2 .5

3.4.1.2.6

3.4.1.2.7

3.4.1.2.8

3.4.1.2.9

3.4.1.2.10

3.4.1.2.11

3.4.1.2.12

3.4.1.2.13

3.4.1.2.14

3.4.1.2.15

3.4.1.2.16

3.4.1.2.17

3.4.1.2.18

3.4.1.2.19

3.4.1.2.20

3.4.1.3

3.4.1.3.1

3.4.1.3.2
Administrative Area

Lunch/Conference Room

Quality Assurance

Shift Manager

HPT/Radiation Monitoring

Control Room

Electrical/Telecommunication Room

Fire Riser Room

Men's and Women's Restroom

Men's and Women's Change Rooms

Seismic Criteria

HVAC System Design Description

Process Bay Zone III HVAC System

System Function

Design Requirements

Performance and Characteristics

Configuration and Essential Features

Components Part and Materials

Utility Requirements

Confinement Requirements

Operational Requirements

Interfacing Systems

Space Requirements

Structural Requirements

Environmental Requirements/Natural Phenomena

Instrumentation and Control Requirements

Surveillance and Inspection Requirements

Availability/Reliability

Maintenance

Safety

Codes and Standards

Quality Assurance

Installation/Construction

Decommissioning

Hazardous Waste

Pre-Conceptual Design

System Configuration

Process Description 
WHC-SD-SNF-CDR-003, Revision O

TABLE OF CONTENTS

3.4.1.3.3

3.4.1.3.4

3.4.1.3.5

3.4 .1 .4

3.4.1.4.1

3.4 .1 .4 .2

3.4 .1 .4 .3

3.4.1.4.4

3.4 .1 .5

3.4.1.5.1

3.4 .1 .5 .2

3.4 .1 .5 .3

3.4 .1 .5 .4

3.4 .1 .6

3.4.1.6.1

3.4.1.6.2

3.4.1.6.3

3.4.1.6.4

3.4 .1 .6 .5

3.4 .1 .6 .6

3.4.1.7

3.4 .2

3.4.2.1

3.4 .2 .2

3.4.2.2.1

3.4.2.2.2

3.4.2.2.3

3.4.2.2.4

3.4.2.2.5

3.4.2.2.6

3.4.2.2.7

3.4.2.2.8

3.4.2.2.9

3.4.2.2.10

3.4.2.2.11

3.4.2.2.12

3.4.2.2.13

3.4.2.2.14

3.4.2.2.15

3.4.2.2.16

3.4.2.2.17

3.4.2.2.18

3.4.2.2.19
Equipment Description

Instrumentation and Controls

System Interfaces

System Limitations

Operating Limits

Precautions

Failure Modes and Effects

Recovery Procedures

Operations

Startup Operation

Normal Operation

Shutdown Operations

Infrequent Operations

Maintenance

Maintenance Approach

Corrective Maintenance

Preventative Maintenance

In Service Inspection

Surveillance

Equipment Calibration

Appendices

West Corridor Area Zone IV HVAC System

System Function

Design Requirements

Performance and Characteristics

Configuration and Essential Features

Components Parts and Materials

Utility Requirements

Confinement Requirements

Operational Requirements

Interfacing Systems

Space Requirements

Structural Requirements

Environmental Requirements/Natural Phenomena

Instrumentation and Control Requirements

Surveillance and inspection Requirements

Availability/Reliability

Maintenance

Safety

Codes and Standards

Quality Assurance

installation/Construction

Decommissioning 
3.4.2.2.20

3.4.2.3

3.4.2.3.1

3.4.2.3.2

3.4.2.3.3

3.4 .2 .3 .4

3.4.2.3.5

3.4.2.4

3.4.2.4.1

3.4.2.4.2

3.4 .2 .4 .3

3.4.2.4.4

3.4.2.5

3.4.2.5.1

3.4.2.5.2

3.4.2.5.3

3.4 .2 .5 .4

3.4 .2 .6

3.4.2.6.1

3.4.2.6.2

3.4.2.6.3

3.4.2.6.4

3.4.2.6.5

3.4.2.6.6

3.4.2.7

3.4 .3

3.4.3.1

3.4.3.2

3.4.3.2.1

3.4.3.2.2

3.4.3.2.3

3.4.3.2.4

3.4.3.2.5

3.4.3.2.6

3.4.3.2.7

3.4.3.2.8

3.4.3.2.9

3.4.3.2.10

3.4.3.2.11

3.4.3.2.12

3.4.3.2.13

3.4.3.2.14

3.4.3.2.15
Hazardous Waste

Pre-Conceptual Design

System Configuration

Process Description

Equipment Description

Instrumentation and Controls

System Interfaces

System Limitations

Operating Limits

Precautions

Failure Modes and Effects

Recovery Procedures

Operations

Startup Operation

Normal Operation

Shutdown Operations

Infrequent Operations

Maintenance

Maintenance Approach

Corrective Maintenance

Preventative Maintenance

In Service Inspection

Surveillance

Equipment Calibration

Appendices

Administration HVAC Zone IV

System Function

Design Requirements

Performance and Characteristics

Configuration and Essential Features

Components Parts and Materials

Utility Requirements

Confinement Requirements

Operational Requirements

Interfacing Systems

Space Requirements

Structural Requirements

Environmental Requirements/Natural Phenomena

Instrumentation and Control Requirements

Surveillance and Inspection Requirements

Availability/Reliability

Maintenance

Safety 
WHC-SD-SNF-CDR-003, Revision 0

TABLE OF CONTENTS

3.4.3.2.16

3.4.3.2.17

3.4.3.2.18

3.4.3.2.19

3.4.3.2.20

3.4.3.3

3.4.3.3.1

3.4.3.3.2

3.4.3.3.3

3.4.3.3.4

3.4.3.3.5

3.4.3.4

3.4.3.4.1

3.4.3.4.2

3.4.3.4.3

3.4.3.4.4

3.4 .3 .5

3.4.3.5.1

3.4.3.5.2

3.4.3.5.3

3.4.3.5.4

3.4.3.6

3.4.3.6.1

3.4.3.6.2

3.4.3.6.3

3.4.3.6.4

3.4.3.6.5

3.4.3.6.6

3.4.3.7

3.5

3.5 .1

3.5.1.1

3.5.1.2

3.5 .1 .3

3.5 .2

3.5 .3

3.5 .4

3.6

3.6.1

3.6 .2

3.6.3
Codes and Standards

Quality Assurance

Installation/Construction

Decommissioning

Hazardous Waste

Pre-Conceptual Design

System Configuration

Process Description

Equipment Description

Instrumentation and Controls

System Interfaces

System Limitations

Operating Limits

Precautions

Failure Modes and Effects

Recovery Procedures

Operations

Startup Operation

Normal Operation

Shutdown Operations

Infrequent Operations

Maintenance

Maintenance Approach

Corrective Maintenance

Preventative Maintenance

In Service Inspection

Surveillance

Equipment Calibration

Appendices

Mechanical/Utility SDD

Plumbing

Plumbing Fixtures

Sanitary Sewer

Domestic Water

Drainage

Instrument Air

Deionized Water

Electrical Distribution SDD

General

Equipment Connection and Receptacles

Building Electrical Normal Power 
WHC-SD-SNF-CDR-003, Revision 0

\section{TABLE OF CONTENTS}

$\begin{array}{ll}\text { 3.6.4 } & \text { Uninterruptible Power } \\ 3.6 .5 & \text { Grounding } \\ 3.6 .6 & \text { Lightning Protection } \\ 3.6 .7 & \text { Interior Lighting } \\ 3.6 .8 & \text { Exterior Lighting } \\ 3.6 .9 & \text { Emergency and Exit Lighting } \\ 3.6 .9 .1 & \text { Exit Lighting } \\ 3.6 .9 .2 & \text { Emergency Lighting } \\ & \\ 3.7 & \text { Facility Control } \\ 3.7 .1 & \text { Radiation Control } \\ 3.7 .1 .1 & \text { Continuous Air Monitor } \\ 3.7 .1 .2 & \text { Stack Monitoring and Sampling } \\ 3.7 .1 .3 & \text { Liquid Effluent Monitoring } \\ 3.7 .1 .4 & \text { Personnel Monitors } \\ 3.7 .1 .5 & \text { Liquid Leak Detection System } \\ 3.7 .2 & \text { HVAC Control } \\ 3.7 .3 & \text { Security } \\ 3.7 .3 .1 & \text { Main Entry Door } \\ 3.7 .3 .2 & \text { Emergency Doors } \\ 3.7 .3 .3 & \text { Telescoping Truck Doors } \\ 3.7 .4 & \text { Communications } \\ 3.7 .4 .1 & \text { Telephones } \\ 3.7 .4 .2 & \text { Public Address System } \\ 3.7 .4 .3 & \text { HLAN System } \\ 3.7 .5 & \text { Alarms } \\ 3.7 .5 .1 & \text { Fire Alarm Requirements } \\ 3.7 .5 .2 & \text { Continuous Air Monitor } \\ 3.7 .5 .3 & \text { Evacuation Alarm System } \\ 3.7 .6 & \text { Fire Suppression } \\ 3.7 .7 & \text { Safety } \\ 3.7 .7 .1 & \text { Eyewashes } \\ 3.7 .7 .2 & \text { Diesel Fume Mitigation } \\ & \end{array}$

\subsection{DESIGN DRAWINGS}

SK-1-80133 Vicinity Map and Drawing List

SK-1-80134 Block Flow Diagram

SK-1-80135 Process Flow Diagram

SK-1-80136 P\&ID MCO/Cask Interface

SK-1-80137 P\&ID Vacuum Pumping System

SK-1-80138 P\&ID Gas Purge/Backfill System

SK-1-80139 P\&ID Chilled Water System 
WHC-SD-SNF-CDR-003, Revision 0

SK-1-80140 P\&ID MCO/Cast Temperature Control System

SK-1-80141 P\&ID Liquid Handling System

SK-1-80150 Mechanical Process Equipment Layout

SK-1-80151 Process Air Flow Diagrams

SK-1-80161 Conceptual Site Plan

SK-1-80162 Architectural First Floor Plan

SK-1-80163 Architectural Second Floor Plan

SK-1-80164 Architectural Building Sections

SK-1-80165 Architectural Perspectives

SK-1-80166 Architectural Perspectives

SK-1-80167 Mechanical Systems Flow Sheet

SK-1-80168 Mechanical Systems Flow Sheet

SK-1-80169 Electrical Block Flow Diagram

SK-1-80170 Mechanical Control Schematic

\section{ATTACHMENTS}

Attachment 1 Attachment 2 Attachment 3 Attachment 4 Attachment 5 Attachment 6 Attachment 7 Attachment 8 Attachment 9
Performance Specification and F\&R Report Criteria Evaluation Report

Shielding and Radiation Exposure Analysis ALARA Implementation Plan Cold Vacuum Drying Analysis Integrated Test Plan Operations and Maintenance Philosophy Comment Database Calculations
$1-15$

1-23, App A 1-15

$1-13$

$1-7$

1-15, App A 1-1, $1-6$

$1-9$

1-63, App A 1-3

$1-54$ 
WHC-SD-SNF-CDR-003, Revision 0

\subsection{INTRODUCTION}

\subsection{Background}

Approximately 2,100 tons of Spent Nuclear Fuel (SNF) are stored in the K Basins at the Hanford Site. Much of this fuel has been broken as a result of handling, resulting in corrosion of the SNF and contamination of the basin water. Westinghouse Hanford $\mathrm{Co}$. has undertaken a project to remove the SNF from the basins and place it in stable dry storage because the basins, which are approximately 40 years old, have leaked. The project encompasses the following activities:

A. SNF will be repackaged so that it is contained in baskets stacked within an overpack vessel called the Multiple Canister Overpack (MCO). The MCO, which will be loaded in the basin under water so it will contain SNF and contaminated water, will be placed in a shield cask on a transport trailer for removal from the basin building.

B. The transport trailer with the cask and MCO will be pulled from the basin building to a nearby facility at the K Basin site, where the water will be drained from the MCO and the drying process will be performed. This step will dry the fuel and fill the MCO with an inert gas, thus reducing the corrosion rate and stabilizing the fuel so that it can be stored safely while awaiting a final treatment step leading to storage. The product of this step is a dry, inert gasfilled, sealed MCO.

C. The dried and sealed MCO, which will remain in the cask on the transporter, will be towed to a location on the Hanford Site that is approximately 10 miles distant where it will be finally treated and placed into storage.

D. The SNF will be dried at high temperature and passivated by slow oxidation to prepare for 50-year storage in sealed MCOs.

E. The dry, stabilized, SNF contained in the MCOs will be placed into storage in the Canister Storage Building (CSB).

F. Debris will be removed, basin water will be processed, and the basin will be decontaminated and decommissioned once all the SNF has been relocated.

The purpose of the project described in this conceptual design report is to provide the processes and facilities (known as the Cold Vacuum Drying System or CVDS) required to drain and dry the water and SNF-filled MCOs after they have been removed from the $\mathrm{K}$ Basins. 
WHC-SD-SNF-CDR-003, Revision 0

\section{$1.0 \quad$ INTRODUCTION}

A $90 \%$ completion report and design review has preceded this final report. A copy may be found in the WHC project archives. Comments received as a result of the $90 \%$ design review are given in Attachment 8 . The CVDS project design is a continuous process, where the conceptual design leads directly to the detail design phase. Submittal of this report initiates the detail design phase of the project where most of comment resolutions will be incorporated.

\subsection{Overview of the Cold Vacuum Drying System}

The CVDS will be a facility constructed at the K Basin Site in close proximity to the basins. It will contain process bays in which transport trailers can be contained while the free water is drained and a Vacuum/Gas Purge Process dries the SNF. The CVDS will also contain a support area where there will be a control room, change rooms, and other functions required to support and coordinate operations.

The Cold Vacuum Drying process is described in Chapter 2. The Overall Sequence of Operations is described in Section 2.1 and shown graphically on Drawing SK-180134. Ports in the MCO will be connected to hoses that lead to an equipment skid that is capable of drawing the water into a collection system and purging warm dry gas through the MCO or pulling a vacuum on the MCO. Drawing SK-1-80135 gives a process flow diagram for the drying process. Piping and instrumentation diagrams are given on drawings SK-1-80136 through SK-1-80141. A Programmable Logic Controller (PLC) will direct a sequence of purge/vacuum cycles that will dry the MCO contents. The equipment system will also include a hot and chilled water system that will establish and control the temperature of the MCO during the drying process.

The CVDS building design is described in Chapter 3 . The building will be a steel frame structure on a concrete pad located to the west of K Basin West. The site plan given on Drawing SK-1-80161 shows the arrangement of the building relative to the K Basins and utilities at the site. The floor plans given on Drawing SK-180162 through SK-1-80166 include six (6) independent bays where transport trailers will be parked and processed. These bays are connected by a corridor that runs along the south side of the building. Truck access to each bay will be through overhead garage doors along the north side of the building. The corridor allows personnel access through step off pads, as well as acting as a chase for service header piping and conduits. Personnel will enter the building through the support area at the east end of the building where there will be facilities for changing, bathrooms, lunch, and control of the building activities. Each bay will be an independent nuclear material secondary confinement structure that will block release to the outside environment should an accident or Natural Phenomena event cause a release from the drying process. Each bay will be served by a dedicated ventilation system that will circulate and HEPA filter the air, as well as exhaust 
WHC-SD-SNF-CDR-003, Revision 0

\subsection{INTRODUCTION}

process exhaust and vent streams and air collected from a hood at the top of the MCO where connections are made and broken. These exhausts are collected in a stack that will be monitored to detect radioactive emissions. The ventilation system diagrams are shown on Drawing SK-1-80151. Other mechanical systems that are distributed to each bay include chilled water, compressed air, firewater, radioactive liquid waste collection, gasses, and potable water. There will be no sanitary sewer connection to the CVDS. Sewage will be collected in a tank and transferred to a tanker truck that will haul it to a sewage treatment plant off site. Radioactive liquid waste will also be collected in a tank and transferred to a tanker truck periodically. The radioactive liquid waste will be returned to the $K$ Basins. Electrical power will be distributed to each process skid, the ventilation fans, the chiller and air compressor, the lighting system, and to other smaller loads. A oneline diagram indicating the distribution and loads is given on Drawing SK-1-80169. The power source will be an overhead line carrying $13.8 \mathrm{KV}$ three phase power. A transformer and switch gear will be provided to derive 480/277 VAC three phase power and 208/120 VAC power for distribution throughout the facility.

Preliminarily, the CVDS will be considered to be a Hazard Category $3(\mathrm{HC}-3)$ nuclear facility per the guidance of DOE STD-1027. Although the quantity of radioactive material contained in the MCOs is much larger than the $\mathrm{HC}$-2 thresholds given in STD-1027, it is wholly contained in a vessel and cask that are designed to withstand severe accidents. Therefore, this material will not be part of the inventory that is available for release should a credible accident scenario be initiated. The material that could be released is the small amount that could be drawn out of the MCO into the drying process system. This material is wholly contained and mostly entrained in the water. Some of it will be caught on filters and attached to piping walls. Breakage of the process system could only release a very small fraction of this material. It is expected that reasonable assessment of release fractions will determine that application of the provisions in the standard that allow for adjustment of the thresholds will result in a HC-3 determination. This is another way of saying that a credible accident resulting in a release within the facility cannot yield an offsite exposure in excess of 25 Rem even if unmitigated. Therefore, the CVDS will not contain safety class Structures, Systems, or Components (SSCs). A thorough Preliminary Hazards Analysis is required to address these assumptions. Criteria interpretations derived from the $\mathrm{HC}-2$ assumption are discussed in the criteria evaluation report.

A Criteria Evaluation Report that addresses this subject and other regulatory issues that impact the CVDS design is found in Attachment 2.

The hazard category determination is an important consideration when determining the appropriate structural characteristics of the design, particularly the analysis of structural response to Natural Phenomena Hazards. DOE STD-1021 indicates that 
WHC-SD-SNF-CDR-003, Revision 0

\subsection{INTRODUCTION}

generally SSCs that are related to $\mathrm{HC}-3$ facilities can be assigned Performance Category 2 ratings (PC-2), which allows for analysis as specified in the Uniform Building Code (UBC) for a critical facility. However, STD-1021 requires a more stringent categorization (PC-3) if structural failure could damage a specific target containing a large quantity of radioactive material. The MCO is judged to be this type of target. Therefore, the preliminary categorization of the building structure will be PC-3, which requires a dynamic analysis using site specific NPH load spectra. This discussion is amplified in Section 3.3 of the report.

Attachments to this report include trade studies and analysis/plans that support the design. 


\subsection{PROCESS DESIGN}

\subsection{Overall Process Sequence Description}

The sequence of actions that are expected to occur in the CVDS between the time that an MCO is ready for shipping from the basins until the drying bay is ready to receive another MCO has been modeled, using a block diagram technique. The diagram is given on Drawing SK-1-80134. Time estimates for each of the blocks are also given on the diagram.

The process sequence model has been loaded into a time and motion analysis computer program, which then projects the average process duration, allowing for other factors such as time lost for maintenance. The number of process bays in the facility has been selected so that there is sufficient available time to process five MCOs per seven day working week.

The process sequence model is also basic data which is required to estimate the radiation exposure for plant workers.

\subsubsection{Overall Block Flow Diagram Description}

The sequence of actions can be summarized as follows:

1. Transporting/Receiving Activities: The basin workers will notify the CVDS control room that a shipment is ready. The CVDS control room will select a bay and notify the truck driver who will drive to the CVDS and position the transporter trailer in front of the door. The door will be opened and an "elephant trunk" exhauster will be attached to the truck exhaust pipe so that diesel fumes do not enter the CVDS while the transporter is being positioned in the bay. The truck will back in and locate the transporter.

2. Preparation Activities: Once the MCO has been accepted, a number of preparation activities will occur. These are: securing the trailer, disconnecting the tractor, and driving the tractor out of the CVDS.

3. Receiving Inspection/Acceptance Activities: A group of receiving inspection activities will be performed to verify that the MCO is properly labeled so that SNM accountability is maintained; to verify that there is no removable contamination on the exposed surfaces of the cask or MCO; and to assay the radiation field in the vicinity of the cask and MCO top where workers will be present. Decontamination and resurvey will occur if contamination is found. 


\subsection{PROCESS DESIGN}

4. After the MCO/cask assembly is secured and determined to be free of contamination, activities will include: attaching and activating some radiation monitoring instrumentation to the transporter work platform; attaching water hoses to the cask ports; swinging in an overhead boom that carries a local exhaust hood and the process connection spools; and attaching the process hoses to the MCO top ports.

5. Process Activities: Process activities include heating the MCO while full of water to the drying temperature (the water is left in order to obtain effective heat transfer to the materials inside); draining the water from the MCO; executing a sequence of purge/evacuation cycles; verifying dryness by means of a pressure decay test; backfilling with helium; and cooling the cask. All these operations will be run from the control room.

6. Post-Process Activities: These are the reverse of the preparation activities. The process hoses are disconnected. They are to be handled as contaminated items (i.e. ends are bagged). The boom is swung out of the way. The water in the annular space between the cask and the MCO is drained. The cask top is placed, sealed, and the annular space is dried. Helium is injected into the annular space and the cask is leak checked. Instruments are removed from the transporter. The tractor arrives and is connected to the transporter. The transporter is released and driven away.

7. Bay Restoration Activities: Work is required to prepare the bay for the next MCO. This work includes clean-up such as mopping the floor, filter changes, contarninated spool change-out/clean-up, and equipment calibrations.

More detailed brief scope statements for each of the elements on the diagram are as follows:

1. Select Bay: The production schedule calls for a shipment from the basin. Select the bay that will be used for the drying.

2. Verify Readiness: Verify that the bay and systems are ready. This includes: staff is ready, connectors are clean, gas supplies are ready, heating water system is ready, gauges are calibrated, survey and decontamination supplies are ready, survey counters are ready, RLW system is ready, etc. Fill out checklist. 


\subsection{PROCESS DESIGN}

3. Notify Basin of Readiness: Notify the basin that bay \#\# is ready to receive a shipment.

4. Transporter Arrives: The truck and transporter arrives outside the bay drive-in door.

5. Open Door: The door opens to allow the truck to back in.

6. Attach Elephant Trunk to Truck Exhaust: An elephant trunk and small exhaust fan will be provided to vent the truck exhaust out of the bay. Attach the exhaust trunk while the truck is just outside the bay.

7. Drive in Truck: Back the truck into the bay and position transporter.

8. Jack Transporter: Raise the transporter off its wheels and rest on fixed supports.

9. Attach Seismic Restraints: Attach (probably bolt) structures that resist cask turnover in a Design Basis Earthquake.

10. Disconnect Transporter: Disconnect the truck from the transporter trailer.

11. Drive Out: Drive the truck to a point just outside the door.

12. Remove Elephant Trunk: Remove the truck exhaust collector.

13. Close Door: Close the door and verify the proper HVAC flow and differential pressure is achieved.

14. ID Tag OK?: Check the MCO identification tag to verify that the MCO shipped is the one received. If OK, accept the MCO and contained SNF. If not, resolve the issue.

15. Resolve Security Issue: Resolve the MCO identification problem.

16. Remove Shipping Cover: Remove the temporary cover placed over the top of the MCO and annular space.

17. Perform Survey: Survey the cask exterior and MCO top for radiation exposure rates. Swipe key areas and count wipes for alpha, beta, gamma radiation. 
WHC-SD-SNF-CDR-003, Revision O

\subsection{PROCESS DESIGN}

18. Post Exposure Rates: Post the working area with signs indicating exposure rates.

19. Count Wipes: Count the wipes to determine if there was removable contamination on exterior surfaces of the cask and MCO top.

20. Clean ?: If the swipes show positive counts, decontaminate and resurvey. If not, proceed.

21. Decontaminate: Wipe contaminated area with cleaning solution.

22. Low Level Waste Collection: Bag the used decontamination rags; place them in LLW barrel.

23. Verify Receiving Paper Work: The receiving inspection (tag verification and survey) is complete. Verify that the receiving inspection forms have been filled out and entered into the log. Accept the shipment.

24. Attach Instrument Package: Attach the radiation monitoring instrument package to the transporter work platform.

25. Attach Transporter Umbilical: The transporter will have a package of radiation monitors (possibly air compressor and hydraulic pump as well). An umbilical carrying power and signal cables will be attached to provide services for these devices.

26. Check-out Rad Detectors: Check-out and verify that rad detectors on the transporter are functioning properly.

27. Swing In Top Boom: Move the boom with the gas, RLW, and vacuum hoses into position above the MCO.

28. Remove Quick Connect: Remove the quick connect fitting at the draw tube port. This is done to keep it from restricting flow and to keep it free of debris that could accumulate as water flows out of the MCO. Bag the fitting and save.

29. Remove Quick Connect: Remove the quick disconnect fitting at the top port. This is done to keep it from restricting gas flow during evacuation and to keep it clean. Bag the fitting and save. 
WHC-SD-SNF-CDR-003, Revision 0

30. Connect Draw Tube: Install new fitting. Make connection with the hose from the overhead boom.

31. Connect Top Port: Install new fitting. Make connection with the hose from the overhead boom.

32. Connect Filter Cover: Install the cover and valve assembly over the MCO vent filter. Make connection with the hose from the overhead boom.

33. Make Annular Space Connections: Connect the heating water lines to the cask connectors that lead to the annular space. Connect instrument air line to inflate annular space seal.

34. Start The Heating Water Flow: Initiate the flow of water through the annular space.

35. Heat-up Period: Cycle water until the MCO reaches the specified temperature.

36. Bubble Test Connections: With the draw tube valve closed, add gas to achieve a pressure of a few PSI, Perform a bubble test of the MCO connections.

37. Start Drying Cycle: Initiate computer control.

38. Withdraw of $90 \%$ Of The Water: Gas is injected and water is pumped at a controlled rate to draw water out of the draw tube into the RLW collection system. Water flow is integrated to determine volume discharged. Gas flow stops when $90 \%$ of water has been ejected.

39. Hold For Drainage/Dripping: This is a wait period that allows held up liquid to drain into the pool in the bottom of the MCO before final water discharge.

40. Remove Last $10 \%$ of the Water: The vent valve is opened and the last of the water is removed.

41. Collect MCO Pump Water, Pump To Truck: The MCO water will flow to a local storage tank to allow siphon action. Later, it will be pumped from the local tank to a 5,000-gallon collection tank and on a monthly schedule from the collection tank to a tanker truck which will return it to the basin. 
WHC-SD-SNF-CDR-003, Revision 0

\subsection{PROCESS DESIGN}

42. Clean Water Chase: The water lines will be rinsed to clean them after each use.

43. Collect Chase Water, Pump to Tank: The chase water will be pumped to the local storage tank.

44. Purge Gas Flow: The computer changes valve states to establish the gas purge drying mode. Gas enters through the draw tube and is withdrawn from the top port. Gas flow runs for a preset time.

45. Evacuate Until Setpoint Is Reached: Evacuate until a predetermined pressure or time is achieved.

46. $P<75$ torr?: If pressure is less than 75 torr move on. If $P$ is greater than 75 torr go through the purge pump loop again.

47. Pumping Time: When $P<75$ torr is satisfied continue to pump until $\mathrm{P}<0.5$ torr.

48. Pressure Rise Test: Conduct a pressure rise test automatically. The computer will close valves to isolate the $\mathrm{MCO}$ and will monitor the pressure. The duration will be about 15 minutes maximum.

49. Extrapolated Result: The computer will predict the MCO pressure if the test were run for $1 \mathrm{hr}$. If the extrapolated result is good move on. If the prediction is failure, repeat the pump \& test cycle.

50. Finish Rise Test: Complete the $1 \mathrm{hr}$ test period.

51. < 3 torr @ 1 hr: If yes go on. If no, repump and retest.

52. Helium Backfill: Fill the MCO with helium.

53. Start Cold Water Flow: Flow cold water through the annular space to cool the MCO.

54. Cool down Period: Wait until the preset MCO temperature is reached. This will be determined by monitoring the pressure in the MCO.

55. Add more Helium: Fill the MCO with He. 
WHC-SD-SNF-CDR-003, Revision 0

\subsection{PROCESS DESIGN}

56. Disconnect Draw Tube: Disconnect the draw tube port from the boom tube. Remove the fitting and bag it. Save for use on the next MCO.

57. Disconnect Top Port: Disconnect the top port from the boom tube. Remove the fitting and bag it. Save for use on the next MCO.

58. Replace Quick Connect: Reinstall the quick connect fitting in the draw tube.

59. Replace Quick Connect: Reinstall the quick connect fitting in the top port.

60. Bag Boom Connectors: Bag the boom tube ends to contain any contamination that may be on them.

61. Remove Boom: Swing the boom out of the way to leave the area above the MCO clear.

62. Print Drying Report: It is expected that the computer will keep the drying cycle and test data. Print the report.

63. Review Results: Review the drying report to make an acceptance determination.

64. Accept: Accept the drying report. No-pump and test again. Yes - go on.

65. Reconnect: If drying report is unacceptable. Reconnect drying system and return to heating the MCO.

66. Drain Annular Space: Open the top valve to make a vent. Open the bottom valve to the RLW collection tank to drain the space. By pumping the water in the annular space to the local storage tank.

67. Contamination Survey and Decon: Survey the MCO top and clean-up any contamination found.

68. Helium Leak Check Ports and MCO Weld: Perform a helium leak test (sniffing type) around the top penetrations and around the cap to body weld. 


\subsection{PROCESS DESIGN}

69. Leak Check ? - Failed: Replace quick connect fittings with new ones. Run the pump out and test cycle again. Go on if good.

70. Remove Annular Space Seal: Remove the seal that kept water from overflowing the annular space.

71. Inspect Cask Seals and Surfaces: Clean - Inspect the surfaces and seals that make the cask top to body joint. Clean as necessary.

72. Place Cask Top With Crane: Attach the crane and lifting fixture to the top which is on the transporter. Raise it. Place it on the cask.

73. Insert and Tighten the Bolts: Insert the cask top bolts. Using a torque limited driver, tighten the bolts.

74. Torque Check: Make a torque verification with a hand held torque wrench.

75. Purge annular space with nitrogen for a predetermined time to remove residual moisture.

76. Purge annular space with helium for a predetermined time to make a helium atmosphere.

77. Disconnect annular space port connections.

78. Inspect and Clean Port Seals: Inspect and clean the seals for the covers that go over the annular space ports in the cask.

79. Attach The Cask Covers: Place, insert bolt, tighten bolts.

80. Helium Leak Check Cask: Sniff test the cask top joint and the port cover joints.

81. Leak Check?: If the leak check is good, go on to prepare for shipment. If not, go to repair actions.

82. Remove Bolts: If He test failed, remove the bolts that clamp the joint that failed. 
WHC-SD-SNF-CDR-003, Revision 0

\subsection{PROCESS DESIGN}

83. Lift Top With Crane Or Remove Cover: Take apart the joint that failed. Proceed to clean, replace seal, polish surface, etc. as needed.

84. Request Truck: Request that a truck come to pick-up the finished cask.

85. Open Door: Open the exit door.

86. Attach Elephant Trunk: Attach the exhaust trunk while the truck is just outside the bay.

87. Back Truck In: Position the truck to attach to the transporter trailer.

88. Attach Transporter Trailer: Secure the trailer to the truck hitch.

89. Release Seismic Restraints: Disconnect the seismic restraints from the trailer.

90. Release Jacks: Let the truck down onto its wheels.

91. Disconnect Umbilical: Disconnect the external power and signal cables.

92. Remove Instrument Package: Detach the radiation monitoring instrument package from the transporter work platform.

93. Final Inspection: Make a final inspection of the cask and trailer; verify that all test and inspection reports are complete. Official release.

94. Drive Truck Out: Drive the truck until it is just outside the door.

95. Remove Elephant Trunk: Remove the truck exhaust line.

96. Drive truck out of bay.

97. Close Door: Close the bay exit door.

98. Clean-up: Mop floors, remove trash, etc. 


\subsection{PROCESS DESIGN}

99. Replace Contaminated End Spools: Replace the end spools of the boom tubes that are contaminated with new or previously cleaned parts.

100. Replenish Supplies: Resupply gasses, cleaning materials, etc.

101. Perform Calibrations: Calibrate instruments as needed for the next run.

102. Ready For Next Run: Preparations are ready to return to step 1 with a new MCO.

\subsubsection{Time and Motion Model Description}

AT\&T/ISTEL Witness, Version 7.0, was used to analyze the proposed method of operation. Witness, a Windows-based industrial and processing simulation tool, can simulate both discrete and continuous systems, that is, systems handling parts or fluid based systems.

The following assumptions were made:

1. Basis - The model was developed and based on Block Flow Diagram SK-1-8134, sheets 1 and 2.

2. Shifts - The Cold Vacuum Drying bays run 3 shifts per day, 7 days per week. There is no offset for setup.

3. Processing Operations - All operations are provided for on the BFDs. No other operations are required.

4. Labor - The model is not resource restricted. There is an unlimited labor pool available for the required tasks.

The model was run with two specific simulation goals:

1. A single model run was executed in order to develop a base line time for complete processing times.

2. A multiple model run was executed. Eleven trucks were processed through a single truck bay, to determine a non-weighted, arithmetic average for processing time. This was then compared against the single model run. 


\subsection{PROCESS DESIGN}

The overall arithmetic average to process a fuel cask through the cold vacuum drying process was 63 hours. A total of eleven trucks were processed through a single bay in approximately 693 hours.

The computer output for the run is attached in the calculation appendix.

It can be seen that the calculated cycle time allows for each bay to process two MCO's per week. Three operable process bays will meet the average processing demand required to process all $400 \mathrm{MCOs}$ in two years. However, there may be a need to hold MCO's because the CSB is not ready to receive or because the basin desired to ship when the CVDS was not ready to process. In addition, three bays does not offer any opportunity to compensate for an unforeseen event that could take a drying system out of service for an extended period. Three bays also does not allow flexibility to respond to an MCO that dries slowly, to respond to peak rates, to support accelerated rates in the later part of the project to make up for the schedule slippage in the early part of the project that could occur as the retrieval operations staff gains experience. For these reasons, it is recommended that the CVDS be constructed with six(6) bays. 


\subsection{PROCESS DESIGN}

\subsection{Vacuum/Gas Purge System Design Description}

\subsubsection{System Function}

The function of the Vacuum/Gas Purge System (VGPS) is to first remove the bulk water from the SNF contained within the MCO, and, second, to dry it under vacuum using a cycle of evacuation and inert gas backfill/purge stages. The final product will be a dried MCO that has been backfilled with inert gas.

\subsubsection{System Design Requirements}

The VGPS shall remove gas species (volumetric, off-gassing, residual free water, and in-leakage) from the MCO so that the contents of the MCO are dried until a vacuum $<0.5$ torr is achieved and until a one hour pressure rise test started when the pressure is $<0.5$ torr does not result in a final pressure above 3.0 torr. The system shall be sized to achieve these results in 24 hrs or less.

The system shall be capable of injecting helium and nitrogen into the MCO periodically so that an evacuation - purge cycle can be operated.

The VGPS shall support four modes of operation:

1. Bulk water removal where inert gas shall be supplied while water is withdrawn from the $\mathrm{MCO}$

2. Pump-down

3. Inert gas purge

4. Inert gas circulation

The VGPS shall be designed to precede backstreaming of oil into the MCO and also to prevent oil contamination of downstream equipment.

Gas drawn from the MCO shall be filtered as close to the MCO as can be reasonably configured to minimize the migration of radioactive dust particles through the VGPS.

Water in the pump exhaust and circulating inert gas stream shall be condensed. The water shall be directed to the Liquid Handling System.

Table 2.2.1 gives the design requirement parameters: 
WHC-SD-SNF-CDR-003, Revision 0

\subsection{PROCESS DESIGN}

Table 2.2.1: VP/S Design Parameter Specifications

\begin{tabular}{|l|c|c|}
\hline \multicolumn{1}{|c|}{ Parameter } & Units & Specified Rating \\
\hline Material of Construction & NA & 304 or $316 \mathrm{~s} / \mathrm{s}$ \\
\hline Internal Design Pressure & PSIG & 150 \\
\hline External Design Pressure & PSIG & 15 \\
\hline MCO Operating Vacuum Pressure & Torr & 0.1 \\
\hline MCO Net Free Volume & cu.ft. & 24.9 \\
\hline $\begin{array}{l}\text { Surface Areas } \\
\text {-MCO } \\
\text {-Fuel Elements }\end{array}$ & sf & 83 \\
\hline Design Max Temperature & & 918 \\
\hline Operating Max Temperature & ${ }^{\circ} \mathrm{F}$ & 140 \\
\hline Design Min Temperature & ${ }^{\circ} \mathrm{F}$ & 120 \\
\hline Initial Residual Water Content & ${ }^{\circ} \mathrm{F}$ & 50 \\
\hline Final Pressure & cu ft. & $0.18-0.49$ \\
\hline Vacuum Drying Process Time Limit & Torr & 3.0 \\
\hline Duty Cycle For MCOs from K-E & hr & 24 \\
\hline Duty Cycle For MCOs from K-W & \# per year & 113 \\
\hline Vacuum System Availability & \#per year & 101 \\
\hline Inert Gasses & $\%$ & 90 \\
\hline Dose Rate Limits at Vacuum System & NA & He, N \\
\hline Operational Lifetime & mrem/hr & 5 \\
\hline
\end{tabular}

The VGPS shall interface with the following systems:
1. The MCO/Cask Temperature Control System (MCTC)
2. The Liquid Handling System (LHS)
3. The $\mathrm{MCO}$
4. The HVAC System
5. The Electrical System
6. Chilled Water System
7. Compressed Air System
8. The Facility Control System 


\subsection{PROCESS DESIGN}

\subsubsection{Equipment Arrangement and Design Description}

The Piping and Instrumentation Diagram (P\&ID) for the VGPS is given on Drawing SK-1-80137.

The major components of the system are:

1. P-2011 - Vacuum Pump: A Scroll pump with a capacity of $17 \mathrm{cfm}$. This is the main vacuum pump for the system.

2. H-2010 - Super Heater: This $3 \mathrm{KW}$ heater heats the pump intake gas stream so that condensation will not occur in the pump. Heater power is controlled by an SCR.

3. D-2012 - Refrigerated Dryer: This dryer condenses water vapor in the pump offgas or the circulated inert gas stream.

4. B-2014 - Purge Blower (Ring Compressor): A single stage ring compressor capable of circulating $30 \mathrm{CFM}$. This blower circulates the inert gas during the gas drying stages in the VGPS cycle.

5. $\mathrm{H}-2013$ - Purge Gas PreHeater: This $3 \mathrm{KW}$ heater heats the purge gas for injection into the $\mathrm{MCO}$ at $50^{\circ} \mathrm{C}$ to $60^{\circ} \mathrm{C}$. Heater power is controlled by an SCR.

The preliminary arrangement of the VGPS equipment and the supporting MCTC and LHS equipment is given on Drawing SK-1-80150. The equipment is arranged to fit on two skids that sit side by side. Pipe racks and wire ways will connect the skids above the equipment. Consideration of access for equipment maintenance has been made when arranging the components and pipe runs.

\subsubsection{System Limitations, Accident Scenarios, and Response to Accidents}

To be written during Detail Design.

\subsubsection{Operation}

\subsubsection{Water Drainage}

Water will be removed from the MCO through line LW-112 which connects to the draw tube. Nitrogen cover gas will be supplied as the water is drawn out. The gas 
WHC-SD-SNF-CDR-003، Revision 0

\subsection{PROCESS DESIGN}

will flow from the supply bottles through line PG-103 which leads to the top port on the MCO. The LHS pump will be a metering pump so that a preset amount of liquid (determined to be $90 \%$ approximately) will be drawn out. The sequence of operation will call for a waiting period to allow for drainage and dripping. After the waiting period, the water draw will resume until the gas flows into the LHS.

\subsubsection{Evacuation}

Evacuation will draw gas from both MCO ports. This will increase the effective pumping speed. The crossover valve between lines PG-101 and PG-102 will be opened to allow connection of both ports to the pump P-2011. The gas will flow through a filter where micron size particulate matter will be removed. The gas will be heated by $\mathrm{H}-2010$ before entering the pump in order to prevent condensation. PG-101 and PG-102 will be heated to prevent condensation on the interior pipe surfaces. Water in the exhaust from the pump will be condensed in the refrigerated drier D-2012. The exhaust will then be sent to the HVAC system to enter into the hood exhaust stream which is not part of the recirculated building air.

\subsubsection{Once Through Gas Flow}

Gas may be drawn from the bottle supply, passed through the $M C O$, and sent to the plant exhaust. This is accomplished by feeding gas through line PGB-103 to PGB101 which puts gas into the draw tube. Gas is then flows out the top port through PG-102 to PG-103 which leads to the refrigerated dryer D-2012 and then to the exhaust.

\subsubsection{Circulated Gas Flow}

The once through gas flow mode can be run to establish an inert gas atmosphere. The system can be changed to a circulated gas flow. Gas then flows from the MCO through B-2014, through the dryer D-2012, through the heater $\mathrm{HX}-2010$, and back to the MCO.

\subsubsection{Maintenance}

(To be provided during Detail Design). 


\subsection{PROCESS DESIGN}

\subsection{MCO Temperature Control}

\subsubsection{Heat Transfer Estimates}

The time required to heat and dry the $\mathrm{MCO}$ is dependent upon the rate at which heat can be transferred to, and removed from, the MCO. While complex calculations have been performed by $\mathrm{WHC}$ and its subcontractors to define the heat transfer mechanisms and to quantify the component rates, the times used in the overall block flow diagrams and the process flow diagrams are based on simplified calculations (see Appendix 9) that use assumed overall heat transfer coefficients and average temperature differentials. The assumptions used in the simplified calculations draw upon the results of the more complex calculations for their underlying basis.

Heat flows from the heating fluid to the $\mathrm{MCO}$ /cask assembly in two directions, inwards to the $\mathrm{MCO}$ and outward to the cask. These calculations indicate that when water at $60^{\circ} \mathrm{C}$ is pumped through the annular space between the cask and the $\mathrm{MCO}$, the heat flow to the cask will be greater than the heat flow to the MCO by a factor of nearly 30 . The heat transfer coefficient for the MCO is limited by natural convection to the water inside the MCO. The preliminary design process assumes that the water will be in the $\mathrm{MCO}$. If the water must be removed first, then the MCO heat up time will be extended because the natural convection gas transfer rate is less that the natural convection water transfer rate by a factor of 5 to 10 .

For about 40 minutes, the cask will soak up heat rapidly with the limit being how much heat is available in the heat transfer fluid (water). After this time, the cask will be at the temperature of the incoming water and the only heat transferred into it will be to replace that which is lost to the room by natural convection to the air.

The MCO will heat up at a much slower rate and will take about 5 hours to reach $50^{\circ} \mathrm{C}$. After the first 40 minutes, the transfer rate will increase significantly since the average temperature of the heat transfer fluid will be higher. After about 5 hours, very little heat will be transferred to the $\mathrm{MCO} /$ cask assembly; just enough to replace that lost to the room and to vaporize the residual water inside the cask.

At the completion of the vacuum drying process, the $\mathrm{MCO}$ and cask will be at a temperature of about $50^{\circ} \mathrm{C}$. Cool down of the configuration will be essentially the reverse of heat up in that the cask cool down will be 
WHC-SD-SNF-CDR-003, Revision 0

\subsection{PROCESS DESIGN}

limited by the quantity of heat that can be carried away by the cooling water while the MCO will be limited by the natural convection heat transfer rate from the gas inside the MCO to the MCO wall. It is estimated that about 1-1/2 hours will be required to cool the cask down and about 6 hours to cool the MCO down.

\subsubsection{System Design Description}

\subsubsection{System Function}

The function of the MCO/Cask Temperature Control System (MCTC) is to maintain the MCO at the proper operating temperatures during all stages of the MCO drying process. This includes heating the MCO during vacuum drying and cooling the MCO after vacuum drying.

\subsubsection{System Design Requirements}

The MCTC will be required to pump water at various design temperatures through the annular space between the MCO and Cask at a rate of $20 \mathrm{gpm}$ and a design pressure of $20 \mathrm{psi}$, with a maximum allowable pressure of $25 \mathrm{psi}$ in the MCO/Cask annular space. During vacuum drying, the MCTC will be required to heat the MCO and maintain it at a temperature of approximately $50^{\circ} \mathrm{C}\left(122^{\circ} \mathrm{F}\right)$ for a continuous period of not more than two days per drying operation to assist in the release of residual water. After vacuum drying of the MCO, the MCTC will be required to cool the MCO and Cask down to an acceptable temperature for shipping. The MCTC is also required to have the capability to heat the MCO/cask assemble to $75^{\circ} \mathrm{C}$ in the event that drying at the temperature of $50^{\circ} \mathrm{C}$ does not prove to be adequate.

The MCTC will be required to interface with the System Monitoring and Control System (MMCS) to allow for computer control of MCO heating and cooling during all stages of the drying operation.

\subsubsection{Equipment Arrangement and Design Description}

The Piping and Instrumentation Diagram (P\&ID) for the MCTC(s) is located on drawing SK-1-80140. There will be one MCTC for each of the six CVDS bays. The main components of each MCTC will be an electric water heater $\mathrm{H}-5011$, a shell and tube exchanger type water cooler $\mathrm{HX}-5010$, and a centrifugal circulation pump $\mathrm{P}-5014$. In addition, contaminants that may be entrained in the water stream during heating or cooling will be removed by continuously pumping a fraction of the water heater outlet stream through an ion excharige column C-5013 and circulating it back into the water heater. Heated and cooled water will both be pumped to the MCO by pump P-5014. 


\subsection{PROCESS DESIGN}

\subsection{Water Heater}

The water heater $\mathrm{H}-5011$ will be an in-tank, electric element type water heater with sufficient volume and heat load capacity to provide the required supply of hot water to the $\mathrm{MCO} / \mathrm{cask}$ annular space at the design flow rate of $20 \mathrm{gpm}$ and temperature of $60^{\circ} \mathrm{C}$. Water flow into and out of the water heater will be controlled by computercontrolled air-operated valves on the inlet and outlet lines. The water heater tank will be equipped with a level sensor with high-level and low-level alarm set points. Operation of the electric heater element will be controlled through the PLC, and will rely primarily on data from a temperature sensor on the water heater outlet stream.

\subsection{Water Cooler}

The water cooler HX-5010 will be a shell and tube type exchanger with the $\mathrm{MCO} /$ Cask cooling water on the shell side, and chilled water on the tube side. Water flow into and out of the water cooler will be controlled by computer-controlled air-operated valves on the inlet and outlet lines.

\subsection{Ion Exchange Column}

A small ion exchange column will be connected to the water heater tank to continuously circulate a portion of the tempered water. The column will be sized to circulate approximately 0.5 to $1 \mathrm{gpm}$ of tempered water, and will remove contaminants that may be entrained during heating or cooling of the MCO. A metering pump, P-5012, will be used to circulate the water through the column.

\subsection{Pumps}

Pump P-5014 will be used to circulate the tempered water through the MCO/Cask annulus and the MCTC. This pump will be a $20 \mathrm{gpm}$ centrifugal pump that will be controlled by the process PLC. Pump P-5012 will be a 1 to $2 \mathrm{gpm}$ metering pump that will continuously circulate approximately $1 \mathrm{gpm}$ of the tempered water through an ion exchange column. This pump will also be controlled by the PLC.

\subsubsection{Operation}

\subsection{MCO Heating}

The first step in the vacuum drying process is to heat the $\mathrm{MCO}$ and its contents prior to bulk liquid removal, since the water in the MCO will transfer heat to the SNF and baskets more effectively than gas. Once the necessary connections are made to the MCO lid, the MCTC piping will be connected to the tempered water inlet and 
WHC-SD-SNF-CDR-003, Revision O

\subsection{PROCESS DESIGN}

outlet fittings on the cask. The MCTC will then begin pumping heated water at $60^{\circ} \mathrm{C}$ $\left(140^{\circ} \mathrm{F}\right)$ through the MCO/cask annular space until the MCO has reached a temperature of approximately $50^{\circ} \mathrm{C}\left(122^{\circ} \mathrm{F}\right)$, which will be estimated from the temperature of the heating water as it exits the annular space. The MCTC will keep the MCO heated continuously until the entire vacuum drying process is completed, the one hour vacuum leak test has been conducted, and the MCO is ready to be cooled down for shipping.

\subsection{MCO Cooling}

After the vacuum drying process has been completed and the MCO has passed a one hour vacuum leak test, the water heater element will be shut off, the tempered water circulation pump will be shut off, and the air-operated valves on the water cooler bypass line will be closed. The valves on the water cooler inlet and outlet lines will then be opened, chilled water will be allowed to circulate through the cooler, and the tempered water circulation pump will be restarted. The tempered water will be cooled to a temperature of about $10^{\circ} \mathrm{C}\left(50^{\circ} \mathrm{F}\right)$ in the water cooler. The cooled water will be circulated continuously until the appropriate MCO temperature has been reached for shipping.

\subsection{Ion Exchange}

A 1 to $2 \mathrm{gpm}$ metering pump P-5012 will continuously circulate approximately $1 \mathrm{gpm}$ of the tempered water through the ion exchange column $\mathrm{C}-5013$. This will be done throughout the heating and cooling stages to remove contamination that may be picked up by the water in the MCO/cask annular space. An appropriate ion exchange media will be chosen based on a determination of the potential contaminants that will need to be removed.

\subsubsection{Maintenance}

Due to the relatively short operating life of the facility, the MCTC equipment is expected to require little maintenance. In addition, the presence of six identical CVDS bays precludes equipment redundancy within the MCTC(s), since one of the bays may be closed for maintenance or repairs without significantly impacting the MCO vacuum drying schedule. However, all equipment will be connected with isolation valves and any other measures that will promote ease of maintenance or replacement. 
WHC-SD-SNF-CDR-003, Revision O

\subsection{PROCESS DESIGN}

\subsection{Liquid Handling System Design Description}

\subsubsection{System Function}

The primary function of the Liquid Handling System (LHS) is to provide a local point of collection for process liquids in each of the six process bays. Liquids will be pumped from the LHS in each CVDS bay to a 5,000 gallon central liquid holding tank. This liquid will then be transported by tanker to another facility for final treatment and disposal.

\subsubsection{System Design Requirements}

The LHS in each of the six bays will be required to provide pumping and hold-up capability for all process liquids generated during vacuum drying of the MCO. These liquids will primarily include pool water drained from the $M C O$, and tempered water used by the MCTC to heat and cool the MCO. Each LHS will provide capacity for liquid generated by the vacuum drying of one MCO. The inlet line to the LHS holding tank will be equipped with a flow meter and totalizer to track the volume of liquid that is pumped to the LHS. Air-operated, computer-controlled valves will control flow of liquid to the LHS tank from the vacuum drying process, and from the LHS tank to the central collection tank. Pumps will be used to transfer the liquid to and from the LHS tank. The LHS tank will be vented through a HEPA filter to the facility HVAC exhaust.

The LHS will be required to interface with the System Monitoring and Control System (MMCS) to allow for computer control of liquid handling to and from the LHS.

\subsubsection{Equipment Arrangement and Design Description}

The Piping and Instrumentation Diagram (P\&ID) for the LHS(s) is located on drawing SK-1-80141. There will be one LHS in each of the six CVDS bays. The main components of each LHS will be a 200 gallon holding tank and two pumps, one diaphragm pump for pumping waste liquid to the LHS tank from the MCO and vacuum drying process, and one centrifugal pump for pumping the liquid in the full LHS tank to the central collection tank. The valves and instrumentation shown on drawing SK-1-80141 will interface with the MMCS to control the flow of liquid into and out of the LHS holding tank.

1. Holding Tank: The liquid holding tank TK-6011 will be a 200 gallon capacity stainless steel tank with ports for process liquid inlet, liquid drain, and vent exhaust. The tank will be equipped with a liquid level sensor which will be connected to the process PLC for control of the inlet and outlet valves and pumps. The vent 
WHC-SD-SNF-CDR-003, Revision 0

\subsection{PROCESS DESIGN}

exhaust from the tank will pass through a HEPA filter before being connected to the facility HVAC exhaust.

2. Pumps: Pump P-6010 will be used to pump process liquid from the various sources into the liquid tank TK-6011. Pump P-6012 will be used to pump liquid from TK-6011 to the central holding tank.

\subsubsection{Operation}

\subsubsection{MCO Bulk Liquid Draining}

One of the first steps in the MCO vacuum drying process is drainage of the bulk liquid (about $90 \%$ ) from the MCO. After the appropriate connections have been made to the MCO lid, the local liquid line valve at the MCO end and the LHS inlet valve will be opened remotely by the MMCS. Pump P-6010 will then begin pumping the bulk liquid out of the MCO and into the LHS holding tank. Once the bulk liquid has been pumped out, the pump will be shut off and the valves will be closed. Depending on the liquid level in the tank, the water in the LHS holding tank may then be pumped to the central collection tank by opening the LHS tank drain valve and turning on pump P-6012. This process is repeated to remove the remaining water in the MCO once the MCO has been backfilled with helium.

\subsubsection{Other Liquids}

In addition the bulk liquid from the MCO that will be pumped to the LHS, several other sources of liquid will be pumped to the LHS. These will include condensate from the refrigerated purge gas dryer (D-2012 on drawing SK-1-80137), MCO residual water pumped through the Vacuum Pumping System (VPS), and spent tempered water from the MCO/cask Temperature Control System (MCTC). Like the MCO bulk liquid, these liquids will all be pumped to the LHS by $P-6010$, which will involve opening a local liquid drain line valve by the MMCS.

\subsubsection{Maintenance}

Due to the relatively short operating life of the facility and simplicity of the Liquid Handling System design, the LHS equipment is expected to require little maintenance. In addition, the presence of six identical process bays precludes equipment redundancy within the LHS(s), since one of the bays may be closed for maintenance or repairs without significantly impacting the MCO vacuum drying schedule. However, all equipment will be connected with isolation valves and any other measures that will promote ease of maintenance or replacement. 
WHC-SD-SNF-CDR-003, Revision 0

\subsection{PROCESS DESIGN}

\subsection{Solid Waste Disposal}

During the course of normal operations within each of the Cold Vacuum Drying System Bays and other areas of the facility, solid waste will be generated from various sources. These sources primarily include, but are not limited to the following items:

1. Smears from cask survey

2. Decontamination rags

3. Plastic hose end and boom covering bags

4. Wipes from bubble test clean-up

5. Rags used to clean cask top seal

These items and other similar types of potentially contaminated solid waste will be placed into a designated drum located within the area or in each bay. When drums are full, they will be monitored to determine waste class and placed in a temporary storage area in the facility. The drums will then be picked up by others for treatment or disposal. 
WHC-SD-SNF-CDR-003, Revision 0

\subsection{PROCESS DESIGN}

\subsection{Process Control SDD}

\subsubsection{Control System Design}

The System Monitoring and Control System (MMCS) is designed as a fullyintegrated control system that will provide not only process control but data acquisition and management. This type of system is called Supervisory Control and Data Acquisition (SCADA). The system will use digital signaling between a distributed network of PLC and driver software, which can now be handled by personal computer sized hardware. Interface between local hardware and remote hardware may also be achieved via modem transfer.

The suggested hardware is a $200 \mathrm{MHz}$ Pentium Pro computer, 64 MB RAM with $4 \mathrm{~GB}$ hard drive, $4 \mathrm{~GB}$ MO backup drive, 3.5" floppy disk drive, 4X CDROM, SVGA color monitor, and a laser printer. The operating system may be Windows NT or Windows 95. Software brand names are Intellution, Wonderware, and Labview.

Each local personal computer will have a view screen with dynamic graphical display to show by color or movement the change in an operating parameter. All personal computers will allow total access to all systems so redundancy is achieved if a computer becomes inoperative.

A printer may be connected to each PLC or any combination of PLCs. The network may be set up to acquire data and then print out the accumulated data in various formats, including alarm logs and graphical data.

Access to the level of control can be programmed into the software of the control system so that only authorized personnel may operate the system to any desired level, such as view only.

\subsubsection{Visual Monitoring}

A television camera will be located in each process bay and outside viewing the truck area entry in order to allow the control room personnel to view the operation. A television screen will be situated near each personal computer control station. The channels on the television may be changed to view any particular area.

\subsubsection{Programmable Logic Controllers}

A PLC will be located in each process bay to allow redundancy and protection if a contamination accident occurred. A PLC is also located in the office area 
WHC-SD-SNF-CDR-003, Revision 0

\subsection{PROCESS DESIGN}

for central equipment control. Each PLC will accept both digital and analog signal input and control.

The PLCs are 120 volt powered interface units between real-world sensor measurement and control devices, and the software driving the control. The PLC hardware is recommended to be Allen Bradley, Modicon, or Siemens. Each PLC has in-place programmable control logic allowing stand-alone control and shutdown capabilities if the computer control is lost. Each PLC will be equipped with a 4-hour battery backup supply to assure operation during an emergency shutdown. 
WHC-SD-SNF-CDR-003, Revision 0

\subsection{PROCESS DESIGN}

\subsection{System Design Description}

\subsubsection{System Function}

The function of the chiller $(\mathrm{CH}-4001)$ is to provide chilled water to the tempered water cooler in each of the six process bays. The coolers will be used to cool the $\mathrm{MCO} /$ Cask for shipping after the drying process has been completed.

\subsubsection{System Design Requirements}

The chiller will be required to provide chilled water at $7 \circ \mathrm{C}(45 \circ \mathrm{F})$ and 20 psi to each of the six MCTC coolers. The MCTC coolers will provide cooling water to the MCO and Cask to cool them down prior to shipping. The chiller will be a 100 ton refrigerant fluid air cooled type.

The chiller will be required to interface with the central facility control system to allow for computer control of chilled water supply during all stages of drying operations.

\subsubsection{Equipment Arrangement and Design Description}

The Piping and instrumentation Diagram (P\&ID) for the chiller is located on drawing SK-1-80139. There will be one central chiller supplying chilled water to all six of the MCTC coolers. The condenser for the chiller will be located outside the facility, while the chilled water tank (TK-4001), exchanger, and the two chilled water pumps (P-4002 and P-4003) will be located just inside the facility. The exchanger will be located so as to minimize the distance between it and the condenser. The condenser will contain a refrigerant such as freon, and will be air cooled. 


\subsection{PROCESS DESIGN}

\subsection{Process Interfaces}

The following Table lists CVD interfaces with the other sub-projects. Changes in these interfaces can effect the design or performance of the CVD process. Design data baselines should be agreed to and placed under control of the configuration management system before initiation of the definitive design. The CVDS design team should review and agree to proposed designs and changes related to these interfaces as part of the design approval process. The relative time phasing of the various sub-project design developments does not allow determination of most of the entries at this time: for example, the cask/transporter preliminary design will be completed after the CVDS preliminary design. For this reason, most entries in the requirements column are TBD. 
WHC-SD-SNF-CDR-003, Revision 0

\subsection{FACILITY DESIGN}

\subsection{Site Description}

\subsubsection{Site Development}

\subsubsection{Site Area and Access}

The site selected for the CVDS is to the southwest of Building $165 \mathrm{KW}$, Power Control Building and 105KW, Reactor Building. This site is in close proximity to all of the required utilities, and is within the inner security boundary. The new facility will not be seen from the road and is located away from the central area population. It is located near the path the fuel transport would take in leaving $105 \mathrm{KW}$ and is close to the rail lines that may facilitate removal of waste products.

The site area required for the facility and vehicle circulation is approximately 2.0 acres. Access and egress is provided by the main entrance to the $100 \mathrm{~K}$ inner area using a combination of existing and new roadways. The surface of the new roads that will be used for fuel transport will be paved. The access and loop roads used for emergency and maintenance vehicle access will be gravel.

\subsubsection{Site Grading}

The CVDS site is gradually sloping from south to north towards the river. The building will be situated so that the transport access doors will be a flat, level surface, with the building slab at grade on the south, and the above grade to the north. Site drainage will be accomplished by grading to the north, and no collection basin or piping of stormwater is anticipated.

\subsubsection{Landscaping}

There will be minimal landscaping at the CVDS. A parking area for maintenance vehicles will be provided and a large asphalt area for transport vehicle turnaround will also be included in the project. Disturbed areas will be stabilized to prevent erosion and provide dust control.

\subsubsection{Site Utilities}

\subsubsection{Sanitary Water}

Sanitary water will be supplied to the CVDS from the existing $100 \mathrm{~K}$ Area sanitary water loop on the west side of $165-\mathrm{KW}$. The sanitary water service main will be a 1-1/2 inch diameter copper pipe. Backflow preventors and pressure reducing valves will be inside the CVDS. 
WHC-SD-SNF-CDR-003, Revision 0

\subsection{FACILITY DESIGN}

\subsubsection{Fire Protection Water}

Fire protection water will be supplied to the CVDS from the existing 100K Area fire protection system on the west side of $165-\mathrm{KW}$. The fire protection line to the CVDS will be an 8 inch diameter ductile iron pipe in accordance with DOE Order 5480.7 . The system will include the required isolation valves, two fire hydrants, a post indicator valve, and supervisory functions.

\subsubsection{Liquid Systems}

\subsection{Basin Water}

All water collected from the vacuuming modules in the CVDS will be pumped to a 5,000 -gallon holding tank inside the CVDS. The water will then be pumped from this tank into a tanker truck for disposal from the facility.

\subsection{Fire Water Collection}

Surface drains in the process areas will collect fire sprinkler discharge water and route the water in double wall contained piping to an above ground retention basin located south of the facility. The holding capacity of the basin is 20,000 gallons. The fire water requirement is 20 minutes of water flow at the largest area or 7,200 gallons.

\subsection{Sanitary Sewage Collection}

Sanitary sewage from the CVDS will be gravity drained to a 5,000-gallon surfacemounted holding tank located north of the building. The holding tank is estimated to have the capacity to store 2 weeks of liquid effluent with maximum occupancy of the facility. 
WHC-SD-SNF-CDR-003, Revision O

\subsection{FACILITY DESIGN}

\subsection{Building System SDD}

\subsubsection{General}

The CVDS consists of six process bays within a single-story pre-engineered metal building containing a second level mezzanine. Attached to the process bays is a single story pre-engineered metal building that encloses administrative and change room functions. The exterior skin will be a mixed use of pre-cast concrete panels and insulated metal panels.

Construction material types utilized shall be durable, cleanable, and maintainable. The construction of the CVDS shall be in accordance with the Uniform Building Code and the DOE Order $6430.1 \mathrm{~A}$, with egress requirements conforming to NFPA 101.

The recommended configuration of the CVDS requires a building footprint of approximately $14,400 \mathrm{sq}$. ft. for the process bays and support areas and $3,000 \mathrm{sq}$. $\mathrm{ft}$. for administrative and change room functions.

The occupancy of the CVDS has been identified as 20 persons with an equal division for 10 males and 10 females.

\subsubsection{Process Bays}

Each process bay is designed to enclose an MCO cask transporter without the tractor attached and operational space necessary to meet the function of the CVDS. Process bay construction must be designed to provide radiological separation and containment within each bay. The criteria for an envelope capable of maintaining a negative internal pressure within each process bay has a strong influence on the types of materials selected.

The process bay building design utilizes a pre-engineered metal building system that has a bay width of 30 feet and a rigid steel frame system that has a nominal width of 60 feet. The height of the process bays is nominally 32 feet, which is dictated by the manned access working level of the shipping cask, the crane access to remove the cask lid, and the physical/functional requirements for all of the operations necessary in the CVDS.

Access to the process building is accomplished with a corridor that is contiguous with the main change room for radiological control of access/egress from the process area. Individual process bay access/egress control is through a change room. 
WHC-SD-SNF-CDR-003, Revision 0

\subsection{FACILITY DESIGN}

\subsubsection{Process Bay Space Requirements}

Each process bay shall provide ground floor space for the following:

- $\quad$ Enclose a cask transporter without the tractor attached.

- Personnel circulation and functional space around the cask transporter.

- Seismic restraint hold-down devices at the front of the cask transporter.

- Vacuum drying module equipment and pump assemblies.

- $\quad$ Access to the working level of the cask transporter.

- Radiological control between a process bay and the access corridor where operators change clothing and are monitored for radiological contamination prior to admittance to the access corridor.

- Bridge crane access to remove the cask lid and perform maintenance on equipment.

- A cabinet for supplies.

Access to the working level of the cask is accomplished using a mezzanine level with space for the following:

- Access to the working level of the cask transporter for connections from the vacuuming model to the cask.

- HVAC equipment and electrical panels.

- Jib crane with pumping hood assembly.

\subsubsection{Process Bay Support Areas}

The process bay support areas serve as airlock between the controlled process bay and the uncontrolled circulation corridor. Functional requirements for each process bay are:

- $\quad$ Seating space for two allowing for the dressing/undressing of SWP clothes.

- $\quad$ Storage of clean SWP clothing.

- $\quad$ Storage of dirty SWP clothing.

- $\quad$ Space for PCM equipment.

\subsubsection{Decontamination Room}

A single decontamination room shall serve all process bays. Access is required prior to entering the common change room area. Requirements for this space are: 
WHC-SD-SNF-CDR-003, Revision 0

\subsection{FACILITY DESIGN}

- $\quad$ Clear standing space for the decontamination process.

- Storage of decontamination materials and detection equipment.

- One decontamination shower.

\subsubsection{Swipe/Count Room}

A swipe/count room shall be provided to analyze and store samples taken from process bays or areas that have the potential for contamination. Requirements for this space are:

- $\quad$ Desk space for preparing testing reports.

- File storage of records.

- Wall space for the mounting of gas bottle equipment.

\subsubsection{Process Water Tank Room}

Water removed from a cask has the potential for being contaminated, thus will be stored in a tank located in an isolated room with controlled access. This room is located directly adjacent to a process bay to allow a tanker truck to enter the bay and receive the transfer of cask water liquid from the storage tank to the tanker truck.

\subsubsection{Miscellaneous Materials Storage Room}

Approximately 120 sq. ft. of enclosed floor space in the support area is required for a miscellaneous materials storage room.

\subsubsection{Equipment Storage Room}

Approximately 120 sq. ft. of enclosed floor space in the support area is provided for equipment storage.

\subsubsection{Administrative Area}

The administrative area will control personnel access into the CVDS and provide space for:

$\begin{array}{ll}\text { - } & \text { Lunch/Conference Room } \\ \text { - } & \text { Quality Assurance } \\ \text { Shift Manager } \\ \text { HPT/Radiation Monitoring } \\ \text { Control Room } \\ \text { Electrical/Telecommunications Room }\end{array}$




\subsection{FACILITY DESIGN}

- Fire Riser Room

- Men's and women's restrooms

- Men's and women's change rooms

- Access/egress control and personnel control monitoring of the process bays

\subsubsection{Lunch/Conference Room}

A lunch/conference room is required with space for seating 12 people. Additional requirements are:

- Space for refrigerator.

- Casework with sink and storage

\subsubsection{Quality Assurance}

Provide office space for two persons performing quality assurance duties.

- Work spaces with desks and associated equipment.

\subsubsection{Shift Manager}

Provide office space for one person performing shift management duties.

- Work space with desks and associated equipment.

\subsubsection{HPT/Radiation Monitoring}

Provide office space for one health physics technician performing radiation monitoring.

- Work space with desks and associated instrumentation equipment.

- $\quad$ Storage space for HPT equipment.

- Wall space for the mounting of gas bottle equipment.

\subsubsection{Control Room}

Provide space for process bay control room functions.

- $\quad$ Computer monitoring stations. 
WHC-SD-SNF-CDR-003, Revision 0

\subsection{FACILITY DESIGN}

\subsubsection{Electrical/Telecommunication Room}

Provide space for electrical / telecommunication systems and equipment.

\subsubsection{Fire Riser Room}

Provide space for mechanical fire riser equipment.

\subsubsection{Men's and Women's Restrooms}

Restroom facilities shall be provided for both men and women employees. This function should be in close proximity to the respective change rooms.

- Men's toilet and urinal fixtures.

- Women's toilet fixtures.

- Men's and women's lavatory fixtures.

\subsubsection{Men's and Women's Change Rooms}

Change room facilities shall be provided for both men and women employees. This function should be in close proximity to the respective restrooms.

- Men's shower facilities.

- Women's shower facilities.

- Men's and women's storage lockers and benches.

- Space for change room supplies storage. 


\subsection{FACILITY DESIGN}

\subsection{Seismic Criteria}

DOE Order 5480.28, "Natural Phenomena Hazards Mitigation" establishes a graded approach for determining the PC of an SSC when subjected to Natural Phenomena Hazards based on the probability that SSC response will exceed a safety limitation. Guidance for PC determination is given in DOE STD 1021-93, "Natural Phenomena Hazards Performance Categorization Criteria for Structures, Systems, and Components". Figure 1-1 of STD 1021 summarizes the guidance. It can be seen from the figure that SSCs that perform a safety function in a $\mathrm{HC}-3$ rated facility will be rated PC-2. Since the CVDS will be an $\mathrm{HC}-3$ facility, the safety SSCs will be qualified to the criteria defined by PC- 2 .

A PC-2 rating does not require dynamic finite element analysis. The critical facility methodology given in UBC may be applied.

In Section 2.5 of the STD-1021 it is stated that,

If the behavior or failure of a source can adversely effect the performance of more than one target, the source shall have additional NPH requirements corresponding to the highest performance category that is determined by applying the rules provided in Paragraph (a), (b), and (c) above separately for each target. ....... If the adverse interaction is possible only after the source fails or exceeds its acceptable behavior limits, either of the following two requirements shall be met to preclude adverse interaction : (I) The source shall have additional NPH requirements corresponding to the performance category of the target, if the failure probability of the target is greater than one percent. If the implementation of this criterion is judged not to be cost effective, the additional NPH mitigation requirements for the source shall be in accordance with Table 2-1 ... For, the CVDS, the MCO / cask is the target and the source is the building structure. Given the potential severe consequences of a building structure failure leading to damage and failure of an MCO, the building structure will be assigned a PC-3 rating. Other safety related functions in the facility will be treated as PC-2 SSCs.

Seismic loads shall be calculated in accordance with DOE-STD-1020-94 (Reference 5). For PC-2 SSCs seismic provisions, e.g. UBC-94. PC-3 structures, systems, components and equipment shall have a dynamic analysis performed in accordance with the provisions of ASCE 4-86 (Reference 6). 
WHC-SD-SNF-CDR-003, Revision 0

\subsection{FACILITY DESIGN}

For PC-2 SSCs, the seismic design and evaluation criteria employ the UBC provisions with the exception that site-specific information, if available, is used to define the Design Basis Earthquake (DBE). The maximum ground acceleration and ground response spectra are used in the appropriate terms of the UBC equation for base shear. The maximum ground acceleration is also used in the UBC equation for seismic force on equipment and non-structural components. In the base shear equation, inelastic energy absorption capacity of structures is accounted for by the parameter $R_{w}$. Elastically computed seismic response is reduced by $R_{w}$ values ranging from 4 to 12 as a means of accounting for inelastic energy absorption capability in the UBC provisions. This reduced response is combined with nonseismic concurrent loads and then compared to code allowable response limits. The design detailing provisions from the UBC are required such that SSCs can fully achieve potential inelastic energy absorption capability.

The procedure that will be followed for PC-2 SSCs includes the following:

1. Evaluation of element forces for non-seismic loads, $D_{\mathrm{NS}}$, expected to be acting concurrently with the earthquake.

2. Evaluation of element forces, $D_{S 1,}$ for seismic loads using a static force method where $\mathrm{V}=\mathrm{ZICW} / \mathrm{R}_{\mathrm{w}}$ is applied as a load distributed over the height of the structure for regular facilities.

Where:

$Z$ is the peak ground acceleration from site-specific seismic hazard curves at an exceedance probability of $2 \times 10^{3}$. Taken as $0.14 \mathrm{G}$ from Table C-5a of DOE-STD-1020-94 as reported by Geomatrix for the Hanford 100K Area.

C is the spectral amplification at the fundamental period of the facility from the 5 percent damped median site response spectra. For systems and components, spectral amplification is accounted for by $C_{p}$ in the UBC equipment force equation.

I, the importance factor, should be taken as 1.25 .

$\mathrm{R}_{\mathrm{w}}$, for structures are shown in Table 2-2 of DOE-STD-1029-94.

3. Responses from the seismic and non-seismic loadings, $D_{S 1}$ and $D_{\mathrm{Ns}}$, are combined and evaluated by code specified load combination rules. 
WHC-SD-SNF-CDR-003, Revision 0

\subsection{FACILITY DESIGN}

4. Evaluation of capacities of SSCs, $\mathrm{C}_{0}$ from code ultimate values when strength design is used or from allowable stress levels when allowable stress design is used. Minimum specified or $95 \%$ non-exceedance in-situ values for material strengths should be used for capacity estimation.

5. Comparison of demand, $D_{\mathrm{T}}$, with capacity, $\mathrm{C}_{\mathrm{C}}$, for all SSCs.

6. Evaluation of story drifts. Calculated story drifts should not exceed $0.04 / R_{w}$ times the story height nor 0.005 times the story height for buildings with a fundamental period less than 0.7 seconds. For more flexible buildings, the calculated story drift should not exceed $0.03 / R_{w}$ nor 0.004 times the story height.

For PC-3 SSCs, seismic evaluation must be accomplished by dynamic analysis. The recommended approach is to perform and elastic response spectrum dynamic analysis to evaluate elastic seismic demands on SSCs. Inelastic energy absorption capacity of structures is accounted for by the parameter $F_{k}$. Elastically computed seismic response is reduced by $F_{\mu}$ values ranging from 1 to 3 as a means of accounting for inelastic energy absorption capability. The resulting factored seismic response is combined with non-seismic concurrent loads and then compared to code ultimate response limits. The design detailing provisions from the UBC are also required such that SSCs can fully achieve potential inelastic energy absorption capability.

Response spectra for the Design Basis Earthquake for PC-3 structures, systems, components, and equipment are specified in Figure 1, normalized to a zero period ground acceleration of $0.2 \mathrm{G}$, the peak ground acceleration from site-specific seismic hazard curves at an exceedance probability of $5 \times 10^{-4}$. These design response spectra are applied for two horizontal directions in the free field. For vertical motion, the design response spectra shall be taken as $2 / 3$ the horizontal spectra over the entire range of frequencies.

The procedure that will be followed for PC-2 SSCs includes the following:

1. Evaluation of element forces, $D_{N S}$, for the non-seismic loads expected to be acting concurrently with the earthquake.

2. Calculation of the elastic seismic response to the $D B E, D_{s}$, using a dynamic analysis approach and response Level 3 damping values from Table 2-3 of DOE-STD-1020-94. The dynamic analysis must consider 3 orthogonal components of earthquake ground motion (two horizontal and one vertical). Responses 
WHC-SD-SNF-CDR-003, Revision O

\subsection{FACILITY DESIGN}

from the various direction components shall be combined in accordance with ASCE 4-86. It should be noted that to determine response of SSCs which use $F_{\mu}>1$, that for fundamental periods lower than the period at which the maximum spectral amplification occurs, the maximum spectral acceleration should be used. For higher modes, the actual spectral acceleration should be used.

3. Calculation of the inelastic seismic demand element forces, $D_{s \mid}$, as

$\mathrm{D}_{\mathrm{sl}}=\mathrm{D}_{\mathrm{S}} / \mathrm{F}_{\mu}$

Where $F_{\mu}=$ Inelastic energy absorption factor from DOE-STD1020-94 "Table 2-4 for the appropriate structural system and elements.

4. Evaluation of the total inelastic-factored demand $D_{T 1}$ as the sum of $D_{S 1}$ and $D_{\text {NS }}$.

5. Evaluation of the capacities of elements, $C_{c}$, from code ultimate or yield values such as $\mathrm{ACl} 318$ for reinforced concrete and ANSI/AISC N690 for structural steel.

6. Comparison of demand, $D_{T,}$, to capacity, $C_{c}$.

7. Evaluation of story drifts due to lateral forces, including both translation and torsion. Calculated story drifts should not exceed 0.010 times the story height for structures with contribution to distortion from both shear and flexure. For structures in which shear distortion is the primary contributor to drift, such as those with low rise shear walls, the calculated story drift should not exceed 0.004 times the story height.

8. Check elements to assure that good detailing practice has been followed. 
WHC-SD-SNF-CDR-003, Revision $0^{\circ}$

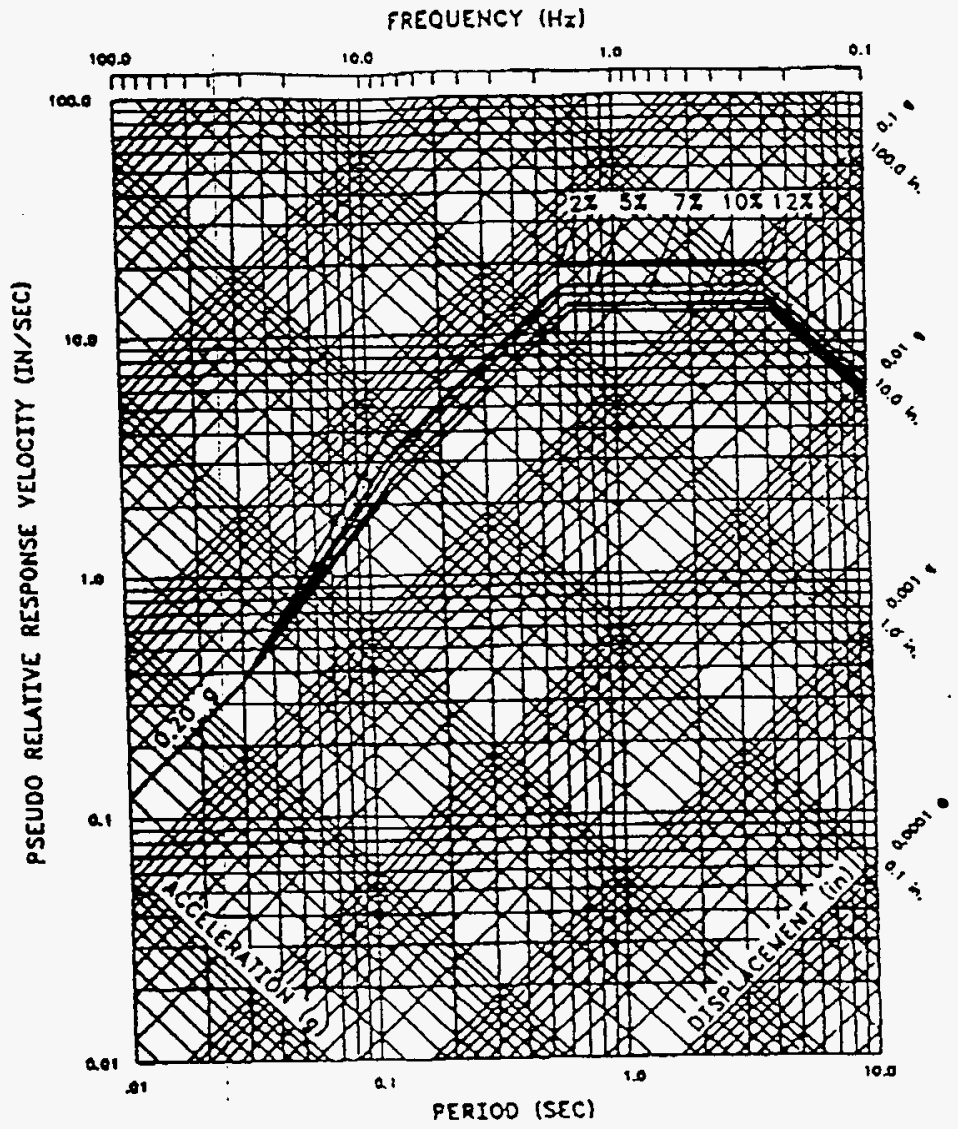

Figure 1

PC-3 Design Response Spectra - $0.2 \mathrm{~g}$

$(2 \%, 5 \%, 7 \%, 10 \%$ and $12 \%$ Critical Damping $)$ 


\subsection{FACILITY DESIGN}

References:

1. WHC-SD-SNF-DB-003, Revision 1, Spent Nuclear Fuel Project Path Forward, Additional NRC Requirements, Westinghouse Hanford Company, Richland, WA, December, 1995.

2. WHC-SD-SNF-DB-004, Revision 0, Spent Nuclear Fuel Project, Seismic Design Criteria, Westinghouse Hanford Company, Richland, WA, October, 1995.

3. DOE Order 5480.28 , Natural Phenomena Hazards Mitigation, U.S. Department of Energy, Washington, D.C.

4. DOE-STD-1021-92, Natural Phenomena Hazards Performance Categorization Criteria for Structures, Systems and Components, U.S. Department of Energy, Washington, D.C., December, 1992.

5. DOE-STD-1020-94, Natural Phenomena Hazards Design and Evaluation Criteria for Department of Energy Facilities, U.S. Department of Energy, Washington, D.C., April, 1994.

6. ASCE 4-86, Seismic Analysis of Safety-Related Nuclear Structures and Commentary on Standard for Seismic Analysis of Safety Related Nuclear Structures, American Society of Civil Engineers, New York, N.Y., September, 1986. 
WHC-SD-SNF-CDR-003, Revision 0

\subsection{FACILITY DESIGN}

\subsection{HVAC System Design Description}

The HVAC system for the CVDS consists of one HVAC supply system for each Process Bay, one for the west corridor area, and one for the Administration Building. Each supply system operates independently but interfaces with the building control system. The Process Bay HVAC system is a constant volume recirculating system with two stage HEPA filtration in the return air system. Each bay incorporates a local slot hood which continuously exhausts a portion of the air from the bay area. Air exhausted through slot hoods in each bay combines into a single system and is then filtered through a two stage HEPA plenum. Partially redundant exhaust fans, running in parallel, direct the exhaust air to the stack. Each bay also has a general exhaust system which is used to maintain design pressures. This general exhaust combines with the west corridor exhaust system.

The West Corridor Area HVAC system is a constant volume once-through system. Air is ducted to the access corridor and support rooms. Air supplied to the access corridor is transferred to the material storage room and change rooms. The change rooms will maintain a positive pressure with respect to the Process Bays. Air in the West Corridor support rooms, the controlled rooms in the administration area, and general exhaust from the Process Bays is exhausted to a separate two-stage HEPA plenum. A separate set of partially redundant exhaust fans, running in parallel, directs the exhaust air to the stack.

The Administration Area is served by a packaged unit with chilled water cooling and electric heat. Air is recirculated through the Administration Area and an economizer is used to reduce energy costs. Air from the restrooms and shower areas is exhausted to the outside. 
WHC-SD-SNF-CDR-003, Revision 0

\subsection{FACILITY DESIGN}

\subsubsection{Process Bay Zone III HVAC System}

\subsubsection{System Function}

The HVAC system for a typical Process Bay ventilates, conditions, and maintains required space design pressures. The HVAC system maintains the integrity of the confinement zone by maintaining a pressure differential between the Process Bay and any surrounding zone. This ensures all airflow is into areas of highest possible contamination. A portion of the air supplied to the Process Bay area is recirculated to reduce energy costs in maintaining comfort air conditioning. Recirculated air is filtered through two stages of HEPA filters to ensure adequate air quality. A general exhaust system is provided for each bay and is utilized to maintain design space pressure. Local slot hoods are provided for each Process Bay. Slot hoods are located near work areas with potential for contamination releases. Exhaust air from slot hoods are filtered through two stages of HEPA filters and routed to the exhaust stack. The major features of the Process Bay HVAC system are:

A. Maintain a negative pressure differential between the Process Bay and surrounding areas.

B. Each Process Bay contains an independent HVAC supply system to prevent cross contamination of individual Process Bays and ensure other Process Bays are operational in the event one or more is shut down.

C. The exhaust system incorporates a slot hood providing local exhaust at point sources of possible air borne contamination.

D. The HVAC system maintains design room temperature.

E. The HVAC system maintains the space air quality.

\subsubsection{Design Requirements}

\subsection{Performance and Characteristics}

The Process Bay HVAC system must satisfy the following requirements to perform its functions:

A. Maintain the operating pressure of the Process Bay a minimum of $-0.10^{\prime \prime}$ W.C. with respect to atmosphere and adjoining spaces when the garage door is closed. 
WHC-SD-SNF-CDR-003, Revision 0

\subsection{FACILITY DESIGN}

B. The HVAC system should be sized to ventilate the Process Bay at a minimum rate of six (6) air changes per hour.

C. Outside air must be provided to the Process Bay at a minimum of $0.5 \mathrm{cfm} / \mathrm{sq}$. $\mathrm{ft}$.

D. The minimum space relative humidity is to be $30 \%$, and the maximum relative humidity is to be $50 \%$.

E. Spaces are to be maintained at $78^{\circ} \mathrm{F}$ in cooling mode and $72^{\circ} \mathrm{F}$ in heating mode.

F. The temperature shall be actively controlled by the HVAC system.

G. Instrumentation must be provided for temperature, radiation, smoke, and fire.

H. The exhaust and return ductwork must be welded - stainless steel construction and demonstrated to be leak tight.

I. The local slot hood must extend to a position to adequately capture potential contamination point sources.

\subsection{Configuration and Essential Features}

The Process Bay HVAC system must supply clean, filtered air, at a constant flow rate. Recirculated air must be HEPA filtered to remove contamination before mixing with outside air and recirculated to the space. General exhaust and slot hood exhaust will be HEPA filtered and directed to the stack. Exhaust air from the stack shall be monitored for contamination.

\subsection{Components Parts and Materials}

The Process Bay HVAC system is comprised of the following major components:
A. Outside air intake louver.
B. Roughing Filter (30\% ASHRAE Efficiency)
C. Final Filter ( $85 \%$ - 95\% ASHRAE Efficiency)
D. Chilled Water Cooling Coil 
WHC-SD-SNF-CDR-003, Revision 0

\subsection{FACILITY DESIGN}
E. Supply Fan
F. Duct Heating Coils
G. Isolation Dampers
H. HEPA Filters
1. Exhaust Air Fans, Two Fans in Parallel
J. Exhaust Stack
K. Instrumentation and Controls

The supply duct need only be constructed of galvanized steel. The exhaust and return ductwork and other components exposed to the air stream are to be constructed of stainless steel.

The slot hood exhaust system is to include the following features and components:

A. A moveable boom to locate the slot hood in close proximity to the work site to ensure an adequate capture velocity.

B. The slot hood face area must be sized to match the dimensions of the local work area.

C. The slot hood air flow rate must be adequate to produce an adequate capture velocity at the extreme point source of potential contamination release.

D. The slot hood and connecting ductwork shall be constructed of stainless steel.

E. The air flowing through the slot hood shall be once through and is connected to an exhaust system with two stages of HEPA filters.

\subsection{Utility Requirements}

The Process Bay HVAC system will require normal distributed power consisting of $120 \mathrm{~V}$, single phase, $60 \mathrm{HZ}$, and $480 \mathrm{~V}$, three phase, $60 \mathrm{HZ}$ power feeds. The exhaust fans should be powered by separate power panels to provide an inherent level of redundancy if a power panel should fail. 
WHC-SD-SNF-CDR-003, Revision 0

\subsection{FACILITY DESIGN}

\subsection{Confinement Requirements}

Each Process Bay supply air handler shall be independent and located within the confined space of the Process Bay to eliminate the possibility of cross contamination between separate Process Bays.

\subsection{Operational Requirements}

The operational requirements of the Process Bay HVAC systems are to provide clean, filtered, and conditioned air to the Process Bay confinement areas and maintain a negative pressure differential with respect to surrounding areas.

\subsection{Interfacing Systems}

The Process Bay HVAC system is to be monitored and controlled through the building's control system. Temperatures, pressures, flow rates, and alarm indications are to be both monitored and controlled to enhance the operating efficiency of the system.

\subsection{Space Requirements}

Space allocations for filter/coil change out and general equipment maintenance should be included in the equipment layout of the building.

\subsection{Structural Requirements}

Components of the Process Bay HVAC system are required to be seismically supported in accordance with the building seismic classification.

\subsection{Environmental Requirements/Natural Phenomena}

The Process Bay HVAC system in conjunction with the radiation detection (RD) system will not exhaust or recirculate air with contamination above federally mandated levels. To enhance the dispersion of the exhaust air, an exhaust stack is to be included with a minimum discharge velocity of $3,500 \mathrm{fpm}$. The exhaust stack shall have a minimum height of 1.3 times the height of the facility in accordance with American Conference of Governmental Industrial Hygienists (ACGIH).

\subsection{Instrumentation and Control Requirements}

Instrumentation is required for all components of the Process Bay HVAC system such that their operation and performance can be monitored. The HVAC system 
WHC-SD-SNF-CDR-003, Revision 0

\subsection{FACILITY DESIGN}

is to monitored and controlled through the building's control system. To ensure Process Bay areas do not become pressurized, the supply fans and the exhaust air system will be interlocked to prevent the supply fans from operating upon detection of failure of the exhaust air fans. Local controls for specific components may be utilized as long as their operation can be monitored by the building's control system.

\subsection{Surveillance and Inspection Requirements}

The components of the Process Bay HVAC system should be regularly inspected for their proper operation and to prevent future failures. The majority of this investigation will be accomplished through monitoring by the building's control system.

\subsection{Availability/Reliability}

All components which comprise the Process Bay HVAC system should be readily available through the provisions of adequate spares. Each component of the HVAC system must have a high reliability to ensure that the system can perform its previously stated functions. Redundant exhaust fans should be provided to ensure negative differential pressure requirements stated previously are maintained.

\subsection{Maintenance}

The Process Bay HVAC system should require only periodic maintenance.

\subsection{Safety}

The Process Bay HVAC system should not present any abnormal safety hazards.

\subsection{Codes and Standards}

The following lists of codes and standards should be reviewed and adhered to as required to ensure a properly designed contamination control HVAC system:

$\begin{array}{ll}\text { DOE 6430.1A } & \text { General Design Criteria } \\ \text { ERDA 76-21 } & \text { Nuclear Air Cleaning Handbook } \\ \text { ACGIH } & \text { Industrial Ventilation } \\ \text { ASHRAE } & \\ \text { SMACNA } & \\ \text { NFPA } & \\ \text { ASME } & \end{array}$


WHC-SD-SNF-CDR-003, Revision 0

\subsection{FACILITY DESIGN}

\subsection{Quality Assurance}

TBD

\subsection{Installation/Construction}

TBD

\subsection{Decommissioning}

TBD

\subsection{Hazardous Waste}

TBD

\subsubsection{Pre-Conceptual Design}

\subsection{System Configuration}

The conceptual design for the Process Bay Zone III HVAC systems consists of an outside air intake louver, supply air handling unit, isolation dampers, duct mounted airflow measuring stations, duct heating coils, return air and exhaust air two stage HEPA filter assemblies, local slot exhaust hoods, exhaust air fans, and an exhaust air stack. The supply air handling unit is comprised of the following equipment: an outside air/return air mixing box with dampers, $30 \%$ and $85 \%$ rated ASHRAE filters, a chilled water cooling coil, an access section, and a centrifugal supply air fan. Electric heating coils located in the supply air duct will provide heating.

A general exhaust system is provided for each bay and is used to maintain design space pressure. This exhaust combines with the west corridor exhaust system. Two stage HEPA filtration and redundant fans are provided for this system.

Local slot hoods provided for each Process Bay will exhaust air from the space through two stages of HEPA filters to the exhaust stack.

\subsection{Process Description}

A typical Process Bay HVAC system is designed to ventilate, condition, and maintain the required pressure differentials between the Process Bay and surroundings zones. The HVAC system recirculates a portion of the air in the Process Bay to reduce operating costs in providing comfort air conditioning and ventilation. Outside air is drawn through an intake louver and mixed with return air. 


\subsection{FACILITY DESIGN}

The mixed air is then drawn through two stages of filtration ( $30 \%$ and $85 \%)$, cooled by a chilled water coil, and supplied by a backward-inclined supply fan. Electric heating coils located in the supply duct provide heating when required.

The air in the Process Bay area which is not recirculated is exhausted through a general exhaust system and a local slot hood. The general exhaust combines with the west corridor exhaust system before entering a two stage HEPA filter and continuing to the stack. Air exhausted through the slot hoods is combined into a common system and HEPA filtered and directed to the exhaust stack. Partially redundant exhaust fans serve each exhaust system. The fans, each sized at a minimum of $60 \%$ total exhaust air capacity, are used to draw the exhaust air to the stack. If one fan in a parallel system goes down, the other will ramp up to approximately $80 \%$ of design flow. The supply system will be interlocked to the exhaust system to maintain space pressure differentials.

\subsection{Equipment Description}

A. Supply Fan: Backward-inclined, double-width, double-inlet, class III, centrifugal fan. Fans will be belt driven with high efficiency motors.

B. Exhaust Fans: Backward-inclined, single-width, single-inlet, class III, centrifugal fans. Fans will be belt driven with high efficiency motors and variable frequency drives.

C. Cooling Coil: Chilled water cooling coil.

D. AHU Filters: $30 \%$ ASHRAE roughing filter and $85 \%$ ASHRAE final filter.

E. Ductwork: Galvanized supply ductwork and type 304 stainless steel exhaust and return ductwork.

F. HEPA Filter Housing: 304 stainless steel, bag-out type, transitions on both ends, and assembled in the direction of air flow as follows: prefilter section, test section, first stage HEPA filter section, test section, second stage HEPA filter section, and final test section.

G. HEPA Prefilter: $24 \times 24 \times 6$ inches thick, UL Class 1, $65 \%$ efficiency per ASHRAE standard 52-76. 
WHC-SD-SNF-CDR-003, Revision 0

\subsection{FACILITY DESIGN}

H. HEPA Filters: $24 \times 24 \times 11 \frac{1 / 2}{2}$ inches thick, UL Class $1,99.97 \%$ efficiency per DO test, fire retardant plywood or stainless steel frame.

I. Isolation Dampers: Isolation dampers at HEPA filter plenums and exhaust fans will be ANSI Class 150 butterfly valves with motorized actuators and will meet the requirements of ASME N 509-1989, leakage class I. Isolation dampers at outside air intakes will be industrial grade, galvanized opposed blade control dampers and will meet the requirements for ASME $\mathrm{N}$ 509-1989, leakage class II.

\subsection{Instrumentation and Controls}

TBD

\subsection{System Interfaces}

The Process Bay Zone III HVAC system is interfaced with the building control system and the RD system.

\subsubsection{System Limitations}

\subsection{Operating Limits}

TBD

\subsection{Precautions}

TBD

\subsection{Failure Modes and Effects}

TBD

\subsection{Recovery Procedures}

TBD 
WHC-SD-SNF-CDR-003, Revision 0

\subsection{FACILITY DESIGN}

\subsubsection{Operations}

\subsection{Startup Operation}

TBD

\subsection{Normal Operation}

TBD

\subsection{Shutdown Operations}

TBD

\subsection{Infrequent Operations}

TBD

\subsubsection{Maintenance}

\subsection{Maintenance Approach}

TBD

\subsection{Corrective Maintenance}

TBD

\subsection{Preventative Maintenance}

TBD

\subsection{In Service Inspection}

TBD

\subsection{Surveillance}

TBD

\subsection{Equipment Calibration}

TBD 
WHC-SD-SNF-CDR-003, Revision 0

\subsection{FACILITY DESIGN}

\subsubsection{Appendices}

\subsubsection{West Corridor Area Zone IV HVAC System}

\subsubsection{System Function}

The HVAC system for West Corridor Area ventilates, conditions, and maintains required space design pressures. The HVAC system maintains the integrity of the confinement zone by maintaining a pressure differential between the West Corridor Area and the Process Bays. This ensures all airflow is into areas of highest possible contamination. Exhaust air from the support rooms along the east wall of the corridor area are filtered through two stages of HEPA filters and routed to the exhaust stack. The major functions of the West Corridor Area HVAC system are:

A. Maintain a positive pressure differential between the corridor area/support rooms and the Process Bay area. A negative pressure differential shall be maintained between the support rooms air loads and the access corridor.

B. The HVAC system maintains design room temperature.

C. The HVAC system maintains the space air quality.

\subsubsection{Design Requirements}

\subsection{Performance and Characteristics}

The West Corridor Area HVAC system must satisfy the following requirements to perform its functions:

A. Maintain a positive operating pressure with respect to the Process Bay areas.

B. The HVAC system should be sized to ventilate the support rooms at a minimum rate of six (6) air changes per hour.

C. Outside air must be provided to the space at a minimum of 0.5 $\mathrm{cfm} / \mathrm{sq}$. ft.

D. The minimum space relative humidity is to be $30 \%$, and the maximum relative humidity is to be $50 \%$. 
WHC-SD-SNF-CDR-003, Revision 0

\subsection{FACILITY DESIGN}

E. Spaces are to be maintained at $78^{\circ} \mathrm{F}$ in cooling mode and $72^{\circ} \mathrm{F}$ in heating mode.

F. The temperature shall be actively controlled by the HVAC system.

G. Instrumentation must be provided for temperature, radiation, smoke, and fire.

$\mathrm{H}$. The exhaust ductwork must be welded - stainless steel construction and demonstrated to be leak tight.

\subsection{Configuration and Essential Features}

The West Corridor Area HVAC system must supply clean, filtered air, at a constant flow rate. Exhaust air must be HEPA filtered to remove contamination before exhausting to the stack. Exhaust air from the stack shall be monitored for contamination.

\subsection{Components Parts and Materials}

The West Corridor Area HVAC system is comprised of the following major components:
A. Outside air intake louver.
B. Roughing Filter (30\% ASHRAE Efficiency)
C. Final Filter (85\% - 95\% ASHRAE Efficiency)
D. Chilled Water Cooling Coil
E. Preheat Coil
F. Supply Fan
G. Duct Heating Coils
H. Isolation Dampers
I. HEPA Filters
J. Exhaust Air Fans, Two Fans in Parallel 
WHC-SD-SNF-CDR-003, Revision 0

\title{
3.0 FACILITY DESIGN
}

\author{
K. Exhaust Stack (common for all exhaust systems) \\ L. Instrumentation and Controls
}

The supply duct need only be constructed of galvanized steel. The exhaust ductwork and other components exposed to the air stream are to be constructed of stainless steel.

\subsection{Utility Requirements}

The West Corridor Area HVAC system will require normal distributed power consisting of $120 \mathrm{~V}$, single phase, $60 \mathrm{HZ}$, and $480 \mathrm{~V}$, three phase, $60 \mathrm{HZ}$ power feeds. The exhaust fans should be powered by separate power panels to provide an inherent level of redundancy if a power panel should fail.

\subsection{Confinement Requirements}

The West Corridor Area supply air handler shall be independent. General airflow shall be from the access corridor towards the support rooms and truck bays.

\subsection{Operational Requirements}

The operational requirements of the West Corridor Area HVAC systems are to provide clean, filtered, and conditioned air to the space and maintain a positive pressure differential with respect to the truck bay.

\subsection{Interfacing Systems}

The West Corridor Area HVAC system is to be monitored and controlled through the building's control system. Temperatures, pressures, flow rates, and alarm indications are to be both monitored and controlled to enhance the operating efficiency of the system.

\subsection{Space Requirements}

Space allocations for filter/coil change out and general equipment maintenance should be included in the equipment layout of the building.

\subsection{Structural Requirements}

Components of the West Corridor Area HVAC system are required to be seismically supported in accordance with the building seismic classification. 
WHC-SD-SNF-CDR-003, Revision 0

\subsection{FACILITY DESIGN}

\subsection{Environmental Requirements/Natural Phenomena}

The West Corridor Area HVAC system in conjunction with the RD system will not exhaust air with contamination above federally mandated levels. To enhance the dispersion of the exhaust air, an exhaust stack is to be included with a minimum discharge velocity of 3,500 fpm. The exhaust stack shall have a minimum height of 1.3 times the height of the facility in accordance with ACGIH.

\subsection{Instrumentation and Control Requirements}

Instrumentation is required for all components of the West Corridor Area HVAC system such that their operation and performance can be monitored. The HVAC system is to monitored and controlled through the building's control system. To ensure the areas exhausted in the corridor do not become pressurized, the supply fan and the exhaust air system will be interlocked to prevent the supply fan from operating upon detection of failure of the exhaust air fans. Local controls for specific components may be utilized as long as their operation can be monitored by the building's control system.

\subsection{Surveillance and Inspection Requirements}

The components of the West Corridor Area HVAC system should be regularly inspected for their proper operation and to prevent future failures. The majority of this investigation will be accomplished through monitoring by the building's control system.

\subsection{Availability/Reliability}

All components which comprise the West Corridor Area HVAC system should be readily available through the provisions of adequate spares. Each component of the HVAC system must have a high reliability to ensure that the system can perform its previously stated functions. Redundant exhaust fans should be provided to ensure differential pressure requirements stated previously are maintained.

\subsection{Maintenance}

The West Corridor Area HVAC system should require only periodic maintenance.

\subsection{Safety}

The West Corridor Area HVAC system should not present any abnormal safety hazards. 
WHC-SD-SNF-CDR-003, Revision 0

\subsection{FACILITY DESIGN}

\subsection{Codes and Standards}

The following lists of codes and standards should be reviewed and adhered to as required to ensure a properly designed contamination control HVAC system:

DOE 6430.1A
ERDA 76-21
ACGIH
ASHRAE
SMACNA
NFPA
ASME

General Design Criteria Nuclear Air Cleaning Handbook Industrial Ventilation

\subsection{Quality Assurance}

TBD

\subsection{Installation/Construction}

TBD

\subsection{Decommissioning}

TBD

\subsection{Hazardous Waste}

TBD

\subsubsection{Pre-Conceptual Design}

\subsection{System Configuration}

The pre-conceptual design for the West Corridor Zone IV HVAC system consists of an outside air intake louver, supply air handling unit, isolation dampers, duct mounted airflow measuring stations, duct heating coils, exhaust air two stage HEPA filter assemblies, exhaust air fans, and an exhaust air stack (exhaust stack is common to Process Bay and West Corridor area). The supply air handling unit is comprised of the following equipment: an outside air/return air mixing box with dampers, $30 \%$ and $85 \%$ rated ASHRAE filters, a chilled water cooling coil, an access section, and a centrifugal supply air fan. Electric heating coils located in the supply air duct will provide heating. 
WHC-SD-SNF-CDR-003, Revision 0

\subsection{FACILITY DESIGN}

\subsection{Process Description}

The West Corridor Area HVAC system is designed to ventilate, condition, and maintain the required pressure differentials between the corridor spaces and the Process Bays. The HVAC system is a once-through system. All exhaust air is sent through a two stage HEPA filter before exhausting out the stack. This exhaust system is separate from the truck bay exhaust system up to a converging point at the stack. Outside air is drawn through two stages of filtration ( $30 \%$ and $85 \%)$, cooled by a chilled water coil, and supplied by a backward-inclined supply fan. Electric heating coils located in the supply duct provide heating when required. Partially redundant exhaust fans of a minimum of $60 \%$ total exhaust air capacity are used to draw the exhaust air to the stack.

\subsection{Equipment Description}

A. Supply Fan: Backward-inclined, double-width, double-inlet, class III, centrifugal fan. Fans will be belt driven with high efficiency motors.

B. Exhaust Fans: Backward-inclined, single-width, single-inlet, class III, centrifugal fans. Fans will be belt driven with high efficiency motors.

C. Preheat Coil: Electric

D. Cooling Coil: Chilled water cooling coil.

E. Heating Coil: Electric reheat coils.

F. AHU Filters: $30 \%$ ASHRAE roughing filter and $85 \%$ ASHRAE final filter.

G. Ductwork: Galvanized supply ductwork and type 304 stainless steel exhaust ductwork.

H. HEPA Filter Housing: 304 stainless steel, bag-out type, transitions on both ends, and assembled in the direction of air flow as follows: prefilter section, test section, first stage HEPA filter section, test section, second stage HEPA filter section, and final test section.

I. HEPA Prefilter: $24 \times 24 \times 6$ inches thick, UL Class $1,65 \%$ efficiency per ASHRAE standard 52-76. 
WHC-SD-SNF-CDR-003, Revision 0

\subsection{FACILITY DESIGN}

J. HEPA Filters: $24 \times 24 \times 11 \frac{1}{2}$ inches thick, UL Class $1,99.97 \%$ efficiency per DO test, fire retardant plywood of stainless steel frame.

K. Isolation Dampers: Isolation dampers at HEPA filter plenums and exhaust fans will be ANSI Class 150 butterfly valves with motorized actuators and will meet the requirements of ASME N 509-1989, leakage class I. Isolation dampers at outside air intakes will be industrial grade, galvanized opposed blade control dampers and will meet the requirements for ASME N 509-1989, leakage class II.

\subsection{Instrumentation and Controls}

TBD

\subsection{System Interfaces}

The West Corridor Zone IV HVAC system is interfaced with the building control system and the RD system.

\subsubsection{System Limitations}

\subsection{Operating Limits}

TBD

\subsection{Precautions}

TBD

\subsection{Failure Modes and Effects}

TBD

\subsection{Recovery Procedures}

TBD 


\subsection{FACILITY DESIGN}

\subsubsection{Operations}

\subsection{Startup Operation}

TBD

\subsection{Normal Operation}

TBD

\subsection{Shutdown Operations}

TBD

\subsection{Infrequent Operations}

TBD

\subsubsection{Maintenance}

\subsection{Maintenance Approach}

TBD

\subsection{Corrective Maintenance}

TBD

\subsection{Preventative Maintenance}

TBD

\subsection{In Service Inspection}

TBD

\subsection{Surveillance}

TBD

\subsection{Equipment Calibration}

TBD 
WHC-SD-SNF-CDR-003, Revision 0

\subsection{FACILITY DESIGN}

\subsubsection{Appendices}

\subsubsection{Administration HVAC Zone IV}

\subsubsection{System Function}

The HVAC system for Administration Area ventilates, conditions, and maintains required space design pressures. The major functions of the Administration Area HVAC system are:
A. Maintain a general airflow direction from office areas towards the West Corridor Area.
B. The HVAC system maintains design room temperature and humidity.
C. The HVAC system maintains the space air quality.

\subsubsection{Design Requirements}

\subsection{Performance and Characteristics}

The Administration Area HVAC system must satisfy the following requirements to perform its functions:

A. Maintain the operating pressure of the office areas positive with respect to change room areas and West Corridor area.

B. The HVAC system should be sized to ventilate the Administration Area at a minimum rate of six (6) air changes per hour.

C. Outside air must be provided to the Administration Area at a minimum of $20 \mathrm{cfm} / \mathrm{sq}$. $\mathrm{ft}$. with a design load of 20 people in the Administration Area.

D. The minimum space relative humidity is to be $30 \%$, and the maximum relative humidity is to be $50 \%$. 
WHC-SD-SNF-CDR-003, Revision 0

\subsection{FACILITY DESIGN}

E. General spaces are to be maintained at $78^{\circ} \mathrm{F}$ in cooling mode and $72^{\circ} \mathrm{F}$ in heating mode. The minimum heating temperature in the change room areas shall be $75^{\circ} \mathrm{F}$.

F. The temperature shall be actively controlled by the HVAC system.

G. Instrumentation must be provided for temperature, radiation, smoke, and fire.

H. The exhaust and return ductwork shall be galvanized steel construction and demonstrated to be leak tight. Exhaust ductwork in shower areas shall be aluminum.

\subsection{Configuration and Essential Features}

The Administration Area HVAC system must supply clean, filtered air, at a constant flow rate.

\subsection{Components Parts and Materials}

The Administration Area HVAC system is comprised of the following major components:

A. Packaged air handling unit with supply fan, filter, chilled water, cooling coil, electric preheat coil, dry bulb economizer, and night set back thermostat.

B. Electric terminal coils.

C. Roof ventilators for restrooms and shower areas.

D. Instrumentation and controls.

\subsection{Utility Requirements}

The Administration Area HVAC system will require normal distributed power consisting of $120 \mathrm{~V}$, single phase, $60 \mathrm{HZ}$, and $480 \mathrm{~V}$, three phase, $60 \mathrm{HZ}$ power feeds 
WHC-SD-SNF-CDR-003, Revision 0

\subsection{FACILITY DESIGN}

\subsection{Confinement Requirements}

The Administration Area supply air handler shall operate independently of other air handling systems. The exhaust fans shall be interlocked to the supply unit to prevent pressurization of the change room areas in the event an exhaust fan shuts down.

\subsection{Operational Requirements}

The operational requirements of the Administration Area HVAC systems are to provide clean, filtered, and conditioned air to the Administration Area.

\subsection{Interfacing Systems}

The Administration Area HVAC system is to be monitored and controlled through the building's control system. Temperatures, pressures, flow rates, and alarm indications are to be both monitored and controlled to enhance the operating efficiency of the system.

\subsection{Space Requirements}

Space allocations for filter/coil change out and general equipment maintenance should be included in the equipment layout of the building.

\subsection{Structural Requirements}

Components of the Administration Area HVAC system are required to be seismically supported in accordance with the building seismic classification.

\subsection{Environmental Requirements/Natural Phenomena}

TBD

\subsection{Instrumentation and Control Requirements}

Instrumentation is required for all components of the Administration Area HVAC system such that their operation and performance can be monitored. The HVAC system is to monitored and controlled through the building's control system. A smoke detector shall be installed in the supply air duct. 
WHC-SD-SNF-CDR-003, Revision 0

\subsection{FACILITY DESIGN}

\subsection{Surveillance and Inspection Requirements}

The components of the Administration Area HVAC system should be regularly inspected for their proper operation and to prevent future failures. The majority of this investigation will be accomplished through monitoring by the building's control system.

\subsection{Availability/Reliability}

All components which comprise the Administration Area HVAC system should be readily available through the provisions of adequate spares. Each component of the HVAC system must have a high reliability to ensure that the system can perform its previously stated functions.

\subsection{Maintenance}

The Administration Area HVAC system should require only periodic maintenance.

\subsection{Safety}

The Administration Area HVAC system should not present any abnormal safety hazards.

\subsection{Codes and Standards}

The following lists of codes and standards should be reviewed and adhered to as required to ensure a properly designed HVAC system:

DOE $6430.1 \mathrm{~A}$
ERDA $76-21$
ACGIH
ASHRAE
SMACNA
NFPA
ASME

General Design Criteria

Nuclear Air Cleaning Handbook Industrial Ventilation

\subsection{Quality Assurance}

TBD

\subsection{Installation/Construction}

\section{TBD}


WHC-SD-SNF-CDR-003, Revision 0

\subsection{FACILITY DESIGN}

\subsection{Decommissioning}

TBD

\subsection{Hazardous Waste}

TBD

\subsubsection{Pre-Conceptual Design}

\subsection{System Configuration}

The conceptual design for the Administration Area Zone IV HVAC systems consists of a packaged air handling unit and local exhaust fans. The supply air handling unit is comprised of the following equipment: an outside air/return air mixing box with dampers, $30 \%$ rated ASHRAE filter, a chilled water cooling coil, an electric preheat coil, and a centrifugal supply air fan. Powered roof ventilators will exhaust air from the restrooms and shower areas.

\subsection{Process Description}

The Administration Area HVAC system is designed to ventilate, condition, and maintain the required pressure differentials within the Administration Area. The HVAC system recirculates a portion of the air in the Administration Areas to reduce operating costs in providing comfort air conditioning and ventilation. A minimum amount of outside air is drawn through an intake louver and mixed with return air. The mixed air is then drawn through a filter, cooled by a chilled water coil, or heated by an electric preheat coil and terminal heating coils, and supplied by a supply fan. Exhaust air in the controlled areas of the Administration Area is directed to the West Corridor Area HEPA exhaust system.

\subsection{Equipment Description}

A. Supply Fan: Backward-inclined, double-width, double-inlet, class II, centrifugal fan. Fans will be belt driven with high efficiency motors.

B. Exhaust Fans: Powered roof ventilators.

C. Preheat Coil: Electric

D. Cooling Coil: Chilled water cooling coil. 
WHC-SD-SNF-CDR-003, Revision 0

\subsection{FACILITY DESIGN}

E. Terminal Heating Coils: Electric

F. AHU Filters: $30 \%$ ASHRAE filter.

G. Ductwork: Galvanized and aluminum ductwork .

\subsection{Instrumentation and Controls}

TBD

\subsection{System Interfaces}

The Administration Area Zone IV HVAC system is interfaced with the building control system and the RD system.

\subsubsection{System Limitations}

\subsection{Operating Limits}

TBD

\subsection{Precautions}

TBD

\subsection{Failure Modes and Effects}

TBD

\subsection{Recovery Procedures}

TBD

\subsubsection{Operations}

\subsection{Startup Operation}

TBD

\subsection{Normal Operation}

TBD 
WESTINGHOUSE HANFORD COMPANY

Cold Vacuum Drying System CDR

Contract \#MW6-SW-310416, Task \#14
MERRICK \& COMPANY

Advanced Technology Sector

Project No. 30012131

WHC-SD-SNF-CDR-003, Revision 0

\subsection{FACILITY DESIGN}

\subsection{Shutdown Operations}

TBD

\subsection{Infrequent Operations}

TBD

\subsubsection{Maintenance}

\subsection{Maintenance Approach}

TBD

\subsection{Corrective Maintenance}

TBD

\subsection{Preventative Maintenance}

TBD

3.4.3.6.4 In Service Inspection

TBD

\subsection{Surveillance}

TBD

\subsection{Equipment Calibration}

TBD

\subsubsection{Appendices}


WHC-SD-SNF-CDR-003, Revision 0

\subsection{FACILITY DESIGN}

\subsection{Mechanical/Utility SDD}

\subsubsection{Plumbing}

\subsubsection{Plumbing Fixtures}

The plumbing in the facility is conventional. There will be a men's and women's change room / restroom with two showers each. The men's room has two toilets, one urinal, and two sinks. The women's restroom has two toilets and two sinks. There will be an electric water cooler, janitor's sink, and a lunchroom coffee bar sink. The decontamination room will have a shower. Each process bay mezzanine shall have an emergency eye wash fountain with drainage plumbed to the process bay floor drains.

\subsubsection{Sanitary Sewer}

The sanitary sewer will be routed to a 5,000 gallon, underground collection tank. The tank will be located to the west of the office area and will have a fluid level sensor. The pipe material shall be ABS, except where exposed, which will be galvanized. The tank is expected to be pumped by site forces using a pumper truck designed for such purposes.

\subsubsection{Domestic Water}

Domestic water will feed the plumbing fixtures and safety eyewashes in standard copper piping. The water will also feed two residential type 52-gallon hot water heaters to provide adequate hot water for the four showers. The domestic water will supply the process deionized water unit via a reduced pressure backflow preventer. All domestic water lines are to be insulated.

\subsubsection{Drainage}

Surface drains in the process areas will serve to provide spill containment and to collect fire water discharge water. All of the spill containment fire discharge water will be routed in double wall contained piping to an above ground retention basin located south of the facility. The containment piping will be routed through a monitoring sump sized for 200 gallons where the spill discharge occurrence may be detected by a moisture sensor. The discharge may then be tested by plant personnel for contamination. The spill containment monitoring box will have a low discharge opening to drain the tank and a sump pump to transfer the collected water to a reclaim tanker or barrel. 
WHC-SD-SNF-CDR-003, Revision 0

\subsection{FACILITY DESIGN}

In case of a fire, the monitoring tank has an overflow that will allow the high water flow of a fire to pass through the monitoring tank and into the 20,000-gallon retention basin. The retention basin also serves as the double containment for the monitoring tank. The holding capacity of the basin is 20,000 gallons. The fire water requirement is 20 minutes of water flow at the largest area or 7,200 gallons.

\subsubsection{Instrument Air}

Instrument air is used to drive air-operated control valves. In order to reduce equipment, nitrogen has been selected to provide the "instrument air" for the control functions instead of an air compressor. The nitrogen is also necessary for process requirements. Nitrogen will be provided by a tube truck to be situated on the west side of the facility where it will be piped to a nitrogen and helium manifold to service the process and control requirements of the operation.

\subsubsection{Deionized Water}

Deionized water will be supplied to the process via a package deionized water unit. The deionized unit is sized for a minimum of $5 \mathrm{gpm}$. The unit will be located in the process access area storage room. 
WHC-SD-SNF-CDR-003, Revision 0

\subsection{FACILITY DESIGN}

\subsection{Electrical Distribution SDD}

The Electrical System will provide power distribution, lighting, grounding, and lightning protection for the Cold Vacuum Drying Facility, equipment and instruments as required.

Normal power will be provided with a grounding system to ensure safety to personnel and equipment, to provide a connection to earth for transformer neutrals, to provide a discharge path to ground through lightning and surge arresters, and to provide a reference point for electronic systems.

\subsubsection{General}

The electrical design will follow the guidelines and incorporate the following regulations and requirements. The applicable portions will be included in the construction specifications.

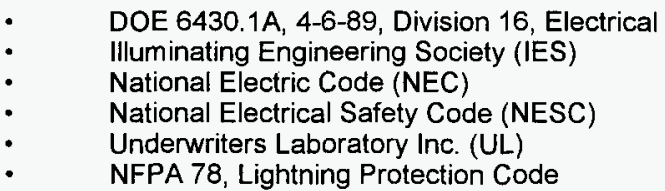

All electrical equipment will be specified to be energy efficient where applicable and available.

\subsubsection{Equipment Connections and Receptacles}

At a maximum of $20^{\prime}-0^{\prime \prime}$ on center, 120 volt duplex receptacles will be provided around the inside perimeter of the process bays. Ground Fault Circuit Interrupting (GFCl) type receptacles will be provided for the receptacles located within $5^{\prime}-0$ " of wet surfaces and sinks, and as additionally required by the NEC. Office areas will be provided with 120 volt duplex receptacles. Appropriate receptacles will be provided for cord-connected equipment such as lunchroom equipment, computer equipment, and radiation monitoring equipment.

The design will provide installation of feeders (conduit and wire) adequately sized for equipment to be installed. Where equipment packages (such as the VDM) have several motors or electrical loads, not all of which will operate simultaneously, the feed will be sized for the loads expected to operate simultaneously. 
WHC-SD-SNF-CDR-003, Revision 0

\subsection{FACILITY DESIGN}

Process and building support equipment will generally be specified to be provided with prepackaged and prewired control panels with an integral local power disconnect device.

All process equipment will be installed by the Construction Contractor under this project.

Generally, all power and control conduit used within the facility will be GRC, with the exception of that used in the alarm systems.

\subsubsection{Building Electrical Normal Power}

The design will include extension of an overhead $(\mathrm{OH}) 13.8 \mathrm{kV}$ primary circuit from existing poles at a point adjacent to the site. The existing circuit will be extended and routed $\mathrm{OH}$ to a point near the south edge of the construction site. Using fused cutouts and lightning arrestors, the extended $\mathrm{OH}$ circuit will be converted to an underground circuit to supply the new building pad-mount transformer.

All underground primary conduit will be concrete encased, buried a minimum of 3 feet below finished grade. The backfill will be done in 6 -inch layers with each layer compacted to $95 \%$ of maximum density according to the Modified Proctor Method. The backfill in the immediate area of conduit will be done with clean sand to a depth of 6 inches above and below conduit. Succeeding layers of backfill may be with fill material compacted after each layer. A conduit marking tape will be provided above the underground conduit route at a depth of $18^{\prime \prime}$ below finished grade. The final energization tie-in of the extended $\mathrm{OH}$ circuit to the existing $13.8 \mathrm{kV} \mathrm{OH}$ circuit will be performed by ICF $\mathrm{KH}$.

A nonflammable oil-filled pad-mounted transformer will be located on the south side of the facility. The transformer will be sized to accommodate the electrical requirements. The transformer pad will be sized to accommodate the pad-mounted transformer. Secondary power at $277 / 480 \mathrm{~V}$ will be routed into the building through underground conduits.

Power will be distributed by a free-standing metal-enclosed switchboard. Phase, neutral, and ground bussing will be provided. The switchboard bussing will have capacity to accommodate a $20 \%$ increase in electrical demand. Switchboard main and feeder circuit breakers will have adjustable solid-state trip units responsive to long-time, short-time, instantaneous, and ground-fault current characteristics.

A kilowatt-hour demand meter will be installed on the switchboard to measure power usage and demand. Additional meters will include indicating voltmeters and ammeters with selector switches. 
WHC-SD-SNF-CDR-003, Revision 0

\subsection{FACILITY DESIGN}

Motor loads that are not part of prepackaged equipment will be powered from a $480 \mathrm{~V}$ 3-phase motor control center located in the electrical room. The motor control center will be free-standing and metal enclosed with modular plug-in combination motor controllers. Assembly and wiring will comply with the National Electrical Manufacturer's Association (NEMA) ICS Standards Type II-C, and all wiring will be extended to terminal compartments for ready access. Controllers will be NEMA rated and will contain spare interlocks. Motors above $50 \mathrm{hp}$ will use reduced voltage controllers. Capacitors will be installed on large motor circuits as necessary to maintain power factor at a minimum of 0.95 . Two speed motor controllers and reduced voltage motor controllers will be provided with power factor improvement capacitors as required.

Panelboards for power distribution, lighting, receptacles, and small loads will be constructed in accordance with Federal Specification (FS) W-P-115, Type 1, Class 1. Main circuit breakers will be provided in panelboards. Panelboard circuit breakers will be the molded case bolt-on type.

\subsubsection{Uninterruptible Power}

One $50 \mathrm{kVA}, 480 \mathrm{~V}$ to $208 / 120 \mathrm{~V}$, uninterruptible power system, complete with battery packs, battery disconnect switch and circuit breaker, maintenance bypass cabinet, and computer power center, will be provided to assure safety class critical systems have continuous power supplied during and after a design-base accident.

Other backup power will be provided for specific systems only by use of direct current (dc) battery systems and battery chargers. The battery backup systems will be provided for:

- Fire alarm control panel

- Emergency egress and exit illumination

Emergency battery backed power will not be provided for:

$\begin{array}{ll}\text { - } & \text { Evacuation alarm systems } \\ \text { - } & \text { Publock door monitor systems } \\ & \text { Continuous air monitors (CAM) }\end{array}$

\subsubsection{Grounding}

A grounding electrode system will be constructed in accordance with NEC Article 250. Interconnected elements will include building reinforcing steel, water piping, 
WHC-SD-SNF-CDR-003, Revision 0

\subsection{FACILITY DESIGN}

and a perimeter ground loop. A separate equipment ground conductor will be routed with all power conductors and lighting circuits.

\subsubsection{Lightning Protection}

Lightning protection will be provided for the building using roof-mounted air terminals with a minimum of four building down conductors. All materials shall be to be copper. The lightning protection system will comply with all requirements of the latest edition of NFPA-78 Lightning Protection Code and the NEC.

\subsubsection{Interior Lighting}

Interior facility lighting will consist of energy-efficient fixtures typically operated at $277 \mathrm{~V}$. Lighting levels will be as recommended in the IES Lighting Handbook. High-bay area lighting will consist of metal-halide fixtures when ceiling height permits good lighting design. Lighting for storage areas and mechanical areas will be high-output industrial fluorescent fixtures. Other interior lighting will consist of surface or flush-mounted commercial fluorescent fixtures. Multiple level switching will generally be provided for areas with fluorescent fixtures.

\subsubsection{Exterior Lighting}

Exterior building lighting will be provided. Metal-halide, wall-mounted fixtures with photocells will be installed at all exterior doors. Metal-halide fixtures with photocells on metal poles will illuminate roadway and walkway areas.

\subsubsection{Emergency and Exit Lighting}

\subsubsection{Exit Lighting}

Exit signs will be provided at the interior of each building exit. In areas where means of egress are not readily apparent, directional exit signs will be provided. Exit signs will include integral chargers, batteries, and relays to provide illumination automatically upon failure of the normal power source.

\subsubsection{Emergency Lighting}

Emergency lighting will be provided inside the building in accordance with NFPA 101. Emergency lighting in areas with fluorescent lighting will be provided by use of fluorescent fixtures with integrally-mounted backup battery packs. Emergency lighting in other areas will be provided by use of shelf-mounted battery backed emergency lighting units with PAR lamps. The self-contained battery backup units 
WHC-SD-SNF-CDR-003, Revision 0

\subsection{FACILITY DESIGN}

will be provided with integral 3-prong plugs. Receptacles provided adjacent to the emergency lighting unit locations will be supplied with normal power. 
WHC-SD-SNF-CDR-003, Revision O

\subsection{FACILITY DESIGN}

\subsection{Facility Control}

\subsubsection{Radiation Control}

\subsubsection{Continuous Air Monitor}

Continuous air monitors (CAMs) are used to provide warning of significant airborne contamination, and are usually associated with work areas. CAM will be used to warn personnel of airborne contamination that exceeds control limits due to failures in containment devices, equipment, or systems.

Only one CAM has been identified as being required in each process bay. This unit will be located above the mezzanine area and will primarily detect a release of airborne contamination due to failure around the cask lid. A portable cart-mounted unit consisting of a regulated air pump and a particulate air monitor will be specified. The air monitor will be an Eberline AMS-3A beta particulate unit with a RAP-1 air pump or equivalent. A flashing red light and bell will be activated upon an alarm condition. The alarm signal will also be sent to Central Control for alarm and record.

\subsubsection{Stack Monitoring and Sampling}

Monitoring and/or sampling of airborne effluents from the stack is required by WHCCM-7-5, Environmental Compliance Manual, to assure compliance with federal, Washington State, and local regulations, DOE orders, and WHC policy. These systems are also required by the FDC, Section 2.5 . The operational objective for management of airborne effluents is to control concentrations of radionuclides released to the environment within ALARA requirements. Both continuous monitoring and record sampling will be used in the CVDS.

The general design of the stack monitoring and sampling system will be in accordance with the following documents:

- WHC-CM-4-9, Radiological Design, Section 10.0 - Sampling and Monitoring

WHC-CM-7-5, Environmental Compliance Manual, Part D Radioactive Airborne Emissions

ANSI N13.1-1969, Guide to Sampling Airborne Radioactive Materials in Nuclear Facilities

ANSI N42.18-1974, Specifications and Performance of On-site Instrumentation for Continuous Monitoring Radioactivity in Effluents 
WHC-SD-SNF-CDR-003, Revision 0

\subsection{FACILITY DESIGN}

- 40 CFR Part 61 Subpart H - National Emission Standards for Emissions of Radionuclides other than Radon from Department of Energy Facilities

An isokinetic probe assembly will be installed in the exhaust stack. If multiple samples are required, separate probes will be used if possible. Otherwise, a flow splitter that divides the sample near-isokinetically will be used. Transport lines will be designed with a minimum of disturbances to minimize particle deposition. The lines will also be insulated and heat traced as necessary to eliminate condensation.

Monitoring and sampling equipment will be located in the stack fan room on the mezzanine next to the stack. This enclosure will be heated to protect the electronic equipment. Continuous monitoring of the air sample for gross alpha and betagamma radiation will take place. The monitors will analyze the sample for both rateof-rise and time-integrated activity. In addition, a record sample will be obtained for detailed analysis in a laboratory.

Hanford currently has a "Generic Stack Monitor Assembly" drawing set. In addition, commercially available units have been identified that appear to meet design requirements. The most economical of these options will be included in the final specification.

\subsubsection{Liquid Effluent Monitoring}

Similar to airborne effluents, monitoring and/or sampling of liquid effluents is required to assure environmental compliance. Continuous monitoring for radionuclides is required for releases that could exceed $1 \mathrm{DCG}$ equivalent at the point of release averaged over 1 year or that could result in unanticipated releases to the environment.

There will be no liquid effluent discharges from the CVDS to the environment. The sanitary sewer will be completely separated from the process area where any contamination may occur. The sanitary sewer line will be routed to a collection tank where the effluent will be transferred for final processing in lieu of actual subsurface absorption at the building site.

The process water reclaim system is entirely contained within the facility by pumping the reclaimed water to a 5,000-gallon retention tank for later transfer to a processing station.

Spill containment was discussed in Section 3.5 .2 but is essentially the same as process water reclaim in that there is no actual liquid effluent discharges other than to reclaim tankage of one sort or another. 
WHC-SD-SNF-CDR-003, Revision 0

\subsection{FACILITY DESIGN}

Therefore, continuous monitoring for environmental record purposes will not be performed on the spill collection system piping. If moisture is detected in the floor drain system monitoring tank, then a physical test can be performed to detect any contamination problems. The process water reclaim system will be monitored with an off-line system that will monitor activity in a side stream taken from the process water reclaim line. The system will be capable of measuring beta activity using a plastic scintillator and gamma activity using a sodium iodide scintillator.

In addition to monitoring, a sample of the final effluent will be obtained and tested. Flow measurement data including volume and flow rate will also be recorded.

\subsubsection{Personnel Monitors}

Personnel monitors will be used to monitor regulated workers for contamination. Commercially available whole body personnel monitors will be specified. These monitors will be located in passageways from the men's and women's change rooms to the non-regulated portion of the process bay access corridor. An additional hand monitor will be located at the control point from the process bay to the access walkway. The monitors will alarm both visually and audibly upon detection of contamination. The alarms will also be sent to Central Control for acknowledgement and recording.

\subsubsection{Liquid Leak Detection System}

A liquid leak detection (LLD) system will be provided at the CVDS process water reclaim storage tank room to detect leakage.

LLD equipment will also be provided in the annular space between the inner and outer pipes of the process bay floor drain line routed to the outside retention basin.

A central alarm panel shall be installed in the main control area that indicates the status of each monitor location.

\subsubsection{HVAC Control}

See HVAC SDD

\subsubsection{Security}

All exterior doors to the facility, including the emergency exists and telescoping doors, shall be provided with security locks in accordance with WHC-CM-4-33 and NFPA 101. 
WHC-SD-SNF-CDR-003, Revision 0

\subsection{FACILITY DESIGN}

\subsubsection{Main Entry Door}

The main entry door shall be equipped with a card key operator to allow only authorized entry. All entry both in and out, shall be logged and recorded by the Central Control system.

\subsubsection{Emergency Doors}

All the emergency doors shall be equipped with an alarm to indicate that the door has been opened. The central control system will log and maintain historical data on emergency door opening.

\subsubsection{Telescoping Truck Doors}

The telescoping truck doors shall only be operated on a signal from the central control panel. The doors shall be equipped with an end switch to indicate that the doors are fully closed.

\subsubsection{Communications}

\subsubsection{Telephones}

Telephone service from the exterior to the interior of the building will be limited to providing one 4-inch underground conduit with pull rope. This conduit will route to the telecommunications room in the office area.

Raceways with pull cords will be provided by the Contractor between the telephone outlets and the telecommunications room. Telephone outlet cables will be furnished, installed, and terminated by WHC. Telephone jacks and desk and wall hand sets will be furnished, installed, and terminated by WHC.

\subsubsection{Public Address System}

A PA system will be provided interior to the building. The PA system will consist of:

- Telephone paging provided in specific locations.

- PA speakers provided throughout the CVDS.

- $\quad$ Preamplifier and amplifier located in the office electrical room.

The PA system will permit announcements to be sent to all locations of the CVDS by use of telephone all-page number dialing. Emergency power will be provided for the PA system. 
WHC-SD-SNF-CDR-003, Revision 0

\subsection{FACILITY DESIGN}

\subsubsection{HLAN System}

HLAN service from the exterior to the interior of the building will be limited to providing one 4-inch underground conduit with pull rope. This conduit will route feeder to the telecommunications board in the electrical room.

HLAN outlets will be provided by the Contractor. HLAN outlet cables will be furnished, installed, and terminated by WHC.

\subsubsection{Alarms}

The design and construction of the building includes fire and evacuation alarms, liquid leak detection system, telephone system, HLAN system, and CAMs. Each of these systems will be consistent with and compatible to the existing systems to which they connect. In order to achieve this compatibility, specific equipment and construction methods will be as follows:

\subsubsection{Fire Alarm Requirements}

The fire alarm initiating and indicating devices for the building will consist of the following:

- Manual fire alarm pull stations provided at each exterior exit.

- $\quad$ Fire water flow detector.

- $\quad$ Supervised post indicator valves (PIV).

- $\quad$ Supervised fire riser tamper switches.

- Fire alarm bells and gongs provided throughout the facility.

- Area smoke detectors in office areas, electrical/mechanical rooms, and transfer corridor.

- Duct detectors in bay recirculation fans.

The fire alarm control panel will be provided with battery backup. A radio fire alarm repeating (RFAR) box and antenna will be provided to interface with the Hanford site wide fire alarm network. The fire alarm control panel will be selected to accommodate future expansion. The RFAR box and antenna will be Government Furnished Equipment (GFE) installed by the Contractor.

All fire alarm components will be per Westinghouse Hanford Company Manual WHC-CM-4-3, Standard FS-4, Rev 0 "Approved Standardized Fire Protection System Equipment" dated October 20, 1989. An Acceptance Test Procedure (ATP) for the fire alarm system will be prepared for performance by the Contractor. 


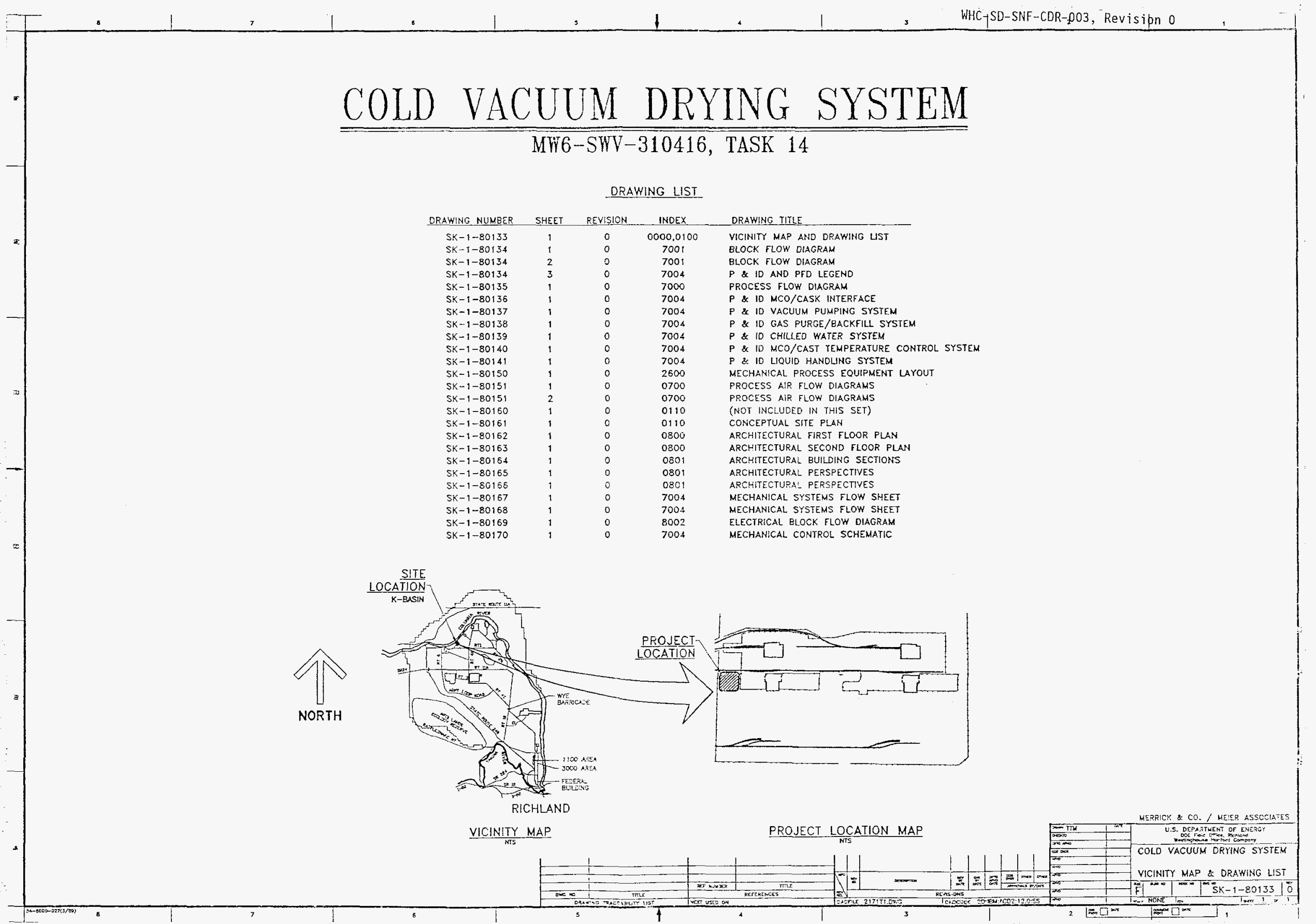




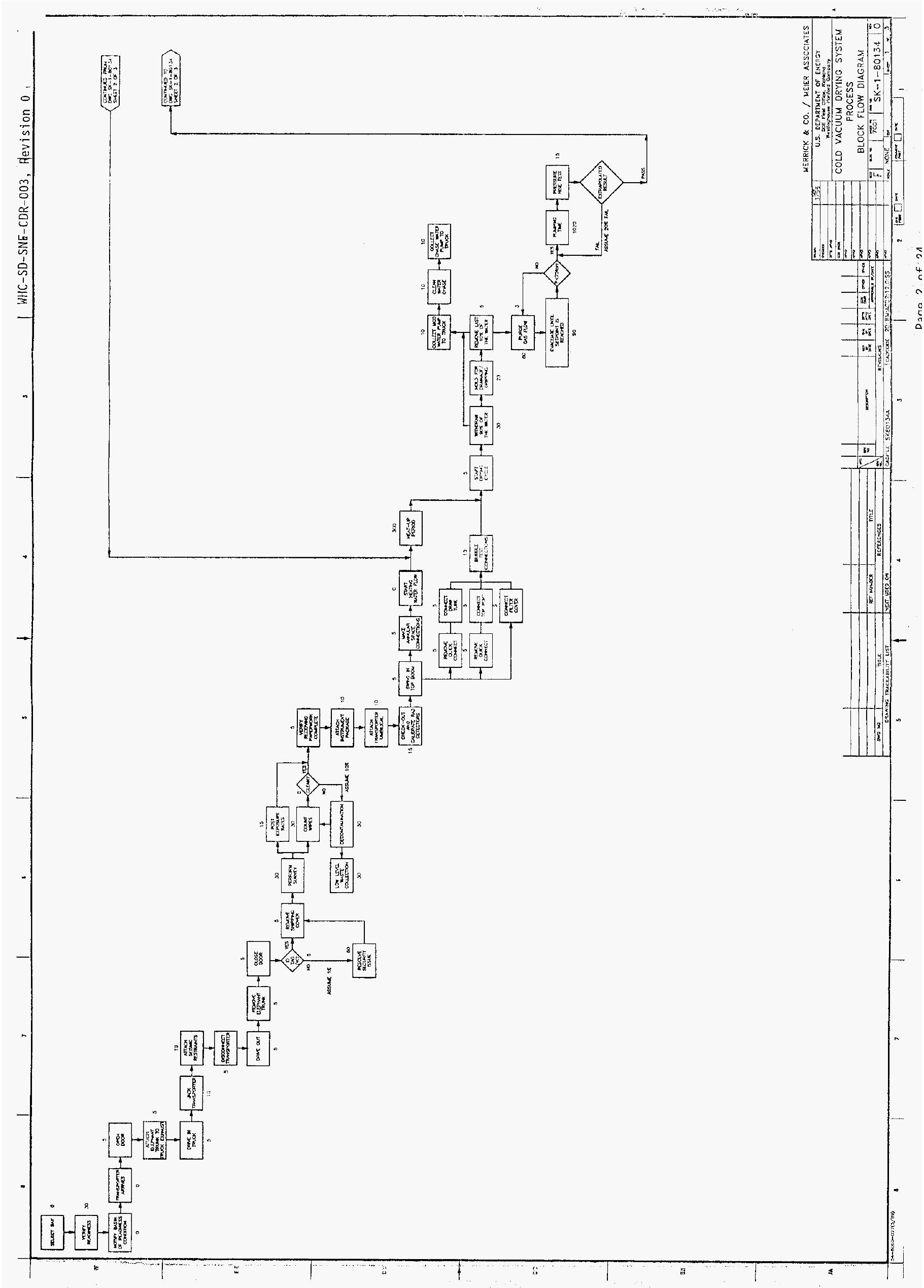




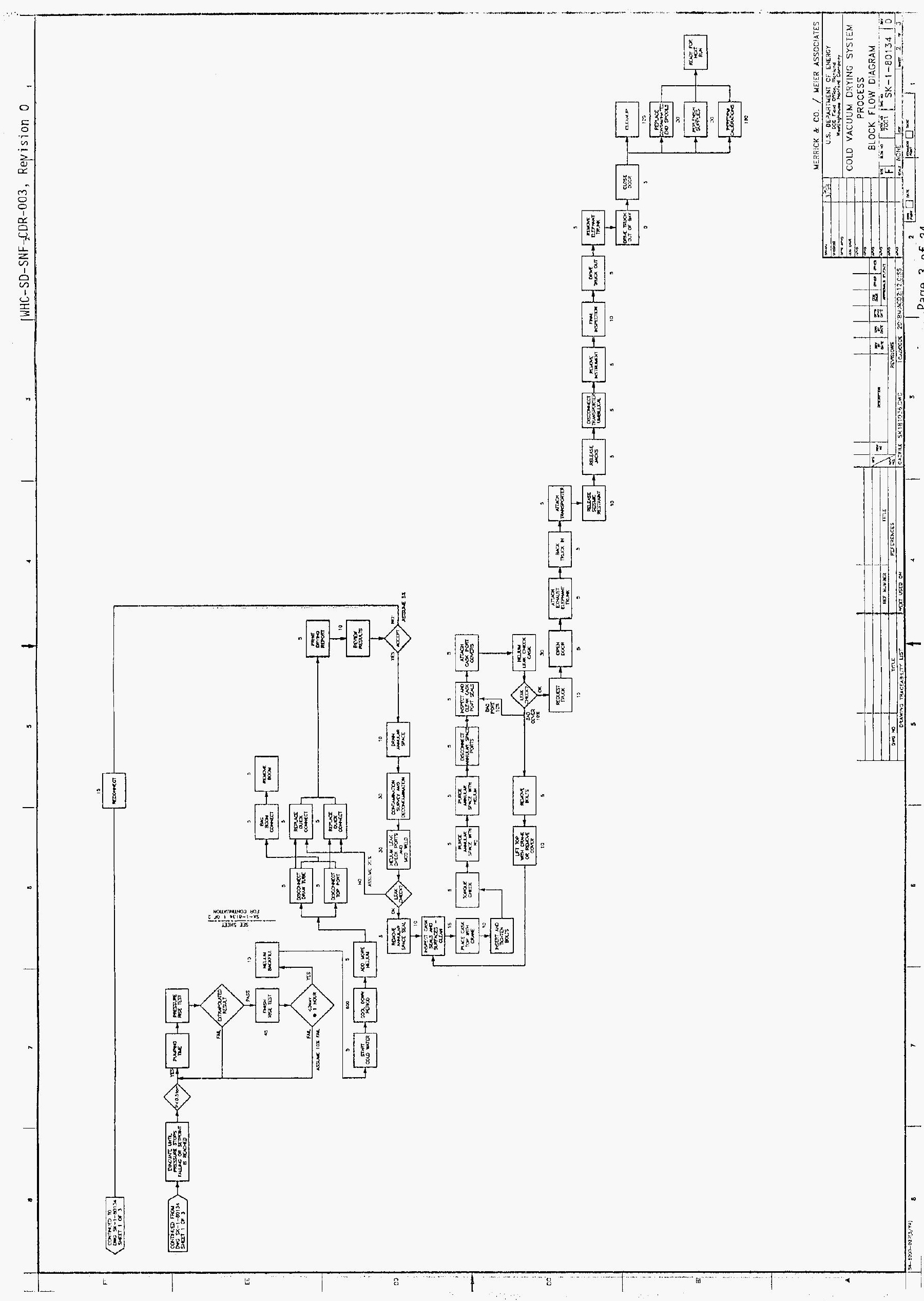




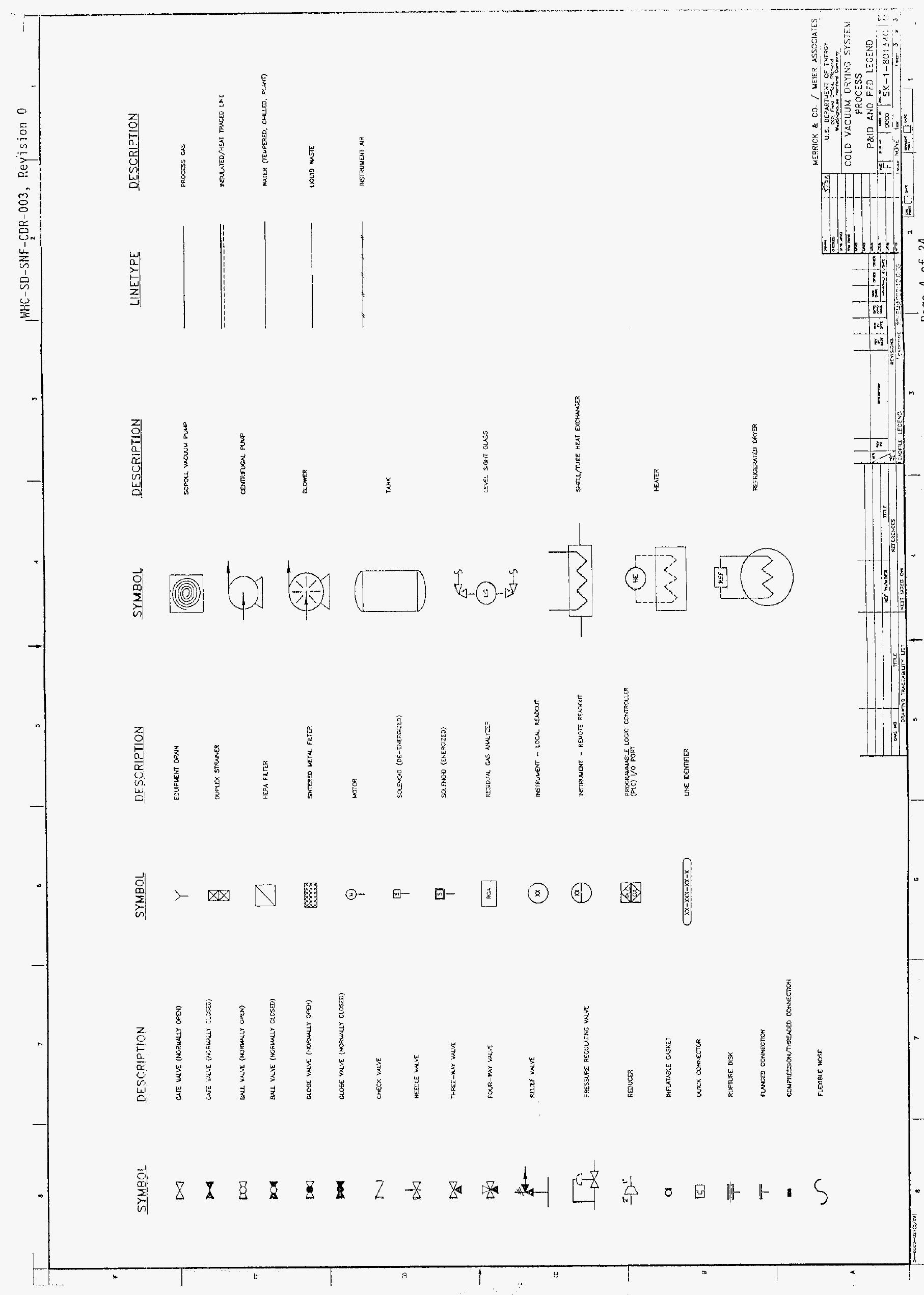




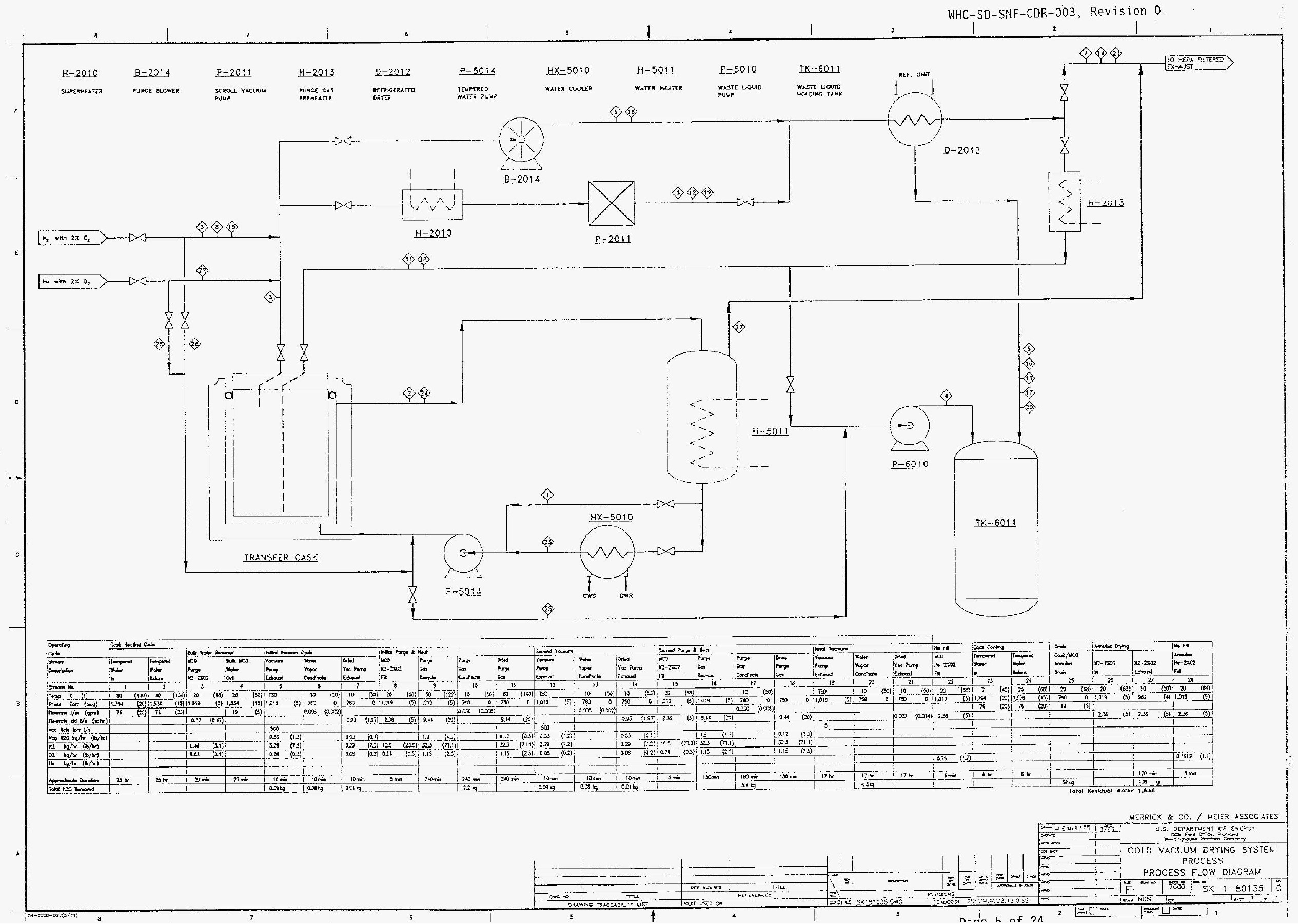




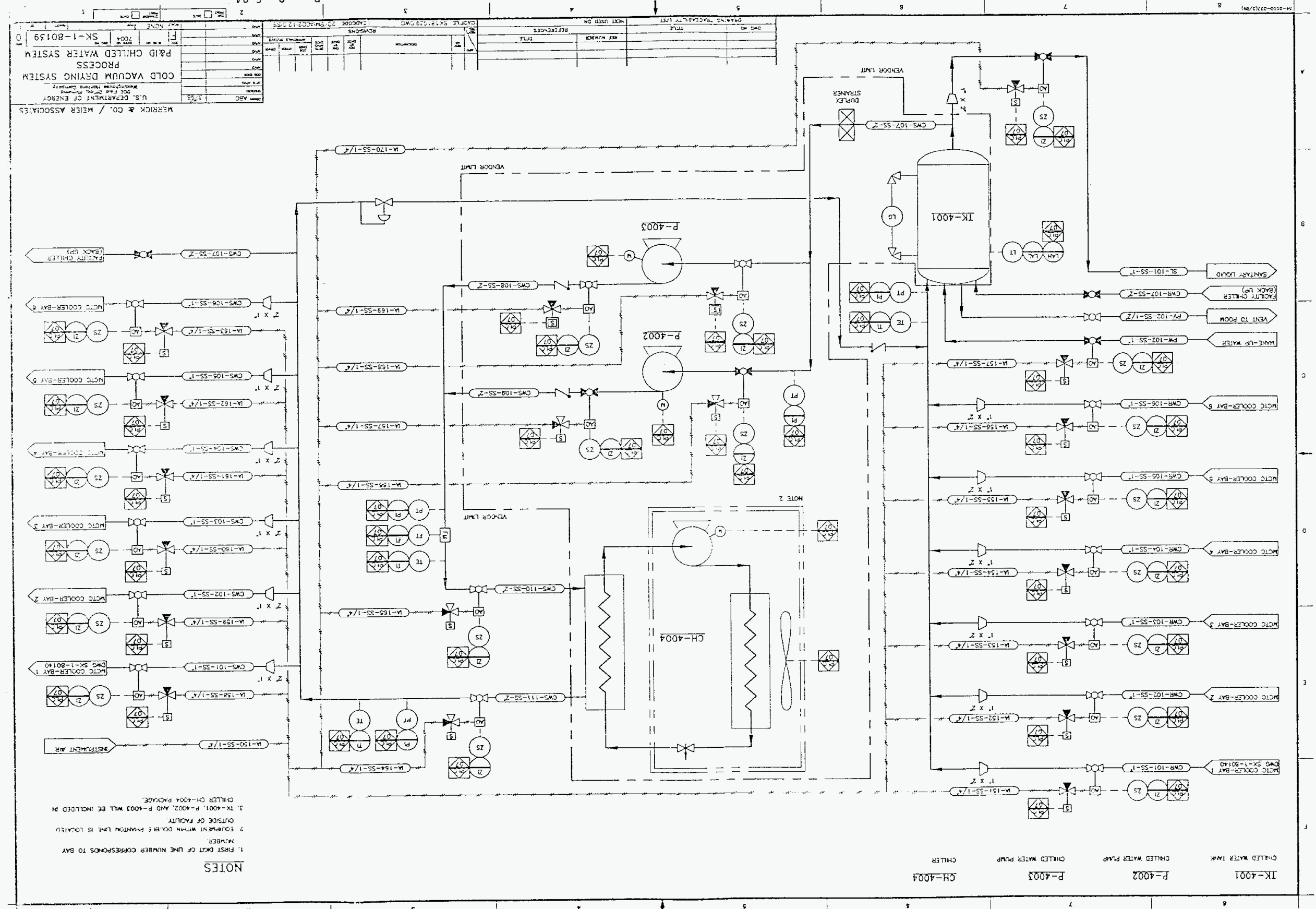

0 иоเร!กละ ' 


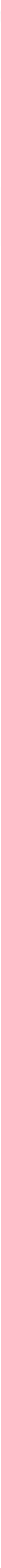




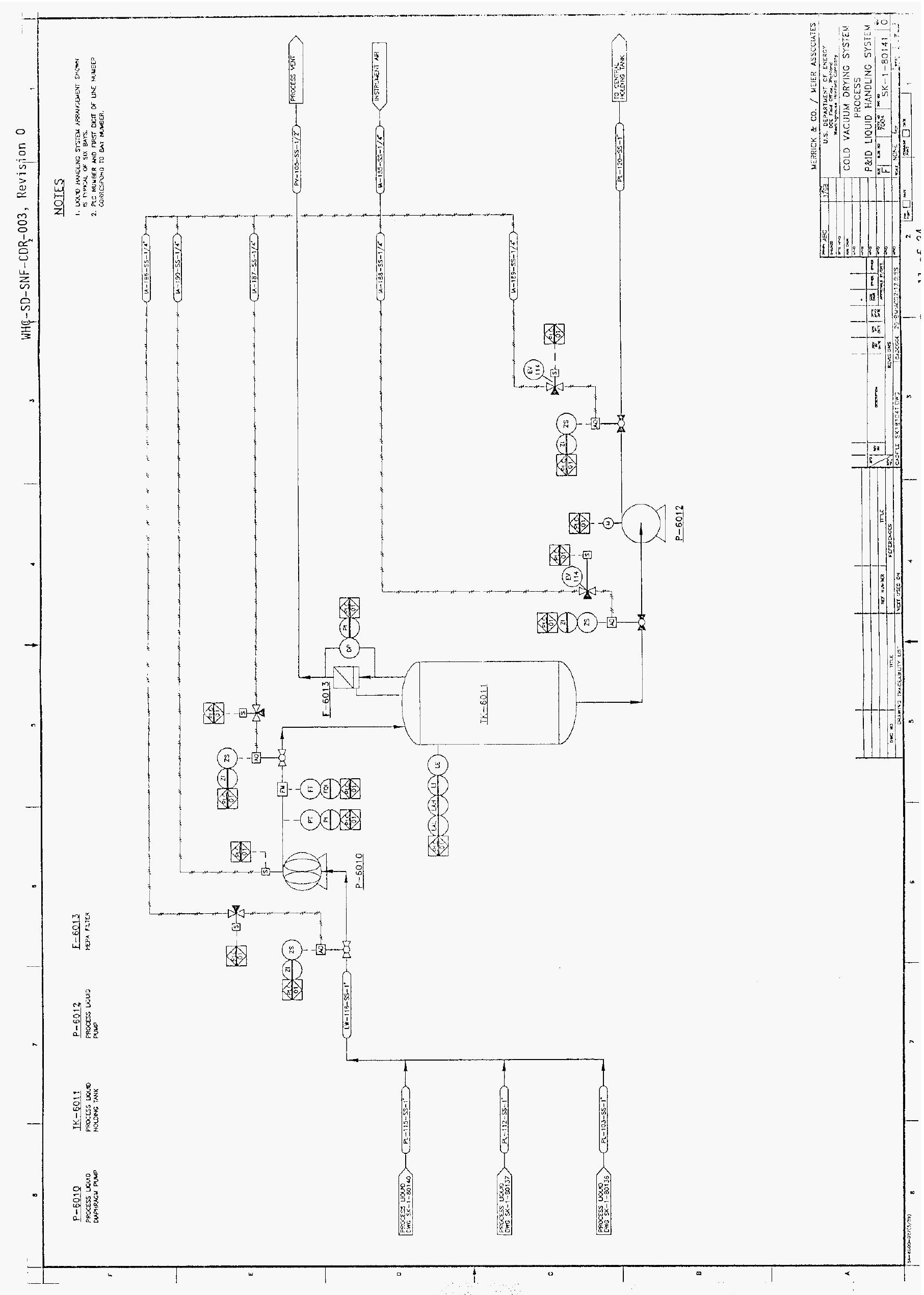




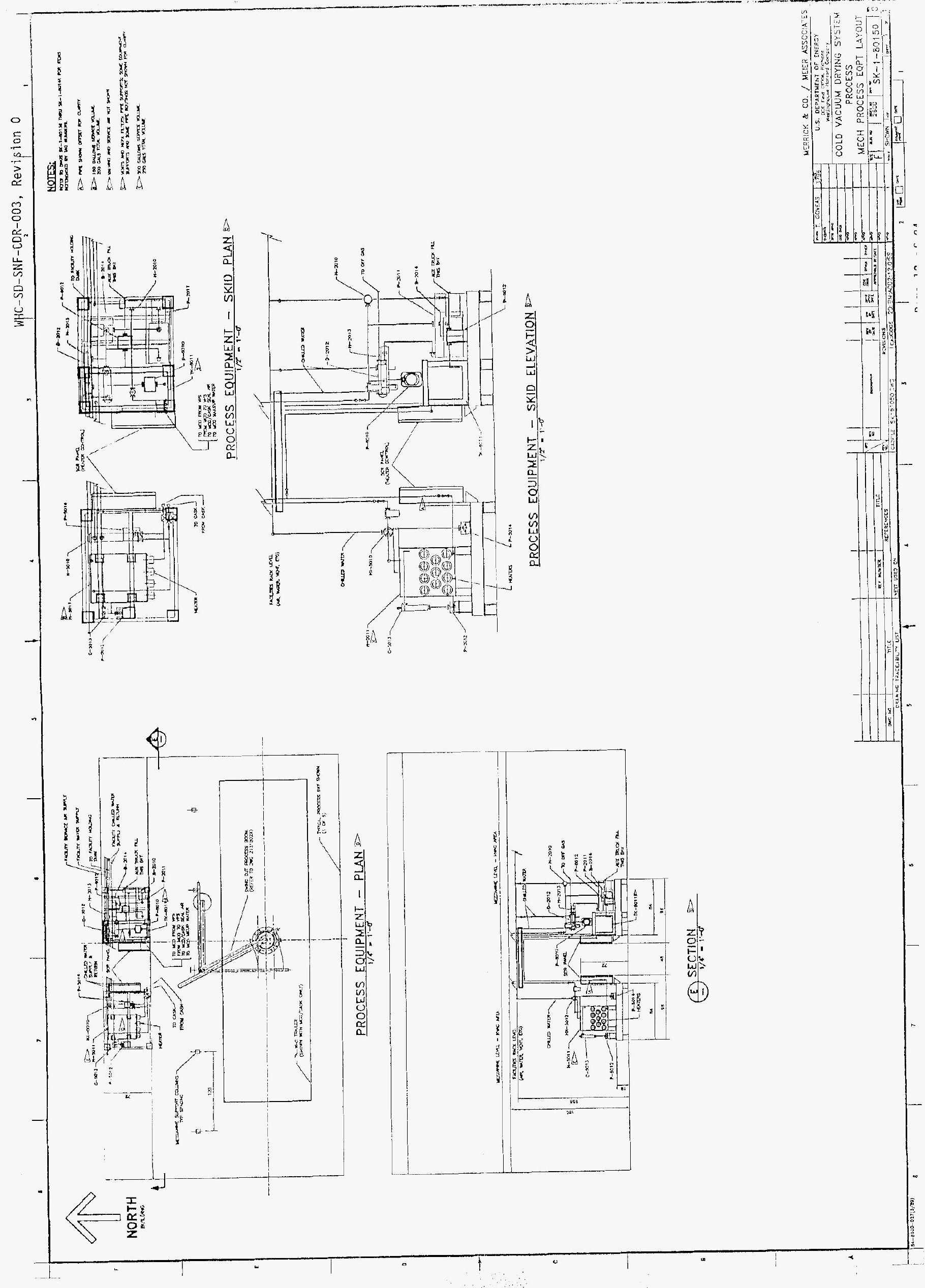




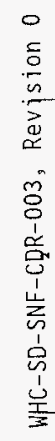

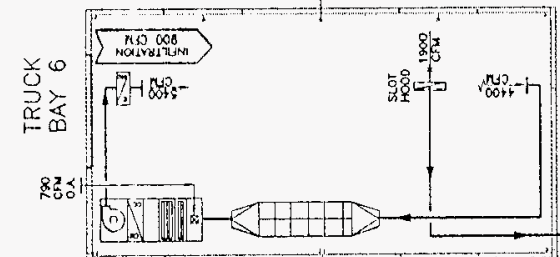

$-$
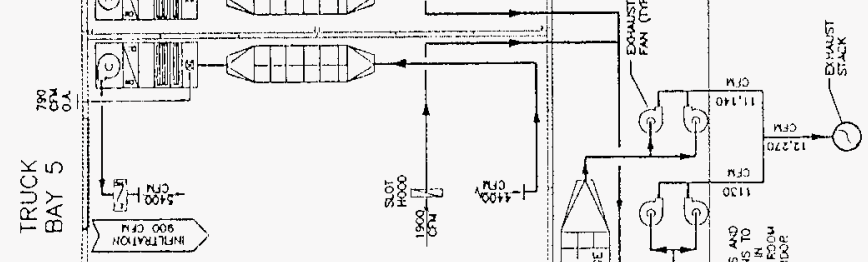

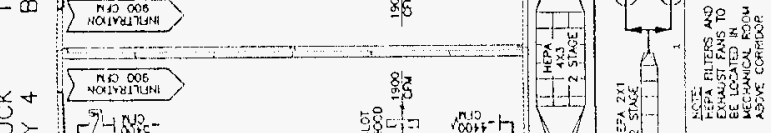

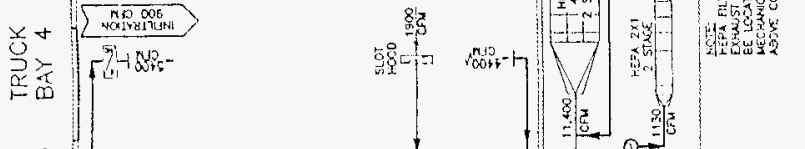

gृat

6) W

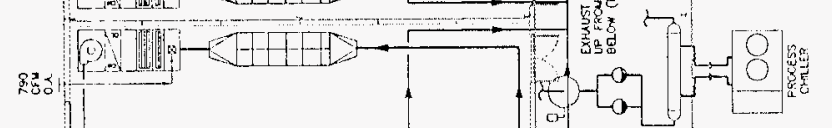

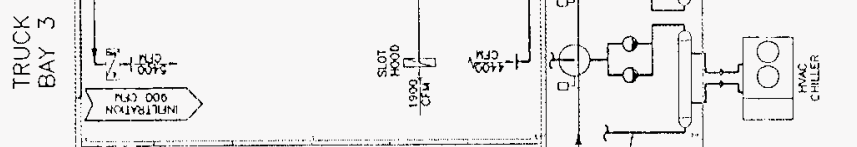

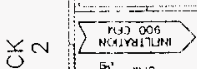

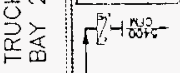

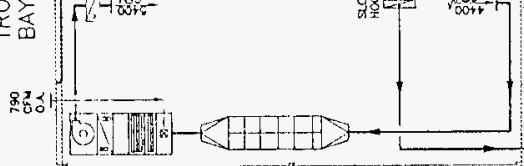

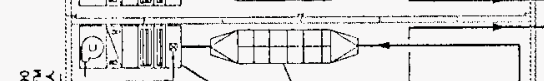

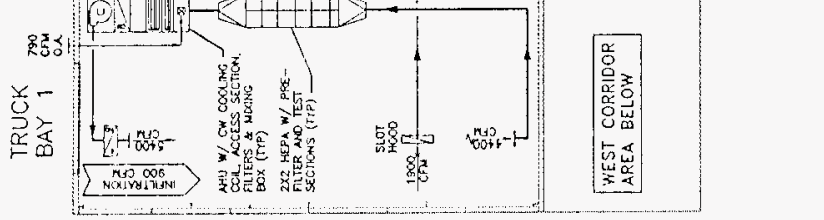

\begin{tabular}{|l|}
$\mid$ \\
\\
\end{tabular}

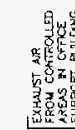

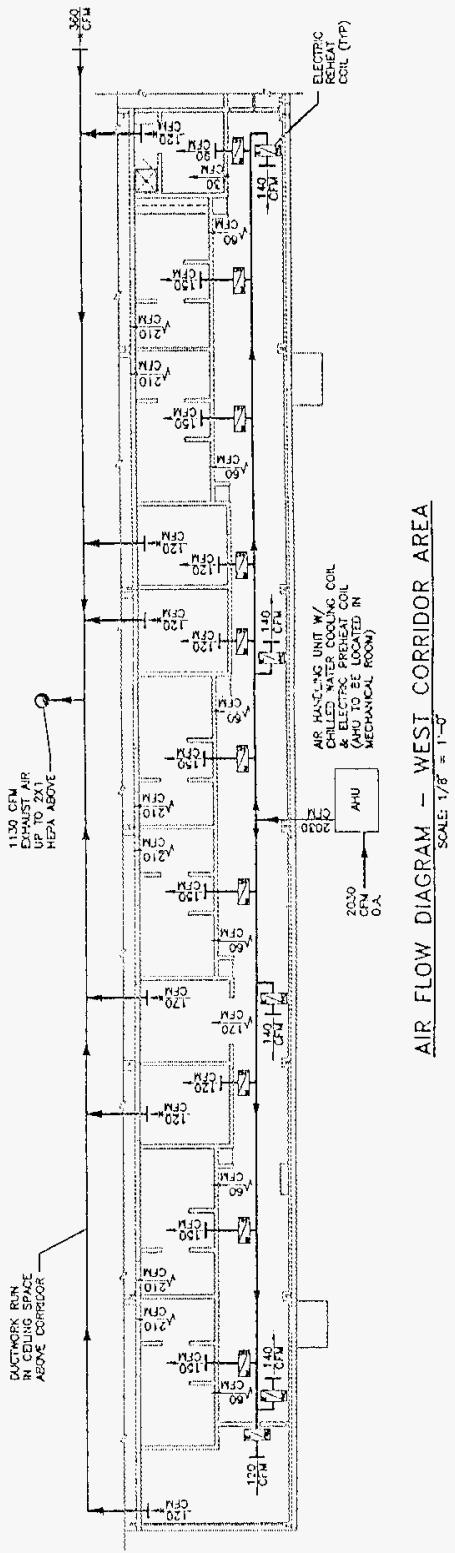

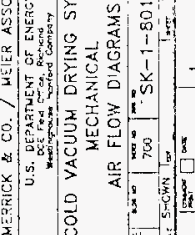

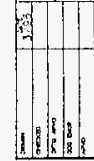

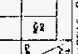

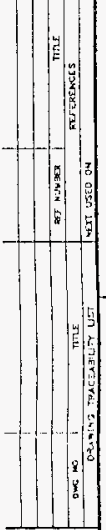




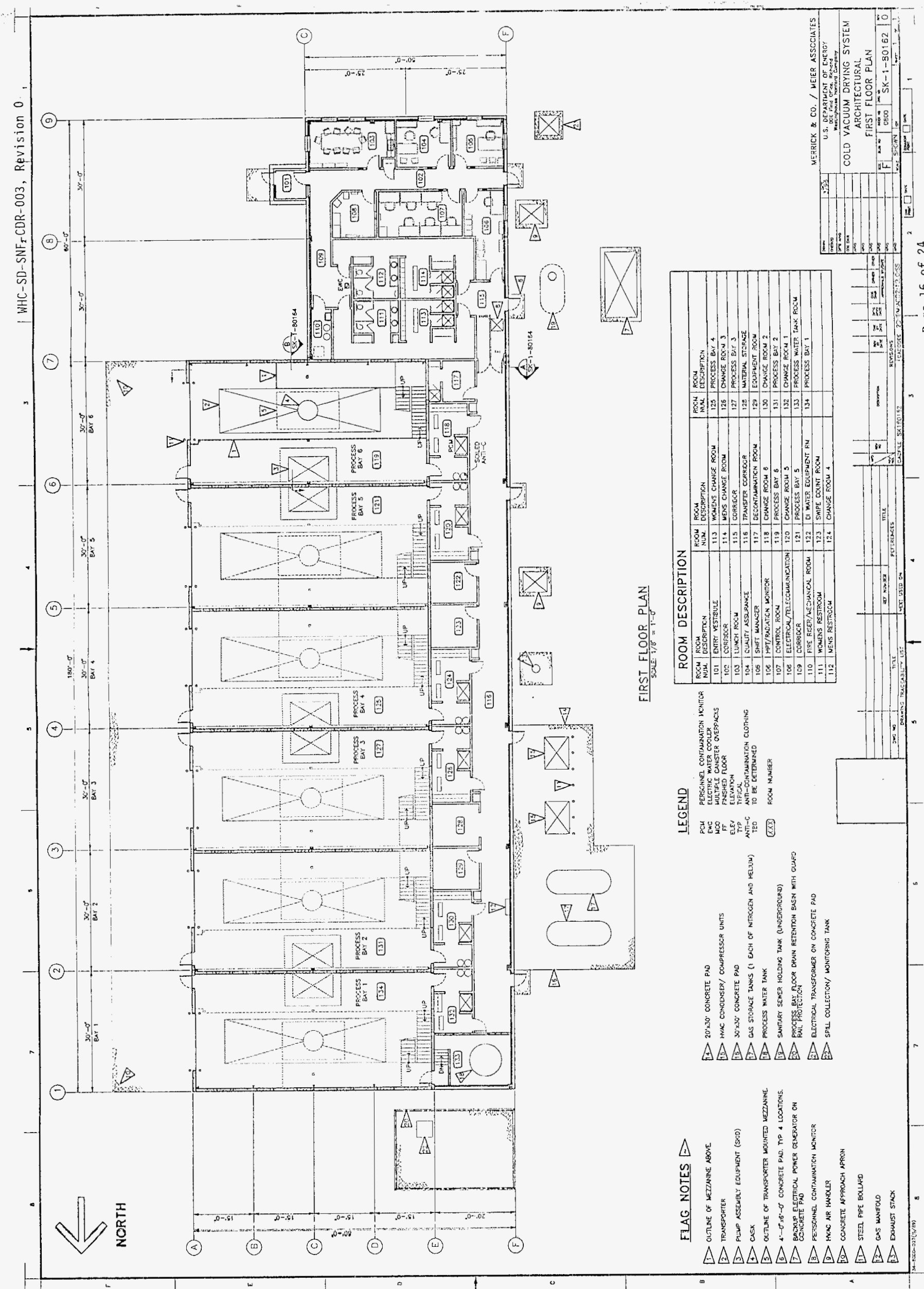




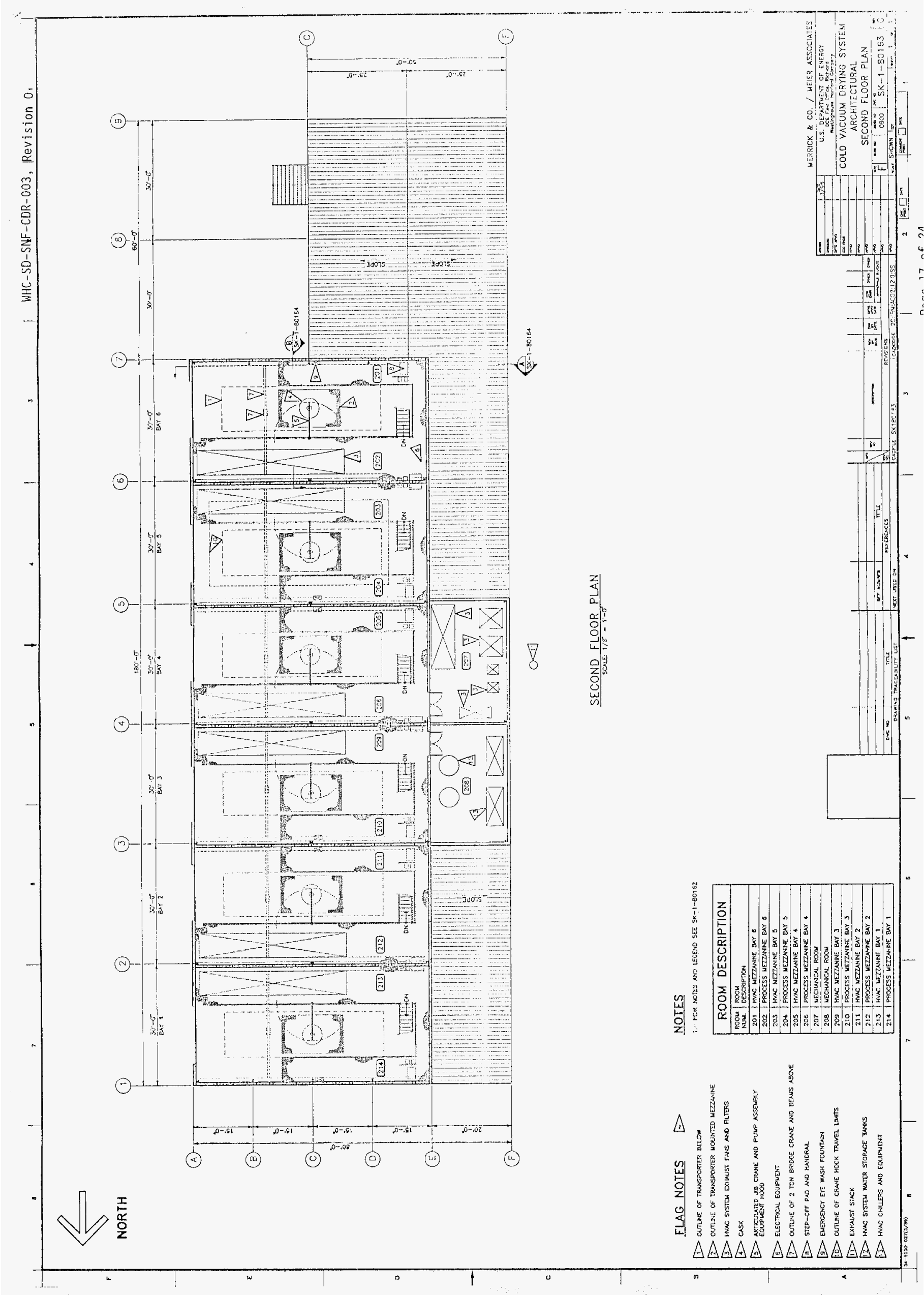


$3=0$ 


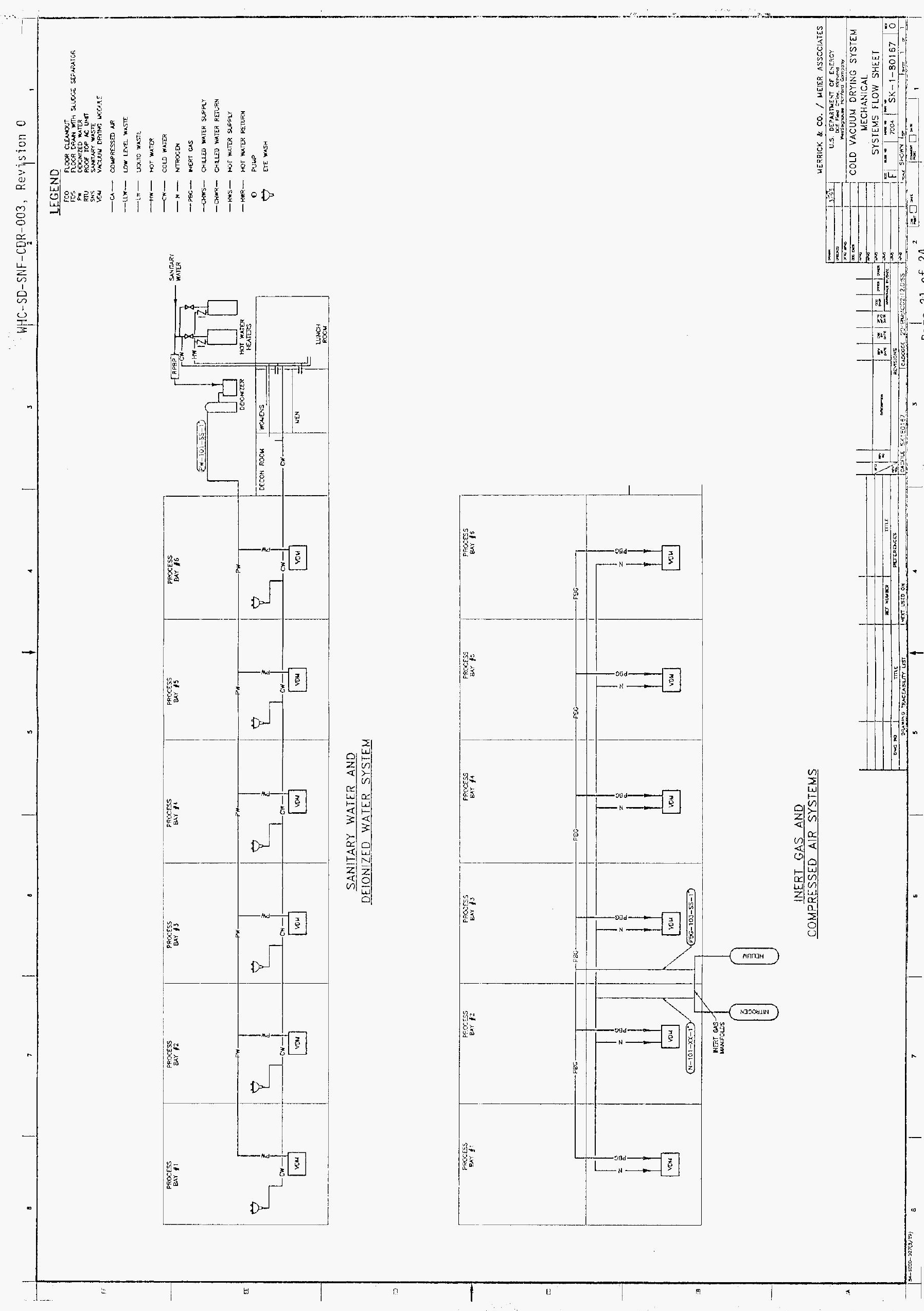




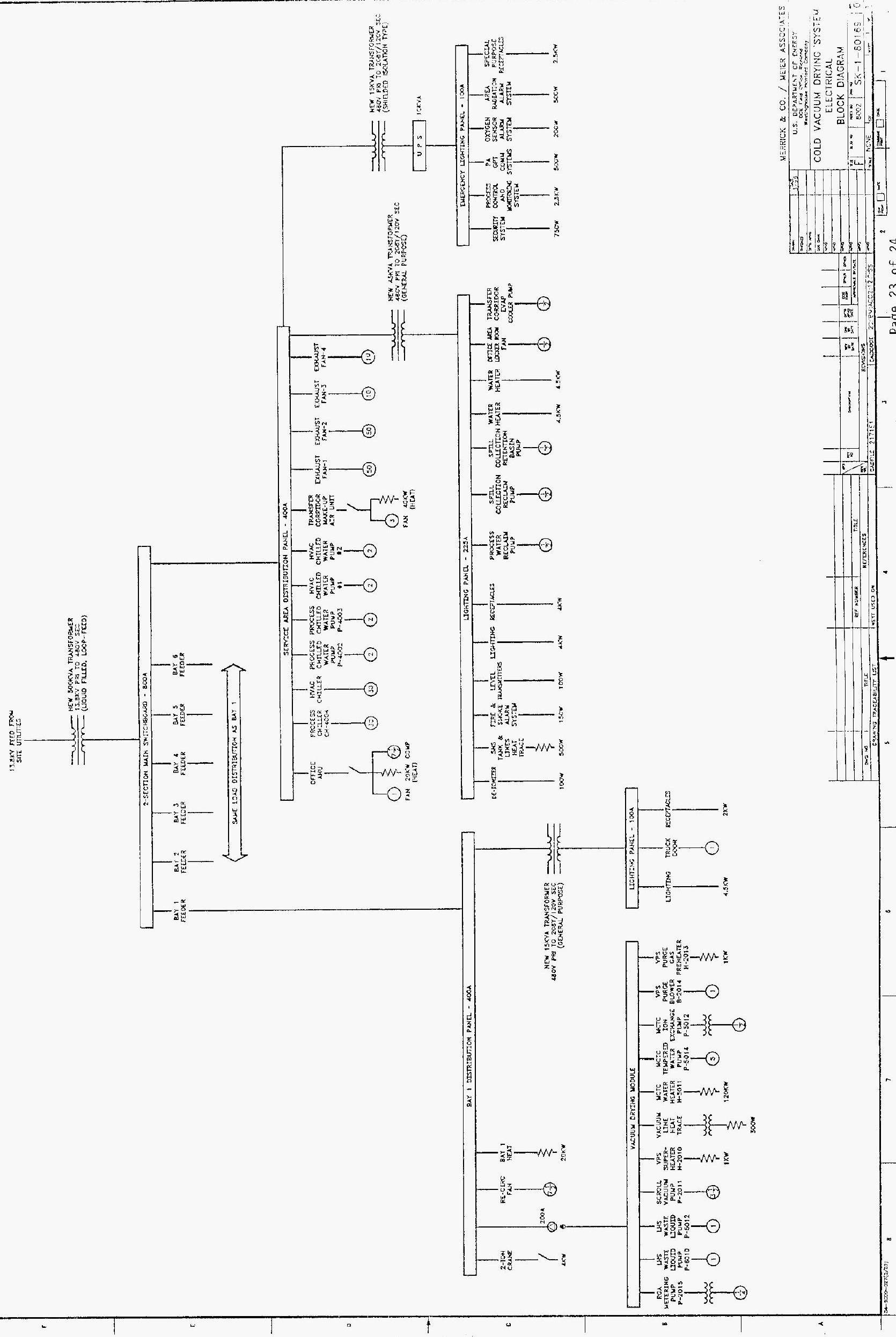


WHC-SD-SNF-CDR-003, Revision 0

ATTACHMENT 1

PERFORMANCE SPECIFICATION AND F\&R REPORT

for the

COLD VACUM DRYING SYSTEM

of the

K BASIN SPENT NUCLEAR FUEL STORAGE PROJECT 


\title{
UNDERSTANDING OF K-BASIN SPENT NUCLEAR FUEL
}

\author{
COLD VACUUM DRYING MODULE SUBPROJECT
}

\author{
PERFORMANCE SPECIFICATIONS AND
}

FUNCTIONS \& REQUIREMENTS

\subsection{INTRODUCTION}

The objectives of the Department of Energy (DOE) at Hanford include cleanup of the site, protecting the health and safety of workers and the public, and protecting the environment. The cleanup will be accomplished in accordance with the Hanford Federal Facility Agreement and Consent Order (the Tri Party Agreement), and in compliance with applicable Federal, State, local laws, and American Indian Treaty Rights. The Hanford cleanup must also comply with DOE policies and directives.

The Cold Vacuum Drying Module (CVDM) Subproject is an important step in the cleanup of Spent Nuclear Fuel (SNF). In order to provide a design for the safe and efficient performance of this function, numerous regulations, policies, and directives must be used for guidance. The K-Basin Spent Nuclear Fuel Vacuum Drying Module Subproject Functions \& Requirements, (F\&R) WHC-SD-SNF-FRD-020 Rev. 0 , January 8,1996 , summarizes the requirements of the CVDM subproject and identifies Federal, State, and local regulations and laws that may be applicable to the CVDM Subproject. The Performance Specifications for the K-Basin Spent Nuclear Fuel Vacuum Drying Module, WHC-S-0435 Rev. O, January 12, 1996. provides functional design and performance requirements for the K-Basin SNF CVDM. These performance requirements provide the basis for the design, development, and testing of the equipment to safely and efficiently vacuum dry the K-Basin SNF.

The scope of this evaluation is to demonstrate an understanding of the documents that are applicable to the Cold Vacuum Drying Module Subproject and that have an impact on the design. The documents can be roughly categorized as 1) design basis guidance and 2) reference material. The F\&Rs identify a considerable number of documents that are passed down from the project level functional hierarchy and as such, may have an impact on the design of the CVDM subproject. This review has determined that the bulk of the documents are applicable to the CVDM subproject but do not have an impact on the design. 


\subsection{IDENTIFICATION OF REQUIREMENTS}

The F\&R outlines the CVDM functions and traces the relationship to the Spent Nuclear Fuel Project (SNFP) through the Work Breakdown Structure (WBS) and organizational block diagrams. The technical requirements and descriptions are organized by WBS number and the associated requirement references are listed.

The requirements listed include Federal, State, and local laws and regulations as well as Westinghouse Hanford Company (WHC) rules and regulations. The functions and requirements in the F\&R report implement the requirements set forth in the Spent Nuclear Fuel Program Project Management Plan, which requires management, development, and maintenance of baseline documentation.

The requirements listed in the F\&R report mainly consist of the Code of Federal Regulations (CFRs), DOE Orders, Washington State Administrative Codes (WACs) including Revised Codes of Washington (RCW), WHC control manuals (WHC-CM), and other miscellaneous documents.

The Code of Federal Regulations is a codification of applicable regulations promulgated by an issuing Federal Agency and published in the Federal Register. The Code is divided into 50 titles which represent broad areas subject to Federal Regulations. Each title is divided into chapters which usually bear the name of the issuing agency. Each chapter is further suboivided into several parts to address specific regulations. Historically, CFRs have applied to commercial nuclear reactor facilities but not to Government Owned Contractor Operated (GOCO) sites such as Hanford. The Federal Government desires to provide adequate protection of the public from radioactive material releases associated with normal operations and accident/natural phenomena. To this end, the Congress has legislated that this is generally the responsibility of the DOE where DOE facilities are involved and generally the responsibility of the NRC where commercial facilities are involved. The Congress has further established the DNFSB as the watch dog over the DOE. 10 CFR 30.12 indicates that prime contractors of the DOE are exempt from the regulations to the extent that the contractor working under his prime contract manufactures, produces, transfers, receives, acquires, owns, possesses, or uses byproduct material for the performance of work for the DOE at a GOCO site. The wording very specifically says prime contractors because such contractors operate DOE owned facilities on the DOE's behalf. This exemption applies to the CVDM. The DOE established in the K-Basin Spent Nuclear Fuel Project - Regulatory Policy, dated August 4, 1995, the requirement for the SNFP facilities to achieve "nuclear safety equivalency" comparable to NRC licensed facilities. An evaluation was performed to identify any additional requirements that were needed to supplement the existing and applicable DOE requirements to establish nuclear safety equivalency with the NRC licensed facilities. The additional requirements were 
consolidated into 29 items. All items are to be implemented per the NRC regulations with the exception of the design earthquake which will be implemented in a manner that established equivalence in safety, as opposed to direct equivalence to the regulation.

The DOE Orders establish policies, guidelines, and requirements for the safe operation and maintenance of DOE owned facilities. Historically, these orders have been considered to be the governing regulations, and not the CFRs, for the DOE GOCO sites. In addition to DOE orders, several supplemental guidance documents, which are specific to Hanford, are also listed in the F\&R report.

The Washington Administrative Codes (WACs) and Revised Codes of Washington (RCWs) are compiled by the various agencies of the State of Washington. WACs and RCWs are normally considered to be additional requirements to Federal guidelines rather than as replacements. However, WACs promulgate similar requirements as CFRs for many instances. Hence, compliance with either Federal or State regulations is normally considered adequate. Since 10 CFR 30.12 exempts the CVDM from the CFRs, in this case it is the State regulations that apply.

The goals of WHC are to make the Hanford site a model for environmental management, demonstrate and apply advanced and innovative technologies for cleanup, and restore the land for productive use. To accomplish these goals, WHC has created several control manuals (CMs). The purpose of these control manuals is to establish various compliance requirements and guidelines in conjunction with applicable DOE Orders, and Federal, State, and local laws and regulations.

\subsection{CLASSIFICATION OF REQUIREMENTS}

DOE Order $6430.1 \mathrm{~A}$ (General Design Criteria) gives the main requirements needed for the design. The quality assurance requirements are given in 10 CFR Part 830.120. These and other applicable requirements are listed in Appendices $A$ and B. Requirements that do not have any significant direct impact, but may affect the design process, are listed in Appendix $C$. These requirements are maintained for reference. Although these requirements may not have direct influence on the actual design of the Cold Vacuum Drying Module, each requirement may impact the design process. The extent of impact will be determined later.

\subsection{DESCRIPTION OF APPLICABLE REQUIREMENTS}

Five requirements listed in Appendix $A$ are judged to be applicable for the Cold Vacuum Drying Module design. Of these five, DOE 6430.1A and 10 CFR Part 830.120 are the two significant documents. Detailed descriptions of each of the five requirements are given below. 
A. 10 CFR Part 830.120, Quality Assurance

The ten criteria of 10 CFR Part 830.120 prescribe a comprehensive management system for DOE work. The quality management program described in 10 CFR Part 830.120 provides a results-oriented management system that focuses on the customer while providing a method for the organization to become more efficient through constant process improvement. The ten criteria are as follows:

1. Program: The contractor shall develop and maintain a written Quality Assurance Plan (QAP). The QAP shall describe the organizational structure, functional responsibilities, levels of authority, and interfaces for those managing, performing, and assessing adequacy of work. The QAP shall describe the contractors management system, including planning, scheduling, and cost control considerations.

2. Personnel Training and Qualifications: Personnel shall be trained and qualified to ensure that they are capable of performing their assigned work. Personnel shall be provided continuing training to ensure that job proficiency is maintained.

3. Quality Improvement: The contractor shall establish and implement processes to detect and prevent quality problems and to ensure quality improvement. Items and processes that do not meet established requirements shall be identified, controlled, and corrected. Correction shall include identifying the causes of problems and preventing recurrence. Item reliability, process implementation, and other quality-related information shall be reviewed and the data analyzed to identify items and processes needing improvement.

4. Documents and Records: Documents shall be prepared, reviewed, approved, issued, used, and revised to prescribe processes, specify requirements, or establish design. Records shall be specified, prepared, reviewed, approved, and maintained.

5. Work Processes: Work shall be performed to establish technical standards and administrative controls. Work shall be performed under controlled conditions using approved instructions, procedures, or other appropriate means. Items shall be identified and controlled to ensure their proper use. Items shall be maintained to prevent their damage, loss, or deterioration. Equipment used for process monitoring or data collection shall be calibrated and maintained. 
6. Design: Items and processes shall be designed using sound engineering/scientific principles and appropriate standards. Design work, including changes, shall incorporate applicable requirements and design bases. Design interfaces shall be identified and controlled. The adequacy of design products shall be verified or validated by individuals or groups other than those who performed the work. Verification and validation work shall be completed before approval and implementation of the change.

7. Procurement: Procured items and services shall meet established requirements and perform as specified. Prospective suppliers shall be evaluated and selected on the basis of specified criteria. The contractor shall ensure that approved suppliers can continue to provide acceptable items and services.

8. Inspection and Acceptance Testing: Inspection and acceptance testing of specified items and processes shall be conducted using established acceptance and performance criteria. Equipment used for inspections and tests shall be calibrated and maintained.

9. Management Assessment: Management at all levels shall periodically assess the integrated quality assurance program and its performance. Problems that hinder the organization from achieving its objectives shall be identified and corrected.

10. Independent Assessment: Planned and periodic independent assessments shall be conducted to measure items' quality and process effectiveness and to promote improvement. The organization performing independent assessments shall have sufficient authority and freedom from the line organization to carry out its responsibilities. Persons conducting independent assessments shall be technically qualified and knowledgeable in the areas assessed.

Merrick will develop a QAP that is in accordance with these criteria and that shows how the criteria will be satisfied. A QA matrix will also be developed to provide a cross walk between the criteria and the Merrick quality assurance, administrative, and design procedures.

\section{B. DOE 6430.1A General Design Criteria}

This DOE Order provides General Design Criteria (GDC) for various engineering disciplines. This GDC is mandatory for all DOE related work and provides minimal acceptable design requirements for DOE Facilities. 
Although DOE facilities are not mandated to follow state, county, and other requirements, it is recommended to interface with the non-DOE authorities to accommodate their intent as much as possible. The GDC contains 16 numerical divisions devoted to major building systems or design specialities. According to DOE instructions, GDC must be used in the planning, design, and development of specifications for facilities, including the development of site and equipment-specific designs. Provided the GDC is not adequate, supplemental standards may be used. The ASME B31.3 Chemical Plant and Petroleum Refinery Piping standard and the Industrial Vacuum Practices are considered to be supplemental standards that will be used for the CVDM design.

The following sections of the GDC are considered applicable for the Cold Vacuum Drying Module Design. The criteria evaluation document developed for the Cold Vacuum Drying Module goes into the applicability of the GDC in more extensive detail.

\section{Division 1. General Requirements}

Section 0111-99.0.1, Non-Reactor Nuclear Facilities

Paragraphs 1, 4, 5, and 6 on Page 1-97,

Paragraphs 2 and 3 on Page 1-98.

Section 0111-99.0.2, Tornado of Extreme Wind

Portions of this section are applicable.

Section 0111-99.0.4, Earthquakes

The entire section is applicable.

Section 0111-99.0.7, Explosion, Internal Pressurization, Criticality, and Other DBA Causes.

Section 0140 on Quality Assurance.

Division 13, Special Facilities

Section 1300-1, Coverage and Objectives

Many sub-sections are applicable.

Section 1300-2, Safety Analysis

Section 1300-3.2, Safety Class Items

Most of this section's contents are applicable. This section also proposes the use of ASME Boiler and Pressure Vessel Codes wherever they are applicable.

Section 1300-3.3, Single Failure Criterion and Redundancy

Section 1300-3.4, Equipment Environment Considerations

Most of the requirements specified in the three subsections are applicable. 
Section 1300-3.5, Maintenance

Second paragraph of this section is especially applicable.

Section 1300-3.6, Testing

Portions of first and second paragraphs are applicable.

Section 1300-4, Nuclear Criticality Safety

This section describes the procedures to assess as early as possible if the potential for nuclear criticality exists. Several portions of this section may be applicable.

Section 1320 Irradiated Fissile Material Storage Facilities

This section describes irradiated fissile material storage facilities (ISMSF). Portion of subsections $1320-1,-2$, and -3 are applicable.

\section{WHC-CM-4-2 Quality Assurance Manual}

This manual describes the requirements that apply to WHC Divisions and Departments which prescribe, perform, or verify activities affecting quality including operations, decommissioning and decontamination, and environmental activities. This manual emphasizes that quality assurance controls must be applied to any items and activities performed under WHC Management. The manual consists of 19 sections with each section dedicated to a certain aspect of quality control.

This is a compulsory requirement for each operation involved in the SNF transfer from K-Basins. Requirements of this manual in conjunction with 10 CFR Part 830.120 should provide more than adequate quality control.

\section{WHC-CM-6-1 Standard Engineering Practices}

This manual establishes the engineering practices which ensure that uniform methods are in place for performing all tasks under WHC Control. These procedures provide methodologies for tasks such as design review, configuration management, change control, specification preparation, and review and approval requirements. The use of this document is strongly recommended on all engineering, development, and project tasks which culminate in a document design and/or deliverable hardware end items.

Of several sections in this manual, Section 4 on Design Verification Requirements is the most applicable for Cold Vacuum Drying Module Design. This section provides methods and procedures governing design verification measures to verify the design adequacy. This requirement and DOE Order $6430.1 \mathrm{~A}$ provide comprehensive guidelines for the design task. 


\section{E. NRC Regulations}

The DOE established in the K-Basin Spent Nuclear Fuel Project - Regulatory Policy, dated August 4,1995 , the requirement for the SNFP facilities to achieve "nuclear safety equivalency" comparable to NRC licensed facilities. An evaluation was performed to identify any additional requirements that were needed to supplement the existing and applicable DOE requirements to establish nuclear safety equivalency with the NRC licensed facilities. The additional requirements were consolidated into 29 items. All items are to be implemented per the NRC regulations with the exception of the design earthquake which will be implemented in a manner that established equivalence in safety, as opposed to direct equivalence to the regulation.

\subsection{DESCRIPTION OF REFERENCE REQUIREMENTS}

The requirements listed in Appendix $\mathrm{C}$ will be used as reference documents. These requirements have no direct impact on the design, but may affect the design methodologies.

10 CFR 20 and 10 CFR 71 are promulgated by the Nuclear Regulatory Commission (NRC). It shouid be noted that DOE nuclear facilities are not required to comply with NRC regulations. DOE, however, use the NRC requirements as a source of guidance and good practice for the SNF transfer program.

10 CFR 20, Standards for Protection Against Radiation, establishes standards for individual protection from ionizing radiation resulting from activities conducted under licenses issued by NRC. These regulations quantify the permissible radiation doses to various body parts of an individual. The prescribed dose limits do not apply to doses due to background radiation and radiation received as part of a medical therapy or due to voluntary participation in medical research programs.

This regulation does not have direct impact on the Cold Vacuum Drying Module Design. However, this regulation will be maintained for reference as dose rates may have to be considered in the design process.

10 CFR 71, Packaging and Transportation of Radioactive Material, is also an NRC Regulation which establishes requirements for packaging, preparation for shipment, and transportation of licensed material. This regulation also describes procedures and standards for NRC approval of packaging and shipping procedures for fissile material. The packaging and shipping aspects are also subject to other NRC regulations and requirements of other agencies, such as the Department of Transportation. 
This regulation does not have direct bearing on the Cold Vacuum Drying Module Design. However, these regulations may have to be consulted to verify that the Cold Vacuum Drying Module Design poses no problems for packaging and transportation.

\section{A. DOE Regulations}

10 CFR 835, Occupational Radiation Protection, is a DOE Regulation which is very similar to $10 \mathrm{CFR} 20$. 10 CFR 835 promulgates radiation protection standards, limits, and program requirements for protecting individuals from ionizing radiation resulting from the conduct of DOE activities. Activities conducted under NRC license are not covered by this regulation. Like 10 CFR 20, this requirement is also considered as a reference requirement.

\section{B. OSHA Requirements}

29 CFR 1910, Occupational Safety and Health Standard, is promulgated by the Occupational Safety and Health Administration of the Department of Labor. The intent of this directive is to carry out OSHA requirements which have been found to be National Consensus Standards or Established Standards. All routine industrial operations are covered under this requirement. From a simple administrative function such as maintaining worker's exposure and medical surveillance records to complex operations such as handling hazardous materials are covered by 29 CFR 1910. Minimum environmental controls required for a work area, provisions of proper personal protective equipment, fire protection requirements, noise control, and providing medical and first aid during emergencies are also covered under this requirement. These regulations may be exempt if it is determined that these standards do not improve health and safety for specially designated employees.

These is no direct impact of these regulations on the Cold Vacuum Drying Module Design, but the design may have to be accomplished such that the Cold Vacuum Drying Module usage adheres to $29 \mathrm{CFR} 1910$. Hence, this regulation is maintained for reference.

\section{DOE 1300.2A Department of Energy Technical Standards Programs}

This DOE Order sets forth policies and responsibilities for development and application of technical standards under DOE controlled programs. This order stipulates that any applicable Non-Government Standards (NGSs) must be used and the usage must be properly documented. This Order also states that all DOE facilities, programs, and projects will use NGSs in their 
design, construction, testing, modification, operation, decommissioning, decontamination, and remediation when such standards are adequate. If the existing Federal Standards is more conservative than NGSs, DOE requirements will be used. Uses of all standards in the design have to be properly documented.

This DOE Order is a general guideline for using the Technical Standards. This document is kept on the reference list.

\section{DOE 1540.2 Hazardous Material Packaging for Transport -} Administrative Procedures

This Order establishes administrative procedures for the certification and use of packaging methods for radioactive and hazardous materials. The administrative procedures also summarize the actions associated with the review and approval of packaging for the transportation of radioactive and hazardous materials. This Order details the review and approval procedure that provides a basis for DOE to assure DOT, NRC, and other agencies that regulations are compiled with and the entire process is relevant to that of NRC.

This DOE Order has no direct impact on the Cold Vacuum Drying Module Design. As the packaging process has very little effect on the Cold Vacuum Drying Module Design, it is unlikely that this Order will be used during the design process. However, DOE 1540-2 is retained for reference.

E. DOE 1540.3A Base Technology for Radioactive Material Transportation Packaging Systems

DOE 1540-A is a culmination of DOE Orders 1330.1D, 1540.1A, 15402, and 5480.3; 10 CFR 71 and 49 CFR 171 through 179; Atomic Energy Act; and the Department of Energy Organization Act of 1977. This Order establishes DOE policies and responsibilities for coordinating and planning base technology for radioactive material, transportation packaging systems. Radioactive material is defined as any material having a specific activity greater than 0.002 microcuries per gram.

This DOE Order is more of an administrative document than a design document. Consequently, this Order will have very little impact on either the Cold Vacuum Drying Module Design or the design process. However, this document is maintained for reference purposes. 


\section{F. DOE 5480.4 Environmental Protection, Safety, and Health}

This DOE Order provides listing of requirements for the application of the mandatory Environmental Protection, Safety, and Health (ES\&H) Standards applicable to all DOE Operations. This Order must be followed during design, construction, modification, and decommissioning. All permanent and temporary facilities must comply with this Order. The requirements listed in this DOE Order are divided into the following three categories:

1. Mandatory ES\&H Standards (Statutory Requirements): Those standards that are mandatory as a result of Non-DOE Federal or State Statutes are addressed in this category. None of these standards are applicable to Cold Vacuum Drying Module Design.

2. Mandatory ES\&H Standards (Policy Requirements): Standards that are mandatory because of DOE Policies are listed under this category. Subsection F which addresses Nuclear Safety may be used for guidance for Cold Vacuum Drying Module Design. However, these standards are mainly oriented for nuclear reactors.

3. Reference ES\&H Standards: Those standards that are not mandatory but are useful to refer to as good practice and for general ES\&H purposes. None are directly applicable for Cold Vacuum Drying Module Design.

This DOE Order does not appear to have any direct impact on the Cold Vacuum Drying Module Design. However, this document will be retained as reference.

G. Fiscal Year 1995, Hanford Mission Plan, Volume 1, Site Guidance, September 1994

The Hanford Mission is to cleanup the site, develop new technologies, and to help the economic diversification of the region. The transfer of K-Basin fuel is a part of the cleanup mission. This document has no impact on either CVDM design or the design process. However, this document is the basic report in which all Hanford cleanup programs are described. This document is maintained on the reference list.

\section{H. WHC-CM-2-14 Hazardous Material Packaging and Shipping}

This WHC Manual describes requirements and procedures for packaging and shipping hazardous wastes both on-site and off-site of Hanford. This 
manual has been prepared by WHC based on several CFRs, DOE Orders, WACs, and other pertinent documents including WHC-CMs. In addition to other requirements, instructions of this requirement have to be followed only when the SNF is categorized as hazardous material.

This requirement has no direct impact on the Cold Vacuum Drying Module Design. This document is maintained for reference.

\section{WHC-CM-3-5 Document Control and Records Management Manual}

This manual was developed to provide requirements and procedures for maintaining the information that is produced for any project. The information could be as paper, punched cards, magnetic tapes, computer disks, etc. The main objective of this program is to preserve records that may be useful and of future value in a proper manner.

There is no impact of this requirement on the Cold Vacuum Drying Module Design. However, all the paper work and computer formatted data will be transferred to WHC for up keeping the records. This manual is retained for reference purposes only. 
WHC-SD-SNF-CDR-003, Revision O

Attch 1

\section{APPENDIX A}

\section{APPLICABLE REQUIREMENTS FOR THE VACUUM DRYING MODULE SUBPROJECT DESIGN}

1. 10 CFR Part 830.120, Quality Assurance

2. DOE 6430.1A, General Design Criteria

3. WHC-CM-4-2, Quality Assurance Manual

4. WHC-CM-6-1, Standard Engineering Practices

5. WHC-SD-SNF-DB-003, Rev 1, Additional NRC Requirements 


\section{APPENDIX B \\ MISCELLANEOUS APPLICABLE DOCUMENTS}

1. DNFSB letter of May 26,1994, to Secretary O'Leary recommending expediting the SNF removal from K-Basins to an interim storage until an option is chosen for ultimate disposal.

2. J. E. Lytle letter to T. P. Grumbly, Approval of Path Forward for N-Reactor Spent Fuel Interim Storage, DOE EM-36, 9 November 1994, regarding the expeditious transfer of N-Reactor SNF to interim storage, but still within the applicable regulatory requirements.

3. SNF Project K-Basins Path Fonward Acquisition Strategy (WHC-SP-1144, December 1994 draft) which describes the following four key interconnecting subsystems:

- $\quad$ Staging and Storage Facility (SSF)

- Multi-canister Over packs (MCO)

- Transportation System

- Fuel Stabilization Facility (FSF)

4. U. S. Department of Energy (DOE) October 1994, Spent Nuclear Fuel Program Requirements Document (SNF-RD-PM-001), Revision 1, describing the management approach to integrate, coordinate, and optimize activities necessary for conditioning, handling, and transporting SNF to interim storage and preparing SNF for final disposal.

5. WHC-EP-009, WHC Reference Guide Acronyms and Abbreviations, Vol. 1, part 1.

6. WHC-IP-0117, Procedure Development Specification Manual.

7. WHC-SP-0708, Westinghouse Hanford Company Conduct of Operation. 


\section{APPENDIX C \\ REQUIREMENTS FOR REFERENCE}

1. 10 CFR 20, Standards for Protection Against Radiation

2. 10 CFR 71, Packaging and Transportation of Radioactive Material

3. 10 CFR 835 , Occupational Radiation Protection Standards

4. 20 CFR 1910 , Occupational Safety and Health Act of 1976

5. DOE 1300.2A, Department of Energy Technical Standards Program

6. DOE 1540.2, Hazardous Material Packaging for Transportation

7. DOE 1540.3A, Base Technology for Radioactive Material Transportation Packaging Systems

8. DOE 5480.4, Environmental Protection, Safety, and Health Protection

9. Fiscal Year 1995 Hanford Mission Plan, Volume 1, Site Guidance, September 1994

10. MRP 5.20, Packaging and Transportation of Hazardous Material

11. DOE 5480.28, Natural Phenomena Hazards Mitigation

12. Spent Nuclear Fuel Project, K-Basins Path Forward Acquisition Strategy, WHC-SP-1144, December 1994 (Draft)

13. WHC-CM-2-14, Hazardous Material Packaging and Shipping

14. WHC-CM-3-5, Document Control and Records Management Manual 
WHC-SD-SNF-CDR-003, Revision 0

\title{
ATTACHMENT 2
}

\section{CRITERIA EVALUATION REPORT}

\author{
for the
}

Cold Vacuum Drying System

of the

K BASIN SPENT NUCLEAR FUEL STORAGE PROJECT 
WHC-SD-SNF-CDR-003, Revision 0

\section{CRITERIA EVALUATION REPORT}

for the

COLD VACUUM DRYING SYSTEM

of the

\section{K-BASIN SPENT NUCLEAR FUEL STORAGE PROJECT}

\subsection{INTRODUCTION}

The design of a nuclear facility necessarily requires iteration between design concept development, hazards analysis, and criteria definition in order to arrive at a consistent package of criteria and designs that complies with the criteria. This is because the hazard classification $(\mathrm{HC})$, which is key to the criteria selection and design characteristics of the facility can be controlled to some extent by controlling the amount and form of the radioactive materials that will be present in the process systems and facility. The performance categorization (PC) of structures, systems, and components (SSCs) that are subjected to postulated Design Basis Accidents (DBAs) is dependent on the HC. And, the determination of whether an SSC is "safety class" is determined by the off-site consequences of releases that might occur as a result of DBAs. However, calculation of off-site consequences requires some model of the facility and the processes that it contains. PC and safety class determinations imply certain structural loads and analysis, as well as special design features to assure that there are no single point failure modes for an SSC.

A similar issue regarding selection of appropriate criteria exists with regard to DOE $6430.1 \mathrm{~A}$ requirements. It is necessary to select a facility type. But, often some level of design concept is required in order to make the necessary comparison between the facility and the type definition statements in the criteria documents.

It is the goal of the CVDS project to achieve "NRC Equivalency". Interpretation of the application and appropriateness of specific NRC regulations and guidelines is also dependent upon knowledge of the design concept and preliminary hazards assumptions.

For these reasons, the definition of criteria and design concepts must be completed simultaneously and iteratively, in conjunction with hazard assessment, so that the design team can make decisions that will control the criteria that are applicable. 
The purpose of this document is to report the key criteria (and associated interpretations) that are deemed appropriate for the Cold Vacuum Drying System when concurrently developing the Conceptual Design and the Preliminary Hazards Assessment. Assumptions are required in order to proceed with the Conceptual Definition of the CVDS. Formal safety analysis is required to verify or modify these assumptions. This report should be considered to be a living document in the sense that it should be revisited and updated as the design and safety analysis processes progress.

\subsection{Pre-Conceptual Features of The Cold Vacuum Drying System}

The Cold Vacuum Drying System will be a new building located at the K-Basins site in close proximity to the Basins. It is anticipated that it will be a steel frame building containing process bays and a support area constructed on a concrete pad. Wall materials will be selected to provide radiation shielding if determined necessary by radiation exposure analysis. It will receive transport trucks / trailers carrying Multiple Canister Overpack (MCO) vessels that are filled with approximately 5 tons of SNF elements and contaminated water. The MCOs will be transported vertically in stainless steel shielding casks. The cask will be DOT certified for over the road shipping of SNF. As received, the MCOs will have their tops secured by welding. The MCOs will be received with a filter and sealed fittings installed in the ports that lead to the MCO interior.

The drying process will be carried out with the MCO remaining in the cask on the trailer. The top will be removed from the cask and connections will be made to the ports so that the water can be drained and the MCO can be purged and evacuated. The process system will contain a pump and catch tank so that the free water can be drawn out of the MCO; it will contain a blower , condenser, heater loop that will allow for gas purge drying; it will contain a vacuum pump that will vacuum dry the $\mathrm{MCO}$; and it will contain a water heater and circulation loop that will allow the MCO to be warmed during drying by circulating water through the annular space between the MCO and the cask. Filters will be included in order to minimize the spread of contamination in the system. The process equipment will be packaged on a structural steel skid frame that will sit beside the transporter trailer.

Throughput analysis, allowing for recalcitrant MCOs that dry slowly and for preparation activities conducted between shipment of a dried MCO and the next wet one, indicate that six "garage like" bays will be required to complete the campaign of $400 \mathrm{MCO}$ in the two (2) year project duration. 
WHC-SD-SNF-CDR-003, Revision O

Since the CVDS will be a stand-alone facility, it will contain necessary support functions such as radioactive waste (liquid and solid) collection and handling, change rooms, HEPA filtered ventilation systems, control room, counting room, and so forth.

\subsection{FACILITY CLASSIFICATION CRITERIA}

\subsection{DOE STD -1027 "Hazard Categorization"}

DOE Order 5480.23, "Nuclear Safety Analysis Reports", requires that a Hazard Categorization $(\mathrm{HC})$ be performed for planned nuclear facilities for the purpose of establishing a graded approach to safety analysis. Ratings range from $\mathrm{HC}-1$ for the most hazardous rating to $\mathrm{HC}-4$ for non-nuclear facilities. The methodology for assessing the Hazard Category is given in DOE STD-1027-92, "Hazard Categorization and Accident Analysis Techniques for Compliance with DOE Order 5480.23, Nuclear Safety Analysis Reports".

In a general sense DOE STD - 1027 defines HC's as follows :

HC-3: Hazard analysis shows potential for only significant localized consequences. Facilities with quantities of radioactive materials in excess of the Table A-1 values which would yield a does of 10 Rem in $24 \mathrm{hrs}$ at 30 $m$ using the calculation method given in Attachment 1 .

HC-2: Hazard analysis shows potential for significant on-site consequences. The facility has potential for nuclear criticality events or has quantities of material at risk and energy sources to effect a release that would exceed 1 Rem exposure at a distance of $100 \mathrm{~m}$. using the calculation method given in Attachment 1 , or would require on-site emergency planning activities.

HC-1: Hazard analysis shows the potential for significant off-site consequences. Category A reactors ( $>20 \mathrm{MW}$ ) and facilities designated by PSO.

The STD - 1027 methodology is based on comparing the radiological inventory of a facility to HC Threshold Quantities (TQ) provided in Attachment 1. The Standard recognizes that large quantities of radioactive materials may be present in a facility, but in a containment vessel, distribution, or a form that precludes release, and which need not be counted in the inventory when making the $\mathrm{HC}$ determination. 
WHC-SD-SNF-CDR-003, Revision 0

"The concept of independent facility segments should be applied where facility features preclude bringing material together or causing harmful interaction among from a common severe phenomena. ... It is not desirable to estimate the potential consequences from an inventory of hazardous materials when facility features would preclude bringing this material together. Therefore, the standard permits the concept of facility segmentation provided the hazardous material in one segment could not interact with hazardous materials in other segments."

"Additionally, material contained in DOT Type B shipping containers (with or without overpack) may also be excluded from summation of a facilities radioactive inventory."

"Alternatively, for facilities initially classified as Hazard Category 2, if release fractions can be shown to be significantly different than these values based on physical and chemical form and available dispersive energy sources, the threshold inventory values for Category 2 in Table A-1 may be divided by the ratio of the maximum potential release fraction to that found on Page A-9. All assumptions which are used to reduce the inventory at risk should be supported in the Hazards Analysis."

Facilities that have radioactive material inventories in excess of the $\mathrm{HC}-2$ may be derated to $\mathrm{HC}-3$ by demonstrating that hazardous material is not part of the at-risk inventory and by scaling the threshold values according to the ratio of realistic facility specific release fractions to the release fractions that were assumed when the thresholds were established. A discussion of the TQ assumptions and calculations is given in Attachment 1 of the standard.

There is further guidance with regard to HC determination in DOE STD 3009 , "Guide For US DOE Nonreactor Safety Analysis Reports" where application of the graded approach is discussed as follows: "For example, simple Hazard Category 3 facilities or facilities that have a short operational life may only require a limited but adequate analysis..... facilities with short operational lives (or other compelling circumstances) should consider the appropriateness of applying for an exemption from the requirements of DOE 5480.23 ."

Application of these criteria to determine an HC rating for the CVDS will ultimately be determined by the calculation of off-site exposure resulting from releases initiated by postulated Design Basis Accidents. The method will be as described in STD-3009, "Quantification methods are typically limited to calculating the dose I exposure profile of a release. The process is iterative, starting by taking no credit 
for mitigative feature and comparing results to Evaluation Guidelines. Continue taking credit for additional mitigative features incrementally and comparing results to Evaluation Guidelines until below the guidelines. This iterative process, however, does not require denying the physical design of facility structures, systems, and components. For example, if liquid hazardous material is brought into a facility in steel piping and stored in steel tanks, it is not meaningful to disregard the existence of these physical features in the analysis. Simply admitting they exist does not require safety class designation either."

From this statement it is clear that the definition of a safety class SSC is that it is a mitigative feature that must function in order to assure that the Evaluation Guidelines are not exceeded. HC-3 facilities do not have safety class SSCs and HC-2 facilities may have safety class SSCs. Therefore, selection of the Hazard Category is dependent upon this evaluation.

The term "Evaluation Guidelines" is not quantitatively defined in the DOE Orders or Standards. A draft standard (DOE STD - 3005) was written, which set the following values:

- 25 Rem For Natural Phenomena events and for operational accidents with frequency between $1 \mathrm{E}-06$ and $1 \mathrm{E}-04$

- 10 Rem for operational accidents with frequency between 1 E-04 and 1 E-02

- $\quad 0.5$ Rem for operational accidents with frequency greater than $1 \mathrm{E}-02$

However, this standard was not accepted and has been dropped from consideration.

In this regard DOE $6430.1 \mathrm{~A}$ states, "Facility design shall provide attenuation features for postulated accidents (up to and including DBAs) that preclude off-site releases that would cause doses in excess of the DOE 5400 series limits for public exposure." It also defines the SSCs required to achieve the necessary attenuation as Safety Class. There are two issues that have rendered this criteria meaningless during the 7 years that DOE $6430.1 \mathrm{~A}$ has been applied as a fundamental criteria document. First, the DOE 5400 series document that defines public exposure limitations is DOE 5400.5 which states, "Doses not included in evaluations. The public dose limits do not apply to doses from medical exposures, consumer products, and generally do not apply to doses from naturally occurring radiation sources or from exposure due to accident conditions where control of exposures cannot be maintained. "Thus, DOE 6430.1A refers to a directive that excludes 
consideration of releases from Design Basis Accidents. Second, DOE 6430.1A, Section 0200-1.3 states a limitation of $25 \mathrm{Rem}$ as a result of low probability occurrences when making site selection. The normal conclusion drawn from the DOE $6430.1 \mathrm{~A}$ references is that high probability occurrences that can be controlled should not result in an exposure off site in excess of 0.5 Rem (from DOE 5400.5) and low probability occurrences should not result in an off site exposure in excess of $25 \mathrm{Rem}$. This is a similar conclusion to the recommendation that was given in Draft DOE STD 3005. Safety Class SSCs are those that are required to attenuate a release resulting from a DBA so that public dose is less than 25 Rem.

A comparison of the CVDS to the above considerations is as follows :

- The facility is segmented. There may be as many six MCOs containing 30 tons of SNF in the building at any given time, but compartmentalization is such that multiple MCOs cannot be adversely affected by a single initiator. Only a single MCO need be considered.

- The MCO is a rugged container which is secondarily contained in a DOT Type B container. The STD - 1027 guidance would be clear regarding exclusion of the material in the MCO from the at risk inventory if the cask were to remain closed. However, in the CVDS the cask top is off and the connections to the MCO top do offer a small pathway through which some material could pass. None-the-less, in spite of this imperfection, the partial containment in the cask does offer a significant degree of protection and the $\mathrm{MCO}$ is a vessel that severely restricts the release fraction. As noted in the STD 3009 guidance the existence of the vessel is of value.

- Should material be drawn from the MCO, it will be contained in process piping and tanks. Most will be in the water drawn from the MCO. So that it will be contained in piping and will not be immediately released out of the building if a rupture were to occur in the collection system. The total amount of material that will likely be withdrawn from any given MCO will be a few grams of particles suspended in the water and gas streams. This is the material at risk in the CVDS.

- It is possible, although highly unlikely and maybe not credible, that a pyrophoric event could occur within the $\mathrm{MCO}$ as a result of uranium reacting with water vapor. The operating temperature is low and the MCO is either filled with inert gas or is under vacuum while it is being processed. If such an event were to occur it is most likely to be a localized ignition that extinguishes because the water vapor that is available to fuel the fire will be 
consumed quickly. It is unlikely that such an event would rupture the connected drying system plumbing and it is impossible for the event to involve the facility HEPA filters. An event large enough to rupture the MCO is judged to be very unlikely.

- The MCO partially contained in a DOT Type B shipping container, given the available energy sources for credible accidents, is adequate containment to exclude the material in the MCO from the inventory at risk in the CVDS. The inventory at risk is below the $\mathrm{HC}-2 \mathrm{TQs}$.

- The facility will operate only as long as it takes to work off the K-Basin SNF, which is scheduled for two years. It is a short lifetime facility as discussed in STD - 3009 .

1. The small inventory available for release will not cause an off-site exposure in excess of $25 \mathrm{Rem}$, which would require the presence of safety class SSCs. Formal calculational verification of this assertion is required.

It is concluded from these comparisons that a preliminary $\mathrm{HC}-3$ rating (pending completion of a Hazards / Accidents Analysis) is appropriate for the CVDS

\subsection{DOE STD - 1021 "Performance Categorization"}

DOE Order 5480.28, "Natural Phenomena Hazards Mitigation" establishes a graded approach for determining the Performance Categorization PC of a Structure, System, and Component (SSC) when subjected to Natural Phenomena Hazards based on the probability that SSC response will exceed a safety limitation. Guidance for PC determination is given in DOE STD 1021-93, "Natural Phenomena Hazards Performance Categorization Criteria for Structures, Systems, and Components". Figure 1-1 of STD 1021 summarizes the guidance. It can be seen from the table that SSCs that perform a safety function in a $\mathrm{HC}-3$ rated facility will be rated PC-2. Since the CVDS will be an HC-3 facility, the safety SSCs will be qualified to the criteria defined by PC-2. (In this context there are no safety class SSCs but there are safety - significant SSCs that protect workers).

PC-2 rating does not require dynamic finite element analysis. The critical facility methodology given in UBC may be applied.

In Section 2.5 of the STD-1021 it is stated that, "If the behavior or failure of a source can adversely effect the performance of more than one target, the source 
shall have additional NPH requirements corresponding to the highest performance category that is determined by applying the rules provided in Paragraph (a), (b), and (c) above separately for each target. If the adverse interaction is possible only after the source fails or exceeds its acceptable behavior limits, either of the following two requirements shall be met to preclude adverse interaction : (I) The source shall have additional NPH requirements corresponding to the performance category of the target, if the failure probability of the target is greater than one percent. If the implementation of this criterion is judged not to be cost effective, the additional NPH mitigation requirements for the source shall be in accordance with Table 2-1 ..." For, the CVDS, the MCO / cask is the target and the source is the building structure. Given the potential severe consequences of a building structure failure leading to damage and failure of an MCO, the building structure will be assigned a PC-3 rating. The criteria for the structure will not require that the structure perform a confinement function during and after a DBA. Other safety related functions in the facility will be treated as PC-2 SSCs

\subsection{DOE 6430.1a "Facility Type Categorization"}

The CVDS will be a "Nuclear Facility" as defined in the glossary of terms (page 21). Therefore, it will be a "Special Facility" as defined by paragraph 1300-1.1. The criteria given in Division 13 "Special Facilities" are the basic guidance for the design of the facility. Application of Division 13 requirements involves the general requirements given in Section 1300 as well as the requirements given in the applicable facility type section. In addition, the special facilities specific paragraphs labeled - 99.0 in the Discipline Divisions apply.

The nuclear facility type choices are:

1. Plutonium Processing and Handling Facilities

2. Plutonium Storage Facilities

3. Unirradiated Enriched Uranium Storage Facilities

4. Explosive Facilities

5. Uranium Enrichment Facilities

6. Uranium Processing and Handling Facilities

7. Irradiated Fissile Material Storage Facilities 
8. Reprocessing Facilities

9. Uranium Conversion and Recovery Facilities

10. Radioactive Liquid Waste Facilities

11. Radioactive Solid Waste Facilities

12. Laboratory Facilities (Including Hot Laboratories)

13. Tritium Facilities

14. Fusion Test Facilities

The CVDS does not exactly fit any of these classifications. The radioactive material is contained in a storage container and cask so that the hazards are similar to those in an Irradiated Fissile Material Storage Facility. On the other hand the material is transient and a simple process is performed on the SNF without removing SNF from the MCO.

The assignment of a facility type for the CVDS has been based on the following considerations :

The material present in the facility is irradiated fissile material

- The material, although large in quantity, is completely contained within a sealed container. The sealed container is further protected, at least partially, at all times by a rugged steel cask. The MCO - Cask - Transporter - Seismic restraint will be designed to cause the Cask and MCO to remain upright during a Design Basis Earthquake. Similarly, the vacuum equipment skid / frame will be designed to remain structurally sound during and after a DBA. The connection spool of the process piping will be metal hose to allow for mechanical flexing. These features assure that a DBE will not result in a major release to the facility that might migrate into the environment.

- There will not be removable contamination on exterior surfaces that could be readily released.

- $\quad$ Radioactive material that escapes from the cask as a result of the vacuum drying process will mostly be suspended in the water discharge which will be collected in tanks and trucked away from the facility. There is no airborne 
WHC-SD-SNF-CDR-003, Revision 0

release mechanism for this material. Dry radioactive dust will be caught on filters within the process system. Residual material clinging to process system interior surfaces will be minor. This material may pose a hazard to workers performing maintenance and repair activities but it is insufficient (and the releasable fraction is even less) to pose a threat to safety outside the building.

These considerations suggest that the most appropriate facility type is "Irradiated Fissile Material Storage Facilities" which is governed by the requirements of Section 1320. Additionally -99.14 paragraphs in the Discipline Requirements Divisions apply as well.

Paragraph 1320-1 defines the criteria covered by this section. The key criteria are:

1. The material has been exposed to neutron fluence in a nuclear reactor (e.g., spent nuclear fuel and target elements)

2. The irradiated material is properly clad or canned when received such that leakage from the assemblies is minimized

3. The integrity of the canning must be ensured

4. The section applies to water pool type or dry type storage

The existence of some contamination in the drying process system is considered to be a minor perturbation that does not significantly change the character of the facility from being a temporary storage facility.

\subsection{CFR Part 72 "Licensing Requirements For The Independent Storage Of Spent Nuclear Fuel And High Level Radioactive Waste"}

The scope of this regulation is limited to the storage of spent fuel generated by power reactors in either a wet or dry storage condition. It does not apply to the DOE except when the DOE accepts spent fuel from power reactors for storage as directed by the Nuclear Waste Policy Act. The SNF stored in the K-Basins was generated by a DOE owned isotope production reactor. Therefore, it does not fall within the scope governed by the regulation.

The DOE has stated that it generally desires to comply with the requirements of the CFRs except for the licensing requirements, except for those instances and facility types that are not specifically addressed by the CFRs, and except for those 
WHC-SD-SNF-CDR-003, Revision O

instances where the DOE policies are more conservative than the requirements of the CFRs.

Assignment of the DOE 6430.1A facility type to be : "Irradiated Fissile Material Storage Facilities" suggests by that the provisions of 10 CFR Part 72 might be appropriate. However, the underlying assumption of 10CFR72 is that the material being stored is spent fuel from a power reactor. This fuel is not analogous to the SNF that will be present in the CVDS for the following reasons :

- The decay heat power from commercial power reactor fuel is typically 30 to 50 times greater than the K-Basin fuel.

- The radiation field from the commercial fuel is much higher than the field from the K- Basin fuel.

These two facts suggest that CVDS will have significantly lesser risk than would normally be associated with an ISFSI.

Furthermore, the scope statement of 10CFR72.2 states that it applies to facilities that are "designed and constructed specifically for storage of power reactor spent fuel aged at least one year". Even, if it were judged that spent power reactor fuel and the K-Basin SNF were analogous, the CVDS is designed specifically to dry fuel and the "storage" time is really the transient time in the facility required by the process.

The conclusion of these considerations is that selection of the "Irradiated Fissile Material Storage Facility" facility type in DOE $6430.1 \mathrm{~A}$, which best describes the condition of the SNF and its associated hazards in the context of the DOE General Design Criteria, does not imply the CVDS is the type of storage facility regulated by 10 CFR 72 . It is concluded that 10 CFR 72 is not appropriate for application to the CVDS.

\subsection{DESIGN CRITERIA}

\subsection{DOE Orders \& Standards}

Table 3.1 contains a list of DOE Orders and DOE Technical Standards that contain provisions that will effect features of the design of the CVDS or that may effect the contents of the engineering / design documentation of the CVDS.

A brief description of each of the entries is as follows : 
WHC-SD-SNF-CDR-003, Revision 0

5400.1 General Environmental Protection Program -This order states that environmental notification and reporting requirements are to be determined on a facility case by case basis. It requires an annual environmental report which is essentially an emissions summary. It requires that an environmental protection plan and an environmental monitoring plan be developed and approved. These should be approved before authorization to initiate operations is given. The CVDS design will have to include appropriate monitoring capability.

5400.3 Hazardous and Radioactive Mixed Waste Program - This order implements RCRA in the DOE. The CVDS will generate radioactive waste that is regulated by RCRA.

5400.4 CERCLA Requirements - This order implements CERCLA in the DOE.

5400.5 Radiation Protection of the Public and the Environment -Sets limits on public doses from normal operations. Defines Derived Air Concentrations and implements ICRP recommendations.

5440.1E NEPA Compliance Program - This order implements the National Environmental Protection Act in the DOE.

5480.1B Environment, Safety, and Health Program - This document is the master document for the 5480 series of orders.

5480.4 Environmental Protection, Safety, and Health Protection Standards - This order implements a list of regulations that apply to private organizations but which are not automatically applied to the DOE. The order is a useful reference list.

N5480.6 DOE RadCon Manual - This notice sets policy regarding radiation exposure limits, radiation area practices, and ALARA considerations. A design program is required to achieve the ALARA goal. Thwe guideline also contains criteria governing the design of change rooms and other radiation / radioactive material control procedures. One key criteria is the ALARA design guideline of $500 \mathrm{mR}$ per year for an individual radiation exposure.

5480.7A Fire Protection - This order relates to nuclear facility safety issues such as fire protection of safety class equipment, fire hazards analysis for the design basis fire to be included in the SAR, seismic criteria for the fire protection system, and life safety codes. It sets forth provisions that address loss limitation for government owned facilities. 
WHC-SD-SNF-CDR-003, Revision 0

DOE ORDERS SUMMARY

\begin{tabular}{|c|c|}
\hline $\begin{array}{l}\text { ORDER } / \\
\text { STANDARD }\end{array}$ & TITLE \\
\hline 5400.1 & General Environmental Protection Program \\
\hline 5400.3 & Hazardous and Radioactive Mixed Waste Program \\
\hline 54004 & Comprehensive Environmental Response, Compensation, and Liability Act Requirements \\
\hline 5400.5 & Radiation Protection of the Public and the Environment \\
\hline $5440.1 \mathrm{E}$ & National Environmental Policy Act Compliance Program \\
\hline $5480.1 \mathrm{~B}$ & Environment, Safety, and Health Program \\
\hline 5480.4 & Environmental Protection, Safety and Health Protection Standards \\
\hline N5480.6 & DOE RadCon Manual \\
\hline $5480.7 \mathrm{~A}$ & Fire Protection \\
\hline 5480.9 & Construction Safety and Health Program \\
\hline 5480.19 & Conduct of Operations Requirements for DOE Facilities \\
\hline 5480.21 & Unreviewed Safety Questions \\
\hline 5480.22 & Technical Safety Requirements \\
\hline 5480.23 & Nuclear Safety Analysis Reports \\
\hline 5480.28 & Natural Phenomena Hazards Mitigation \\
\hline 5481.31 & Start-Up and Restart of Nuclear Facilities \\
\hline$-5483.1 \mathrm{~A}$ & $\begin{array}{l}\text { Occupational Safety and Health Program for DOE Contractor Employees at Government- } \\
\text { Owned Contractor-Operated Facilities }\end{array}$ \\
\hline $5700.6 \mathrm{C}$ & Quality Assurance \\
\hline $5820.2 \mathrm{~A}$ & Radioactive Waste Management \\
\hline $6430.1 \mathrm{~A}$ & General Design Criteria \\
\hline STD-0101 & $\begin{array}{l}\text { Compilation of Nuclear Safety Criteria for Potential Application to DOE Non-Reactor } \\
\text { Nuclear Facilities }\end{array}$ \\
\hline STD-1020 & Natural Phenomena Hazards Design and Evaluation Criteria for DOE Facilities \\
\hline STD-1021 & $\begin{array}{l}\text { Natural Phenomena Hazards Performance Categorization Guidelines for Structures, } \\
\text { Systems, and Components }\end{array}$ \\
\hline STD-1027 & $\begin{array}{l}\text { Guidance For Preliminary Hazard Classification and Accident Analysis Techniques for } \\
\text { Compliance With DOE Order } 5480.23 \text {, Safety Analysis Reports }\end{array}$ \\
\hline STD-1044 & Guide To Good Practices for Equipment and Piping Labeling \\
\hline STTD-3003 & Backup Power Sources for DOE Facilities \\
\hline STD-3006 & Planning and Conduct of Operations Readiness Reviews \\
\hline STD-3009 & Preparation Guide for U.S. DOE Nonreactor Nuclear Facility Safety Analysis Reports \\
\hline STD-3011 & $\begin{array}{l}\text { Guidance for Preparation of DOE } 5480.22 \text { (TSR) and DOE } 5480.23 \text { (SAR) Implementation } \\
\text { Plans }\end{array}$ \\
\hline
\end{tabular}


5480.9 Construction Safety and Health Program -This order implements requirements found in the OSHA regulations regarding construction safety. Construction specifications should reference appropriate requirements.

5480.19 Conduct of Operations Requirements for DOE Facilities - Safety of workers and protection of the public requires that nuclear facilities be formally managed by operations program that meets high standards of discipline. In the nuclear power, NRC, arena the conduct of operations requirements are specified by the ICRP. This order implements similar requirements for facilities regulated by the DOE. It addresses operations procedures, shift changes, operator training, and so forth. The design team will write a draft Conduct of Operations Plan.

5480.21 Unresolved Safety Questions - Is analogous to 10CFR50.59. Establishes a process for changing the operating basis of the facility. Allows the operator the freedom to perform experiments and investigate safety issues that may arise while conducting day - to - day operations.

5480.22 Technical Safety Requirements - This order requires that safety limits for the operating parameters of the facility be established, that procedures for assuring that these limits are not exceeded be established, that these parameters be monitored, and that response actions for conditions outside the safety limits be determined.

5480.23 Nuclear Safety Analysis Reports - This order applies in its entirety because it is the document that defines the requirements for safety analysis and SARs, which are the means of demonstrating that the public/environment and workers are adequately protected. The major impacts on the project are:

- A preliminary hazards analysis is to be performed and published. Guidance is given by DOE STD - 1027 .

- A Preliminary Safety Analysis Report (PSAR) is to be developed. The PSAR is developed simultaneously with design. There is iteration between safety analysis and design. The PSAR analysis demonstrates that the design adequately mitigates the consequences of the hazards presented in the hazards analysis. The PSAR must normally be reviewed by DOE and approved before procurement and construction is initiated (generally accepted practice per DOE 4700.1 , not required by DOE 5480.23 ). The requirement for approval before initiation of procurement and construction has been implemented to limit the federal government's financial risk and to assure that the DOE does not have a conflict of interest in that those performing the review could be biased because the Department has a commitment requiring protection

- A Final Safety Analysis Report is to be developed. This report updates the PSAR to reflect the as-built facilities and incorporates the operating procedures for the facilities. Approval of the SAR constitutes agreement that the nuclear facility safety issues have been properly addressed and is required to initiate operations. 
5480.28 Natural Phenomena Hazards Mitigation - Establishes requirements for response of facilities to natural phenomena such as earthquakes and high winds.

5480.31 Start-up and Restart of Nuclear Facilities - Sets out requirements for authorization to initiate operations utilizing nuclear materials. Essentially this document establishes the DOE "licensing" criteria. The Operating Readiness Plan should be written by the design team. The plan should follow the guidance of DOESTD-3006.

5483.1A Occupational Safety and Health Program for DOE Contractor Employees at Government Owned Contractor Operated Facilities - This order implements OSHA within the DOE.

5700.6C Quality Assurance - The document is analogous to ASME NQA-1 which is a nuclear facilities quality assurance guideline required by DOE6430.1A.

5820.2A Radioactive Waste Management - This order requires a waste management plan, has $D \& D$ requirements, and sets waste characterization standards, as well as establishing numerous other requirements that affect both the design and operations of the CVDS.

6430.1A General Design Criteria - This order sets forth design criteria for all engineering disciplines as well as special facility and special equipment criteria. Facility type classification and safety class SSC requirements are discussed in Section 2..3 above, where its is concluded that the most appropriate classification is Intermediate Spent Fuels Storage Installation which is governed by the specific requirements of Section 1320 .

The order is far too extensive to review here. Some of the key highlights are described below.

A summary of the key criteria from the 1320 paragraphs is :

1. Criticality safety shall be maintained by geometry control preferably. Neutron absorbers may be used but there are restrictions.

2. To the extent possible passive cooling will be used in dry storage facilities

3. Detection systems are to be included to detect accidental release of radioactive materials into the plant. 
WHC-SD-SNF-CDR-003, Revision 0

4. Shielding and radiation field monitoring instruments are to be provided to achieve ALARA radiation exposure conditions.

5. There shall be provision for temporary handling of leaking containers.

6. There shall be two levels of confinement. The can (MCO) shall be the primary confinement structure. The building shall be the secondary confinement structure. The can shall provide confinement during normal operating and anticipated operational occurrences. The building shall additionally function as a confinement barrier as necessary to perform its safety functions during Design Basis Accidents including Natural Phenomena. The necessary safety functions for the building are to be determined by safety analysis using the off-site release exposure analysis guidelines given in Paragraph 1300-1.4.2.

7. Recirculation of the secondary confinement air is acceptable provided that it is HEPA filtered. (Note : This practice has been successfully implemented for 20 years in PF-4 at TA-55 of Los Alamos National Laboratory. This is the only operational plutonium processing facility in the DOE complex at this time).

8. The extent of exhaust filtration (number of HEPA filter stages, iodine absorbers, etc.) is to be determined by safety analysis considering the consequences of credible releases and the guidelines of Section 1300-1.4.2.

9. Provisions for handling solid and liquid waste are to be provided.

10. Exhausts shall be monitored for transuranic and fission product contaminants. The exhaust monitoring shall comply with the requirements of Section 1589-99.0.1.

Key confinement system ventilation requirements are referred to ERDA 76-21 and to the 1550-99 paragraphs of the order. The key statement comes from 1550-99.0.1 "General Ventilation and Off-Gas Criteria", "These criteria cover ventilation and offgas systems, or portions of them, that are identified as safety class items in accordance with Section 1300-3.2, Safety Class Items". Strictly speaking, this means that the CVDS will not be governed by these requirements. None-the-less the principles stated in 1550-99.0.2 "Confinement Ventilation Systems" should be followed as a matter of good engineering practice (except where specific references 
to the safety class characteristics of the system are made). The basic design concepts for exhaust filtration performance and stack design should be derived from safety analysis that analyzes the consequences of credible release scenarios.

Section 0110-12.8.1 requires that an energy conservation report should be written for new buildings over $10,000 \mathrm{sq}$. ft. A waver from this requirement should be requested given that the facility operating lifetime is only two years and the ventilation system recirculates the majority of the air in the building so that heat lost through exhaust has already been minimized.

Section 1300-12 "Human Factors Engineering" requires that a human factors program plan be written. The level of detail of the plan is to be determined by the complexity or safety issues associated with human activities. The subsections also set out extensive human factors requirements for human factors engineering. The CVDS should write and implement a plan given that the radiation exposure during operations can severely restrict the staff planning.

STD-0101 Compilation of Nuclear Safety Criteria For Potential Application to DOE Non-Reactor Nuclear Facilities - This is STD contains a listing of references.

STD-1020 Natural Phenomena Hazards Design and Evaluation Criteria for DOOE Facilities - This standard gives guidance regarding the selection of design criteria to be applied to nuclear facilities structural design.

STD-1021 Natural Phenomena Hazards Performance Categorization Guidelines For Structures, Systems and Components - See discussion in Section 2.2.

STD-1027 Guidance for Preliminary Hazard Classification and Accident Analysis Techniques for Compliance With DOE Order 5480.23, Safety Analysis Reports See discussion in Section 2.1.

STD - 1044 Guide To Good Practices For Equipment and Pipe Labeling - Sets forth guidelines for labeling equipment and piping.

STD -3003 Backup Power Sources For DOE Facilities - There is no safety requirement for backup power in the CVDS. The guidance in the is guideline will be followed if backup power is included for other reasons. 
STD-3006 Planning and Conduct of Operations Readiness Reviews - ORR planning will be addressed by the design team in order to assure that the necessary engineering documentation is ready for the ORR.

STD-3009 Preparation Guide for U.S. DOE Nonreactor Nuclear Facility Safety Analysis Reports - See discussion in Section 2.1.

STD-3011 Guidance for Preparation of DOE 5480.22 (TSR) and DOE 5480.23 (SAR) Implementation Plans - These plans will be drafted as part of the design process.

\subsection{NRC Equivalency}

Report WHC-SD-SNF-DB-003 Rev.1, December, 1995, "Spent Nuclear Fuel Project Path Forward Additional NRC Requirements" addresses implementation of the U.S. DOE K Basin Spent Nuclear Fuel Regulatory Policy (august 4, 1995) to achieve "nuclear safety equivalency" to comparable U.S. Nuclear Regulatory Commission (NRC) licensed facilities. This report addresses the project as a whole. Each of the components of the project is required to look at application for the specific features of the components. This section addresses application of each of the 29 items in WHC-SD-SNF-DB-003 to the CVDS as follows :

1. Fire Protection - Assure that DOE 5480.7A and DOE 6480.1A are equivalent to 10 CFR50, Appendix R. DOE orders are more comprehensive in their fire protection requirements than are the comparable NRC requirements (see letter from Walter W. Maybee to Lester A. Ettlinger regarding comparison of DOE and NRC fire protection standards). The primary focus of NRC requirements is protection of safety class SSCs. The CVDS will not have safety class systems. Implementation of the DOE Orders requirements will adequately satisfy the NRC equivalency goal.

2. Response to Natural Phenomena Hazards. The key difference is that NRC includes a Design Basis Tornado and missile analysis for safety class 1 systems. The CVDS will not have any safety class 1 SSCs. References are to sections in 10 CFR Part 72, which is not applicable to the CVDS as described in Section 2.4 above. Therefore, the DOE prescribed approach based on DOE 5480.28, which has no design basis tornado for the Hanford site, is appropriate. 
3. In the event that safety class 1 electrical equipment may be required and may be exposed to harsh environments .... The CVDS will not have any safety class 1 SSCs. Note that referenced sections are all specific to Nuclear Power Plant Safety and Light Water Reactors which are facilities that are in no way comparable to the CVDS.

4. SAR should include a loss of power accident analysis. The CVDS will be designed to shut down safely to a passive condition in the event of a (Loss Of operating Power) LOOP incident. Inclusion of LOOP incidents in safety analysis is standard practice in DOE $\mathbf{5 4 8 0 . 2 3}$ safety analysis as prepared according to DOE-STD-3009.

5. Incorporate the requirements of IEEE Std 484-1987 into the design and installation of safety class 1 batteries. The CVDS will not have safety class 1 batteries.

6. Incorporate the requirements of IEEE Std 535-1986 into the design and installation of safety class 1 batteries. The CVDS will not have safety class 1 batteries

7. Incorporate the requirements of IEEE Std 603-1991 into the design of safety class 1 instrumentation and control systems. The CVDS will not have any safety class 1 instrumentation and control systems.

8. Incorporate the requirements of ANSI / ANS 8.31986 for criticality alarm systems. The CVDS will not have a criticality alarm system because criticality cannot occur in the facility.

9. Human factors planning and engineering. See discussion about the DOE $6430.1 \mathrm{~A}$ human factors engineering requirements in Section 3.1 above.

10. Use Regulatory Guide 1.26 to assist in assigning appropriate code class to ASME Section III systems and components. The CVDS will not contain any ASME Section III systems or components. 
11. Regulatory Guides 1.84 and 1.85 regarding application of ASME Section III requirements to safety class 1 systems. The CVDS will not have any safety class 1 systems.

12. Ensure that the requirements of ANSI / ANS 509 and ANSI / ANS 510 are incorporated into HEPA filter design. The NRC and DOE 6430.1A requirements are the same. HEPA filter systems will be designed and specified according to these standards.

13. Incorporate the requirements of ANSI / ANS 57.1 and 57.2. Does not apply to the CVDS since there will be no cranes with the capacity to lift the cask or $\mathrm{MCO}$.

14. Incorporate the applicable design requirements of Generic Letters 88-14, 8910 , and $89-13$ into safety class $1 \ldots .$. The CVDS will not have safety class 1 SSCs.

15. $10 \mathrm{CFR}$ Part 21 requires that manufacturers of procured items report defects in items or services for safety class 1 SSC procurement. Standard clause in WHC procurement terms and conditions. The CVDS will not have any safety class 1 SSCs.

16. 10 CFR 830.120 Quality Assurance program requirements. The normal DOE requirements for compliance with DOE $5700.6 \mathrm{c}$ exceeds this requirement. The CVDS will follow the DOE requirements.

17. 10 CFR 50.55 requires reporting of unusual occurrences during construction. This is covered by WHC-CM-1-5. The CVDS will observe this requirement.

18. 10 CFR 50, Appendix B Quality Assurance Criteria for Nuclear Power Plants and Fuel Reprocessing Plants. The normal DOE requirements for compliance with DOE $5700.6 \mathrm{c}$ exceeds this requirement. The CVDS will follow the DOE requirements.

19. Institute a process to identify safety class 1 equipment that has been identified in the commercial nuclear power industry via IE Bulletins and 
Notices as being potentially defective. The CVDS will not have safety class 1 SSCs.

20. 10 CFR Part 20 - incorporate control devices for access to high radiation areas that conform to the requirements of section 20.161 . The definition of High Radiation area is greater than 100 mrem per hour at $30 \mathrm{~cm}$ (per 10 CFR 20.1003). Note 10 CFR 835 is ten (10) times higher. The exposure rate $30 \mathrm{~cm}$ from the cask is less than 100 mrem per hour. Therefore this requirement does not apply.

21. Apply the radiological exposure criteria of Section 72.104 .... The CVDS is not governed by 10 CFR Part 72 requirements as discussed above in Section 2.4. Therefore, the stated NRC requirements can not be compared to the DOE requirements for the purposes of assessing equivalency.

22. Use a deterministic value of 5 Rem in safety analyses for the on-site worker at the boundary of the controlled area ( $100 \mathrm{~m}$ from the CVDS release point) for design basis accidents to assist in determining safety class 2 and 3 SSCs (refs. 10 CFR 72.106, .100, .126). 10 CFR Part 72 requirements do not apply to the CVDS. The DOE orders and STDs do not address safety class 2 and 3 specifically. Equivalently they discuss SSCs that are safety significant to encompass those systems that protect on site workers and plant workers. The DOE criteria is 1 Rem at $100 \mathrm{~m}$. (see HC-2 criteria in Section 2.1 above) which is more restrictive than the referenced NRC requirement. The CVDS is expected to be an $\mathrm{HC}-3$ facility so that compliance will be achieved.

23. Implementation of RG 8.8, Information Relative to Ensuring That Occupational Radiation exposures at Nuclear Power Stations Will Be As Low As Reasonably Achievable, Rev. 3, DOE requirements from DOE N 5480.6 are more restrictive than RG 8.8. The design process will include a thorough ALARA analysis that estimates exposure considering source terms, work sequences, and anticipated repair requirements.

24. Implementation of RG 3.26, Standard Format and Content of Safety Analysis Reports for Fuel Reprocessing Plants or RG 3.48 Standard Format and Content of Safety Analysis Reports for an Independent Spent Fuel Storage Installation (Dry Storage). The CVDS is neither similar to a fuel reprocessing plant or an ISFSI. Neither requirements is appropriate for the CVDS especially given its very short operational lifetime. The site is currently being 
used as a fish farm. It is anticipated that this use will expand and that the CVDS may be ultimately used as a support building for these activities once the drying systems have been removed and the facility has been surveyed and released for public use.

25. Review the monitoring requirements of 10 CFR 20, 10 CFR70.59, 10 CFR50, Appendix A. These are analogous to DOE 6430.1A 1589-99.0.1. which is a project requirement stated above in DOE 6430.1A review in Section 3.1.

26. The 10CFR50, Appendix 50 general design criteria are adequately covered in the CVDS by application of the other criteria in this report.

27. Incorporate a criticality safety value of keff $=0.95$. The CVDS cannot achieve a critical condition. Criticality analysis for the configuration of the SNF inside the MCO will be the responsibility of the MCO design team. No criticality analysis will performed.

28. Review ANSI / ANS 57.9 and RG 3.60 which set forth ISFSI design criteria. The CVDS is not analogous to an ISFSI ( see discussion in Section 2.4 above).

29. Identify items that are "important to safety" in accordance with 10 CFR 72.3 and impose safety class 1 requirements. The CVDS is not an ISFSI covered by 10 CFR Part 72 . The requirement is not appropriate.

\subsection{NUCLEAR SAFETY PROGRAM CRITERIA}

Key nuclear facility safety documents that define public safety aspects of the CVDS criteria are discussed in Sections 2.1 through 2.4 above. The key DOE Orders are the DOE 5480 series and the DOE 5400 and 5500 series.

Worker radiation exposure safety within the plant is defined by HSRCM - 1, 10 CFR 20 equivalency, 10 CFR 835, and DOE N5480.6. Of these the DOE N 5480.6 is the most comprehensive and restrictive document. A program to achieve radiation exposure As Low As Reasonably Achievable with an administrative control limitation of 500 mrem per year per person is the stated whole body exposure criteria in HSRCM - 1, DOE N 5480.6. 10 CFR 835 defines the DOE ALARA design target as 
1.0 Rem per year. 10 CFR 20 and DOE 5480.11 state the maximum allowable annual exposure is 5 Rem. Thus the two ALARA design targets are $10 \%$ and $20 \%$ of the maximum allowable value. The CVDS design criteria will the DOE N 5480.6 value $(500 \mathrm{mrem})$ unless features required to achieve this value prove to be unreasonable (in which case the 10 CFR 835 / DOE 5480.11 limit of 1.0 rem will be observed).

\subsection{OPERATIONS PREPARATIONS CRITERIA}

The transition from the end of the CVDS construction project to operations will be an Operations Readiness Review. This review will be conducted according to the requirements of DOE 5480. 31. The ORR will determine that the facility is complete, that the safety analysis is complete, that TSRs (DOE 5480.22 and DOE STD $-3011,1082)$ are complete, that appropriate design criteria have been established and met, that systems operations tests are complete, that personnel training has been completed (DOE STD 1005, 1007, 1008, 1009, 1011, 1056, 1060, 1070,1074 , and 1078) that safety programs are operational (DOE STD - 1082), that an appropriate conduct of operations program (DOE 5480.19 and DOE STD - 1032, $1033,1034,1035,1036,1037,1038,1039,1040,1041,1042,1043,1045,1051$, 1054, and 1055) is in place, that emergency preparedness programs are appropriate. In order to activate the transition and ORR plan is required per DOE STD-3006. This plan should be developed in parallel with the detailed design.

\section{Appendix A : Listing of Reference Criteria Documents}




\begin{tabular}{|c|c|c|c|c|c|}
\hline (1) & sow & 115. & SW & $15 \%$ & COMNENT \\
\hline \multicolumn{6}{|c|}{ DOE DIRECTIVES } \\
\hline $\begin{array}{l}\text { DOE } 1300.2 \mathrm{~A} \\
\text { Technical Standards Program }\end{array}$ & & & & $\mathrm{x}$ & No Design Impact \\
\hline $\begin{array}{r}\text { DOE } 1324.5 \mathrm{~B} \\
\text { Records Management }\end{array}$ & & $x$ & & $\mathrm{x}$ & No Design Impact \\
\hline $\begin{array}{l}\text { DOE } 1332.1 \mathrm{~A} \\
\text { Uniform Reporting System }\end{array}$ & $\mathrm{x}$ & & & $x$ & $\begin{array}{l}\text { WACs aiso apply } \\
\text { No Design Impact }\end{array}$ \\
\hline $\begin{array}{l}\text { DOE } 1360.2 \mathrm{~B} \\
\text { Records Management Program }\end{array}$ & & & & $x$ & No Design Impact \\
\hline $\begin{array}{l}\text { DOE } 1540.1 \mathrm{~A} \\
\text { Materials Transport \& Traffic Management } \\
\end{array}$ & & & & $x$ & No Design Impact \\
\hline $\begin{array}{l}\text { DOE } 15.40 .2 \\
\text { Hazardous Material Packaging } \\
\end{array}$ & & & & $x$ & $\begin{array}{l}\text { WACs also apply } \\
\text { No Design Impact }\end{array}$ \\
\hline $\begin{array}{l}\text { DOE } 15.40 .3 \mathrm{~A} \\
\text { RM Transportation Packaging } \\
\end{array}$ & & & & $x$ & No Design Impact \\
\hline $\begin{array}{r}\text { DOE 43:30.4B } \\
\text { Mairitenance Management } \\
\end{array}$ & & & & $x$ & No Design Impact \\
\hline $\begin{array}{r}\text { DOE } 4700.1 \\
\text { Project Management }\end{array}$ & $\mathrm{X}$ & & $\mathrm{X}$ & $x$ & No Design Impact \\
\hline $\begin{array}{l}\text { DOE N } 4700.5 \\
\text { Project Control Guidelines }\end{array}$ & $\mathrm{x}$ & & & & Expired a/21/94 \\
\hline RLID 4900.1 & & & $x$ & & Has been cancelled \\
\hline $\begin{array}{r}\text { DOE } 5000.3 \mathrm{~B} \\
\text { Occurrence Reporting }\end{array}$ & & & & $x$ & \\
\hline $\begin{array}{r}\text { RLID } 5000.3 \mathrm{~B} \\
\text { Occurrence Reporting }\end{array}$ & & & & $x$ & Use DOE 5000.3B \\
\hline RLID 5000.12 & & & $\mathrm{x}$ & & Has been cancelled \\
\hline $\begin{array}{l}\text { DOE } 5300.1 \mathrm{C} \\
\text { Telecommunications }\end{array}$ & & $x$ & & $x$ & No Design Impact \\
\hline $\begin{array}{r}\text { DOE } 5400.1 \\
\text { Environmental Protection } \\
\end{array}$ & & & & $x$ & WACs also apply \\
\hline $\begin{array}{l}\text { DOE } 5400.2 \mathrm{~A} \\
\text { Environmental Compliance Issue Coord }\end{array}$ & & & & $x$ & \\
\hline $\begin{array}{l}\text { DOE } 5400.3 \\
\text { Hazardous and Mixed Waste Program }\end{array}$ & & & & & \\
\hline $\begin{array}{r}\text { DOE } 5400.4 \\
\text { CERCLA Requirements } \\
\end{array}$ & & & & $\mathrm{x}$ & WACs also apply \\
\hline $\begin{array}{l}\text { DOE } 54100.5 \\
\text { Radiation Protection } \\
\end{array}$ & & & & $\mathrm{x}$ & Use HSRCM- 1 also \\
\hline $\begin{array}{r}\text { DOE } 54.40 .1 \mathrm{E} \\
\text { NEPA Compliance } \\
\end{array}$ & & & & $\mathrm{x}$ & WACs also apply \\
\hline $\begin{array}{r}\text { DOE } 5480.1 \mathrm{~B} \\
\text { ES\&H Program }\end{array}$ & & & & $x$ & \\
\hline $\begin{array}{r}\text { DOE } 54.80 .3 \\
\text { Safety for HAZMAT Transportation }\end{array}$ & & & & $\mathrm{x}$ & $\begin{array}{l}\text { WACs also apply } \\
\text { No Design Impact }\end{array}$ \\
\hline $\begin{array}{r}\text { DOE } 5480.4 \\
\text { ES\&H Protection Standards } \\
\end{array}$ & & & & $x$ & WACs also apply \\
\hline $\begin{array}{r}\text { DOE } 5480.6 \\
\text { Safety of Nuclear Reactors }\end{array}$ & & & & $x$ & No Design Impact \\
\hline $\begin{array}{l}\text { DOE } 5480.7 \mathrm{~A} \\
\text { Fire Protection } \\
\end{array}$ & & $x$ & & $\mathrm{x}$ & \\
\hline
\end{tabular}




\begin{tabular}{|c|c|c|c|c|c|}
\hline 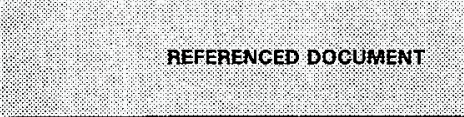 & sow & $\begin{array}{l}15 \\
110 \\
0435\end{array}$ & & 15 & COMMENT \\
\hline $\begin{array}{l}\text { DOE } 5480.8 \mathrm{~A} \\
\text { Contractor Medical Program }\end{array}$ & & & & $\mathrm{x}$ & $\begin{array}{l}\text { WACs also apply } \\
\text { No Design Impact }\end{array}$ \\
\hline $\begin{array}{l}\text { DOE } 5480.9 \mathrm{~A} \\
\text { Construction Safety \& Health }\end{array}$ & & & & $\mathrm{x}$ & WACs also apply \\
\hline $\begin{array}{r}\text { DOE } 5.480 .10 \\
\text { Contractor Hygiene Program }\end{array}$ & & & & $x$ & $\begin{array}{l}\text { WACs also apply } \\
\text { No Design Impact }\end{array}$ \\
\hline $\begin{array}{l}\text { DOE } 5.480 .11 \\
\quad \text { Radiation Protection for Workers }\end{array}$ & & & & $x$ & Use HSRCM-1 \\
\hline $\begin{array}{l}\text { DOE } 5480.18 \mathrm{~B} \\
\text { Training Accreditation Program } \\
\end{array}$ & & & & $\underline{x}$ & \\
\hline $\begin{array}{l}\text { DOE } 5.480 .19 \\
\text { Conduct of Operations } \\
\end{array}$ & & $\mathrm{x}$ & & $\mathrm{x}$ & \\
\hline $\begin{array}{l}\text { DOE } 5.480 .20 \mathrm{~A} \\
\text { Personnel Selection, Qualification, Training }\end{array}$ & & & & $\mathrm{X}$ & \\
\hline $\begin{array}{r}\text { DOE } 5.480 .21 \\
\text { Unreviewed Safety Questions }\end{array}$ & & & & $\mathrm{x}$ & \\
\hline $\begin{array}{l}\text { DOE } 5.480 .22 \\
\text { Tech. Safety Requirements }\end{array}$ & & & & $\mathrm{x}$ & \\
\hline $\begin{array}{r}\text { DOE } 5.480 .23 \\
\text { Nuclear SARs }\end{array}$ & & & & $\mathrm{x}$ & \\
\hline $\begin{array}{r}\text { DOE } 5.480 .24 \\
\text { Criticality Safety } \\
\end{array}$ & & $\mathrm{x}$ & & $\mathrm{X}$ & No Design Impact \\
\hline $\begin{array}{c}\text { DOE } 5.480 .26 \\
\text { Trending } \\
\end{array}$ & & & & $x$ & No Design Impact \\
\hline $\begin{array}{r}\text { DOE } 5.480 .28 \\
\text { Natural Phenomena } \\
\end{array}$ & & $x$ & & $\mathrm{x}$ & \\
\hline $\begin{array}{l}\text { DOE } 5.480 .29 \\
\text { Employee Concerns Management }\end{array}$ & & & & $\mathrm{x}$ & No Design Impact \\
\hline $\begin{array}{r}\text { DOE } 5.480 .31 \\
\text { Readiness Review }\end{array}$ & & & & $x$ & \\
\hline $\begin{array}{r}\text { DOE } 5481.1 \mathrm{~B} \\
\text { Safety Analysis and Review System }\end{array}$ & & & & $x$ & No Design Impact \\
\hline $\begin{array}{l}\text { DOE 5482.1B } \\
\text { ES\&H Appriasal Program }\end{array}$ & & & & $\underline{x}$ & $\begin{array}{l}\text { WACs also apply } \\
\text { No Design Impact }\end{array}$ \\
\hline $\begin{array}{l}\text { DOE } 5.483 .1 \mathrm{~A} \\
\text { OSHA for Contractors }\end{array}$ & & & & $x$ & $\begin{array}{l}\text { WACs also apply } \\
\text { No Design Impact }\end{array}$ \\
\hline $\begin{array}{l}\text { DOE } 5.484 .1 \\
\text { ESi\&H Reporting } \\
\end{array}$ & & & & $x$ & $\begin{array}{l}\text { WACs also apply } \\
\text { No Design Impact }\end{array}$ \\
\hline $\begin{array}{l}\text { DOE5500.1B } \\
\text { Emergency Management System }\end{array}$ & & & & $x$ & $\begin{array}{l}\text { Use DOE action only. } \\
\text { See 1OCFR } 840 \text { also }\end{array}$ \\
\hline $\begin{array}{l}\text { DOE } 5500.2 \mathrm{~B} \\
\text { Emergency Categories }\end{array}$ & & & & $x$ & \\
\hline $\begin{array}{l}\text { DOE } 5500.3 \mathrm{~A} \\
\text { Planning for Emergencies } \\
\end{array}$ & & & & $x$ & \\
\hline $\begin{array}{l}\text { DOE } 5500.78 \\
\text { Emergency Records Protection }\end{array}$ & & & & $x$ & $\begin{array}{l}\text { WACs also apply } \\
\text { No Design Impact }\end{array}$ \\
\hline $\begin{array}{l}\text { DOE } 5500.10 \\
\text { Emergency Readiness Assurance }\end{array}$ & & & & $x$ & No Design Impact \\
\hline $\begin{array}{l}\text { DOE } 5630.1 \mathrm{~B} \\
\text { Safeguards and Security }\end{array}$ & & & & $x$ & No Design Impact \\
\hline $\begin{array}{r}\text { DOE } 5630.12 \mathrm{~A} \\
\text { S\&5 inspection } \\
\end{array}$ & & & & $\mathrm{x}$ & No Design Impact \\
\hline
\end{tabular}




\begin{tabular}{|c|c|c|c|c|c|}
\hline ( & 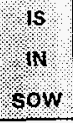 & $\begin{array}{l}15,+1 \\
1040 \\
0405\end{array}$ & 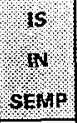 & $\begin{array}{l}15, \\
020\end{array}$ & GOMMENT \\
\hline $\begin{array}{l}\text { DOE } 5630.15 \\
\text { S\&S Training }\end{array}$ & & & & $x$ & No Design Impact \\
\hline $\begin{array}{l}\text { DOE } 5632.1 \mathrm{C} \\
\text { Protection and Control S\&S Interests }\end{array}$ & & & & $\mathrm{x}$ & No Design Impact \\
\hline $\begin{array}{l}\text { DOE } 5633.3 \mathrm{~B} \\
\text { Control and Accountability of Nuc Mat }\end{array}$ & & & & $x$ & No Design Impact \\
\hline $\begin{array}{l}\text { DOE } 5700.6 \mathrm{C} \\
\text { Quality Assurance } \\
\end{array}$ & & & & $x$ & Use project QA plan. \\
\hline $\begin{array}{l}\text { DOE } 5700.7 \mathrm{C} \\
\text { Work Authorization }\end{array}$ & & & & $\underline{x}$ & For DOE action only. \\
\hline $\begin{array}{l}\text { DOE } 5820.2 \mathrm{~A} \\
\text { Radioactive Waste Management }\end{array}$ & & & & $x$ & \\
\hline $\begin{array}{r}\text { DOE } 6430.1 \mathrm{~A} \\
\text { Design Criteria }\end{array}$ & & $x$ & & $x$ & \\
\hline $\begin{array}{l}\text { DOE-STD-0101 - Compilation of Nuclear Safety } \\
\text { Criteria for Potential Application to DOE NRNF }\end{array}$ & & & & & \\
\hline $\begin{array}{l}\text { DOE-STD-1020-94 } \\
\text { Nat Phen Haz Design \& Eval Crit }\end{array}$ & & & & $\mathrm{x}$ & \\
\hline $\begin{array}{l}\text { DOE-STD-1021-94 } \\
\text { Nat Phen Haz Perf Cat Guidelines }\end{array}$ & & & & $x$ & \\
\hline $\begin{array}{l}\text { DOE-STD-1022-94 } \\
\text { Nat Phenomena Haz Site Char Crit }\end{array}$ & & & & $\mathrm{x}$ & \\
\hline $\begin{array}{l}\text { DOE-STD-1023-95 } \\
\text { Natural Phenomena Hazards Assessment Crit }\end{array}$ & & & & $x$ & \\
\hline $\begin{array}{l}\text { DOE-STD-1024 - Guidelines for Use of } \\
\text { Probabilistic Seismic Hazard Curves at DOE Sites }\end{array}$ & & & & & \\
\hline $\begin{array}{l}\text { DOE-STD-1027 - Guidelines for Prelim Haz Class } \\
\text { \& Accident Analysis to comply with DOE } 5480.2\end{array}$ & & & & & \\
\hline $\begin{array}{l}\text { DOE-STD-1044-Guide to Good Practices for } \\
\text { Equipment and Piping Labeling }\end{array}$ & & & & & \\
\hline $\begin{array}{l}\text { DOE-STD-3003 } \\
\text { Backup Power Sources for DOE Facilities }\end{array}$ & & & & & \\
\hline $\begin{array}{l}\text { DOE-STD-3006 } \\
\text { Plarining and Conduct of ORRs } \\
\end{array}$ & & & & & \\
\hline $\begin{array}{l}\text { DOE-STD-3009-94 } \\
\text { Prep Guide for DOE Non-Reactor Nuc SARs }\end{array}$ & & & & $\mathrm{x}$ & \\
\hline $\begin{array}{l}\text { DOE-STD-3011- Guidance for Preparation of TSR } \\
\text { and SAR Implementation Plans }\end{array}$ & & & & & \\
\hline $\begin{array}{l}\text { DOE-M-5632.1C-1 } \\
\text { Protection and Control of S\&S }\end{array}$ & & & & $x$ & No Design Impact \\
\hline $\begin{array}{r}\text { OOE/EH-0173T } \\
\text { Effluent Monitoring }\end{array}$ & & & & $x$ & WACs also apply \\
\hline $\begin{array}{l}\text { DOE/EF-0108 } \\
\text { Fire Protection for Elec Comp/Data Proc }\end{array}$ & & & & $x$ & \\
\hline $\begin{array}{l}\text { DOE/EV-0043 } \\
\text { Fire Protection for Portable Structures }\end{array}$ & & & & $x$ & No Design Impact \\
\hline $\begin{array}{l}\text { DOE/EV-1830-TS } \\
\text { Guide to Reducing Rad Exposure to ALARA }\end{array}$ & & & & $x$ & \\
\hline $\begin{array}{l}\text { DOE Memorandum } \\
\text { Revised Policy for Acceptance for ER }\end{array}$ & & & & $x$ & \\
\hline $\begin{array}{l}\text { RLID } 1360.2 \mathrm{~B} \\
\text { Unclassified Computer Security }\end{array}$ & & & & $\mathrm{x}$ & No Design Impact \\
\hline $\begin{array}{l}\text { R.ID } 5480.7 \\
\text { Fire Protection }\end{array}$ & Alppe & A & & $x$ & \\
\hline
\end{tabular}




\begin{tabular}{|c|c|c|c|c|c|}
\hline (1) REFERECED DOCUMENT & sow & is: 15 & SENP & .10 & COMMENT \\
\hline $\begin{array}{l}\text { RLID } 5480.29 \\
\text { RL Employee Concerns Program }\end{array}$ & & & & $x$ & No Design Impact \\
\hline $\begin{array}{l}\text { RLID } 5480.31 \\
\text { Startup and Restart of Nuclear Facilities }\end{array}$ & & & & $\mathrm{x}$ & \\
\hline $\begin{array}{l}\text { RLID } 5484.1 \mathrm{~A} \\
\text { EPS\&H Reporting Requirements }\end{array}$ & & & & $x$ & No Design impact \\
\hline $\begin{array}{l}\text { DOE/RL. 92-36 } \\
\text { Hoisting \& Rigging }\end{array}$ & & $\mathrm{x}$ & & $\mathrm{x}$ & \\
\hline \begin{tabular}{|l} 
DOE/RI 93.102 \\
Fy 95 Mission Plan
\end{tabular} & & & & $x$ & No Design Impact \\
\hline $\begin{array}{l}\text { DOE/RI_-XX } \\
\text { Systems Engineering Criteria }\end{array}$ & & & $x$ & & $\begin{array}{l}\text { Document not approved } \\
\text { by RL. }\end{array}$ \\
\hline $\begin{array}{l}\text { DOE-STD-1073-93 } \\
\text { Guide for Configuration Management }\end{array}$ & & & $x$ & & For guidance only. \\
\hline $\begin{array}{c}\text { SEN } 15-90 \\
\text { NEPA }\end{array}$ & & & & $x$ & WACs also apply \\
\hline $\begin{array}{l}\text { SEN 35-91 } \\
\text { Nuclear Safety Policy }\end{array}$ & & & & $\mathrm{x}$ & Use HSRCM-1 \\
\hline $\begin{array}{l}\text { HPS-SDC-4.1, Rev } 12 \\
\text { Facility Design Loads }\end{array}$ & & $x$ & & $x$ & $\begin{array}{l}\text { Applicable Seismic } \\
\text { Criteria }\end{array}$ \\
\hline $\begin{array}{c}\text { HPS-SDC- } 5.1 \\
\text { HVAC }\end{array}$ & & & & $x$ & \\
\hline $\begin{array}{l}\text { SNF-RD-PM-001 } \\
\text { SNF Program Requirements }\end{array}$ & & & & $\mathrm{x}$ & \\
\hline & ADMIN & TRATI & E CODE & & \\
\hline $\begin{array}{l}51-13 \\
\text { Energy Code }\end{array}$ & & $x$ & & $x$ & \\
\hline $\begin{array}{l}173-160 \\
\text { Construction and Maint of Wells }\end{array}$ & & & & $x$ & \\
\hline $\begin{array}{l}\text { 173-201A } \\
\text { Water Quality Standards }\end{array}$ & & & & $x$ & \\
\hline $\begin{array}{l}173-200 \\
\text { Water Quality for Ground Water }\end{array}$ & & & & $\mathrm{x}$ & \\
\hline $\begin{array}{l}173-216 \\
\quad \text { Waste Discharge Permit Program }\end{array}$ & & & & $x$ & \\
\hline $\begin{array}{l}173-218 \\
\quad \text { Underground Injection }\end{array}$ & & & & $x$ & \\
\hline $\begin{array}{l}173-224 \\
\text { Water Discharge Permit Fees }\end{array}$ & & & & $x$ & \\
\hline $\begin{array}{l}173-240 \\
\text { Sut) of Plans for Waste Water Fac }\end{array}$ & & & & $x$ & \\
\hline $\begin{array}{l}173-3013 \\
\text { Darngerous Waste Regulations }\end{array}$ & & $x$ & & $x$ & \\
\hline $\begin{array}{l}173-304 \\
\text { Mir Stds for Solid Waste Handling }\end{array}$ & & & & $x$ & \\
\hline $\begin{array}{r}173-307 \\
\text { Plans } \\
\end{array}$ & & & & $x$ & \\
\hline $\begin{array}{l}173-340 \\
\text { Model Toxic Control Regs }\end{array}$ & & & & $\mathrm{x}$ & \\
\hline $\begin{array}{l}173-360 \\
\text { UST Regulations }\end{array}$ & & & & $\mathrm{x}$ & \\
\hline
\end{tabular}




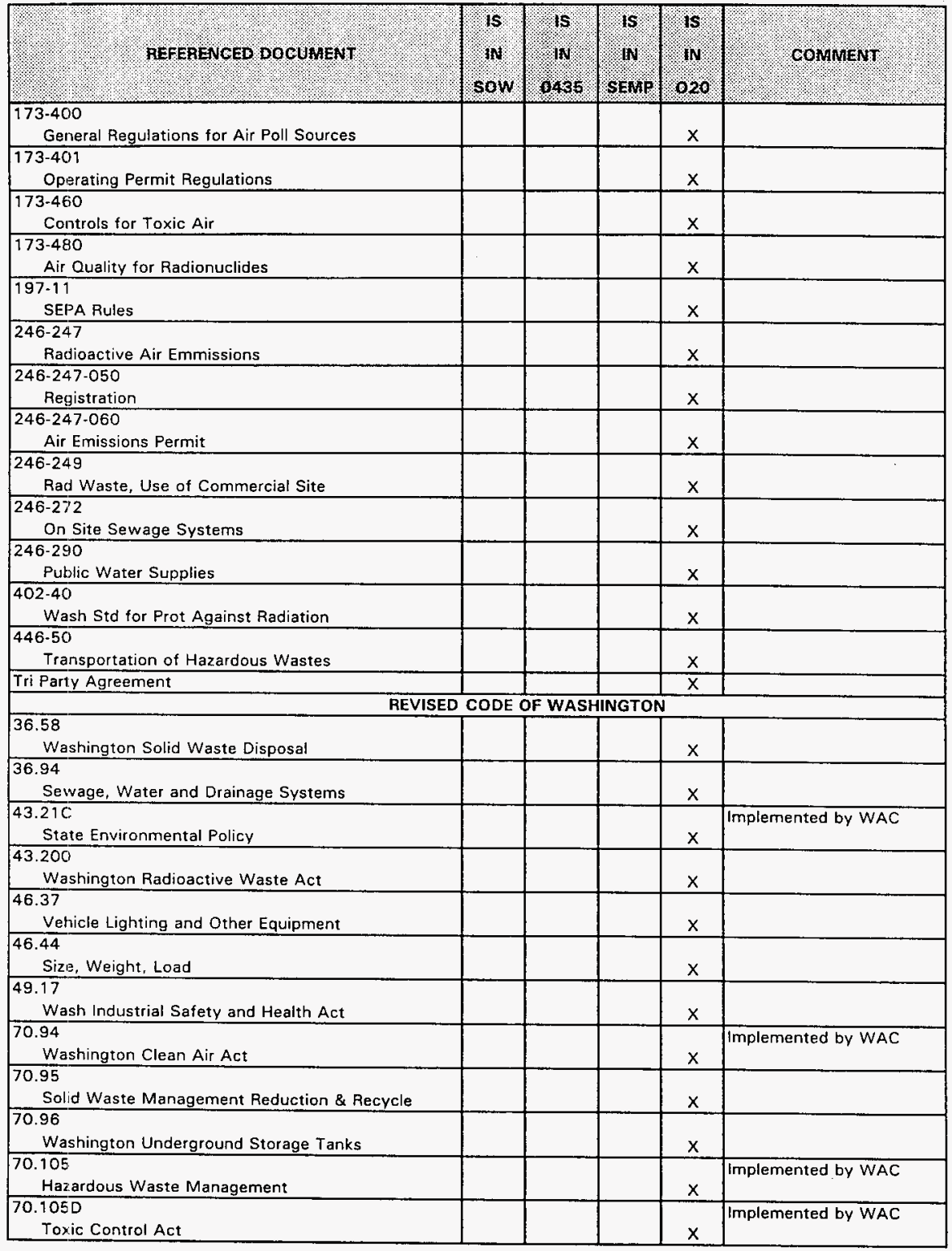




\begin{tabular}{|c|c|c|c|c|c|}
\hline 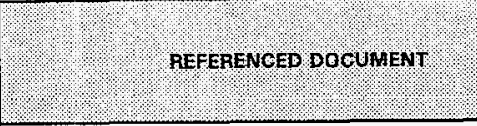 & sow & 15 & $\begin{array}{l}\text { कs } \\
\mathrm{s} \\
\mathrm{SENP}\end{array}$ & 15 & COMMENT \\
\hline $\begin{array}{l}90.03 \\
\text { Water Code }\end{array}$ & & & & $\mathrm{x}$ & Implemented by WAC \\
\hline $\begin{array}{l}90.42 \\
\text { Washington Water Resource Management }\end{array}$ & & & & $x$ & Implemented by WAC \\
\hline \begin{tabular}{|c|}
90.44 \\
Regulation of Public Groundwaters
\end{tabular} & & & & $x$ & Implemented by WAC \\
\hline $\begin{array}{c}90.48 \\
\text { Water Pollution Control }\end{array}$ & & & & $\mathrm{x}$ & Implemented by WAC \\
\hline $\begin{array}{r}90.52 \\
\text { Pollution Disclosure Act }\end{array}$ & & & & $x$ & Implemented by WAC \\
\hline \begin{tabular}{|l|}
$\begin{array}{l}90.76 \\
\text { Underground Storage Tank }\end{array}$ \\
\end{tabular} & & & & $x$ & \\
\hline \multicolumn{6}{|c|}{ ICRP PUBLICATIONS } \\
\hline $\begin{array}{ll}37 & \\
& \text { Rad, Protect Cost } \\
\end{array}$ & & $x$ & & $x$ & Use HSRCM-1 \\
\hline \multicolumn{6}{|c|}{ NUCLEAR REGULATORY COMMISSION } \\
\hline $\begin{array}{r}\text { NRC Reg Guide } 1.36 \\
\text { Thermal Insulation }\end{array}$ & & $x$ & & & \\
\hline $\begin{array}{l}\text { NUREG } 0700 \\
\text { Control Room Design }\end{array}$ & & $x$ & & & \\
\hline $\begin{array}{r}\text { NUREG CR-3264 } \\
\text { ALARA Maintenance } \\
\end{array}$ & & $\mathrm{x}$ & & & Use HSRCM-1 \\
\hline \multicolumn{6}{|c|}{ COMMERCIAL \& MILITARY STANDARDS/GUIDES } \\
\hline \begin{tabular}{|l} 
Americ an Water Works \\
61
\end{tabular} & & $\mathrm{x}$ & & & \\
\hline $\begin{array}{l}\text { ICBO } \\
\text { Uniform Building Code }\end{array}$ & & $\mathrm{x}$ & & & \\
\hline $\begin{array}{l}\text { NFPA-70 } \\
\text { National Electric Code }\end{array}$ & & $\mathrm{x}$ & & & \\
\hline $\begin{array}{l}\text { ORNL TM-10864 } \\
\text { Remotely Maintained Equipment Des Guide }\end{array}$ & & $\mathrm{x}$ & & & \\
\hline $\begin{array}{r}\text { PAL- } 1988 \\
\text { Health Physics Manual }\end{array}$ & & $x$ & & & \\
\hline $\begin{array}{r}\text { MIL-STD-1472D } \\
\text { Human Engineering } \\
\end{array}$ & & $x$ & & & \\
\hline \multicolumn{6}{|c|}{ ANSI/ASME } \\
\hline $\begin{array}{r}\text { ASME } 331.1 \\
\text { Refinery Piping } \\
\end{array}$ & & $x$ & & & \\
\hline $\begin{array}{l}\text { ASME } 14.5 \\
\text { Dimensioning and Tolerancing }\end{array}$ & & $x$ & & & \\
\hline $\begin{array}{r}\text { NOA-1 } \\
\text { Quality Assurance }\end{array}$ & & $x$ & & & \\
\hline \multicolumn{6}{|c|}{ CODE OF FEDERAL REGULATIONS } \\
\hline $\begin{array}{l}10 \mathrm{CFF}^{2} 2 \mathrm{O} \\
\text { Radiation Protection Standards }\end{array}$ & & $x$ & & $x$ & $\begin{array}{l}\text { Use HSRCM-1 } \\
\text { DOE } 5480.11\end{array}$ \\
\hline $\begin{array}{l}10 \text { CFF } 50 \\
\text { Domestic Licensing of Production \& Util }\end{array}$ & & & & $x$ & $\begin{array}{l}\text { Section } 50.48 \text { and } A p p R \\
\text { for NRC equivalency }\end{array}$ \\
\hline $\begin{array}{r}10 \text { CFF } 51 \\
\text { Regulations for Licensing }\end{array}$ & & & & $\mathrm{x}$ & Not applicable to SNFP \\
\hline $\begin{array}{l}10 \text { CFF, } 71 \\
\text { Raclioactive Pkg \& Trans }\end{array}$ & & & & $\times$ & Use 49 CFRs \\
\hline
\end{tabular}


SNF DOCUMENT REFERENCES

\begin{tabular}{|c|c|c|c|c|c|}
\hline , & WS & $\begin{array}{l}15 \\
1 N \\
0435\end{array}$ & $\begin{array}{l}\text { ss } \\
\text { wN } \\
\text { SENAP }\end{array}$ & $\begin{array}{l}1 S P \\
110 \\
020\end{array}$ & GONMENT \\
\hline $\begin{array}{l}10 \text { CFR } 72 \\
\text { Licensing of Spent Fuel Storage }\end{array}$ & & $x$ & & $x$ & Not Applicable \\
\hline $\begin{array}{l}10 \text { CFR } 73 \\
\text { Protection of Plants and Materials }\end{array}$ & & & & $x$ & Use RLID 5632.1B \\
\hline $\begin{array}{l}10 \text { CFR } 436 \\
\text { Life Cycle Cost Methods \& Procedures }\end{array}$ & & & & $\underline{x}$ & Not Applicable \\
\hline $\begin{array}{l}10 \text { CFR } 830.120 \\
\text { Quality Assurance }\end{array}$ & $\mathrm{X}$ & $x$ & & $\mathrm{x}$ & \\
\hline $\begin{array}{l}10 \text { CFR } 835 \\
\text { Radiation Protection }\end{array}$ & & $x$ & & $x$ & \\
\hline $\begin{array}{l}10 \text { CFR } 840 \\
\text { Extraordinary Nuclear Occurances }\end{array}$ & & & & & \\
\hline $\begin{array}{l}10 \text { CFR } 961 \\
\text { Std Contact for Disposal of SNF \& HLRW }\end{array}$ & & & & $x$ & \\
\hline $\begin{array}{l}10 \text { CFR } 1021 \\
\text { NEPA }\end{array}$ & & & & $x$ & Use WAC \\
\hline $\begin{array}{r}29 \text { CFR } 1910 \\
\text { OSHA ACt }\end{array}$ & & $x$ & & $x$ & \\
\hline $\begin{array}{l}29 \text { CFR } 1926 \\
\text { Coristruction OSHA }\end{array}$ & & & & $x$ & \\
\hline $\begin{array}{l}40 \text { CFR } 6.302 \mathrm{~g} \\
\text { Fish \& Wildlife }\end{array}$ & & & & $x$ & \\
\hline $\begin{array}{l}40 \text { CFR } 52 \\
\text { Ambient Air Quality } \\
\end{array}$ & & & & $x$ & Use WAC \\
\hline $\begin{array}{l}40 \text { CFR } 58 \\
\text { Ambient Air Quality Surveillance } \\
\end{array}$ & & & & $x$ & \\
\hline $\begin{array}{l}40 \text { CFR } 60 \\
\text { Stds of Perf for New Stationary Sources }\end{array}$ & & & & $x$ & \\
\hline $\begin{aligned} 40 \text { CFR } 61 \\
\text { Haz Air Emissions Stds } \\
\end{aligned}$ & & & & $x$ & Use WAC \\
\hline $\begin{array}{l}40 \text { CFR } 122 \\
\text { Permitting Reqmnts for Land Disp Fac }\end{array}$ & & & & $\underline{x}$ & \\
\hline $\begin{array}{l}40 \text { CFR } 124 \\
\text { Procedures for Decision Making } \\
\end{array}$ & & & & $x$ & \\
\hline $\begin{array}{l}40 \text { CFR } 125 \\
\text { Criteria and Stds for NPDES } \\
\end{array}$ & & & & $x$ & \\
\hline $\begin{array}{l}40 \text { CFR } 191 \\
\text { Management \& Disposal of SNF \& TRW } \\
\end{array}$ & & & & $x$ & \\
\hline $\begin{array}{l}40 \text { CFR } 240 \\
\text { Guidelines for Thermal Processing } \\
\end{array}$ & & & & $x$ & \\
\hline $\begin{array}{l}40 \text { CFR } 241 \\
\text { Guidelines for Land Disp of Solid Waste }\end{array}$ & & & & $x$ & \\
\hline $\begin{aligned} 40 \text { CFR } 260 \\
\text { Haz Waste Management System }\end{aligned}$ & & & & $x$ & \\
\hline $\begin{array}{l}40 \text { CFR } 261 \\
\text { Identification and Licensing } \\
\end{array}$ & & & & $x$ & \\
\hline $\begin{array}{l}40 \text { CFR } 262 \\
\text { Stds Applicable to Generators }\end{array}$ & & & & $x$ & Use WAC \\
\hline $\begin{array}{l}40 \text { CFR } 264 \\
\text { Stds for Owners \& Operators }\end{array}$ & & & & $x$ & WACs also apply \\
\hline $\begin{array}{l}40 \text { CFR } 265 \\
\text { Interim Status Standards } \\
\end{array}$ & & & & $\mathrm{X}$ & \\
\hline
\end{tabular}


SNF DOCUMENT REFERENCES

\begin{tabular}{|c|c|c|c|c|c|}
\hline (4) & sow & 115 & SENP & 15 & COMMENT \\
\hline $\begin{array}{l}40 \text { CFF } 268 \\
\text { Land Disposal Restrictions }\end{array}$ & & & & $x$ & Use WAC \\
\hline $\begin{array}{l}40 \text { CFF } 271 \\
\text { Rec for Auth of State Haz Waste Prog }\end{array}$ & & & & $x$ & \\
\hline $\begin{array}{l}40 \text { CFR } 300 \\
\text { Nat Oil \& Haz Sub Poll Cont Plan }\end{array}$ & & & & $x$ & \\
\hline $\begin{array}{l}40 \text { CFR } 1500 \\
\text { Purpose, Policy and Mandate } \\
\end{array}$ & & & & $x$ & \\
\hline $\begin{array}{l}40 \text { CFF } 1501 \\
\text { NEPA \& Agency Planing }\end{array}$ & & & & $x$ & \\
\hline $\begin{array}{l}40 \text { CFF } 1502 \\
\text { Environmental Impact Statement }\end{array}$ & & & & $x$ & \\
\hline $\begin{array}{l}40 \text { CFF } 1503 \\
\text { Commenting }\end{array}$ & & & & $x$ & \\
\hline $\begin{array}{l}40 \text { CFFl } 1504 \\
\text { Predecision Referrals } \\
\end{array}$ & & & & $x$ & \\
\hline $\begin{array}{l}40 \text { CFF } 1505 \\
\text { NEPA \& Agency Decision Making }\end{array}$ & & & & $x$ & \\
\hline $\begin{array}{l}40 \text { CFR } 1506 \\
\text { Other Requirements of NEPA }\end{array}$ & & & & $x$ & \\
\hline $\begin{array}{r}40 \text { CFA } 1507 \\
\text { Agency Compliance } \\
\end{array}$ & & & & $x$ & \\
\hline $\begin{array}{l}40 \text { CFFI } 1508 \\
\text { Terminology \& Index }\end{array}$ & & & & $x$ & \\
\hline $\begin{array}{l}41 \text { CFF } 109 \\
\text { DOE Property Management }\end{array}$ & & & & $x$ & For DOE action only \\
\hline $\begin{array}{l}43 \text { CFFl } 11 \\
\text { Nat Resources Damage Assessments }\end{array}$ & & & & $x$ & \\
\hline $\begin{array}{l}49 \text { CFFl } 172 \\
\text { Dims for Placard Holder }\end{array}$ & & & & $x$ & \\
\hline $\begin{array}{l}49 \text { CFFI } 173 \\
\text { Requirements for Pack \& Ship }\end{array}$ & & & & $x$ & \\
\hline $\begin{array}{l}49 \text { CFF } 393 \\
\text { Parts \& Accessories Nec for Safe Op }\end{array}$ & & & & $x$ & \\
\hline $\begin{array}{l}49 \text { CFFi } 566 \\
\text { Manufacturer Identification } \\
\end{array}$ & & & & $x$ & \\
\hline $\begin{array}{r}49 \text { CFR } 567 \\
\text { Certification } \\
\end{array}$ & & & & $x$ & \\
\hline $\begin{array}{l}49 \text { CFFi } 571 \\
\text { Federal Motor Vehicle Safety Stds }\end{array}$ & & & & $x$ & \\
\hline & US CO & & & & \\
\hline $\begin{array}{l}15 \text { USC } 2601 \\
\text { Toxic Substance Act } \\
\end{array}$ & & & & $x$ & Use RCW \\
\hline $\begin{aligned} 16 \text { UCS } 661 \\
\text { Protection and Conservation of Wildlife }\end{aligned}$ & & & & $x$ & \\
\hline $\begin{array}{l}16 \text { USC } 1531 \\
\text { Endangered Species Act } \\
\end{array}$ & & & & $\mathrm{x}$ & \\
\hline $\begin{array}{l}16 \text { USC } 2901 \\
\text { Fish and Wildlife Conservation }\end{array}$ & & & & $x$ & \\
\hline $\begin{array}{l}25 \text { USC } 3001 \\
\text { Native American Graves Protection }\end{array}$ & & & & $x$ & \\
\hline
\end{tabular}




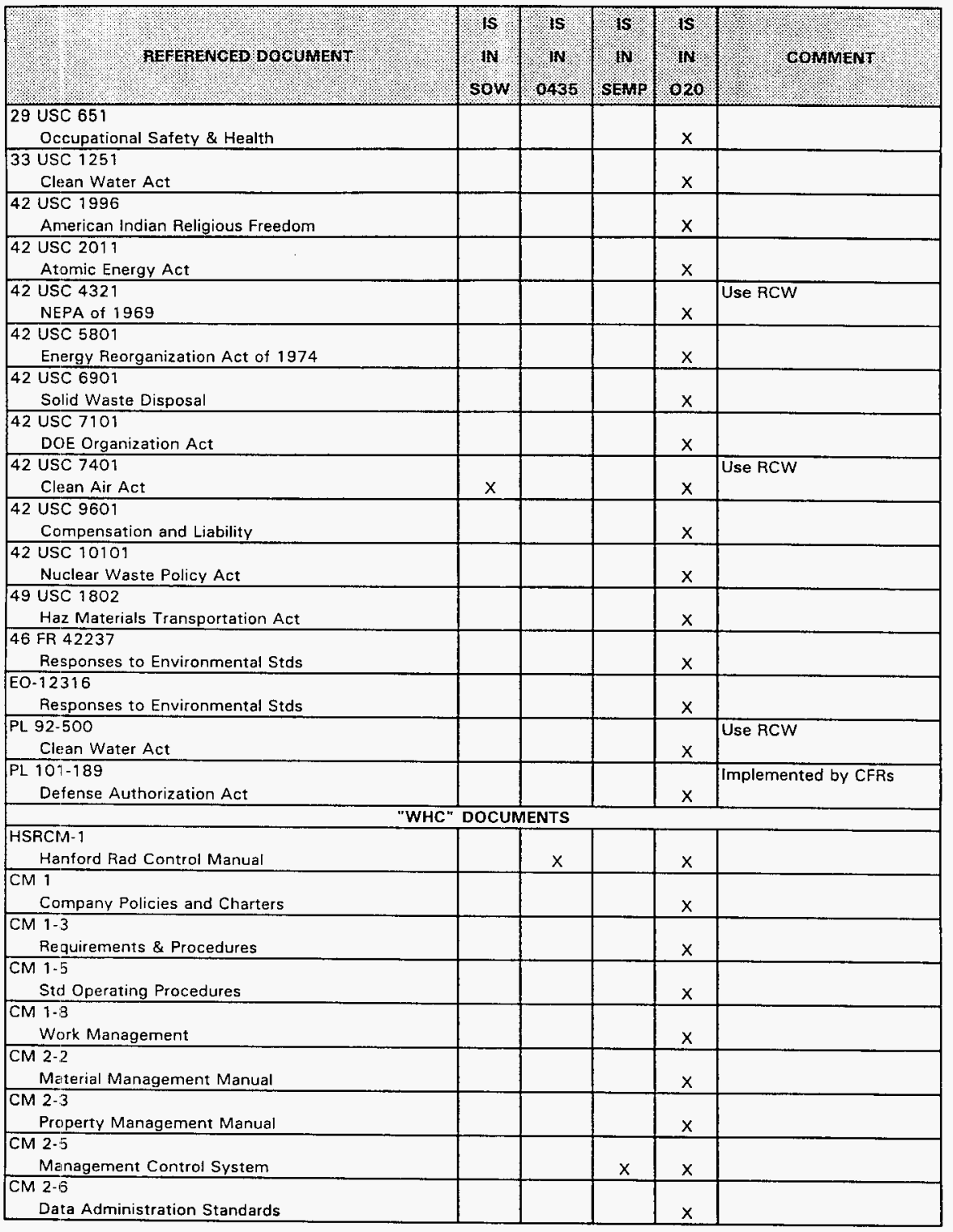

Attch 2 Appendix A 


\begin{tabular}{|c|c|c|c|c|c|}
\hline (1. & sow & $\begin{array}{l}15 \\
11 \\
0435\end{array}$ & $\begin{array}{l}15 \\
15 \\
\text { SENP }\end{array}$ & 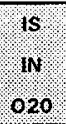 & 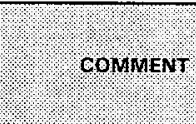 \\
\hline $\begin{array}{l}\text { CM } 2-10 \\
\text { Cost. Accounting Manual }\end{array}$ & & & & $x$ & \\
\hline $\begin{array}{l}\text { CM 2-1.4 } \\
\text { Haz Material Packaging \& Shipping }\end{array}$ & & & & $x$ & \\
\hline $\begin{array}{l}\text { CM 2-15 } \\
\text { Training Administration }\end{array}$ & & & & $x$ & \\
\hline $\begin{array}{l}\text { CM 3-5 } \\
\quad \text { Document Control }\end{array}$ & & & & $x$ & \\
\hline $\begin{array}{l}\text { CM 3-10 } \\
\quad \text { Software Practices }\end{array}$ & & $x$ & & $x$ & \\
\hline $\begin{array}{r}\mathrm{CM} \mathrm{4-2} \\
\text { Quality Assurance } \\
\end{array}$ & & $x$ & & $x$ & \\
\hline $\begin{array}{r}\mathrm{CM} \mathrm{4-3} \\
\text { Industrial Safety }\end{array}$ & & & & $x$ & \\
\hline $\begin{array}{l}\text { CM 4-5 } \\
\text { QA Qual \& Instructions }\end{array}$ & & & & $x$ & \\
\hline $\begin{array}{l}\text { CM 4-6 } \\
\quad \text { Compliance Assurance }\end{array}$ & & & & $x$ & \\
\hline $\begin{array}{l}\text { CM 4-7 } \\
\text { Unclassified Computer Security }\end{array}$ & & & & $x$ & \\
\hline $\begin{array}{l}\text { CM 4-11 } \\
\text { ALARA Program Manual }\end{array}$ & & & & $x$ & \\
\hline $\begin{array}{l}\text { CM 4-1.4 } \\
\text { Radiological Controls }\end{array}$ & & & & $x$ & \\
\hline $\begin{array}{l}\text { CM 4-15 } \\
\text { Dosimetry/Medical Services }\end{array}$ & & & & $x$ & \\
\hline \begin{tabular}{|l}
$\mathrm{CM} 4.29$ \\
Criticality Safety
\end{tabular} & & $x$ & & $x$ & \\
\hline $\begin{array}{l}\text { CM 4-33 } \\
\text { Security Manual }\end{array}$ & & & & $x$ & \\
\hline $\begin{array}{l}\text { CM 4-35 } \\
\text { Safeguards Material Control }\end{array}$ & & & & $x$ & \\
\hline $\begin{array}{l}\text { CM } 4.33 \\
\text { NDE Process }\end{array}$ & & & & $x$ & \\
\hline $\begin{array}{l}\text { CM 4-40 } \\
\text { Industrial Hygiene }\end{array}$ & & & & $x$ & \\
\hline $\begin{array}{l}\mathrm{CM} 4-41 \\
\quad \text { Fire Protection } \\
\end{array}$ & & & & $x$ & \\
\hline $\begin{array}{r}\text { CM } 4-43 \\
\text { Emergency Management }\end{array}$ & & & & $\underline{x}$ & \\
\hline 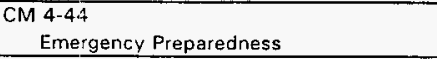 & & & & $x$ & \\
\hline $\begin{array}{l}\text { CM 4-46 } \\
\quad \text { Safety Analysis } \\
\end{array}$ & & $x$ & & $x$ & \\
\hline $\begin{array}{l}\text { CM 4-50 } \\
\text { Safeguards Accounting }\end{array}$ & & & & $x$ & \\
\hline $\begin{array}{l}\text { CM 5-4 } \\
\quad \text { Laboratories Administration }\end{array}$ & & & & $x$ & \\
\hline $\begin{array}{l}\text { CM 5.8 } \\
\text { Pu Finishing Plarit Administration }\end{array}$ & & & & $x$ & \\
\hline $\begin{array}{l}\text { CM 5-9 } \\
\text { PUREX/UO3 Plant Administration }\end{array}$ & & & & $x$ & \\
\hline
\end{tabular}




\begin{tabular}{|c|c|c|c|c|c|}
\hline (1. & sow & 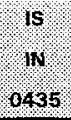 & senp & is. & COMMENT \\
\hline $\begin{array}{l}\text { CM 5-13 } \\
\text { K Easins Policy Manual }\end{array}$ & & & & $x$ & \\
\hline $\begin{array}{l}\text { CM 5-16 } \\
\text { Solid Waste Management }\end{array}$ & & & & $x$ & \\
\hline $\begin{array}{l}\text { CM 5-34 } \\
\text { SWD Operations Administration }\end{array}$ & & & & $x$ & \\
\hline $\begin{array}{l}\mathrm{CM} \text { 6-1 } \\
\text { Standard Engineering Practices }\end{array}$ & & $x$ & $x$ & $x$ & \\
\hline $\begin{array}{l}\text { CM 6-2 } \\
\text { Project Management }\end{array}$ & & & & $x$ & \\
\hline $\begin{array}{l}\text { CM } 6-3 \\
\text { Drafting Standards }\end{array}$ & & & & $x$ & \\
\hline $\begin{array}{l}\mathrm{CM} 6-10 \\
\text { Welding Manual }\end{array}$ & & & & $x$ & \\
\hline $\begin{array}{l}\text { CM } 6-12 \\
\quad \text { Project Procedures }\end{array}$ & & & & $x$ & \\
\hline $\begin{array}{l}\text { CM } 7.4 \\
\text { Environmental Monitoring }\end{array}$ & & & & $x$ & \\
\hline $\begin{array}{l}\text { CM 7-5 } \\
\text { Environmental Compliance }\end{array}$ & & $x$ & & $x$ & \\
\hline $\begin{array}{l}\text { CM } 8-7 \\
\text { Operations Support Systems }\end{array}$ & & & & $x$ & \\
\hline $\begin{array}{l}\text { CM } 8.9 \\
\text { Workmanship Standards }\end{array}$ & & & & $x$ & \\
\hline $\begin{array}{l}\text { EP-000 } \\
\text { Acronyms and Abbreviations }\end{array}$ & & & & $x$ & \\
\hline $\begin{array}{l}\text { EP-ODE } 3 \cdot 4 \\
\text { Solid Waste Acceptance }\end{array}$ & & & & $x$ & \\
\hline $\begin{array}{l}\text { EP-0231.5 } \\
\text { Surplus Facilities Program Plan }\end{array}$ & & & & $x$ & \\
\hline $\begin{array}{l}\text { EP-0496 } \\
\text { Pollution Prevention Implementation }\end{array}$ & & & & $x$ & \\
\hline \begin{tabular}{|l} 
EP-0722 \\
Systems Engineering F\&Rs
\end{tabular} & & & & $x$ & \\
\hline $\begin{array}{r}\text { EP-0779 } \\
\text { Architecture Systhesis Basis } \\
\end{array}$ & & & & $x$ & \\
\hline $\begin{array}{l}\text { EP-0830 } \\
\text { SNF Path Forward }\end{array}$ & & & $x$ & & \\
\hline $\begin{array}{l}\text { GG-DWG-01 } \\
\text { Preperation \& Control of Drawings }\end{array}$ & & & & $x$ & \\
\hline $\begin{array}{l}\text { GG-DWG-02 } \\
\text { Layering Conventions }\end{array}$ & & & & $x$ & \\
\hline $\begin{array}{c}\text { GG-DWG-03 } \\
\text { Drawing Index }\end{array}$ & $x$ & $x$ & & & \\
\hline $\begin{array}{l}\text { GG-DWG-04 } \\
\text { Parts List/BOM }\end{array}$ & $x$ & $x$ & & & \\
\hline $\begin{array}{l}\text { GH-CLIM-01 } \\
\quad \text { Hanford Site Climate Data }\end{array}$ & & $\mathrm{x}$ & & & \\
\hline $\begin{array}{r}\text { PP-0117 } \\
\text { Procedure Development }\end{array}$ & & & & $x$ & \\
\hline $\begin{array}{r}\text { IP-0240 } \\
\text { Operating Procedures Format }\end{array}$ & & & & $x$ & \\
\hline
\end{tabular}

Attch 2 Appendix A 


\begin{tabular}{|c|c|c|c|c|c|}
\hline (1. & sow & is. & SEAP & 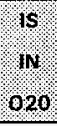 & 4 COMMENT \\
\hline $\begin{array}{l}\text { P-0263 } \\
\text { Bldg Emergency Plan East Patrol Bldg }\end{array}$ & & & & $x$ & \\
\hline $\begin{array}{l}\text { P-0382 } \\
\text { Nuclear Materials Safeguards Users }\end{array}$ & & & & $x$ & \\
\hline $\begin{array}{l}\text { PP-0565 } \\
\text { Safeguards Disk Procedures }\end{array}$ & & & & $x$ & \\
\hline $\begin{array}{l}\text { PP-0821 } \\
\text { Plutonium Operation Admin }\end{array}$ & & & & $x$ & Not applicable to SNFP \\
\hline $\begin{array}{l}\text { IP-0836 } \\
\text { Order Compliance Admin }\end{array}$ & & & & $x$ & Not applicable to SNFP \\
\hline $\begin{array}{r}\text { IP-1026 } \\
\text { Engineering Practice Guidelines }\end{array}$ & & & & $x$ & \\
\hline $\begin{array}{l}\text { PP-1043 } \\
\text { Occupational ALARA Program }\end{array}$ & & & & $x$ & Use HSRCM-1 \\
\hline $\begin{array}{l}\text { IP-1117 } \\
\quad \text { Systems Engineering Manual }\end{array}$ & & & $x$ & & \\
\hline $\begin{array}{l}\text { IP-114C } \\
\text { Procedure Development \& Control Services }\end{array}$ & & & & $\mathrm{x}$ & \\
\hline $\begin{array}{l}\text { S-0436 } \\
\text { Performance Specifications }\end{array}$ & $x$ & & & & \\
\hline $\begin{array}{l}\text { SD-GN-DGS-30011 } \\
\text { Radiological Design Guide }\end{array}$ & & $\mathrm{x}$ & & $\mathrm{x}$ & \\
\hline $\begin{array}{c}\text { SD-GN-ER-1006 } \\
\text { K-Basin Floor Loads } \\
\end{array}$ & & & & $\mathrm{x}$ & \\
\hline $\begin{array}{l}\text { SD-GN-ES-30006 } \\
\text { Criteria for Uniform Bolting Preloads }\end{array}$ & & & & $x$ & \\
\hline $\begin{array}{l}\text { SD-MA.SPP-001 } \\
\text { Welding Procedure Supporting Document }\end{array}$ & & & & $x$ & \\
\hline $\begin{array}{l}\text { SD-NR-SA-024 } \\
\text { Structural Feasibility of Consolidation }\end{array}$ & & & & $\mathrm{x}$ & \\
\hline $\begin{array}{l}\text { SD-SNF-CM-001 } \\
\text { SNF Configuration Management } \\
\end{array}$ & & & $x$ & & \\
\hline $\begin{array}{l}\text { SD-SNF-CM-003 } \\
\text { SNF Interface Control } \\
\end{array}$ & & & $x$ & & \\
\hline $\begin{array}{l}\text { SD-SNF-DB-004 } \\
\text { SNF Project Seismic Design Criteria, NRC Equiv. }\end{array}$ & & & & & \\
\hline $\begin{array}{l}\text { SD-SNF-DGS-001 } \\
\text { K-Basin Design Guidelines }\end{array}$ & & & & $x$ & \\
\hline \begin{tabular}{|l} 
SD-SNF-SD-002 \\
SNF Technical Baseline \\
\end{tabular} & & & $\underline{x}$ & & \\
\hline $\begin{array}{l}\text { SD-SNF-SD-003 } \\
\text { SNF Technical Baseline }\end{array}$ & & & $x$ & & \\
\hline $\begin{array}{l}\text { SD-SNF-SEMP-001 } \\
\text { SNF Engr Management Plan }\end{array}$ & $x$ & & & & \\
\hline $\begin{array}{l}\text { SD-SNF-TI-009 } \\
\text { Design Basis Feed Preparation }\end{array}$ & & & & $x$ & \\
\hline $\begin{array}{l}\text { SD-SNF-T1-012 } \\
\text { Underwater Fuel Survey } \\
\end{array}$ & & & & $\mathrm{x}$ & \\
\hline $\begin{array}{l}\text { SD-WM-OSR-OOG } \\
\text { OSFIs for KE \& KW Basins }\end{array}$ & & & & $x$ & \\
\hline $\begin{array}{l}\text { SD-WM-SAR-062 } \\
\text { SAF for N-Reactor Fuel }\end{array}$ & & & & $x$ & \\
\hline
\end{tabular}




\begin{tabular}{|c|c|c|c|c|c|}
\hline 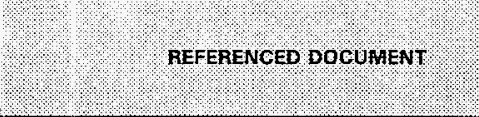 & sow & (15, & SEMP & $\begin{array}{l}15 \\
111 \\
020\end{array}$ & QONAMENJ \\
\hline $\begin{array}{l}\text { SN-SNF-SP-005 } \\
\text { Integrated Process Survey }\end{array}$ & & & & $\mathrm{x}$ & \\
\hline $\begin{array}{l}\text { SNFP-SE-006 } \\
\text { Managing SNF } \\
\end{array}$ & & & $\mathrm{x}$ & & \\
\hline $\begin{array}{l}\text { SNF-RD-PM-001 } \\
\text { Program Requirements Document }\end{array}$ & & & & $\mathrm{x}$ & \\
\hline $\begin{array}{l}\text { SP-078 } \\
\text { Conduct of Operations Manual }\end{array}$ & & & & $x$ & \\
\hline $\begin{array}{r}\text { SP-0843 } \\
\text { FMEF Maintenance Inspection Plan } \\
\end{array}$ & & & & $\mathrm{x}$ & \\
\hline $\begin{array}{r}\mathrm{SP}-08 \epsilon_{6} 6 \\
\text { Conduct of Maintenance }\end{array}$ & & & & $x$ & Use WHC-SP-0835 \\
\hline $\begin{array}{l}\text { SP-1144 } \\
\text { Path Forward Acquisition Strategy }\end{array}$ & & & & $x$ & Has been replaced \\
\hline $\begin{array}{l}\text { SP- } 1148 \\
\text { SNF Project Management Plan }\end{array}$ & & & $x$ & & \\
\hline \multicolumn{6}{|c|}{ OTHER DOCUMENTS } \\
\hline Imp Plan for DNFSB 92-3 \& 92.7 & & & $\mathrm{x}$ & & \\
\hline $\begin{array}{l}\text { DOE-RI 95-AHW-003 } \\
\text { Approval of Path Forward } \\
\end{array}$ & & & & $x$ & Has been replaced. \\
\hline $\begin{array}{l}\text { DOE-RL 95-SFD-132 } \\
\text { Approval of Path Forward }\end{array}$ & & & & $\mathrm{x}$ & Has been replaced. \\
\hline $\begin{array}{l}\text { DOE-RL. 95-SFD-135 } \\
\text { Additional IPS Comments }\end{array}$ & & & & $\mathrm{X}$ & \\
\hline Memo of Agreement on Path Forward & & & & $x$ & \\
\hline Revised Policy of Acceptance for ER & & & $\mathrm{x}$ & & \\
\hline Hanford Site Systems Engr Manual & & & $\mathrm{x}$ & & Not specific to SNFP \\
\hline Site Sys engr config Mngmt Plan & & & $x$ & & Not specific to SNFP \\
\hline Sitewide Sys Engr Management Plan & & & $\mathrm{x}$ & & Not specific to SNFP \\
\hline $\begin{array}{l}\text { DNFSB } 92-3-\mathrm{HB} \\
\text { Operational Readiness Review } \\
\end{array}$ & & & & $\mathrm{x}$ & \\
\hline $\begin{array}{l}\text { DNFSB } 92-7 \\
\text { Training and Qualifications }\end{array}$ & & & & $\underline{x}$ & \\
\hline $\begin{array}{l}\text { DNFSB } 94-1 \\
\text { DNFSB Safety Board Recommendation }\end{array}$ & & & & $x$ & \\
\hline $\begin{array}{l}\text { Memorandum, } 3 / 1 / 95 \\
\text { SNF Vulnerability Action Plan }\end{array}$ & & & & $x$ & \\
\hline $\begin{array}{l}\text { Record of Decision } \\
\text { Prog SNF Management \& INEL ER\&WM }\end{array}$ & & & & $\mathrm{x}$ & \\
\hline Future Site WG & & & & $\mathrm{x}$ & \\
\hline $\begin{array}{l}\text { FY1995 Hanford Mission Plan } \\
\text { Vol 1, Site Guidance, Sept } 1994\end{array}$ & & & & $x$ & \\
\hline $\begin{array}{l}\text { MRP } 1.1 \\
\text { Managing DOE Directives }\end{array}$ & & & & $x$ & \\
\hline $\begin{array}{l}\text { MRP } 2.16 \\
\text { Processing Control Manual Sys Proc }\end{array}$ & & & & $x$ & \\
\hline $\begin{array}{l}\text { MRP } 4.16 \\
\text { Adrninistering Progressive Discipline }\end{array}$ & & & & $\mathrm{x}$ & \\
\hline $\begin{array}{l}\text { MRP } 4.19 \\
\text { Overtime and Shift Diff for Nox-Exempt Emp }\end{array}$ & & & & $x$ & \\
\hline $\begin{array}{l}\text { MRP } 5.44 \\
\text { Waste Minimization Program } \\
\end{array}$ & & & & $\underline{x}$ & \\
\hline
\end{tabular}




\begin{tabular}{|c|c|c|c|c|c|}
\hline 1. & sow & 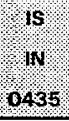 & $\begin{array}{l}\text { SP } \\
\text { SENP }\end{array}$ & IS & COMMENT \\
\hline $\begin{array}{l}\text { MRP 6. } 15 \\
\text { Facility Shutdown, Standby \& Transfer }\end{array}$ & & & & $x$ & \\
\hline $\begin{array}{l}\text { WHC } \$ 553866 \cdot \text { Letter } \\
\text { Rec: Ingegrated Process Strategy }\end{array}$ & & & & $\mathrm{X}$ & \\
\hline $\begin{array}{l}\text { DOE EM-36, } 9 \text { Nov } 94 \\
\text { Lytle Ltr to Grumbly, App of Path Forward }\end{array}$ & & & & $\mathrm{x}$ & Not specific to SNFP \\
\hline \multicolumn{6}{|c|}{ ADDITIONAL NRC REQUIREMENTS } \\
\hline $\begin{array}{c}\text { WHC-SD-SNF-DB-002, Table } 5 . b \\
\text { As relates to fire protection }\end{array}$ & & & & & $\begin{array}{l}\text { Confirm Safety Class } \\
\text { Fire Protection not req. }\end{array}$ \\
\hline $\begin{array}{l}10 \text { CFF Part } 50.48 \text { \& Appendix } \mathrm{R} \\
\text { As relates to fire protection }\end{array}$ & & & & & $\begin{array}{l}\text { Confirm Safety Class } \\
\text { Fire Protection not req. }\end{array}$ \\
\hline $\begin{array}{l}10 \text { CFF Part } 72.122(\mathrm{c}) \\
\text { As relates to fire protection }\end{array}$ & & & & & $\begin{array}{l}\text { Confirm Safety Class } \\
\text { Fire Protection not req. }\end{array}$ \\
\hline $\begin{array}{l}\text { Regula tory Guide } 1.76 \\
\text { As relates to tornado criteria } \\
\end{array}$ & & & & & $\begin{array}{l}\text { Not applicable, No } \\
\text { Safety Class equipment }\end{array}$ \\
\hline $\begin{array}{l}\text { SECY- } 93-087 \\
\text { As relates to tornado criteria }\end{array}$ & & & & & $\begin{array}{l}\text { Not applicable, No } \\
\text { Safety Class equipment }\end{array}$ \\
\hline $\begin{array}{l}\text { NUREG/CR-4461 } \\
\text { As relates to tornado criteria }\end{array}$ & & & & & $\begin{array}{l}\text { Not applicable, No } \\
\text { Safety Class equipment }\end{array}$ \\
\hline $\begin{array}{l}\text { Potential Revisions to SRP-3.5.1.4, Rev } 2 \\
\text { As relates to tornado criteria }\end{array}$ & & & & & $\begin{array}{l}\text { Not applicable, No } \\
\text { Safety Class equipment }\end{array}$ \\
\hline $\begin{array}{c}\text { WHC-SD-SNF-DB-002, Table 5.C } \\
\text { As relates to tornado criteria }\end{array}$ & & & & & $\begin{array}{l}\text { Not applicable, No } \\
\text { Safety Class equipment }\end{array}$ \\
\hline $\begin{array}{l}\text { 10 CFF Part } 72.24 \\
\text { As relates to tornado criteria }\end{array}$ & & & & & $\begin{array}{l}\text { Not applicable, No } \\
\text { Safety Class equipment }\end{array}$ \\
\hline $\begin{array}{l}10 \text { CFF Part } 72.122 \\
\text { As relates to tornado criteria }\end{array}$ & & & & & $\begin{array}{l}\text { Not applicable, No } \\
\text { Safety Class equipment }\end{array}$ \\
\hline $\begin{array}{l}\text { Reg Guide } 1.97, \text { Section } 50.49(e)(5) \\
\text { As relates to Safety Class } 1 \text { electrical equipment }\end{array}$ & & & & & $\begin{array}{l}\text { Not applicable, No } \\
\text { Safety Class equipment }\end{array}$ \\
\hline $\begin{array}{r}\text { Reg Guide } 1.89 \text {. Section } 50.49 \text { (f) }(1-4) \\
\text { As relates to Safety Class } 1 \text { electrical equipment }\end{array}$ & & & & & $\begin{array}{l}\text { Not applicable, No } \\
\text { Safety Class equipment }\end{array}$ \\
\hline $\begin{array}{l}10 \text { CFF Section } 50.63, \\
\text { Loss of all alternating current power }\end{array}$ & & & & & Evaluate loss of ac power \\
\hline \multicolumn{6}{|l|}{$\begin{array}{l}\text { IEEE Sid } 484-1987 \\
\text { As relates to safety class } 1 \text { batteries }\end{array}$} \\
\hline \multicolumn{6}{|l|}{$\begin{array}{l}\text { IEEE Std } 535-1986 \\
\text { As relates to safety class } 1 \text { batteries }\end{array}$} \\
\hline $\begin{array}{l}\text { IEEE Sid } 603-1991 \\
\text { As relates to safety class } 1 \text { |\&C systems }\end{array}$ & & & & & $\begin{array}{l}\text { Not applicable, No } \\
\text { Safety Class equipment }\end{array}$ \\
\hline $\begin{array}{l}\text { ANSI/ANS-8.3-1986 } \\
\text { As relates to criticality alarm systems }\end{array}$ & & & & & $\begin{array}{l}\text { Confirm that criticality } \\
\text { is not possible }\end{array}$ \\
\hline $\begin{array}{l}\text { NUREG }-0700 \\
\text { Review against DOE6430.1A }\end{array}$ & & & & & Review \\
\hline $\begin{aligned} \text { SRP } 18.1 \\
\text { Review against DOE6430.1A } \\
\end{aligned}$ & & & & & Review \\
\hline $\begin{array}{l}\text { Reg Guide } 1.26 \text { - As relates to assigning appropriate } \\
\text { ASME Section III code classes }\end{array}$ & & & & & Use to assist \\
\hline $\begin{array}{l}\text { Reg Guide } 1.84 \text { and } 1.85 \text { - As relates to assigning } \\
\text { ASME Section III for Safety Class I cases }\end{array}$ & & & & & $\begin{array}{l}\text { Not applicabie, No } \\
\text { Safety Class equipment }\end{array}$ \\
\hline $\begin{array}{l}\text { ANSI/ANS N509-1989, ANSI/ANS N510-1989 } \\
\text { As relates to Safety Class } 2 \& 3 \text { HVAC systems }\end{array}$ & & & & & Applicable \\
\hline
\end{tabular}




\begin{tabular}{|c|c|c|c|c|c|}
\hline REFERENCED DOCUMENT & $\begin{array}{l}\text { 1s } \\
1 \mathrm{~N} \\
\mathrm{sow}\end{array}$ & $\begin{array}{l}15 \\
1 \mathrm{~N} \\
0435\end{array}$ & senp & $\begin{array}{c}1 \mathrm{~s} \\
\mathrm{NN} \\
020\end{array}$ & CONMENT \\
\hline $\begin{array}{l}\text { Reg Guide } 1.140 \\
\text { As relates to Safety Class } 2 \text { \& } 3 \text { HVAC systems }\end{array}$ & & & & & Applicable \\
\hline $\begin{array}{l}\text { ANSI/ANS-57.1 and ANSI/ANS-57.2 } \\
\text { As applies to lifting MCOS and Casks }\end{array}$ & & & & & $\begin{array}{l}\text { Not Applicable, MCOs } \\
\& \text { casks not lifted }\end{array}$ \\
\hline $\begin{array}{l}\text { Generic Letters } 88-14,89-10 \text { and } 89-13-\text { As } \\
\text { applicable to Safety Class } 1 \text { mechanical systems }\end{array}$ & & & & & $\begin{array}{l}\text { Not applicable, No } \\
\text { Safety Class equipment }\end{array}$ \\
\hline $\begin{array}{l}\text { WHC-CM-4-2 App. A, E13, Rev } 1 \text { - As applicable to } \\
\text { safety class } 1 \text { procurement specifications }\end{array}$ & & & & & $\begin{array}{l}\text { Not applicable, No } \\
\text { Safety Class equipment }\end{array}$ \\
\hline $\begin{array}{l}\text { 10 CFR } 830.120 \text { - Applys to changes in WHC QA } \\
\text { Plan WHC-SP-1131 }\end{array}$ & & & & & $\begin{array}{l}\text { DOE ROO to review \& } \\
\text { approve changes }\end{array}$ \\
\hline $\begin{array}{l}10 \text { CFR } 50.55 \text { (e), DOE } 5000.38 \text {, WHC-CM-1-5, Section } \\
\text { Conditions of Construction Permits }\end{array}$ & 7.1. Re & & & & $\begin{array}{l}\text { Implement WHC Occur } \\
\text { Reporting System }\end{array}$ \\
\hline $\begin{array}{l}10 \text { CFR Part } 50 \text {, Appendix } B \text { and } 10 \text { CFR } 72 \text { Subpart } G \\
\text { Apply WHC quality requirements to SNFP }\end{array}$ & & & & & $\begin{array}{l}\text { Ensure WHC quality reqs } \\
\text { remain in effect }\end{array}$ \\
\hline $\begin{array}{l}\text { IEN 95-29 As applies to potentially defective Safety Clas } \\
\text { equipment. }\end{array}$ & & & & & Review bulletins \\
\hline $\begin{array}{l}10 \text { CFR Section } 20.1601 \text {, Section } 20.1003 \text {, Section } 20 . \\
\text { As applies to high radiation areas }\end{array}$ & 301 & & & & $\begin{array}{l}\text { Not applicable, no high } \\
\text { radiation areas as defined }\end{array}$ \\
\hline $\begin{array}{c}10 \text { CFR Section } 72.104 \text { - Criteria for radioactive materia } \\
\text { effluents and direct radiation from an ISFSI or MRS }\end{array}$ & & & & & \\
\hline $\begin{array}{l}10 \text { CFR Section } 72.106 \\
\text { Controlled areas of an ISFSI or MRS }\end{array}$ & & & & & $\begin{array}{l}5 \text { rem for onsite worker } \\
\text { from DBA }\end{array}$ \\
\hline $\begin{array}{l}\text { Reg Guide } 8.8 \text { - As applies to piping design consideration } \\
\text { for systems that carry radioactive material. }\end{array}$ & & & & & Applicable \\
\hline $\begin{array}{l}10 \text { CFR Section } 72.24 \text { and Reg Guide } 3.48 \text { - As applies } \\
\text { not in DOE } 5480.23 \text { and DOE-STD-3009-94 }\end{array}$ & requi & ments & & & Applicable to SARs \\
\hline $\begin{array}{l}10 \text { CFR } 20,10 \text { CFR } 70.59 \text {, and } 10 \text { CFR } 835 \text { - As applic } \\
\text { effluent monitoring. }\end{array}$ & le to & & & & Applicable \\
\hline $\begin{array}{l}10 \text { CFR } 50, \text { Appendix A, General Design Criteria - As ap } \\
\text { to nuclear safety equivalency. }\end{array}$ & licable & & & & $\begin{array}{l}\text { Review during definitive } \\
\text { design }\end{array}$ \\
\hline SRP 9.1.2, Rev 3, and NUREG-0612 & & & & & $\begin{array}{l}\text { Incorporate a criticality } \\
\text { values of } 0.95 \text { for Keff. }\end{array}$ \\
\hline $\begin{array}{l}\text { ANSI/ANS-57.9-1992 } \\
\text { Design Criteria for an Independent SNF Storage Insta }\end{array}$ & lation & & & & Applicable only to CSB \\
\hline $\begin{array}{l}10 \text { CFR Section } 72.3 \text { - As applies to Important to Safety } \\
\text { and consider them as Safety Class } 1 \text {. }\end{array}$ & $\mathrm{CCs}$ & & & & No applicable SCCs \\
\hline
\end{tabular}




\section{WHC-SD-SNF-CDR-003, Revision 0}

\section{ATTACHMENT 3}

SHIELDING AND RADIATION EXPOSURE ANALYSIS

for the

COLD VACUUM DRYING SYSTEM

of the

K BASIN SPENT NUCLEAR FUEL PROJECT 
WHC-SD-SNF-CDR-003, Revision 0

\title{
SHIELDING AND RADIATION EXPOSURE ANALYSIS
}

\author{
for the
}

COLD VACUUM DRYING SYSTEM

of the

\section{K-BASIN SPENT NUCLEAR FUEL STORAGE PROJECT}

\subsection{INTRODUCTION}

The purpose of this analysis is to evaluate the radiation exposure received by workers during each step of the cold vacuum drying process, and to determine the total cumulative exposure (person-rem) for the process. The results of this analysis will be used during the detailed design phase of the Cold Vacuum Drying System (CVDS) to reduce exposure where appropriate, in keeping with the ALARA (As Low As Reasonably Achievable) principle.

The radiological design of the CVDS will incorporate the criteria specified in the applicable orders, regulations, and publications listed in the Performance Specification for the K-Basin SNF Low Temperature Vacuum Drying Module, WHCS-0435. Also, the facility will be designed in accordance with the following documents: HSRCM-1, Hanford Site Radiological Control Manual; WHC-SCGN30011, Radiological Design Guide; 10CFR835, Occupational Radiation Protection; DOE Order 6430.1A, General Design Criteria; and the ALARA Implementation Plan for the K-Basin Spent Fuel Storage Project.

This analysis will be updated during the detailed design of the CVDS to ensure that the radiological design criteria for the facility are met.

\subsection{SUMMARY}

The total exposure received from processing one MCO/cask in the CVDS is approximately 181 person-mrem ( 0.181 person-rem). This exposure is based on the processing bays being individually shielded from each other. If the bays are not individually shielded, the exposure received from an $\mathrm{MCO} / \mathrm{cask}$ in an immediately adjacent bay would be an additional 28 person-mrem ( 0.028 person-rem).

The two major issues that require further review are:

A. Individual shielding of processing bays. The 28 person-mrem exposure from a $\mathrm{MCO} / \mathrm{cask}$ in an adjacent bay is based on conservative assumptions. An 
ALARA evaluation/design alternatives trade-off needs to be performed to determine the most appropriate design feature to reduce exposure from an $\mathrm{MCO} /$ cask in an adjacent bay. Administrative controls could prohibit or reduce the incidence of casks being in adjacent bays at the same time. The density of walls separating the bays has been neglected in this analysis. The use of precast concrete panel walls or steel panel walls is one alternative that can eliminate the neighboring bay exposure issue.

B. Contamination surveys. Of the 181 person-mrem exposure per cask, 30 person-mrem is from a contamination survey of the cask when it enters the facility. The advisability of performing this survey needs to be evaluated, especially if the cask was surveyed before leaving the K-Basins.

C. The crew size performing the activities where radiation doses are received is typically two people. Assuming that the neighboring bay contribution is eliminated and the receiving survey can be dropped, the exposure of an individual is projected to be about $75 \mathrm{mrem}$ per MCO/cask. A given individual would be restricted to working on approximately 7 MCOs per year, by the administrative goal of 500 mrem set in DOE N 5480.6 (DOE Radiation Control Manual). The 1.0 Rem annual exposure limitation given in $10 \mathrm{CFR}$ 835 would allow 14 per year. The minimum number of operators that would be required to support the annual production would be 30 if the $500 \mathrm{mrem}$ limit is observed (15 if the 1.0 Rem limit is observed). The production scheduling will probably require the presence of about 6 people per shift on a 7 day per week three shift operation. This translates to 126 man shifts or 25.2 operators. So if operators were cross trained to perform all tasks and they were perfectly rotated the $500 \mathrm{mrem}$ target could almost be achieved without enlarging the staff size as a result of radiation exposure management. A target of 35 mrem per individual should be established for the detailed design phase of the project. This will assure that the CVDS can be staffed by a full time dedicated crew. It is likely that reasonably simple actions such as using the working deck as a shield will reduce the total exposure to this target.

\subsection{DISCUSSION}

\subsection{Methodology}

All activities to be performed are listed in Table 1. These activities are from the facility Block Flow Diagram, SK-1-80134, Reference 1. Each activity was evaluated to determine if the location at which the activity is to be performed would result in any radiation exposure to the personnel performing that specific activity. If it was determined that there would be exposure from that activity, the location and dose rate associated with that location was listed in 
WHC-SD-SNF-CDR-003, Revision 0

Table 1 for that activity. The estimated dose rate for each location was obtained from references 2 and 3 . The workforce and time required to perform each exposure activity was estimated and the frequency of each activity was determined from the Block Flow Diagram. These values are listed in Table 2. The exposure (person-mrem) for each activity was then calculated and those were summed to determine the total exposure from processing one cask. The total exposure from a cask in an adjacent bay (assuming no shielding between bays) was also calculated based on the same methodology. Resuits are listed in Table 2 and discussed below.

\subsection{Assumptions}

It is conservatively assumed that $100 \%$ of the duration for each activity is spent in the radiation field.

Tasks performed over the top of the Multi-Canister Overpack (MCO) are performed with long-handled tools. This is required because the streaming dose rate directly over the annular space between the cask and MCO is estimated to be on the order of $1500 \mathrm{mrem} / \mathrm{hr}$.

All exposure from an adjacent cask is conservatively assumed to occur at a distance of 6.0 meters from that cask.

It is assumed that there is no shielding on the bottom of the service platform above the cask.

The particulate filter upstream of the vacuum pump will be changed out based on a predetermined dose rate. This filter will be appropriately shield and disposed of in a shielded container such that the exposure from the filter and the change out operation will be essentially zero.

\subsection{Results}

The exposures for each process task are given in Tables 1 and 2 .

The total exposure received from processing one cask in the CVDS is approximately 181 person-mrem ( 0.181 person-rem). This exposure is based on the processing bays being individually shielded from each other. If the bays are not individually shielded, the exposure received from a cask in an immediately adjacent bay would be an additional 28 person-mrem (0.028 person-rem).

The two major issues that require further review are: 
WHC-SD-SNF-CDR-003, Revision 0

A. Individual shielding of processing bays. The 28 person-mrem exposure from a cask in an adjacent bay is based on conservative assumptions.

B. Contamination surveys. Of the 181 person-mrem exposure per cask, 30 person-mrem is from a contamination survey of the cask when it enters the facility.

Other areas that merit further review are:

A. Incorporation of a shield collar over the annular space between the MCO and cask. This could possibly eliminate the need to use longhandled tools to perform the operations over the MCO, reducing the durations and total exposure resulting from these tasks.

1. Incorporation of shielding on the bottom of the service platform above the cask. This would reduce the radial dose contribution to the personnel on the platform. 


\section{REFERENCES}

1) Drawing SK-1-80134

2) DOSE RATE CALCULATIONAL SUMMARY FOR N-REACTOR FUEL IN K-BASIN CASKS AND K-BASIN LOAD-OUT PITS, Internal Memo from Nuclear Physics and Shielding to A.T. Kee, Westinghouse Hanford Company, November 29, 1995.

3) MCO/Cask Gamma Dose Rate Contour Map (MKIV Fuel, Lid-On Case), Memo from A.T. Kee to J.S. Lan, Westinghouse Hanford Company, February 22, 1996.

4) Drawing SK-1-80162. 
WESTINGHOUSE HANFORD COMPANY

Cold Vacuum Dying System Project

Contract \#MW6-SW W-310416. Task \#14
MERRICK \& COMPANY

Advanced Technology Sector

Project No. 30012131

WHC-SD-SNF-CDR-003, Revision 0

Table 1

Exposure Locations and Dose Rates

\begin{tabular}{|c|c|c|c|}
\hline Action & $\begin{array}{l}\text { Exposure } \\
\text { Activity? }\end{array}$ & $\begin{array}{l}\text { Exposure } \\
\text { Location }\end{array}$ & \begin{tabular}{|l|}
$\begin{array}{l}\text { Dose Rate } \\
\text { (mrem/hr) }\end{array}$ \\
\end{tabular} \\
\hline Select Bay & $\overline{\text { No }}$ & N/A & N/A \\
\hline Verify Readiness & No & N/A & N/A \\
\hline Notify Basin of Readiness & No & N/A & \\
\hline Transporter Arrives & No & N/A & N/A \\
\hline Open Door 1 & No & N/A & $N / A$ \\
\hline Attach Elephant Trunk to Truck & Yes & Side: $6.0 \mathrm{~m}$. from side near bottom & 2.00 \\
\hline Drive in - Turn off Truck & Yes & Side: $6.0 \mathrm{~m}$. from side near bottom & 2.00 \\
\hline Close Door 1 & No & N/A & N/A \\
\hline Remove Shipping Cover & Yes & Top: $1.0 \mathrm{~m}$, above and $5.08 \mathrm{~cm}$ from & 0.47 \\
\hline Perform Survey & Yes & Side: $10 \mathrm{~m}$. from side near bottom & 20.00 \\
\hline Post Dose Rates & No & N/A & N/A \\
\hline Count Swipes & No & N/A & N/A \\
\hline Decontaminate Cask & Yes & Side: $10 \mathrm{~m}$. from side near bottom & 20.00 \\
\hline Low Level Waste Collection & No & $\mathrm{N} / \mathrm{A}$ & N/A \\
\hline Verify Receiving Paperwork & No & $\mathrm{N} / \mathrm{A}$ & N/A \\
\hline Attach Instrument Package & Yes & Side: $2.0 \mathrm{~m}$ from side near bottom & 10.00 \\
\hline Attach Transporter Umbilical & Yes & Side: $2.0 \mathrm{~m}$. from side near bottom & 10.00 \\
\hline Jack Transporter & Yes & Side: $6.0 \mathrm{~m}$. from side near bottom & 2.00 \\
\hline Attach Seismic Restraints & Yes & Side: $2.0 \mathrm{~m}$. from side, near bottom & 10.00 \\
\hline Disconnect Transporter & Yes & Side: $6.0 \mathrm{~m}$. from side near bottom & 2.00 \\
\hline Qpen Door 2 & No & N/A & N/A \\
\hline Drive Out & No & $\mathrm{N} / \mathrm{A}$ & N/A \\
\hline Remove Elephant Trunk & No & IN/A & N/A \\
\hline Close Door 2 & No & N/A & N/A \\
\hline Verify HVAC Reset & No & N/A & N/A \\
\hline Check-out and Calibrate Rad. & No & N/A & N/A \\
\hline Remove Cask Top Bolts & Yes. & Top: $1.0 \mathrm{~m}$, above and $5.08 \mathrm{~cm}$, from & 0.47 \\
\hline Remove Top with Crane & Yes & Top: $1.0 \mathrm{~m}$ above and $1.0 \mathrm{~m}$ from side & 2254 \\
\hline Swing in Top Boom & Yes & Top: $1.0 \mathrm{~m}$. above and $1.0 \mathrm{~m}$. from side & 22.54 \\
\hline Remove Quick Connect & Yes & ITop: $1.0 \mathrm{~m}$, above and $1.0 \mathrm{~m}$. from side & 22.54 \\
\hline
\end{tabular}


WHC-SD-SNF-CDR-003, Revision 0

Table 1 (cont.)

\section{Exposure Locations and Dose Rates}

\begin{tabular}{|c|c|c|c|}
\hline Action & $\begin{array}{l}\text { Exposure } \\
\text { Activity? }\end{array}$ & $\begin{array}{l}\begin{array}{l}\text { Exposure } \\
\text { Location }\end{array} \\
\end{array}$ & \begin{tabular}{|l|} 
Dose Rate \\
(mrem/hr)
\end{tabular} \\
\hline Remove Quick Connect & Yes & Top; $1.0 \mathrm{~m}$. above and $1.0 \mathrm{~m}$. from side & 22.54 \\
\hline Make Annular Space Connections & Yes & Side; $1.0 \mathrm{~m}$. from side, near bottom & 20.00 \\
\hline Connect Draw Tube & Yes & Top; $1.0 \mathrm{~m}$. above and $1.0 \mathrm{~m}$. from side & 22.54 \\
\hline Connect Top Port & Yes & Top; $1.0 \mathrm{~m}$. above and $1.0 \mathrm{~m}$. from side & 22.54 \\
\hline Connect Filter Cover & Yes & Top; $1.0 \mathrm{~m}$, above and $1.0 \mathrm{~m}$. from side & 22.54 \\
\hline Bubble Test Connections & Yes & Top; $1.0 \mathrm{~m}$. above and $1.0 \mathrm{~m}$. from side & 22.54 \\
\hline Start Heating Water Flow & No & N/A & $\mathrm{N} / \mathrm{A}$ \\
\hline Heat-up Period & No & N/A & $\mathrm{N} / \mathrm{A}$ \\
\hline Start Drying Cycle & No & $\mathrm{N} / \mathrm{A}$ & N/A \\
\hline Withdraw $90 \%$ of the Water & No & N/A & N/A \\
\hline Hold for Drainage / Dripping & No & N/A & N/A \\
\hline Remove Last $10 \%$ of the Water & No & N/A & N/A \\
\hline Collect MCO Water - Pump to & No & N/A & N/A \\
\hline Clean Water Chase & No & N/A & N/A \\
\hline Collect Chase Water - Pump to & No & $\mathrm{N} / \mathrm{A}$ & N/A \\
\hline Purge Gas Flow & No & $\mathrm{N} / \mathrm{A}$ & N/A \\
\hline Evacuate Until Setpoint is & No & N/A & $\mathrm{N} / \mathrm{A}$ \\
\hline Pumping Time & No & $\mathrm{N} / \mathrm{A}$ & N/A \\
\hline Pressure Rise Test & No & N/A & N/A \\
\hline Helium Backfill & No & $\mathrm{N} / \mathrm{A}$ & $\mathrm{N} / \mathrm{A}$ \\
\hline Start Cold Water & No & N/A & N/A \\
\hline Cool Down Period & No & N/A & N/A \\
\hline Add More Helium & No & N/A & N/A \\
\hline Disconnect Draw Tube & Yes & Top: $1.0 \mathrm{~m}$. above and $1.0 \mathrm{~m}$. from side & 22.54 \\
\hline Disconnect Top Port & Yes & Top; $1.0 \mathrm{~m}$. above and $1.0 \mathrm{~m}$. from side & 22.54 \\
\hline Replace Quick Connect & Yes & Top; $1.0 \mathrm{~m}$. above and $1.0 \mathrm{~m}$. from side & 22.54 \\
\hline Replace Quick Connect & Yes & Top $1.0 \mathrm{~m}$. above and $1.0 \mathrm{~m}$. from side & 22.54 \\
\hline
\end{tabular}


WHC-SD-SNF-CDR-003, Revision O

Table 1 (cont.)

Exposure Locations and Dose Rates

\begin{tabular}{|c|c|c|c|}
\hline Action & $\begin{array}{l}\text { Exposure } \\
\text { Activity? }\end{array}$ & $\begin{array}{l}\text { Exposure } \\
\text { Location }\end{array}$ & \begin{tabular}{|c} 
Dose Rate \\
(mrem/hr)
\end{tabular} \\
\hline Bag Boom Connect & Yes & Top; $1.0 \mathrm{~m}$. above and $1.0 \mathrm{~m}$. from side & $\overline{22.54}$ \\
\hline Remove Boom Connect & Yes & Top $1.0 \mathrm{~m}$. above and $3.0 \mathrm{~m}$. from side & 4.22 \\
\hline Print Drying Report & No & N/A & N/A \\
\hline Review Results & No & N/A & $\mathrm{N} / \mathrm{A}$ \\
\hline Drain Annular Space & No & N/A & N/A \\
\hline Collect Water and Pump to Truck & No & N/A & N/A \\
\hline Disconnect Water & Yes & Side; $1.0 \mathrm{~m}$. from side, near bottom & 20.00 \\
\hline Contamination Survey and Decon. & Yes & Side; $1.0 \mathrm{~m}$. from side, near bottom & 20.00 \\
\hline Helium Leak Check Ports & Yes & Side; $3.0 \mathrm{~m}$. from side, near bottom & 5.00 \\
\hline Remove Annular Space Seal & Yes & Top; $1.0 \mathrm{~m}$. above and $5.08 \mathrm{~cm}$. from & 19.10 \\
\hline Inspect / Clean Cask Seals and & Yes & Top; $1.0 \mathrm{~m}$. above and $5.08 \mathrm{~cm}$. from & 19.10 \\
\hline Place Cask Top With Crane & Yes & Top; $1.0 \mathrm{~m}$. above and $1.0 \mathrm{~m}$. from side & 22.54 \\
\hline Insert and Tighten Bolts & Yes & Top; $1.0 \mathrm{~m}$. above and $5.08 \mathrm{~cm}$. from & 0.47 \\
\hline Torque Check & Yes & Top; $1.0 \mathrm{~m}$. above and $5.08 \mathrm{~cm}$. from & 0.47 \\
\hline Connect Helium Lines & Yes & Side; $1.0 \mathrm{~m}$. from side, near bottom & 20.00 \\
\hline Purge Annular Space with Helium & No & N/A & N/A \\
\hline Disconnect Helium & Yes & Side; $1.0 \mathrm{~m}$. from side, near bottom & 20.00 \\
\hline Inspect / Clean Cask Port Seals & Yes & Side; $1.0 \mathrm{~m}$. from side, near bottom & 20.00 \\
\hline Attach Cask Port Covers & Yes & Side; $1.0 \mathrm{~m}$. from side, near bottom & 20.00 \\
\hline Helium Leak Check Cask & Yes & Top; $1.0 \mathrm{~m}$. above and $3.0 \mathrm{~m}$. from side & 4.22 \\
\hline If Fails - Remove Bolts & Yes & Top; $1.0 \mathrm{~m}$ above and $5.08 \mathrm{~cm}$. from & 0.47 \\
\hline Remove Top with Crane & Yes & Top; $1.0 \mathrm{~m}$. above and $1.0 \mathrm{~m}$. from side & 22.54 \\
\hline If Passes - Request Truck & No & N/A & $\mathrm{N} / \mathrm{A}$ \\
\hline Open Door 2 & No & N/A & N/A \\
\hline Attach Exhaust Elephant Trunk & No & N/A & N/A \\
\hline Back Truck In & No & N/A & N/A \\
\hline Attach Transporter & Yes & Side; $6.0 \mathrm{~m}$. from side, near bottom & 2.00 \\
\hline Release Seismic Res & Yes & Side; $2.0 \mathrm{~m}$. from side, near bottom & 10.00 \\
\hline Release Jacks & Yes & Side; $6.0 \mathrm{~m}$. from side, $n$ & 2.00 \\
\hline
\end{tabular}


WHC-SD-SNF-CDR-003, Revision 0

Table 1 (cont.)

Exposure Locations and Dose Rates

\begin{tabular}{|l|c|l|c|}
\hline Action & $\begin{array}{l}\text { Exposure } \\
\text { Activity? }\end{array}$ & $\begin{array}{l}\text { Exposure } \\
\text { Location }\end{array}$ & $\begin{array}{c}\text { Dose Rate } \\
\text { (mrem/hr) }\end{array}$ \\
\hline \hline Disconnect Transporter Umbilical & Yes & Side; $2.0 \mathrm{~m}$. from side, near bottom & 10.00 \\
\hline Remove Instrument Package & Yes & Side; $2.0 \mathrm{~m}$. from side, near bottom & 10.00 \\
\hline Final Inspection & Yes & Side; $6.0 \mathrm{~m}$. from side, near bottom & 2.00 \\
\hline Drive Truck Out & Yes & Side; $6.0 \mathrm{~m}$. from side, near bottom & 2.00 \\
\hline Remove Elephant Trunk & Yes & Side; $6.0 \mathrm{~m}$. from side, near bottom & 2.00 \\
\hline Close Door 2 & No & N/A & N/A \\
\hline Regenerate Dryers & No & N/A & N/A \\
\hline Replace Contaminated End & No & N/A & N/A \\
\hline Replenish Supplies & No & N/A & N/A \\
\hline Perform Calibrations & No & N/A & N/A \\
\hline Ready for Next Run & No & N/A & N/A \\
\hline
\end{tabular}


Table 2

\section{Exposure Per Cask}

\begin{tabular}{|c|c|c|c|c|c|c|c|c|}
\hline Action & Exposure & Workforce & Duration & Frequency & Dose Rate & (mrem $/ \mathrm{hr})$ & Exposure (1 & erson-mrem) \\
\hline & Activity? & & (min.) & (per Cask) & Subj. & Adj. Cask & Subj. Cask & Adj. Cask \\
\hline Select Bay & No & $\bar{N} / \mathrm{A}$ & N/A & $\mathrm{N} / \mathrm{A}$ & -- & $-\cdots$ & $-\cdots$ & $-\cdots$ \\
\hline Verify Readiness & No & $\mathrm{N} / \mathrm{A}$ & $\bar{N} / \mathrm{A}$ & N/A & $\ldots$ & $\overline{---}$ & $-\cdots$ & $\cdots$ \\
\hline Notify Basin of Readiness Condition & No & $\mathrm{N} / \mathrm{A}$ & $\overline{\mathrm{N} / \mathrm{A}}$ & N/A & $\ldots$ & $\overline{---}$ & - & -- \\
\hline Transporter Arrives & No & N/A & N/A & $\mathrm{N} / \mathrm{A}$ & $-\cdots$ & -- & -- & $\cdots$ \\
\hline Open Door 1 & No & N/A & N/A & N/A & --- & 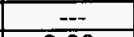 & --- & $-\overline{--}$ \\
\hline Attach Elephant Trunk to Truck & Yes & 1 & 5 & 1.00 & 2.00 & 2.00 & 0.17 & 0.17 \\
\hline Drive in - Turn off Truck & Yes & 1 & 5 & 1.00 & 2.00 & 2.00 & 0.17 & 0.17 \\
\hline Close Door 1 & No & N/A & N/A & N/A & --- & --- & $-\cdots$ & --- \\
\hline Remove Shipping Cover & Yes & 2 & 5 & 1.00 & 0.47 & 2.00 & 0.08 & 0.33 \\
\hline Perform Survey & Yes & 3 & 30 & 1.00 & 20.00 & 2.00 & 30.00 & 3.00 \\
\hline Post Dose Rates & No & N/A & N/A & N/A & $\ldots$ & $-\cdots$ & $-\cdots$ & --- \\
\hline Count Swipes & No & N/A & N/A & N/A & $-\cdots$ & $\ldots$ & $\ldots$ & $\cdots$ \\
\hline Decontaminate Cask & Yes & 3 & 30 & 0.10 & 20.00 & 2.00 & 3.00 & 0.30 \\
\hline Low Level Waste Collection & No & N/A & $\mathrm{N} / \mathrm{A}$ & N/A & $-\overline{--}$ & $\overline{-\cdots}$ & $\because-$ & $-\cdots$ \\
\hline Verify Receiving Paperwork Complete & No & N/A & N/A & $\mathrm{N} / \mathrm{A}$ & $\overline{---}$ & - & -- & -- \\
\hline Attach Instrument Package & Yes & 2 & 10 & 1.00 & 10.00 & 2.00 & 3.33 & 0.67 \\
\hline Attach Transporter Umbilical & Yes & 1 & 10 & 1.00 & 10.00 & 2.00 & 1.67 & 0.33 \\
\hline Jack Transporter & Yes & 2 & 10 & 1.00 & 2.00 & 2.00 & 0.67 & 0.67 \\
\hline Attach Seismic Restraints & Yes & 2 & 10 & 1.00 & 10.00 & 2.00 & 3.33 & 0.67 \\
\hline Disconnect Transporter & Yes & 1 & 5 & 1.00 & 2.00 & 2.00 & 0.17 & 0.17 \\
\hline Open Door 2 & No & N/A & $\mathrm{N} / \mathrm{A}$ & N/A & $\cdots$ & -- & $-\cdots$ & $-\cdots$ \\
\hline Drive Out & No & N/A & N/A & N/A & --- & $\overline{---}$ & --- & $-\cdots$ \\
\hline Remove Elephant Trunk & No & $\mathrm{N} / \mathrm{A}$ & N/A & N/A & -- & - & $-\cdots$ & -- \\
\hline Close Door 2 & No & $\mathrm{N} / \mathrm{A}$ & N/A & N/A & --- & --- & $-\cdots$ & $-\cdots$ \\
\hline Verify HVAC Reset & No & $\mathrm{N} / \mathrm{A}$ & $\mathrm{N} / \mathrm{A}$ & N/A & - & - & --- & $\cdots$ \\
\hline
\end{tabular}


WESTINGHOUSE HANFORD COMPANY

Cold Vacuum Drying System Project

Contract \#MW6-SWW-310416, Task \#14
MERRICK \& COMI . NY

WHC SD-SNF-CDR-003, Revision 0

Table 2 (cont.)

\section{Exposure Per Cask}

\begin{tabular}{|c|c|c|c|c|c|c|c|c|}
\hline Action & Exposure & Workforce & Duration & Frequency & Dose Rate & (mrem/hr) & Exposure (p & erson-mrem) \\
\hline & Activity? & & (min.) & (per Cask) & Subj. & Adj. Cask & Subj. Cask & Adj. Cask \\
\hline Check-out and Calibrate Rad. & $\overline{\mathrm{No}}$ & $\mathrm{N} / \mathrm{A}$ & $\mathrm{N} / \mathrm{A}$ & N/A & 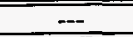 & $\ldots$ & $-\cdots$ & $-\cdots$ \\
\hline Remove Cask Top Bolts & Yes & 2 & 10 & 1.00 & 0.47 & 2.00 & 0.16 & 0.67 \\
\hline Remove Top with Crane & Yes & 2 & 10 & 1.00 & 22.54 & 2.00 & 7.51 & 0.67 \\
\hline Swing in Top Boom & Yes & 2 & 5 & 1.00 & 22.54 & 2.00 & 3.76 & 0.33 \\
\hline Remove Quick Connect & Yes & 1 & 5 & 1.00 & 22.54 & 2.00 & 1.88 & 0.17 \\
\hline Remove Quick Connect & Yes & 1 & 5 & 1.00 & 22.54 & 2.00 & 1.88 & 0.17 \\
\hline Make Annular Space Connections & Yes & 2 & 5 & 1.00 & 20.00 & 2.00 & 3.33 & 0.33 \\
\hline Connect Draw Tube & Yes & 1 & 5 & 1.00 & 22.54 & 2.00 & 1.88 & 0.17 \\
\hline Connect Top Port & Yes & 1 & 5 & 1.00 & 22.54 & 2.00 & 1.88 & 0.17 \\
\hline Connect Filter Cover & Yes & 1 & 5 & 1.00 & 22.54 & 2.00 & 1.88 & 0.17 \\
\hline Bubble Test Connections & Yes & 2 & 10 & 1.00 & 22.54 & 2.00 & 7.51 & 0.67 \\
\hline Start Heating Water Flow & No & N/A & $\mathrm{N} / \mathrm{A}$ & N/A & --- & -- & --- & $-\cdots$ \\
\hline Heat-up Period & No & N/A & N/A & N/A & --- & --- & 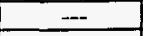 & --- \\
\hline Start Drying Cycle & No & N/A & $\mathrm{N} / \mathrm{A}$ & N/A & --- & 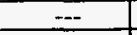 & -- & -- \\
\hline Withdraw $90 \%$ of the Water & No & $\mathrm{N} / \mathrm{A}$ & $\mathrm{N} / \mathrm{A}$ & N/A & --- & --- & $-\cdots$ & $\ldots$ \\
\hline Hold for Drainage / Dripping & No & $\mathrm{N} / \mathrm{A}$ & N/A & $\mathrm{N} / \mathrm{A}$ & $-\cdots$ & --- & -- & $-\cdots$ \\
\hline Remove Last $10 \%$ of the Water & No & N/A & N/A & N/A & --- & -- & -- & $=-$ \\
\hline Collect MCO Water - Pump to Truck & No & N/A & N/A & N/A & --- & --- & -- & --- \\
\hline Clean Water Chase & No & $\mathrm{N} / \mathrm{A}$ & N/A & N/A & --- & $\ldots$ & -- & 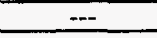 \\
\hline Collect Chase Water - Pump to Truck & No & $\mathrm{N} / \overline{\mathrm{A}}$ & N/A & N/A & -- & $\cdots$ & - & $\cdots$ \\
\hline Purge Gas Flow & No & N/A & $\mathrm{N} / \mathrm{A}$ & N/A & --- & --- & --- & $\overline{-\cdots}$ \\
\hline Evacuate Until Setpoint is Reached & No & N/A & N/A & N/A & --- & --- & --- & $\overline{-\cdots}$ \\
\hline Pumping Time & No & N/A & $\mathrm{N} / \mathrm{A}$ & N/A & $\overline{---}$ & $\cdots$ & $\cdots$ & $=$ \\
\hline Pressure Rise Test & No & N/A & N/A & N/A & $-\cdots$ & $=-$ & - & $\ldots$ \\
\hline Helium Backfill & No & $\mathrm{N} / \mathrm{A}$ & $\mathrm{N} / \mathrm{A}$ & N/A & $-\cdots$ & - & --- & - \\
\hline Start Cold Water & No & N/A & $\mathrm{N} / \mathrm{A}$ & $\mathrm{N} / \mathrm{A}$ & --- & $\cdots$ & --- & -- \\
\hline
\end{tabular}

Page 11 of 13 
Table 2 (cont.)

\section{Exposure Per Cask}

\begin{tabular}{|c|c|c|c|c|c|c|c|c|}
\hline Action & & Workforce & Duration & Frequency & Dose Rat & (mrem/hr) & Exposure ( & rson-mrem) \\
\hline Preturn & Activity? & & (min.) & (per Cask) & Subj. & Adj. Cask & Subj. Cask & Adj. Cask \\
\hline Cool Down Period & No & N/A & N/A & $\bar{N} / \mathrm{A}$ & $--\infty$ & 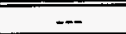 & $\ldots$ & $\overline{---}$ \\
\hline Add More Helium & No & N/A & N/A & N/A & - & $\cdots$ & -- & $\ldots$ \\
\hline Disconnect Draw Tube & Yes & 1 & 5 & 1.10 & 22.54 & 2.00 & 2.07 & 0.18 \\
\hline Disconnect Top Port & Yes & 1 & 5 & 1.10 & 22.54 & 2.00 & 2.07 & 0.18 \\
\hline Replace Quick Connect & Yes & 1 & 5 & 1.32 & 22.54 & 2.00 & 2.48 & 0.22 \\
\hline Replace Quick Connect & Yes & 1 & 5 & 1.32 & 22.54 & 2.00 & 2.48 & 0.22 \\
\hline Bag Boom Connect & Yes & 2 & 5 & 1.32 & 22.54 & 2.00 & 4.96 & 0.44 \\
\hline Remove Boom Connect & Yes & 2 & 5 & 1.32 & 4.22 & 2.00 & 0.93 & 0.44 \\
\hline Print Drying Report & No & N/A & N/A & N/A & -- & -- & -- & $=$ \\
\hline Review Results & No & N/A & N/A & N/A & $-\cdots$ & $\ldots$ & --- & --- \\
\hline Drain Annular Space & No & N/A & N/A & $\mathrm{N} / \mathrm{A}$ & $-\cdots$ & --- & --- & $-\cdots$ \\
\hline Collect Water and Pump to Truck & No & N/A & N/A & N/A & --- & $\cdots$ & -- & --- \\
\hline Disconnect Water & Yes & 1 & 5 & 1.20 & 20.00 & 2.00 & 2.00 & 0.20 \\
\hline Contamination Survey and & Yes & 3 & 30 & 1.20 & 20.00 & 2.00 & 36.00 & 3.60 \\
\hline Helium Leak Check Ports & Yes & 2 & 30 & 1.20 & 5.00 & 2.00 & 6.00 & 2.40 \\
\hline Remove Annular Space Seal & Yes & 2 & 5 & 1.00 & 19.10 & 2.00 & 3.18 & 0.33 \\
\hline Inspect / Clean Cask Seals and & Yes & 2 & 10 & 1.10 & 19.10 & 2.00 & 7.00 & 0.73 \\
\hline Place Cask Top With Crane & Yes & 2 & 10 & 1.10 & 22.54 & 2.00 & 8.26 & 0.73 \\
\hline Insert and Tighten Bolts & Yes & 2 & 10 & 1.10 & 0.47 & 2.00 & 0.17 & 0.73 \\
\hline Torque Check & Yes & 2 & 5 & 1.10 & 0.47 & 2.00 & 0.09 & 0.37 \\
\hline Connect Helium Lines & Yes & 2 & 5 & 1.10 & 20.00 & 2.00 & 3.67 & 0.37 \\
\hline Purge Annular Space with Helium & No & $\mathrm{N} / \mathrm{A}$ & N/A & N/A & $\cdots$ & --- & --- & $-\cdots$ \\
\hline Disconnect Helium & Yes & 2 & 5 & 1.10 & 20.00 & 2.00 & 3.67 & 0.37 \\
\hline Inspect / Clean Cask Port Seals & Yes & 2 & 5 & 1.20 & 20.00 & 2.00 & 4.00 & 0.40 \\
\hline Attach Cask Port Covers & Yes & 2 & 5 & 1.20 & 20.00 & 2.00 & 4.00 & 0.40 \\
\hline
\end{tabular}


Table 2 (cont.)

Exposure per Cask

\begin{tabular}{|c|c|c|c|c|c|c|c|c|}
\hline Action & $\begin{array}{l}\text { Exposure } \\
\text { Activity? }\end{array}$ & Workforce & $\begin{array}{c}\text { Duration } \\
\text { (min.) }\end{array}$ & $\begin{array}{l}\text { Frequency } \\
\text { (per Cask) }\end{array}$ & $\begin{array}{l}\text { Dose Rai } \\
\text { Subj. }\end{array}$ & $\begin{array}{l}\text { (mrem/hr) } \\
\text { Adj. Cask }\end{array}$ & $\begin{array}{l}\mid \text { Exposure (p } \\
\text { Subj. Cask }\end{array}$ & $\frac{\text { eerson-mrem) }}{\text { Adj. Cask }}$ \\
\hline Helium Leak Check Cask & Yes & 2 & 30 & 1.20 & 4.22 & 2.00 & 5.06 & 2.40 \\
\hline If Fails - Remove Bolts & Yes & 2 & 5 & 0.10 & 0.47 & 2.00 & 0.01 & 0.03 \\
\hline Remove Top with Crane & Yes & 2 & 10 & 0.10 & 22.54 & 2.00 & 0.75 & 0.07 \\
\hline If Passes - Request Truck & No & N/A & N/A & N/A & $=$ & - & -- & $\ldots$ \\
\hline Open Door 2 & No & N/A & N/A & $\mathrm{N} / \mathrm{A}$ & - & $\overline{---}$ & $\overline{--}$ & -- \\
\hline Attach Exhaust Elephant Trunk & No & $\mathrm{N} / \mathrm{A}$ & $\mathrm{N} / \mathrm{A}$ & $\mathrm{N} / \mathrm{A}$ & -- & $\cdots$ & $\ldots$ & $\cdots$ \\
\hline Back Truck In & No & N/A & $\mathrm{N} / \mathrm{A}$ & N/A & -- & $\cdots$ & -- & $\overline{-}$ \\
\hline Attach Transporter & Yes & 1 & 5 & 1.00 & 2.00 & 2.00 & 0.17 & 0.17 \\
\hline Release Seismic Restraint & Yes & 2 & 10 & 1.00 & 10.00 & 2.00 & 3.33 & 0.67 \\
\hline Release Jacks & Yes & 2 & 10 & 1.00 & 2.00 & 2.00 & 0.67 & 0.67 \\
\hline Disconnect Transporter Umbilical & Yes & 1 & 10 & 1.00 & 10.00 & 2.00 & 1.67 & 0.33 \\
\hline Remove Instrument Package & Yes & 2 & 5 & 1.00 & 10.00 & 2.00 & 1.67 & 0.33 \\
\hline Final Inspection & Yes & $\overline{1}$ & 10 & 1.00 & 2.00 & 2.00 & 0.33 & 0.33 \\
\hline Drive Truck Out & Yes & 1 & 5 & 1.00 & 2.00 & 2.00 & 0.17 & 0.17 \\
\hline Remove Elephant Trunk & Yes & 1 & 5 & 1.00 & 2.00 & 2.00 & 0.17 & 0.17 \\
\hline Close Door 2 & No & N/A & N/A & $\mathrm{N} / \mathrm{A}$ & - & 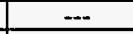 & $-\cdots$ & $=$ \\
\hline Regenerate Dryers & No & N/A & N/A & $\mathrm{N} / \mathrm{A}$ & -- & -- & $\overline{---}$ & $\overline{---}$ \\
\hline Replace Contaminated End Spools & No & $\mathrm{N} / \mathrm{A}$ & $\mathrm{N} / \mathrm{A}$ & $\mathrm{N} / \mathrm{A}$ & -- & -- & -- & - \\
\hline Replenish Supplies & No & $\mathrm{N} / \mathrm{A}$ & N/A & $\mathrm{N} / \mathrm{A}$ & $\overline{---}$ & $\overline{--}$ & $\overline{--}$ & $\overline{--}$ \\
\hline Perform Calibrations & No & N/A & $\mathrm{N} / \mathrm{A}$ & $\mathrm{N} / \mathrm{A}$ & $\cdots$ & -- & $=$ & $\cdots$ \\
\hline Ready for Next Run & No & N/A & $\mathrm{N} / \mathrm{A}$ & $\mathrm{N} / \mathrm{A}$ & -- & -- & -- & $\cdots$ \\
\hline & & & $2 \mathrm{~F}$ & ner & & & 181.25 & 27.62 \\
\hline
\end{tabular}


WHC-SD-SNF-CDR-003, Revision 0

ATTACHMENT 4

ALARA IMPLEMENATION PLAN

for the

COLD VACUUM DRYING SYSTEM

of the

K BASIN SPENT NUCLEAR FUEL PROJECT

Page $\mathbf{i}$ 
ALARA IMPLEMENTATION PLAN

for the

COLD VACUUM DRYING SYSTEM

of the

K-BASIN SPENT NUCLEAR FUEL STORAGE PROJECT

\subsection{INTRODUCTION}

Approximately 2,100 tons of SNF are stored in the K Basins. The Department of Energy (DOE) has agreed to an accelerated schedule to move this material from the basins into interim dry storage. The project requires the construction of a process facility, called the Cold Vacuum Drying System (CVDS), to dewater and dry the fuel outside of the basin buildings, before shipment to a distant storage facility. The SNF elements will be placed within a container called the Multiple Canister Overpack (MCO) in the basin. The MCO, which will be full of basin water as well as fuel, will be placed in a shielded shipping cask on a transport trailer at the basin. This assembly will be transported to the CVDS where it will be drained and dried by a vacuum process. Operations to be performed in the CVDS will involve manual operations in the presence of the radiation field surrounding the MCO and cask .

Drainage of the water will draw some suspended radioactive material from the MCO into a holding tank. Some airborne radioactive particles may also be entrained in the gas stream when the MCO is dried. Controls will be required to protect staff from inhaling or spreading releasable contamination that could escape when MCO connections are broken.

The DOE Radiological Control Manual (DOE N5480.6) and the Hanford Site Radiological Manual (HSRCM-1) require that equipment and procedures shall be designed to ensure that worker whole body exposure will remain below 500 mrem/year. The purpose of this plan is to provide the framework for a design and operations planning program which assures that the requirement will be met. The federal law governing radiation exposure for this type of work is in 10 CFR 835, Occupational Radiation Protection. This is the code that establishes radiation protection standards for the conduct of DOE activities. The annual limit for total effective dose equivalent (TEDE) is 5 rems. An administrative limit of $1.0 \mathrm{rem}$, whole body dose is set by 10 CFR 835 for Occupational Workers. Compliance with this limit will be achieved if the 500 mrem ALARA design target is observed. A guide to useful practices for achieving the objective of the ALARA process is DOE 
publication PNL-6577, "Health Physics Manual of Good Practices for Reducing Radiation Exposure to Levels that are As Low As Reasonably Achievable (ALARA)".

This ALARA Implementation plan provides guidance during the design phase for estimating the expected radiation doses and for selecting appropriate remote or automated operations and shielding features for the Cold Vacuum Drying System. It also provides input for decision making while writing operational procedures.

\subsection{ALARA PRINCIPLES}

The following documents serve as references for ALARA considerations:

10 CFR 835

ASME NQA-1

DOE Order $6430.1 \mathrm{~A}$

PNL-6577

WHC-CM-4-11

WHC-CM-4-46

WHC-CM-7-5

WHC-SD-GN-30011

DOE N5480.6

WHC-IP-1043

HSRCM-1
Occupational Radiation Protection

Quality Assurance Program Requirements for Nuclear Facilities

General Design Criteria

Health Physics Manual of Good Practices for Reducing Radiation Exposure to Levels that are As Low As Reasonably Achievable (ALARA)

ALARA Program Manual

Nonreactor Facility Safety Analysis Manual

Environmental Compliance

Radiological Design Guide

DOE Radiological Control Manual

WHC Occupational ALARA Program

Hanford Site Radiological Control Manual

In combination, the DOE Orders and Guidelines generally require the following radiological design criteria:

A. Individual worker dose shall be ALARA and should be less than 500 mrem per year.

B. Control of contamination should be achieved by containment of radioactive material.

C. Efficiency of maintenance, decontamination, operations, and decommissioning shall be maximized.

The basic principles that are to be adhered to in the design of the Cold Vacuum Drying System are to: 1) determine the major contributors to the dose and examine methods for making the process more efficient, 2) provide shielding to reduce the dose, 3) examine the cost-effectiveness of using robotics, 4) examine the cost- 
WHC-SD-SNF-CDR-003, Revision 0

effectiveness of using remote controls where possible, and 5) incorporate confinement features in the design such as special fittings to confine possible fluid and gas releases. These determinations should include assessment of normal operations exposure and maintenance/repair exposure.

\subsection{COLD VACUUM DRYING MODULE DESCRIPTION}

\subsection{Cold Vacuum Drying Module Process Description}

The process to be implemented in the CVDS will transform a MCO filled with contaminated basin water and spent nuclear fuel into a dried MCO with water vapor pressure below 3 torr. In general terms the process will be as follows:

\subsubsection{Receiving Activities}

The MCO will arrive in a cask, riding on a transporter trailer. The cask will be vertically oriented. The transporter will contain platforms that surround the cask so that people can work at the top of the MCO. The MCO top shield plug will be installed when the cask is received, but the cask top will not be in place. The receiving activities will include verifying the ID tag on the MCO and performing a radiation survey on the cask and exposed portion of the MCO.

\subsubsection{Preparing for Drying}

There are a number of steps that will be taken to prepare for the actual drying. First the transporter will be positioned and seismic restraints will be attached to the transporter. Radiation monitoring instruments will be positioned on the trailer work platforms. Connections will be made to the transporter to provide power and signal transmission for the instruments. Workers will then climb to the top of the MCO where they will move a boom into position above the MCO. The boom will contain an exhaust hood canopy and hoses. They will connect the hoses to the three ports on the top of the MCO. These are the MCO vent, which must be sealed during the process, and the draw tube and top ports. Water connections will be made at the bottom and top of the cask. These will allow warm water to be circulated in the annular space between the MCO and the cask. Once the connections are made, the warm water flow will be established. After heat-up of the MCO and cask is completed, the drying process will commence.

\subsubsection{Drying Process}

The drying process will be run from a control panel that will be remote from the cask. The first action will be to drain the water from the MCO. The water will be drawn by a pump. It will be discharged into a local catch tank and then pumped to 
a tanker truck that will return it to the basin. Once the bulk water has been discharged the control system will initiate a warm gas purge that will warm the MCO contents and evaporate some water. The gas purge will be a circulating system with a condenser. Condensed water will be sent to the catch tank. It is expected that the gas purge will run about an hour. The control system will cause the gas purge to stop and will initiate an evacuation cycle. Water vapor drawn from the MCO will be condensed and sent to the catch tank. All MCO nozzles will be filtered by sintered metal micron filters that will block the flow of radioactive debris out of the MCO. The control system will actuate a sequence of pump/purge cycles until the required pressure is achieved. It will then cause an acceptance test to be run.

\subsubsection{Completion}

After the drying cycle has been completed, workers will remove the connections and swing the boom out of the way. The cask top will be placed and the bolts will be tightened. The seismic restraints will be removed and the connections to the transporter will be released.

A block flow diagram for the process is given in Drawing SK-1-80134 which is attached to this report. Time estimates, which are a basis for estimating exposure, have been made for each of the steps on the block flow diagram. A plant throughput model has been built.

\subsection{Cold Vacuum Drying Module Radiation Hazards}

There are three important radiation sources associated with the cold vacuum drying process. The principle source will be the cask containing the MCO filled with spent nuclear fuel. The shielding integral to the cask will reduce the dose to relatively low levels in the area that the workers will occupy during the cold vacuum drying process. The cask may have local hot spots where penetrations will reduce the effective shielding somewhat. The second source will be the filter. Fission products from leaking fuel and activation products will accumulate in the filter, creating a source. This is anticipated to be significantly below the radiation levels coming from the cask. The third source will be the dewatering tank. This tank will be placed behind a shielded wall in the design to effectively eliminate the dose to workers from this source.

\subsection{RADIATION SAFETY DESIGN}

The means for maintaining exposures ALARA are to be through physical controls confinement, ventilation, remote handling and shielding. Administrative and procedural controls provide supplemental means of controlling exposure and maintaining exposures ALARA. 
In the design phase, the following objectives shall be applied:

A. Optimization. Optimization principles, as discussed in ICRP Publication 37, shall be utilized in developing and justifying design and physical controls.

B. External Exposure shall not exceed 500 mrem per year.

C. Internal Exposure should be limited to zero under normal operating conditions.

D. Maintenance. Ease of maintenance, decontamination and decommissioning shall be considered in the facility design and selection of materials.

Radiation Exposure shall be monitored, recorded and controlled in accordance with the Hanford Site Radiological Control Manual, HSRCM-1.

\section{Normal Operations Design}

Each process step will be analyzed as part of the analysis. Each step will be characterized by:

- The position of the operator(s)

- The dose rate contribution from the cask

- The dose rate contribution from the filter

- The dose rate contribution from the dewatering tank

- The amount of operator time anticipated

- The total operator dose attributable to performing the step

- A description of potential ingestion paths

- A description of mitigating features incorporated in the design or recommended

The total dose for the process will be estimated by summing the expected dose calculated for each step of the process.

The dose rates at various distances from the cask as well as dose rates for spots of lesser shielding (MCO nozzle locations) have been previously calculated. If the dose rate for any specific location has not been determined by the provided calculations, these will need to be calculated using a conservative model for the source. The dose rate from the filter unit must be modeled and calculated as part of this effort. The dose rate from the dewatering tank must be modeled and calculated as part of this effort. 
The dose to any given worker in the CVDS will be determined by the staff size, the extent of cross training allowing for rotation of tasks, and the rotation among shifts. An operating staff plan will be developed during detailed design. Radiation exposure considerations may be used in developing the plan in order to determine how tasks will be grouped for training and assignment. Local and temporary shielding features will be planned and implemented so that the staff is not increased (beyond the amount that would be planned if there were no radiation exposure limitation) for the purposes of spreading the dose.

Airborne release may occur when $\mathrm{MCO}$ connections are made or broken. A local exhaust hood and other ventilation design features will be used to capture any releases that may occur.

2. Maintenance Design

The process flow diagrams and equipment design will be reviewed on a component by component basis during the definitive design to assess likely modes of failure and the implied maintenance/repair activities. Routine maintenance activities will be addressed as well. Each of the anticipated activities will be described, exposure rates will be estimated, and activity durations will be estimated. The combination of these estimates will yield a maintenance exposure estimate for the most likely occurrences. Design features such as temporary shielding, decontamination, or mechanical assistance/ special tools incorporated in the design to reduce the activity time will be described. Control of airborne and releasable contamination will be planned for the maintenance activities. Local or temporary ventilation may be incorporated in the design.

3. Radiation Monitoring Instrumentation

Radiation monitoring and alarm instrumentation will be located at key locations around the process. The design will include source specific radiation detectors to monitor build-up of material in the system (such as on the filters). These will be used to determine when system cleaning or fitter changes are required. The design will include ionization detectors in the area where staff is working to monitor the radiation field and to warn of unacceptable dose rate. The design will include Continuous Air Monitors (CAMs) capable of detecting airborne particles that emit beta / gamma radiation. These will be located at strategic points near potential release points. 


\subsection{LESSONS LEARNED PROGRAM}

One of the greatest potentials for reducing dose is the application of lessons learned from operational experience. The lessons learned from Duke Power Company's Oconee Nuclear Station during the process of loading and storing casks of spent nuclear fuel into the Independent Spent Fuel Storage Installation (ISFSI) on-site at the station will be considered. Other commercial nuclear facilities such as Arkansas Nuclear One, Palisades, and Surry that may have lessons learned will be investigated in the design phase of this project. The experience at these plants is likely to show system modification and optimization actions that have reduced radiation exposure. The crews performing the operation for the first casks will be debriefed immediately after the operation to determine what may be done to improve the efficiency of the process. The ideas from these crews will provide the information necessary to modify equipment and procedures to improve efficiency and thus reduce dose. A video tape of the process will be made. It will be reviewed for additional improvements by others not directly involved in the actual process. Video taping later cold vacuum drying processes after modifications have been implemented will also aid in training additional workers. 
WHC-SD-SNF-CDR-003, Revision 0

\section{ATTACHMENT 5}

\section{COLD VACUUM DRYING ANALYSIS}

for the

COLD VACUUM DRYING SYSTEM

of the

K BASIN SPENT NUCLEAR FUEL PROJECT 
WHC-SD-SNF-CDR-003, Revision 0

Attch 5

COLD VACUUM DRYING ANALYSIS

for the

COLD VACUUM DRYING SYSTEM

of the

K-BASIN SPENT NUCLEAR FUEL STORAGE PROJECT

\subsection{INTRODUCTION}

Approximately 2,100 metric tons of SNF are stored at the Hanford Site 105-K East and West Basins. Some of the fuel elements have broken and uranium corrosion has occurred where the uranium metal has been in contact with the basin water. This fuel will be retrieved and packaged in approximately 400 MCO containers. Ultimate disposition will be dry storage in sealed MCOs in a new CSB. In order to prepare the fuel for dry storage it must be dried to eliminate water vapor which will generate hydrogen as it undergoes radiolysis and as it oxidizes the uranium metal fuel. Drying will involve draining the liquid from the MCO, Cold Vacuum Drying (CVD), and hot treatment, which will also be a vacuum process. The treatment will occur in two facilities. Draining and CVD will take place in a new facility to be constructed at the K-Basin Site. Hot treatment will occur in the CSB.

This study, which focuses on the identification and evaluation of alternatives for accomplishing CVD, is intended to form the basis for the CVDS subproject preliminary process design.

\subsection{PROCESS OVERVIEW}

The CVDS will be a stand alone modular structure located in the Hanford Site 100 $\mathrm{K}$ area. The system functions and requirements are presented in WHC-SD-SNFFRD-020 and the system performance specifications are presented in WHC-S0435. A review of these requirements is given in Appendix B and Appendix C.

The CVDS will receive the loaded $\mathrm{MCO}$, installed inside a transportation cask that is attached to a transporter, perform draining and drying, and prepare the MCO for transportation to the CSB. The process will involve connecting hoses to the MCO and cask; injecting hot water into the annular space to heat the MCO; draining the water from the MCO; purging and/or pumping to dry the MCO; and cooling and backfilling the MCO with Helium. A more detailed discussion of the process sequence is given on Drawing SK-1-80134. The CVDS will provide multiple stations for concurrent processing of MCOs as necessary to meet the timeline requirements. 
The discussions which follow will address the MCO drying function which is the primary function of the CVDS.

\subsection{GENERAL DRYING METHODS - GAS PURGE VS. COLD VACUUM DRYING}

Two options and variations of each were considered for drying the MCOs: 1) vacuum pumping and 2) purging with a dry, heated gas. Drying rate estimates were made for a puddle of water. These are given in Appendix A. The calculations indicate that there is no obvious clear choice for either option as potentially the drying rate for either is similar. Both have advantages and disadvantages as follows:

\subsection{Vacuum Drying}

In general, the case for vacuum pumping is that the drying is not dependent on circulatory flow reaching all recesses and wet surfaces. The evaporation will proceed at a constant and rapid rate dependent only on maintaining temperature on the wet parts and on the vapor removal rate determined by the pumping speed. The problem with ensuring a complete and rapid drying process lies in providing sufficient heat transfer to all surfaces needed to counter the evaporative heat loss and maintain the desired surface vapor pressure. Thus, the drying rate could be slowed if heat input is deficient. An extreme condition would be freezing of the surface water after which the vapor removal rate would drop by orders of magnitude. One advantage of evacuating the space is that it minimizes suspension of radioactive dust in the gas stream that leaves the MCO.

\subsection{Gas Purging}

Purging with a heated dry gas partially avoids the weakness of vacuum drying by providing a heat exchange medium as well as a carrier for vapor removal. So, during purging, cold spots, which support only a lowered water vapor pressure, are warmed by the purge gas and vaporization on these areas is enhanced. The reason why purging alone is not adequate for MCO and SNF drying lies in the difficulty of ensuring flow over all surfaces. The random packing of the fuel will result in flow channeling through the paths of least resistance and surfaces that are bypassed by the purge gas. Thus, purging is not very good at drying tight annular spaces, cracks and crevices. One disadvantage of gas purging is that the gas exits the port in a high velocity jet that diffuses when it strikes a surface. In the MCO these surfaces are likely to be contaminated so that the jet may suspend radioactive dust in the MCO atmosphere and exhaust.

The fastest drying is likely to be achieved by utilizing both techniques in a pump purge - pump - purge sequence. This is consistent with typical industrial drying experience and commercial nuclear power reactor fuel drying experience where a 
sequence of evacuation/backfill - purge cycles are found to dry fastest. While the exact procedure to be followed has yet to be developed, and may only be optimized after operation, some combination of pump and purge will probably prove to be more effective than either a vacuum pump or purge alone approach. Surfaces that chill during evacuation will be warmed by the purge and temperature gradients resulting from rapid vaporization during vacuum pumping will be decreased during purging. Periodic rewarming of the surfaces will restore the evaporation rate while the gas flow removes vapor at approximately the same rate as would be achieved by evacuation.

Vacuum drying of spent nuclear fuel is performed routinely by utilities in the commercial U.S. nuclear power industry prior to on-site dry storage of spent nuclear fuel. Although commercial power plants normally store spent fuel within a spent fuel pool, dry on-site storage at a licensed Independent Spent Fuel Storage Installation (ISFSI) is utilized by utilities desiring to create room in their spent fuel pool for future operation or to allow for plant decommissioning.

Several commercial vendors provide systems for dry on-site storage and transportation of spent nuclear fuel. Although each storage system design is unique, the vacuum drying concepts and practice are similar. This section will focus generally on the vacuum drying approach of one vendor in order to allow comparison with the SNF Cold Vacuum Drying System application.

A commercial pressurized water reactor (PWR) fuel assembly is approximately 8$1 / 2$ inches square and 13 feet long. A standard storage Basket is approximately 5$1 / 2^{\prime}$ diameter and 15' long and holds 24 PWR fuel assemblies. All fuel loading, vacuum drying, and basket sealing is performed within the plant's fuel building, adjacent to the spent fuel pool. Prior to fuel loading, the empty basket is placed in a cask and lowered into the fuel pool. Fuel assemblies are loaded into vertical cells and a thick shield lid is inserted into the basket above the fuel assemblies. The loaded basket is lifted from the fuel pool and placed in a cask decon pit where the draining, drying, and sealing operations are performed.

In addition to providing radiation protection for workers performing the basket draining, drying, and sealing operations, the shield lid contains penetrations with vent and drain connections. The vent connection includes a quick-connect fitting, while the drain connection has a threaded fitting and a pipe which runs to bottom of the basket, allowing for complete drainage.

Draining, vacuum drying, helium backfilling, and leak testing are performed using a single, portable, skid mounted system. The system contains a drain-down pump, a vacuum pump (or multiple vacuum pumps), a piping manifold, hoses, instrumentation, and a control system.

The water in the Basket is partially drained to allow shield lid seal welding. This drain-down is performed by providing a gas overpressure at the vent connection, 
connecting a hose from the basket drain connection to the drain-down pump, and operating the pump to discharge water back to the fuel pool. Some fuel storage vendors and utilities perform this draindown by utilizing only inert gas overpressure to push water out of the draindown connection back to the fuel pool.

Following shield lid welding and subsequent hydrostatic testing, the structural lid is installed and welded to the basket shell above the shield lid. The basket is then completely drained (approx. 1,500 gallons) to the fuel pool. The structural lid has a single penetrations which allows access to the vent and drain connections on the shield lid.

Following complete drain-down, the vacuum drying phase begins. Vacuum drying is performed utilizing the decay heat of the spent fuel assemblies which may be as high as $26 \mathrm{kw}$. Fuel surface temperatures will typically be a few hundred degrees so that water in the MCO after drain-down will be steam. The large amounts of decay heat available eliminate the necessity for any auxiliary heating. The vacuum drying starts by drawing a vacuum though the drain line using a staged Roots blower and water ring vacuum pump. Seal water to the water ring pump is provided by recirculating fuel pool water through the drain-down pump, and directing a sidestream to the water ring pump. Steam extracted from the basket condenses in the water ring pump and merges with the seal water. The discharge of the water ring pump is directed back to the fuel pool. This initial vacuum drying will stabilize pressure at less than 20 torr.

Following initial drying, the drain connection is plugged. The basket is backfilled with helium and a rotary vane vacuum pump takes a suction on the basket vent connection. Multiple helium backfill and vacuum pumpdowns are performed until a stable pressure at less than 3 torr is maintained. Typically the drying cycle requires approximately 8 hrs. Concurrent with the final vacuum drying, a helium leak test of the lid welds is performed.

After vacuum drying is complete, the basket is back filled with helium, all vacuum drying system connections are removed from the basket, and the penetration through the structural lid is double seal welded.

\subsection{Comparison Between Commercial and K-Basin SNF Project Applications}

Comparison with of the K-Basin SNF drying problem and the commercial nuclear power plant fuel drying process is a useful method of verify design reasonableness and of estimating the likely performance of the CVD process. Some key differences exist between the vacuum drying of commercial PWR spent fuel assemblies and the SNF Project application. These include:

A. Commercial spent fuel assemblies typically are structurally sound with few cladding defects, whereas the MCOs will contain ruptured fuel elements, 
fragments, corrosion, and some sludge. In addition, the K-Basin fuel element configuration is not a simple rectangular solid with completely exposed surfaces. This difference suggests that drainage will be less complete than the commercial experience. The K-Basin drying process will have more water to remove. Furthermore, the water on the surfaces of the MCO will be more tightly bound because some of it will be contained in tight pores and cracks in the fuel material, corrosion, and sludge. There will also be chemical force binding of some of the water (waters of hydration). It is likely that the CVD process will continue evacuation after the free water has been removed for a long period of time, whereas the commercial experience is that the vacuum drops to the acceptance value rapidly after the free water is gone.

B. The commercial basket is vented during storage. Therefore, final drying is achieved using the decay heat and the vented gas stream. Because some of the K-Basin fuel is ruptured and the fuel material was uranium metal, there is the possibility that exposure to air could initiate a pyrophoric event. Therefore, the MCOs will be sealed during storage. Water left in the MCO may react with the uranium and may undergo radiolysis, causing a build-up of hydrogen in the MCO. The K-Basin fuel drying processes must achieve a dryer state before storage than the commercial analogue. For the K-Basin fuel drying, the CVD operational pressure limit is < 0.5 torr [WHC-S-0435] compared to the commercial limit of $<3$ torr. This lower SNF pressure will assure a lower final moisture content.

C. In the commercial application vacuum drying operations are performed relatively infrequently (approx. 1 basket per week for 6 months). Approximately $400 \mathrm{MCOs}$ will be dried over a two year period. This higher duty cycle requires more consideration for reliability and maintenance.

D. PWR fuel assembly decay heat (26 kw per basket) is adequate enough to allow vacuum drying in less than 24 hours without the need for auxiliary heat. Average K-Basin SNF decay heat is $0.4 \mathrm{kw}$ per MCO.

E. Commercial fuel and baskets are much larger than the K-Basin SNF. Free volume in a typical loaded PWR basket is $200 \mathrm{ft}^{2}$ compared to $25 \mathrm{ft}^{2}$ for the loaded MCO

F. The commercial spent fuel pool is available for water supplies, drain collection, and a heat sink because the drying is performed next to the pool. The fuel building ventilation system is also available. K-Basin SNF draining and drying will be performed away from the K-Basins in the CVDS, thus requiring additional systems to support draining, cooling, and off-gas control. The presence of the pool in the commercial application reduces the 
complexity of a liquid ring pumping system, because the liquid can be circulated between the liquid ring pump and the pool. If such a system is used in the K-Basin application, a tank, recirculation pump, and heat exchanger to chill the seal water would be required to support the pump. The water in the this system would be contaminated. Thus, the liquid ring pump is not feasible for use in the CVDS.

\subsection{ALTERNATIVE DRYING CONCEPT FLOW DIAGRAMS}

Seven vacuum pump/purge variations were considered for the subject design. The conceptual process flow diagram differs depending on the pumping range, type of pump and method of reclaiming the MCO water. Therefore, the pump/purge options are presented along with the applicable process flow diagrams. The candidate vacuum pump groupings are:

Process Flow Concept \#1 - Wide Pressure Range Mechanical Pumps.

- Rotary Scroll

- Stage Roots Blower

- Claw Pump

- Rotary Vane

Process Flow Concept \#2 - Water Based Pumps/Hybrid Mechanical

- Jet Pump

- Liquid Ring

Process Flow Concept \#3 - Cryogenic Sorption

- Liquid Nitrogen Cooled Sorption Pump

Data on typical models for these alternatives is given in Appendix B.

\subsection{Process Flow Concept \#1 - Wide Pressure Range Mechanical Pumps}

The pumps considered in this section are all capable of pumping directly from atmospheric pressure to sub-torr range without any additional staging. Because an extensive portion of the pumping cycle involves pumping water vapor exclusively, there is the probability that some of the pumped vapor will condense in the pump. To avoid this, the pump must either be maintained at a temperature above saturation at atmospheric pressure $(>100 \mathrm{C})$, or, a purge gas must be introduced in a ratio which assures that the saturation water vapor pressure corresponding to the pump temperature is not achieved. Figure one shows the placement of the mechanical pumps considered in a process flow diagram. Since the pumps pass the entire water load without holdup, a refrigerated dryer is shown in the pump exhaust to trap most of the pumped water. The specific types of pump which could be used in this process flow are described below: 


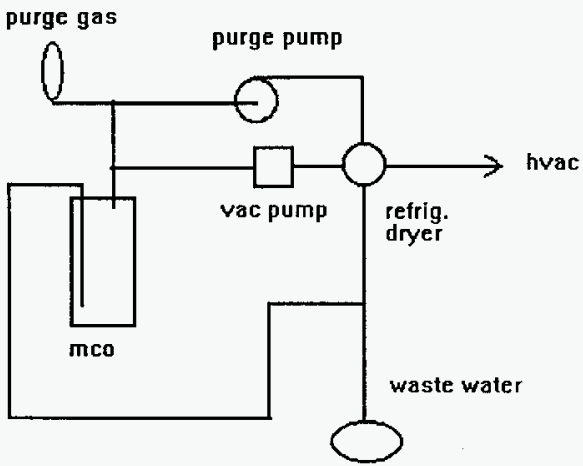

FIGURE 1: Wide Pressure Range Mechanical Pump Flow Paths

A. Rotary Scroll Pump

This type pump has found application pumping radioactive gases in Europe and the United States and is a clean alternative to oil-sealed pumps for backing turbomolecular pumps in high vacuum systems. It pumps from atmospheric to a low ultimate pressure (mid E-3 torr range), is compact, quiet and has minimal maintenance needs. It is completely oil free and does not rely on shaft seals. A weakness of this design is a sensitivity to particulates and condensed water, either of which could jam the interleaved spirals. To preclude condensing within the pump, an upstream heater can superheat the water vapor prior to pumping. Prior to committing to this pump, the ability to pump water vapor under the proposed conditions should be demonstrated. The manufacturer has offered a guarantee that will allow testing of this pump with full refund if its performance is deemed unsatisfactory. Of the wide pressure range mechanical pumps considered, it is the only completely oil free pump.

\section{B. Staged Roots Blower}

Roots pumps are routinely used pumping vapors, acid fumes and fine particulates. The pumping surfaces are oil free. The pump is robust and requires little maintenance. Lubricants in the gear box are separated from the pumping chambers by shaft seals and baffles. Gear box pressure can be manipulated to discourage oil migration. Purge gas control is available on commercial models and can be apportioned to stages to prevent 
condensation without drastically impacting pumping speed. This pumping scheme is capable of achieving an ultimate vacuum of about 0.1 torr.

\section{Claw or Dry Compression Pump}

Somewhat similar to a Roots blower, this multi-staged dry pump also relies on shaft seals to separate the gear box lubricant from the pumping chambers. This pump operates from atmospheric pressure to .05 torr and has peak speed around 1.0 torr. Purge gas can be admitted to any or all of the stages to flush the water vapor and avoid condensation.

\section{Rotary Vane Pump}

Rotary vane pumps are available as either dry carbon vane or oil-sealed types. Pumping range is from atmospheric pressure to E-3 torr. The oilsealed pumps should have the inlet maintained in the viscous pressure range to avoid backstreaming. Gas ballasting can be used to prevent water condensation from mixing with the pump oil. Gas ballasting does reduce the ultimate pressure performance somewhat. Oil vapors in the exhaust are a source of contamination in the waste water and exhaust filters. The dry carbon vane pump does produce particularities as a consequence of normal wear. Maintenance on these pumps includes periodic replacement of shaft seals and vanes and changeout of lubricating oil. There is a modified version of the oil-sealed pump in which the pump oil is heated to prevent hold-up of water vapor in the pump.

\subsection{Process Flow Concept \#2 - Water Based Pumps}

Water based pumps such as jet and liquid-ring pumps will effect condensing and entraining the pumped water vapor as part of their normal operation. Also, the ultimate pressure of these pumps is not sufficient to accomplish the entire drying operation, so their role is to act as backing pumps for a first stage mechanical pump, such as a roots blower. Because of their watertrapping feature, a water-based pump eliminates the need for a refrigerated dryer in the vacuum line. However, one is still needed in the gas purge loop. In this arrangement, the condensing tank supporting the pump would be periodically off-loaded to the waste water tank based upon either radiation level or quantity. The process flow associated with these pumps is shown in Fig 2. The pump is supported by a circulated chilled water loop. This water will become contaminated with radioactive material. 


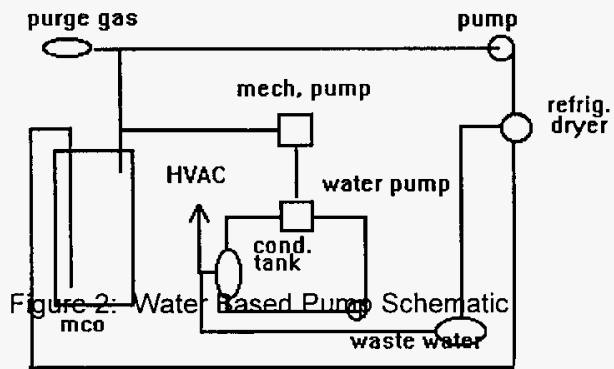

A. Jet Pump

A jet pump is a very simple device which incorporates a pump, venturi and condensing tank in a closed loop to effect suction at the venturi throat. Canister water vapor and purge gases are mixed with the pumped water and transferred to the condensing tank where condensables are separated from purge gases. Non-condensable gases are vented from the condensing tank, and water is transferred to the waste tank as needed based upon fluid level or a radiation monitor. The ultimate vacuum pressure of a jet pump is approximately 100 torr and the pump could serve as the backing pump for a roots blower. During the time when only water vapor is being pumped, the pump acts primarily as a condenser, reducing the water vapor pressure at the exhaust to approximately 18 torr.

\section{B. Liquid Ring Pump}

The pumping mechanism of this pump is basically an eccentrically rotated shape within a pumping chamber whose gas seal is effected by a continually replenished water film established between the rotor and the chamber wall. Since the canister water vapor and purge gas are mixed with the seal water a support loop similar to that of the jet pump is needed to separate condensables and non-condensables and to transfer canister water to the waste tank. The ultimate pressure of a liquid ring pump is limited to the water saturation pressure at the pump's operating temperature. During water-only pumping, this pump also acts primarily as a condenser. 


\subsection{Process Flow Concept \#3 - Cryogenic Sorption Pumping}

Figure 3 shows the process flow diagram as modified to adapt to sorption pumps. Molecular sieve at liquid nitrogen temperatures will readily pump all the gases expected during the drying process except for helium. The system includes a refrigerated dryer and a liquid nitrogen-cooled freezer upstream of the sorption pumps. The dryer and freezer remove virtually all the water vapor to limit the water loading of the sorption pumps. Warming of the system between MCOs will regenerate the dryer, freezer, and sorption pumps.

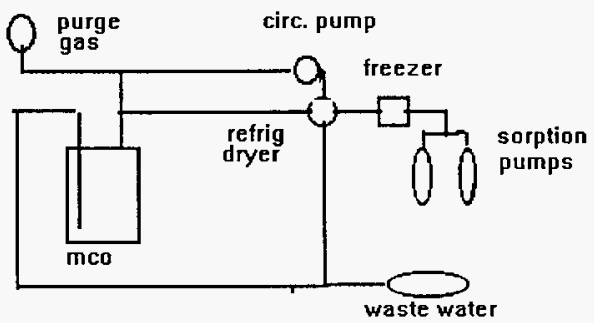

Figure 3: Process Flow for Cryogenic Sorption Pumping

Liquid nitrogen-cooled sorption pumps are commercially available and use molecular sieve $5 \mathrm{~A}$ as the sorbent. Several pumps are valved to inlet and regeneration manifolds to permit staged pump-down and regeneration. Only trace quantities of canister water reach the pumps so that regeneration directly to the atmosphere does not pose a hazard. The reliability of this pumping arrangement is very high and is limited only by the availability of liquid nitrogen and the lifetime of the regeneration heaters.

\subsection{ADVANTAGES/DISADVANTAGES OF THE ALTERNATE PUMPING METHODS}

The following criteria have been selected for evaluating the pump options:

\subsection{Ultimate Pressure Capability}

Pumps that can achieve a final pressure of 0.1 torr or better by themselves (without backing by another pump) receive a positive rating. 


\subsection{Seal Fluid}

Pumps that do not require seal fluids (oil or water) that will become contaminated receive a positive rating.

\subsection{Water Handling}

Pumps that can handle large water loads without fouling, requiring special maintenance, or adding special features such as heaters receive a positive rating.

\subsection{Reliability}

Pumps that do not require routine maintenance; pumps that do not have shaft seals; pumps that are not affected by dust, and pumps that are known from experience to operate with few problems get a positive rating.

\subsection{Maintainability}

Pumps that are readily repaired in place or replaced easily receive a high rating. Pumps where maintenance does not require handling contaminated fluids receive a positive rating.

\subsection{Complexity}

Pumps that do not require extensive support systems receive a high rating.

\subsection{Safety}

Pumps that do not accumulate radioactive materials and pumps that are unlikely to release radio-active material into the worker environment receive a high rating.

\subsection{Cost}

There is a range of pump costs from approximately $\$ 5,000$ to $\$ 30,000$. Lower costs receive a positive rating. 
Attch 5

The various options are rated in the following table:

\begin{tabular}{|c|c|c|c|c|c|c|c|}
\hline & Scroll & $\begin{array}{c}\text { Roots } \\
\text { Packages }\end{array}$ & $\begin{array}{c}\text { Rotary } \\
\text { Vane }\end{array}$ & Claw & Jet & $\begin{array}{c}\text { Liquid } \\
\text { Ring }\end{array}$ & Sorption \\
\hline $\begin{array}{c}\text { Ultimate } \\
\text { Pressure }\end{array}$ & ++ & $+?$ & + & $+?$ & & & ++ \\
\hline Seal Fluid & + & + & $\left(^{*}\right)$ & + & & & + \\
\hline $\begin{array}{c}\text { Water } \\
\text { Handling }\end{array}$ & $?$ & + & + & + & + & + & + \\
\hline Reliability & $?$ & + & & + & + & & + \\
\hline Maintainability & + & + & $\left(^{*}\right)$ & + & & & + \\
\hline Complexity & + & + & + & + & & & \\
\hline Safety & + & + & $\left(^{*}\right)$ & + & & & + \\
\hline Cost & + & & + & & + & & \\
\hline
\end{tabular}

Grade explanations are as follows:

$++=$ Meets and exceeds the requirements. High level of confidence.

$+?=$ Meets the requirement marginally, depending on purge gas injection rate

$+=$ Meets the requirements

$?=\quad$ There is not a lot of industrial experience. Manufacturer claims that it will meet the requirements. Testing required to verify claim.

$\left({ }^{*}\right)=$ The dry sealed sub-type meets the requirement. Oil sealed types do not.

No attempt has been made to assign weighting factors to the criteria or to arrive at "quantitative" scores for each pumping option. A subjective review of the data in Table 1 suggests that the best choice will be the scroll pump if the manufacturers claims can be demonstrated by testing. Roots packages and claw pumps receive mostly positive scores. The two primary drawbacks to these systems is that they only achieve 0.1 torr ultimate pressure when purged with a drying gas feed. While adequate, this limitation does not allow for the flexibility to achieve a better vacuum if criteria should change after a few MCOs have been dried and assessed. Typically, the roots packages have multiple stages which drives the cost to the $\$ 30,000$ range. The sorption pump also appears to satisfy the criteria well. However, it's support systems are complex and expensive. 


\subsection{RECOMMENDATIONS}

The first choice for the pump selection in the preliminary design is the scroll pump. The primary reason is operational simplicity: the system is always ready; the pump is completely oil free and has minimal maintenance needs; relative to the other mechanical pumps considered, the scroll pump has a distinct advantage in simplicity, cost, cleanliness and maintainability. Testing should be performed to verify the performance. The pump has been offered by the manufacturer on a trial basis to assure that it will perform when pumping pure water vapor. The recommended fall back position should the scroll pump prove to be unsatisfactory is multi-stage roots blower with nitrogen purge.

\subsection{COLD VACUUM MODELING}

Pump-out and drying of the MCO was modeled using software marketed by Process Applications, Inc entitled "Cold Vacuum System Design-II". Inputs are the pump type and model, starting and final pressures, initial gas composition, off-gassing rate and system geometry including line size and length, elbows, traps, valves gauges and system volume. The program then computes the pump-down using equations appropriate to the pressure and system dimensions.

Simulation of the drying process was approximated by fixing the off-gassing at a rate consistent with a vapor pressure corresponding to isothermal saturation at $50 \mathrm{C}$. This approximation resulted in a rapid pumpdown to the $50 \mathrm{C}$ saturation vapor pressure followed by constant pressure vapor removal until the assumed water content of the cask was depleted. At this point, the off-gassing rate was changed to an inverse time relationship (one of the program options having the form $\mathrm{Q}=\mathrm{f}(\mathrm{KA} / \mathrm{t})$ The rate at the beginning of the final pump-out was assumed to be equal to the rate at the completion of the liquid water removal.

Using the above assumptions, the time drying relationship of Fig. 1 was generated: 


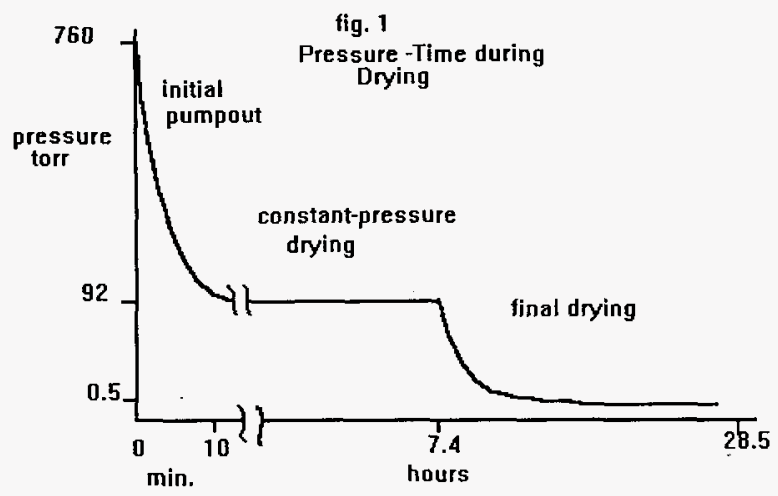

A. Initial pump down to 92 torr: based on a 750 liter cask volume, 20 feet of one inch tubing with two right angle elbows and a right angle valve. The initial pumping requires 10 minutes with a constant water vapor gas load of 500 torr liters/second.

B. Constant pressure drying: with pressure at 92 torr and sufficient heat transfer to maintain water surfaces at $50 \mathrm{C}$, the water removal rate is four pounds per hour. Assuming a total initial water load of $30 \mathrm{lb}$., the time required to remove all the surface water is 7.4 hours.

C. Final pump-out: using the program assumption of an inverse time/offgassing rate, and setting the off-gassing rate at one hour to 5 torr liters/ sec, a pumpdown to 0.5 torr was determined to require 21 hours. The validity of the assumed off-gassing/time relationship is probably pessimistic because this assumption is usually applied in the high vacuum pressure range.

The total pumping time is estimated to be $28 \mathrm{hrs}$. However, the following points suggest that a faster time (less than $24 \mathrm{hrs}$ ) can be achieved:

The rate is thought to be pessimistic The off-gassing rate of 5 torr liters/second results in a smooth transition from the constant pressure drying phase.

If reaction rate calculations prove to be satisfactory the temperature may be raised above $50^{\circ} \mathrm{C}$. This will raise the off-gassing rate. 
Purge cycles have not been included. The addition of purge cycles may improve the time.

INEL test work can be used in the future to adjust the input parameters so that the predicted results can be fit to the test data. The resulting parameters can then be adjusted to reflect the similar conditions expected in the K-Basin CVD process. 
Calculations

Appendix A

\section{Evaporation Rate}

Two models were considered: the first ${ }^{1}$ is the "Land Pan" which predicts the rate in inches/day from a warwe surface exposed to the atmosphere. The second model ${ }^{2}$ approximates isothermal evaporation from a surface and subsequent diffusion through a stagnant air layer.

a. Land Pan Approximation
$\mathrm{E}=(.7)(.37+.0041 \mathrm{u})\left(\right.$ Ps-Pw) $_{\text {where }} 88$

$\mathrm{E}=$ rate in inches/day

$\mathrm{P}_{\mathrm{S}}=$ sat. vapor press in. $\mathrm{Hg}$

$\mathrm{P}_{\mathrm{W}}=$ vapor press ambient, in. $\mathrm{Hg}$

$(.7)=$ pan coefficient

$\mathrm{u}=$ air motion, miles/day

$E=(.7)(.37+.0041)(240)(3.6-0) .88$

$\mathrm{E}=3 \mathrm{inches} / \mathrm{day}=.65 \mathrm{lb} / \mathrm{ft} 2 \mathrm{hr}$

fpr $500 \mathrm{ft} 2 ; m=330 \mathrm{lb} / \mathrm{hr}$

b. Diffusion Model

$\mathrm{m}=(\mathrm{DpMA} / \mathrm{RT}(\mathrm{x} 2-\mathrm{x} 1))(\ln (\mathrm{Pa} 2 / \mathrm{Pal})$

where $\mathrm{D}=$ diff $\operatorname{coef}=.256 \mathrm{~cm} 2 / \mathrm{s}$

$\mathrm{P}=\mathrm{atm}$ press $=1.0132 \times 105 \mathrm{~N} / \mathrm{M} 2$

$\mathrm{Pal}=\mathrm{P}-\mathrm{P} w \mathrm{l}=1.0132-.124=8.8 \times 104$

$\mathrm{m}=\mathrm{A}(2.37 \times 10-4) \mathrm{kg} / \mathrm{sec}$

$\mathrm{Pa} 2=\mathrm{P}-\mathrm{Pw} 2=1.0132-0=1.0132 \times 105$

$\mathrm{m}=86 \mathrm{lb} / \mathrm{hr}$

2 Moisture Removal Rate

With a $30 \mathrm{cfm}$ purge entering the $\mathrm{MCO}$ at $0 \% \mathrm{RH}$ and exiting saturated at $50 \mathrm{C}$, the moisture removal rate is:

$\mathrm{m}=$ density $\times$ Flow Rate

density $=\mathrm{P} / \mathrm{RT}=0.0045 \mathrm{lb} / \mathrm{At} 3$

$\mathrm{m}=0.0045 \times 1800=8.2 \mathrm{lb}$. hr.

For the case considered, the flow rate limits the moisture removal. For a vacuum pump with the same flow rate, the moisture removal rate is the same.

${ }_{2}^{1}$ Heat Transfer, J P Holman, 4th Ed. McGraw Hill, 1976, pg. 483

" " " " " pg. 430 
WHC-SD-SNF-CRD-003, Revision 0

Attch 5

\author{
Appendix B \\ Manufacturer Data Sheets (deleted due to trademark)
}

1 of 1 
WHC-SD-SNF-CDR-003, Revision 0

ATTACHMENT 6

INTEGRATED TEST PLAN

for the

COLD VACUUM DRYING SYSTEM

of the

K BASIN SPENT NUCLEAR FUEL PROJECT

Page $i$ 
WHC-SD-SNF-CDR-003, Revision 0

INTEGRATED TEST PLAN

for the

COLD VACUUM DRYING SYSTEM

of the

K-BASIN SPENT NUCLEAR FUEL STORAGE PROJECT

\subsection{SCOPE}

This test plan describes the tests to be performed on the CVDS, part of the SNF Project at K Basin. Included are responsibilities, personnel, data recording, and reporting requirements.

\subsection{DOCUMENTATION}

TBD

\subsection{ACCEPTANCE TESTS REQUIREMENTS}

\subsection{Description of Tests}

Three classifications shall be used to identify the tests conducted on the CVDS. The first test to be conducted shall be identified as the Installation Verification Test. This test shall verify that all signal, control, and power wiring installed by the contractor shall perform its intended function. Piping, valves, pumps, and instrumentation shall be compared to installation drawings to verify the correctness of flow paths, and, where applicable, the direction of components.

The second test to be conducted is classified as a Static Test. All process lines and components will be leak-tested, and then, an end-to-end demonstration of the control system performed. Each component shall be operated from a control panel command, and the proper function verified manually. This includes all remotely operable valves, pumps, and conditioning equipment, such as heaters and chiller/dryers.

The third system test shall be the Dynamic Test. This test shall demonstrate the successful operation of the vacuum pump, purge gas recirculation pump, MCO cask temperature conditioning pump, and all heaters, chillers, dryers, temperature, pressure, and flow instrumentation. Flow pressure and temperature characteristics 
WHC-SD-SNF-CDR-003, Revision 0

shall be shown to be within specified tolerances. The test will confirm the readiness of the CVDS to perform an MCO drying operation but will not entail cask drying.

\subsection{Location of Tests}

\subsubsection{Contractor's Facility}

Portions of the three tests described in paragraph 3.1 may be performed at the contractor's facility prior to delivery to the CVDS. These preparatory tests will not replace or substitute for the complete test at the CVDS.

\subsubsection{On-Site Testing}

Subsequent to installation of the multi-station drying station at the CVDS, the contractor shall perform the tests described herein on each of six facility drying stations (CVDSs).

\subsection{Test Director}

The contractor's project leader responsible for construction and testing the CVDS shall assign a test director for each of the tests. This person shall be responsible for directing and coordinating all activities associated with the test.

When vacuum pumps, blowers, or like equipment are to be exercised, the appropriate CVDS system designer shall be available to advise on the proper configuration of the system prior to energizing said equipment.

\subsection{Installation Verification Tests}

The installation of all wiring and 1 \& $C$ equipment shall be visually inspected to verify its compliance to design drawings and workmanship standards. Insulation resistance and continuity measurements of all wiring installed by the contractor shall be performed. All piping shall be visually inspected to assure conformance with $P$, I \& $\mathrm{C}$ drawings. Flow paths shall be traced, and blowers, valves, and circulators shall be checked for proper locations and direction of flow; instrumentation shall be visually checked for proper installation and location.

\subsection{Static Tests}

The correct functioning of components, controls, and instrumentation will be tested in a sequenced operation of each component. Where instrumentation is directly related to a component, as in thermocouples installed on a heated length of process piping, the thermocouple response shall be noted as the heater is energized. Valves will be remotely activated as applicable and their operation confirmed 
WHC-SD-SNF-CDR-003, Revision 0

visually. Position indicators will be read and adjusted to read correctly. Pumps and circulators will be activated, and operation verified by observing pump motor operation and, where possible, direction of rotation. Prior to this step, the system configuration will be reviewed with the CVDS system designer to preclude operations which may damage the component, such as blanking off a water pump. Pressure and flow instrumentation will be checked for operation and polarity by pressurizing the various flow loops with inert gas to cause an indication on the transducers. Upon completion of the inert gas positive pressure test, the several flow loops will be leak-checked using positive pressure and soap film or, in the case of vacuum lines, helium gas applied externally to the evacuated system to which a helium leak detector is connected. Blanking of certain connections to the MCO and cask annulus is required to accomplish the leak checks. Any components or transducers which cannot be exercised due to system constraints will undergo a wiring check from the component or transducer to the control panel. The connector closest to the item in question will be disconnected and an appropriate signal applied to the leads to stimulate a response at the control panel. An example of this situation is a vacuum transducer whose appropriate pressure range will not be realized until full system operation.

\subsection{Dynamic Tests}

This test will demonstrate the readiness of the CVDS to begin MCO drying operations. The system will be completely configured except that the MCO and shielding will not be in place. As vacuum inlet and exhaust connections to the MCO and shielding will not be in place, these connections will be "jumped" or a "dummy" vessel will be utilized so that flow paths may be established. Each of the flow loops will be activated after being filled with the appropriate fluid, and pumps, circulators, heaters, and the refrigerated dryer will be operated for a time period sufficient to show design compliance. Flow rate for the purge blower and cask water circulator will be measured; atmospheric pressure flow rate and blank-off pressure for the vacuum pump will be recorded. Thermocouples will be compared with closest adjacent transducers during heating; flowmeters and pressure gauge indications will be recorded. The only components not determined to perform within limits during this test are transducers installed directly on the MCO or shielding. The circuits for these devices will have been checked during Static Testing, paragraph 3.5 .

\subsection{TEST DOCUMENTATION}

\subsection{Acceptance Test Procedure}

A test procedure shall be written to conduct the tests required by this plan and shall be approved by HNL management. The equipment used for these tests and the results of each test performed shall be documented on the test procedure or its data 
WHC-SD-SNF-CDR-003, Revision 0

sheets. The completed procedure and its data sheets shall be dated and signed by the test personnel and the test conductor. A Test Planning meeting shall be held prior to the start of each test and also at the beginning of each work shift to discuss the approved procedure, and to familiarize each member of the test team with the objectives and his/her role in the performance of said tests.

\subsection{Acceptance Test Report}

A test report shall be written within two weeks following completion of the test. The report for the Verification Test and the Static Test shall be combined; a separate report shall be prepared for the Dynamic Test. The system's hardware and control system shall operate to the design and operational requirements before the CVDS can be declared operational. Prior to the CVDS being allowed available for operation, these ATRs shall be accepted and signed by HNL management.

\subsection{DEVELOPMENT TEST PLAN FOR VACUUM DRYING SYSTEM}

\subsection{Purpose of Test}

The purpose of this test is to evaluate the suitability of a rotary scroll pump as the primary vacuum pump for the CVDS. The question of suitability arises because the intended usage of the pump involves long periods of pumping primarily water vapor. Because the compression of water vapor causes condensate to form within the pump chamber, the inlet vapor will be heated to $100^{\circ} \mathrm{C}$ or higher to avoid this. This temperature exceeds the manufacturer stated limit for the pump of $40^{\circ} \mathrm{C}$; however, it is not clear what the basis for this limitation is. The pump supplier has expressed confidence that pre-heating the vapor will not compromise pump reliability and has offered to accept the return of the pump at no charge should this not be the case. The purpose, restated, is to confirm the ability of a commercial rotary scroll pump to pump superheated water vapor for a long time duration at a compression from 92 torr to approximately 760 torr (local atmospheric pressure).

\subsection{Description of Test Apparatus}

The test apparatus will consist of a $17 \mathrm{cfm}$ rotary scroll pump connected to a water vapor generating supply tank maintained at $50^{\circ} \mathrm{C}$. Interconnecting line from the pump inlet to the heated supply tank is one inch in diameter and ten to twenty feet in length. The line is heated and insulated so the superheated vapor can be controlled to 100 to $120^{\circ} \mathrm{C}$ at the pump inlet. The water surface area, heater size and thermal paths in the supply tank are sufficient to support an evaporation rate of $17 \mathrm{cfm}$ at $50^{\circ} \mathrm{C}$. The supply tank is replenished by a water supply controlled by a float valve or a liquid level controlled valve capable of maintaining a constant supply tank water quantity. The water replenishment rate of the supply tank will be 
measured and integrated to determine the equivalent drying rate: temperature transducers in the tank, line, and on the pump body are sufficient to define the thermal environment. Pressure data will be maintained at the supply tank and at the pump inlet. The pump exhausts to a facility line capable of self-draining accumulated condensate.

\subsection{Test Procedure}

A. Connect the pump, heated line, heated water supply tank and instrumentation as described in paragraph 5.2.

B. Heat the supply tank to $50^{\circ} \mathrm{C}$ and the supply line to $100^{\circ} \mathrm{C}$.

C. Open the water supply to the heated tank; ascertain the correct operation of the float valve or level controlled valve.

D. Confirm that temperature and pressure transducers are operating and begin recording data.

E. Turn on the rotary scroll pump; allow pressures and temperatures to equilibrate. The supply tank pressure should approximate saturation vapor pressure at $50^{\circ} \mathrm{C}$, or 92 torr. If this is not the case, the surface area, heat input, or thermal coupling of the tank are not sufficient. Raise the temperature of the supply tank until a supply pressure of 92 torr is attained.

F. Maintain the conditions of number 5. For 60 days: maintain a record of equivalent drying rate, pump case, supply line and pump inlet temperatures, and supply tank and pump inlet pressures. Note any change in pump characteristics: noise, current draw or apparent pumping speed.

G. This concludes the evaluation of the rotary scroll pump.

\subsection{Presentation of Results}

A. Data Presentation

Plots will be prepared showing the variation of drying rate, temperature, and pressure as a function of time.

B. Test Report

A report will be prepared which evaluates pump performance on the basis of pumping speed at the beginning and for the duration of the test program. 
WHC-SD-SNF-CDR-003, Revision 0

Should the pumping speed be satisfactory at the beginning and not decrease by more than $10 \%$ during the program, the pump will be judged satisfactory for the intended application. 
WHC-SD-SNF-CDR-003, Revision 0

\section{ATTACHMENT 7}

\section{OPERATIONS AND MAINTENANCE PHILOSOPHY}

for the

COLD VACUUM DRYING SYSTEM

of the

K BASIN SPENT NUCLEAR FUEL PROJECT 
WHC-SD-SNF-CDR-003, Revision O

\section{OPERATIONS AND MAINTENANCE PHILOSOPHY}

for the

COLD VACUUM DRYING SYSTEM

of the

\section{K-BASIN SPENT NUCLEAR FUEL STORAGE PROJECT}

\subsection{INTRODUCTION}

The purpose of this document is to set forth operating and maintenance philosophies to guide the CVDS design and operations planning process. In the modern DOE nuclear facility project environment, the transition from the engineering/construction phase of the project to operations is critical to project success. It is essential that this transition be planned, that safety documentation including a SAR and TSRs are complete when needed, that operations testing procedures be written, that staff is hired and trained before while construction is ongoing so that they are ready to take the reigns when the facility is ready, and that an appropriate Operations Readiness verification process as required by DOE 5480.31 and guided by DOE STD-3011 is completed smoothly. This philosophy document is a first step in the process of planning for operations.

The operations and maintenance philosophy for the CVDS should reflect the following facts about the facility:

A. The facility is a nuclear facility. It must be operated with the rigor and controls normally associated with a nuclear facility. Only qualified, trained radiation workers shall be allowed into the facility. Workers will wear protective clothing. There will be personnel radiation monitoring programs. Areas of potential contamination or radiation fields will be specially controlled, etc.

B. The radiation does of a given worker will be administratively controlled to 500 mrem per year per HS RCM-1.

C. The active processing life of the facility is scheduled to be two years.

D. The project is schedule driven. Payment is determined by meeting work-off milestones. Lost time for responding to abnormal drying conditions or results, and for repairing essential components must be minimized. The design team needs to attempt to plan for the most likely upsets and incorporate "work arounds" into the design process. 
WHC-SD-SNF-CDR-003, Revision 0

\subsection{INDEPENDENCE OF OPERATIONS IN THE CVDS}

The CVDS will be designed to have independent process bays that will allow for the drying of more than one MCO simultaneously. Each bay will have its own ventilation system, its own drying system, and its own control station in the control room. Redundancy of key components should be a design strategy, where a central service feeds all bays (chilled water for example) so that its failure could potentially take the entire facility out of service for a duration greater than a single shift. The decision driver during design of the facility regarding provision of redundant components should be consideration of lost process time.

\subsection{EQUIPMENT SELECTION AND DEVELOPMENT}

The drying process equipment will be a collection of common commercial components arranged on a skid, connected by pipes and conduits. The equipment should be selected for operations in a radiation field and a contaminated environment. Typical features of equipment suitable for this type of service are:

A. Minimize the use of rubbers, plastics, and polymers that degrade as a result of radiation damage.

B. Sealed equipment, with secondary seals, where contaminated leakage may occur.

C. Avoid equipment that requires oil changes or greasing.

D. Smooth, impervious surfaces that allow for decontamination.

E. Easy replacement (as opposed to repair in place) - flange or union connections, clamp hold-downs, electrical and signal cable plugs, etc.

F. Sealed bagging schemes should be utilized where regular change-outs will be required - MCO connectors, filters.

G. A high degree of reliability should be required. Mean time between failure data should be requested from potential component vendors. The goal will be to assure that all components have at least a $90 \%$ likelihood of operating for two years without a failure.

The equipment arrangement on the skids should allow for easy accesses to components. Clearances should be checked during the detail design to assure that reasonable paths for component access and removal exist, that allowance has been made for bags and tents that may be used to limit the spread of contamination when a component is being used, and that lifting aids can access the maintenance activity 
when a component may be too heavy to be lifted manually. Items requiring frequent access, such as filters should be located conveniently near an outer edge of the skid. Shielding that may surround some components (filters for example) should be modular and should be easily moved or swung out of the way (hinged).

Equipment should be selected to minimize manual operation or verification. A primary design goal is to minimize the presence of staff in the drying bays where they may be exposed to radiation. The operation and status monitoring of the drying system and components should be accomplished from a remote control room. Sensor failure and repair is a potential negative impact that must be considered as the design is developed.

The process equipment system should contain radiation monitors for points in the system where radioactive material may accumulate, such as filters and the water collection tank. These monitors should be used to determine when filters are to be changed or when the tank is to be emptied.

The process system shall contain features, such as an internal wash down that will allow for management of radioactive material accumulation.

An important goal is to limit the spread of radioactive contamination to the maximum extent possible. Ideally all contamination would be trapped in the MCO or within the first few feet of process line immediately above the MCO. Filters are to be installed to accomplish this goal. Contamination may be released and spread when MCO connections are made and broken. A connection design that incorporates an operations within a bag technique are to be implemented to contain potential releases. The top of MCO equipment package should include a hood that will collect any contaminated air that may be present in the area.

Ventilation system HEPA filters that may become contaminated shall include a bagin/bag-out filter changing system that will allow filter changes without release of contamination and without shutting down the ventilation system. HEPA filters will be equipped with DOP test capability so that their efficiency can be certified while in operation.

\subsection{RADIATION SAFETY AND EXPOSURE CONTROL}

The administrative radiation exposure limitation for the CVDS will be 500 mrem per individual per year. Preliminary exposure estimates suggest that this can be achieved provided that a number of design and operations actions are taken. First, the proposed operations activity list requires scrubbing to eliminate steps that may be redundant (ie, receiving cask/MCO contamination survey) as well as scrubbing to investigate steps that may be taken to reduce time estimates or crew size estimates. Detailed operations recipes need to be written for each activity to assess whether it is reasonable to reduce exposure estimates. Second the detailed design 
needs to incorporate some additional shielding between bays and in the operating deck floor. Third, a manual manipulator extending the operator's reach is required at the top of the MCO. Fourth, the operations staff must be thoroughly cross trained so that they can be rotated among all the jobs in the facility. Fifth, the operations scheduling must distribute the steps where doses are received among all shifts and days uniformly (in other words an MCO received on Friday evening may be held until Saturday afternoon so that the dose loading of all staff is uniform).

In order to promote cross training of staff so that they can perform several functions, the design should attempt to minimize actions requiring decisions or actions by the staff. The use of Process Logic Controller software and simplified user friendly control screens are techniques to be used to reduce dependence on specialized training. The implementation of a human factors engineering program in the detailed design (as required by DOE 6430.1A) can also contribute to increasing operator flexibility.

The radiation area requiring special access control shall be limited to a small area on the upper mezzanine near the top of the MCO. The design should provide appropriate support gear and access control for this area. The design should preclude the spread of contamination into other areas in the process bays.

The following radiation safety features will be provided in the CVDS to aid in operating the facility:

\subsection{Respiratory Protection}

Equipment Certification. The facility shall be capable of providing respiratory protection equipment that is tested and certified or had certification extended by the National Institute for Occupational Safety and health/Mine Safety and health Administration (NIOSG/MSHA) or equivalent.

10 CFR 20.1703(a)(1), (2)

\subsection{Respiratory Protection Program}

The facility shall be capable of providing air sampling sufficient to identify the potential hazard, permit proper equipment selection, and estimate exposures; surveys and bioassays, as appropriate, to evaluate actual intakes; testing of respirators for operability immediately prior to each use; and training of personnel. 10 CFR 20.1703(a)(3)

\subsection{Respirator Use}

The facility shall be capable of providing equipment within limitations for type and mode of use and provide proper visual, communication, and other special capabilities (such as skin protection) when needed.

10 CFR 1703(a)(6) 


\subsection{Emergency Respiratory Protection}

The facility shall be capable of providing as emergency devices only respiratory protection equipment that has been specifically certified or had certification extended for emergency use by NIOSH/MSHA.

10 CFR 20.1703(c)

\subsection{Radiological Alarm System}

Radiological alarm systems shall be provided in accessible work areas as appropriate to warn operating personnel of radiation and airborne radioactive material concentrations above a given setpoint and of concentrations of radioactive material in effluent above control limits.

10 CFR 72.126 (b)

Radiation alarm systems shall be designed with provisions for calibration and testing their operability.

10 CFR 72.126(a), (b)

Setpoints shall be established to ensure that exposures are kept below the allowable limits.

10 CFR 72.126(a), (b)

\subsection{Direct Radiation Monitoring}

Areas containing radioactive materials shall be provided with systems for measuring the direct radiation levels in and around these areas.

10 CFR 72.126(c)(2)

The facility shall provide capability to monitor the external surfaces of a package known to contain radioactive material for radioactive contamination and radiation levels if the package is labeled as containing radioactive material; or has evidence of potential contamination, such as packages that are crushed, wet, or damaged. 10 CFR 20.1906(b)

The facility shall provide the capability to perform monitoring required as soon as practicable after receipt of the package.

10 CFR 20.1906(c)

Transferring of special form sources in DOE-owned or DOE-operated vehicles within the facility shall be exempt from the contamination monitoring requirements of paragraph B except for the survey requirement in paragraph B for measuring radiation levels that is required to ensure that the source is still properly lodged in its shield. 
10 CFR $20.1906(f)$

\subsection{Effluent Monitoring}

The facility shall monitor the amount of radionuclides in effluents during normal and off-normal conditions.

10 CFR 72.126(c)(1)

Systems designed to monitor the release of radioactive materials shall have means to calibrate and test their operability.

10 CFR 72.126(d)

\subsection{Airborne Radioactive Material Control}

The design of the facility shall use, to the extent practicable, process or other engineering controls (e.g., containment or ventilation) to control the concentrations of radioactive material in air.

10 CFR 20.1701

When it is not practical to apply process or other engineering controls to control the concentrations of radioactive material in the air to values below those that define an airborne radioactivity area, the design of the facility shall, consistent with maintaining the total effective dose equivalent ALARA, have the capability to increase monitoring and limit intakes by: control of access, limitation of exposure times, use of respiratory protection equipment, or other controls. 10 CFR 20.1702

\subsection{Personnel Dosimeters}

The facility shall provide capability for processing and evaluating all personnel dosimeters that require processing to determine the radiation dose, and that are used by the facility to comply with 10 CFR 20.1201 or with conditions specified in the facility license. this capability does not apply to direct and indirect reading pocket ionization chambers and those dosimeters used to measure the dose to the extremities.

10 CFR 20.1501(c)(1), (2)

\subsection{Shielding and Protective Clothing}

Normally Occupied Areas. The shielding design basis shall limit the maximum exposure to an individual worker to one-fifth of the annual occupational external exposure limits. Within this design basis, personnel exposures must be maintained ALARA. Specifically, the shielding must be designed with the objective of limiting the total EDE (Effective Dose Equivalent) to less than one rem per year to workers, based on their predicted exposure time in the normally occupied area. The EDE is 
WHC-SD-SNF-CDR-003, Revision O

the sum of all contributing external penetrating radiation (gamma and neutron). In addition, appropriate shielding must be installed, if necessary, to minimize non penetrating external radiation exposures to the skin and lens of the eye of the worker. In most cases, the confinement barrier or process equipment provides this shielding.

DOE Order $6430.11300-6.2$

Intermittently Occupied Areas. Shielding and other radiation protection measures shall be provided for areas requiring intermittent access, such as for preventive maintenance, component changes, adjustment of systems and equipment, and so forth, so that the projected dose rates based on occupancy, time, and frequency of exposure do not exceed one rem per year.

DOE Order 6430.1 1300-6.2

Concrete radiation shielding design shall comply with ANS 6.4 and $\mathrm{ACl} 349$ where it provides a critical confinement or structural function.

ANSI/ANS $6.4 \mathrm{Sec} .1$

$\mathrm{ACl} 349$ Pt. 1 Sec. 1.1

DOE Order $6430.11300-6.2$

Concrete radiation shielding design shall consider the material specifications of ANS 6.4.2 where it provides a critical confinement or structural function.

ANSI/ANS-6.4.2 Sec. 1

DOE Order $6430.11300-6.2$

$\mathrm{ACl} 318$ shall be considered for radiation shields, used for other than critical confinement or structural function, since $\mathrm{ACl} 318$ is appropriate and provides adequate strength for design earthquake (DE) loads.

ANSI/ACI-318 Pt. 1 Sec. 1.1.1

DOE Order $6430.11300-6.2$

Penetrations. Straight line penetration of shield walls shall be avoided to prevent radiation streaming.

DOE Order 6430.1 1300-6.2

\subsection{Remote Shield Operation}

Remote shielded operation (i.e., with remote handling equipment such as remote manipulators) shall be considered where it is anticipated that exposures to hands and forearms would otherwise approach the dose guidance in Section 3.2 .2 or where contaminated puncture wounds could occur.

DOE Order $6430.11300-6.3$ 
WHC-SD-SNF-CDR-003, Revision 0

\subsection{Posting}

The facility shall be posted with radiation area, contamination area, and airborne contamination area signs in accordance with federal law.

10 CFR 20.1902(a), (b), (c), (d)

\subsection{MAINTENANCE PHILOSOPHY}

Generally, and to the maximum extent possible, equipment should be selected that will not require routine maintenance during the two year processing lifetime of the CVDS. Equipment with a high degree of reliability should be chosen to reduce the likelihood of breakage. Policy such as requesting two year warranties and reviewing failure data should be instituted when selecting equipment in order to improve reliability. When repair is needed it should be accomplished by replacement of defective components (ie, pump) instead of repair in place procedures (ie. Pump bearing rebuild). Equipment system designers should recommend a spare components list to be kept on site and shouid attempt to select components that can be obtained from manufacturers in 24 hours should an emergency arise.

Maintenance or repair of contaminated items is a particularly hazardous activity because it is not a routine operation that can be included in the training program and because it involves opening a path between the contaminated equipment interior cavity and inhabited space. Provision must be made in the design anticipating the use of bags and tents for contamination control. Provision should also be made for temporary shielding and for lifting assistance.

\subsection{OPERATIONS READINESS VERIFICATION}

DOE 5480.31 requires that a new nuclear facility undergo an Operations Readiness verification process (either an ORR or ORA depending on the nature of the facility and its associated hazards). The extent of the verification process is to be determined by the nuclear safety issues associated with the facility. As argued in the Criteria Evaluation Report for the CVDS, the facility will be considered an HC-3 facility with low potential for severe accidents. Therefore, the project should seek to minimize the extent of the verification. There are three operations program activities that must be accomplished prior to initiating the verification process. First, an Operations Readiness plan must be written and approved by whatever review agency (DOE - HQ, DOE - RL, WHC) is required to certify readiness. Second, test procedures must be prepared so that the verification can be conducted. Third, staff must be trained so that they can demonstrate readiness.

The engineering team should support this process as follows: 
WHC-SD-SNF-CDR-003, Revision 0

A. Write System Design Descriptions (SDDs) with thorough operating recipes included.

B. Write the Operations Readiness Plan draft.

C. Write the test procedures.

Writing these documents in conjunction with the design development/construction will help to assure that the design has the appropriate features to support the facility operations.

\subsection{OPERATIONS SUPPORT}

The CVDS will include operations support functions for a shift supervisor office, a training room, and change rooms/bathrooms. 
WHC-SD-SNF-CDR-003, Revision 0

ATTACHMENT 8

\section{COMMENT DATABASE}

for the

COLD VACUUM DRYING SYSTEM

of the

K BASIN SPENT NUCLEAR FUEL PROJECT 
Project: WHC-SD-SNF-CDR-003 Rev 0

William J. Millsap

ITEM COMMENT

1 In the ALARA plan Include these htgh level ALARA requirement:
Document: CVD 90\% PRELIMINARY DESIGN REVIEW

ALARA Support Team

MO293/376-3676

Comment No:
STATUS

This is only a place holder and does not need to be responded to directly.

Closed
MO293/376-3676

HOLDPT RESPONSE

This is a place holder only and does not need to be responded to directly.

Comment No:

STATUS

Closed

William J. Millsap

ALARA Support Team

ITEM COMMENT

1.1.a 10 CFR 835 Occupational Radiation Protection
MO2933376-3676

HOLD PT RESPONSE

No
Comment No:
STATUS

Closed 
Project: WHC-SD-SNF-COR-003 ReV 0

Document: CVD 90\% PRELIMINARY OESIGN REVIEW

Williarn J. Millsap

ALARA Support Team

MO293/376-3676

Comment No:

ITEM COMMENT

HOLD PT RESPONSE

STATUS

1.1.b HS RCM-1 Rev.2 Hanford Site Radiological Control Manual

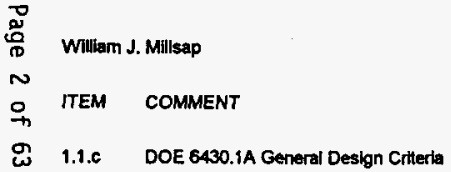

ITEM COMMENT

1.1.d WHC-IP-1043 Occupational ALARA Program
HOLD PT RESPONSE

Accepted; Include in Design Requirements
STATUS

Closed 
Project: WHC-SD-SNF-COR-00.3 Rev 0

William J. Millsap

ALARA Support Team

ITEM COMMENT

1.1.e DOE 5400.5 Radiation Protection of the Public and the Environment

ALARA Support Team

号

$\omega$

$\stackrel{\circ}{\rightarrow}$

w
Document: CVD 90\% PRELIMINARY DESIGN REVIEW

MO293/376-3676

Comment No:

HOLD PT RESPONSE

STATUS

No

Accepted; Inciude In Design Requirements
M0293/376-3676

Comment No:

HOLD PT RESPONSE

Accepted; Include in Design Requirements

\section{ITEM COMMENT}

1.2 In particular, the requirements of 10 CFR 835 Subpart K: Design and Control; shall be

satisfied. Furthermore; the design objective for external exposure for the CVD shall be that no individual worker shall receive an annual dose equivalent in excess of 1 rem/year from all sources including bay-to-bay.
HOLDPT RESPONSE

STATUS

No Accepted; Include In Design Requirements, DOE N5480.6 calls for 0.5

Closed 
ITEM COMMENT more important than doliar evaluation.

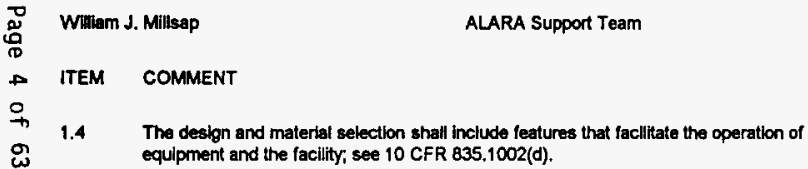

\section{Whilian J. Millsap}

ITEM COMMENT

1.5 The desion and material selection shall Include features that facilitate maintenance of equipment and the facility, see 10 CFR 835.1002(d). Particular attention shall be paid to pumps; valves and any equipment in high and very high radiation areas.
MO293/376-3676

Comment No:

MOLD PT RESPONSE

No

Accepted; Include In Design Requirements
MO293/376-3676

HOLD PT RESPONSE
Comment No:
No

Accepted; Include in Design Requirements; it should be noted that no high radiation or very high radiation areas are anticipated.
STATUS

STATUS

Closed

Closed 


\section{ITEM COMMENT}

1.6

The design and material selection shall include features that facilitate decommissioning of equipment and the facility, see 10 CFR 835.1002 (d). Particular attention shall be paid to any equipment in high and very high radiation areas that will exist at the end of the facilitys life.

\author{
Wralam J. Millsap \\ ALARA Support Team \\ ITEM COMMENT \\ 1.7 All (designer) actions and declsions taken to maintain occupational exposures as low as \\ reasonably achlevable shall be documented; see 10 CFR 835.704 (b). These records shall

HOLD PT RESPONSE

STATUS

\section{Accepted; Include in Design Requirements; it should be noted that no high radiation or very high radiation areas are anticipated. The design shall utilize materials that will allow for standard contamination cleantip} procedures.

\section{ITEM COMMENT}




\section{ITEM COMMENT}

3. An area radiation monitoring system shall be provided. It shall be the same system provided for other SNFP facilities to be built. The system selection shall be approved by WHC Radiological Controls.

\section{ITEM COMMENT}

All piping that will carry contaminated nulds shall be made of stainless steel; shall have smooth radius bends; and shall minimize the number of bends. The pipes shall have hydrolasing ports in accordance with the attached eriterta; the ports will be located in the lowest radiation areas practical and shall have room to accommodate hydrolasing. The number of low points in the piping systems shall be minimized and drains shall be provided at all low points.

\section{HOLD PT RESPONSE}

No

Agree, Conceptual Design indicates portal monitors. Other details of the system will be added in the detailed design. The radiation monitors are described in the Preliminary Report Section 3.7.1.1. WHC Radiological Control will be given the opportunity to approve the monitoring specification through the standard WHC porject review.

\author{
MO293/376-3676
}

Comment No:
STATUS
HOLD PT RESPONSE

\section{All piping will be SIS smooth bends, electro polished Interlor, etc. to facilitate decontamination. Decontamination detalis will be addressed in th detailed design.}

M0293/376-3676

HOLD PT · RESPONSE
Comment No:

\section{ITEM COMMENT}




\section{ITEM COMMENT}

6. Any building concrete that can become contaminated shall be sealed with materlal which is smooth and essentially Impermeable to radioactive material so that it can be readity decontaminated. An acceptable coating material is Bio-Dur.

\section{HOLDPT RESPONSE}

STATUS
Agree, decontaminatable coatings will be shown and specificed during the detalled design.
MO293/376-3676

HOLDPT RESPONSE

Comment No:

Vertical wall surfaces within the process bays shall recelve protective coatings to a height of $4^{-}-0^{\prime \prime}$ above first lloor level since the only anticipated contamination is liquld on the floor.
Any building walls that can become contaminated shali be sealed to a height of at least 4 feet with a material which is smooth and essentially impermeable to radioactive materlal so that is can be readily decontaminated. Areas which might become contaminated at higher than 4 feel shall be coated 4 feet above the potential level of contamination.
William J. Millisap

ALARA Support Team

ITEM COMMENT

8. A leak collection system shall be included in the building and equipment design.

\section{No}

MO293/376-3676

HOLD PT RESPONSE
No
A leak collection system was included in the facility as stated in the preliminary Report Section 3.5.2 and shown on plan SK-1-80168. The plan and description will be enhanced.

STATUS

Closed 


\section{ITEM COMMENT}

9. A leakage detection system which alarms in the CVD control room shall be Installed.

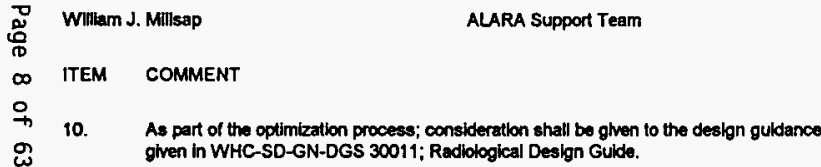

\section{Willam J. Millsap}

ALARA Support Team

\section{ITEM COMMENT}

11. Lighting in any areas that might become high radiation areas or very high radiation areas shall be of the long-life type and shall be designed to be changed with minimum radiation dose. The lighting in radiation and high radiation areas shall be sufficient to support any needed activities.

\section{HOLD PT RESPONSE}

STATUS

A leak detection system was Included In the design as stated in the Preliminary Report Section 3.7.1.3. An expanded description of leak detection, liquid efiluent monitoring will be included.

MO293/376-3676

HOLD PT RESPONSE

Comment No:

STATUS

Closed

MO293/376-3676

HOLDPT RESPONSE
Comment No:
No

$$
\text { Agree, Paragraph } 3.6 .7 \text { on page } 43 \text { of } 49 \text { in tho Facility Design section }
$$
currently discusses the intended interior lighting design.
STATUS 
Project: WHC.SD-SNF-CDR-003 Rev 0

William J. Milisap

ALARA Support Team

ITEM COMMENT

12. Eiectrical outlets shall be readity avallable throughout the facility to support portable air samplers; temporary video systems; and portable ventilation systems.

ALARA Support Team

ITEM COMMENT

If 13. A communication method with the control room is required.

Wullam J. Millsap

ALARA Support Team

\section{ITEM COMMENT}

14. Access control for high and very high rad areas shall be in compliance with the requirements of HS RCM-1; Rev.2
MO293/376-3676

Comment No

HOLDPT RESPONSE

STATUS

Agree, Paragraph 3.6.2 on page 40 of 49 in the facility design section currently discusses the intended interior receptacle design.

Closed
MO293/376-3676

HOLDPT RESPONSE

No

\section{Agree, Paragraph 3.7.4.2 on page 47 of 49 in the facility design section} curtently discusses the Intended communication system design
MO293/376-3676

HOLDPT RESPONSE
Accepted; Include in Design Requirements; it should be noted that no high radiation areas or very high radkation areas are expected. Paragraph 3.7.3

on page $\mathbf{4 6}$ of $\mathbf{4 9}$ in the facility design section currently discusses the

intended security design. The wording to comply with the requirements of HS RCM-1, Rev. 2 will be added to this section. 
ITEM COMMENT

15. The collection tanks shall be designed to slope toward the center of the bottom of the lank Where the drain point shouid be. Any baffles shall be designed so that they can be fushed and minimize crud trapping. Service life of any components on the interlor of the tanks

shall be the same as the facility service life. Each tank shall have an integral spray system

shall be the same as the facility service life. Each tank shall have an integral spray system
for flushing. The interior finish of the tanks shall be smooth and essentially impermeable to

radioactive material. The tanks shall have high level cutoffs. All tanks shall have lifting

lugs. All connections to the tanks shall be throughout the top of the tank. Any tank vent

shall be through double-stage HEPA filters.

\section{ITEM COMMENT}

16. The collection tank room shall be ventilated to maintain negative pressure; shlelded as

o required; and capable of containing the entire contents of the tank if the tank leaks.
HOLD PT RESPONSE
William J. Millisap

ALARA Support Team

ITEM COMMENT

17. If weiding is to be done in the CVD; this decision needs to be made soon. This activity will have a significant Impact of the radiological design.
M0293/376-3676

Comment No: 
Project: WHC-SD-SNF-COR-003 ReV 0

William J. Millsap

ALARA Support Team

ITEM COMMENT

18. Seismic restraints for the transporter; if required; need to be capable of being quickly and easily attached to minimize the exposure needed to do the task.

$$
\text { 员 }
$$

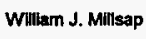

Willam J. Millsap

ALARA Support Team

\section{ITEM COMMENT}

20. We suggest separating the ventilation used to control contamination at the top of the MCO from the ventilation used to keep the bay at a negative pressure with respect to the outside.
MO293/376-3676

Comment No:

HOLDPT RESPONSE

STATUS

Accepted; Include in Design Requlrements.
MO293/376-3676

HOLD PT RESPONSE

No

Accepted; Include in Design Requirements.
Comment No:

STATUS

Closed

\section{MO293/376-3676}

HOLDPT RESPONSE
Comment No: 
Project: WHC-SD-SNF-COR-003 ReV 0

William J. Millsap

ALARA Support Team

ITEM COMMENT

21. The design of the MCO drying skid needs to be carefully optimized for operations and maintenance. There is a potential for a significant amount of activity to be transferred from the MCO to the skid. (Note: During the designer's presentation; a potential of 6 grams of sludge per assembly to be transferred to the skid was discussed. At 240 assemblies per MCO; this is 1440 grams of sludge per MCO. Recent K East floor sludge analyses show these activities for the sludge: Cs-137; 724 microCurie/g and Sr-90; 678 microCurie/g

(maximum values). This indicates a potential of about $\mathrm{Cl}$ of $\mathrm{Cs}-137$ and about $1 \mathrm{Cl}$ of Sr-90 being transferred to skd per MCO. Although the amount to material that will be transferred is speculative and the activity values are the maximums found; this simple analysis shows that there is the potential for a considerable amount of activity to be transferred to the skld.

\section{ITEM COMMENT}

22. Consideration should be given to cleaning the water and gas stream leaving the MCO i before if reaches the skd. This would reduce the contamination in the CVD system.

\section{William J. Milisap}

ALARA Support Team

ITEM COMMENT

23. Floors draining to an outside retention basin probably will not be acceptable. Perhaps should drain to a sump to sample before disposai.

\section{HOLDPT RESPONSE}

Comment accepted; filters are proposed for the gas stream but not the water stream. A feasibility study will be proposed for definitive design to address the proposed water filter.

MO2933376-3676

Comment No:
STATUS

STATUS

Closed 
Project: WHC-SD-SNF-CDR-003 Rev 0

William J. Millsap

Document: CVD 90\% PRELIMINARY DESIGN REVIEW

ALARA Support Team

ITEM COMMENT

24. Fuel cleanllness will be the main determinant of how easy the CVD system will be to operate and maintain. The SNF project should make an effort to ensure that the fue arriving at the CVD facility for processing is as free of sludge as practical.

\section{Bob V. Wnikel}

\section{ITEM COMMENT}

1. In Section 2.4.2.2 of the report; a maxdmum pressure of $25 \mathrm{psi}$ is specified for the $\mathrm{MCO} / \mathrm{Cask}$ annular space. This conflicts with the 30 psi pressure listed on page 41 for the annular space seal. You should also verify that the final pressure used in the CVDM design does not conflict with the external design pressure specified for the MCO (wall differential pressure: annulus pressure and vacuum).

\section{Bob V. Whake!}

\section{ITEM COMMENT}

2. The CVDM project position on the satety issues relative to the stablity of the transporting trailer needs to be addressed. That is; the high center of gravity of the MCO/Cask payoad ralsed abvious concerns for trailer stability, both during transporting and when parked. During transporting; the concerns include sharp turns; hard braking; and transporting during high winds. The position on the need for seismic tiedowns needs to be property oxcumented. It appears to me that when the cask lid is off; seismic tie downs would be required; especially if the MCO welding is to be done in the CVOM facility; since primary containment would not be established until the weld is completed.
No

Accepted; the $25 \mathrm{psi}$ was selected because it was less than the $30 \mathrm{pail}$ limt for the annular space; however to account for the vacuum in the MCO; a pressure of 10 psi will be used in the CVDS design.
HOLDPT RESPONSE

STATUS transporter is in the CVOS bay. Stability during transportation is the 
Bob V. Winkel

ITEM COMMENT

3.

Nothing was said on the bridge crane design criteria. As a new crane for a nuclear facility; I would expect that the crane design would have to meet ASME NOG-1. I would also expect that there is a good chance that lifting the cask and/or MCO lid would be considered to be a critical lift; requiring a type I crane (single failure-proof feature requirements). It may be that a pre-designed ASME NOG-1 type I crane is available that would meet your needs. I have seen Edderer literature advertising this type of product. You need to establish your position on this issue right away, because a custom ASME NOG-1 Type I crane may be a long-leadtime item.
MO-043/376-5736

HOLD PT RESPONSE

Comment No:

The type of crane required will be evaluated during the detailed design portion of the proiect. Once the crane type, size, and capacity has been established. Then possible vendors can be contacted for cost and availablity.

STATUS
Bob V. Winkel
$M 0-043376-5736$

HOLDPT RESPONSE

4. The tight schedule of the CVDM project requires that all criteria with potential design impect be established as earty in the design process as possible. It appears that the project posilion on natural phenomena hazards (HPH) has not been firmed up. The project position on NPH lssues (tornado winds/missiles; floods and seismic) should be documented and appropriate approvals obtained to avold later schedule Impacts. Since the CSB has been going through this process; you may be able to take advantage of the precedence set by the CSB project.

Bob V. Winkel

ITEM COMMENT

5. The selsmic critert presented in Section 3.3 has some inconsistencies. The new DOE requirements documents are referenced (DOE Order 5460.28 and DOE-STD-1020-94); which are not consistent with the Figure 1; $0.2 \mathrm{~g}$ DBE definition; which apparently was taken from SDC-4.1; Rev.12, If the CVDM project is attempting to conform to the new standards; then the new hazards curves and corresponding response spectra will need to be established for the $100 \mathrm{~K}$ area. This may not be necessary for the two year life CVDM project; but whatever the project position; it needs to be consistent.
HOLDPT RESPONSE

While the spectra shown in Figure 1 is, in fact, consistant with that shown in SDC-4.1, Rev 12, Figure 3 "Response Spectra $-0.20 \mathrm{~g}$, Non-reactor Safety Class 1", it is also consistant with the data reported in Table C-5a of DOE-STD-1020-94, where for a PC-3 SSC in the Honford 100K area, the 1993 Geomax work identifies a maximum horizontal ground surface acceleration of $0.20 \mathrm{~g}$. The spectra shown in Figure 1 (and Figure 3 of SDC-4.1, Rev 12) were developed from formulas for the determination of control points for median-centered Newmark-Hall spectra (NUREG/CR0098). The closing paragraph on page C-23 of DOE-STD-1020-94 states: "If median site-specific amplifications are available for these sites, they may be scaled by the peak ground acceleration in Table $\mathrm{C}-5$ to establish 
Bob V. Winkel

ITEM COMMENT

6. Page 8 states that PC-3 structures shall have a dynamic analysis periormed in accordance with the provisions of ASCE 4-86. Section 3 of ASCE 4-86 requires a Soil-Structure interaction (SSI) analysis. An SSI analysis normally requires both the dynamic soil properties of the foundation soils and an acceleration time history corresponding to the input spectra. If new spectra curves are generated then corresponding time histories are needed. Past $\mathrm{K}$ Basin seismic analysis has utilized dynamic soil properties from a soil boring between $100 \mathrm{~N}$ and $100 \mathrm{~K}$ (approx. mile away). This was an issue in Defense Board reviews and some very limited 100K data was obtained which was significantly different that the earlier soil properties. The project position on the need for SSI analysis and the corresponding solf properties and time history acceleratlons needs to be established before beginning the PC-3 analysis.

Bob V. Winke

\section{ITEM COMMENT}

7. The bsue of NRC Equbulency ts not discussed in the selsmic crtteria presented in Section 3.0. This appears to be inconsistent with the CSB precedence; and therelore needs to be addressed. I would expect outside reviewers to question the apparent inconsistency between the $0.35 \mathrm{~g}$ CSB DBE and $0.2 \mathrm{~g}$ DBE presented in Section 3.0 . If appears to me that you must justify seismic criteria differences between the two projects.

MO-043/376-5736

Comment No:

HOLDPT RESPONSE

STATUS 
ITEM COMMENT

2. An ALARA study is needed while it is stitl practical to implement the results of the study (before too much money is spent on detailed design). This should be added to the conceptual design phase or completed early in the detailed design phase.

\section{ITEM COMMENT}


ITEM COMMENT

5. To avoid expensive safety requirements from being placed on the facility structure it may be necessary to consider protection of the lines connected to the MCO up to the first fitter. Altemately it may be possible to argue via anatysis that significant fuel particulates Inventory will not be cartied out if the lines are damaged. The analysis would need to lake credit for small line size and/or low driving forces (vacuum transfers?); and would need to make some assumptions abolt available particulate inventory performance. Note this is fust a heads up Safety Anatysis will dictate what is needed; but we may need to help direct this in direction that everyone can live with.

\section{ITEM COMMENT}

if 1. Is there an assumption on how much sludge comes wth each MCO? Lobbying for no 点 Is there an assumption on ho
criterta on amount of sludge.

\section{ITEM COMMENT}


ITEM COMMENT

1. 21.1.5 Overall Block Flow Dlagram Description. (Also applies to Attachment ALARA implementation Plan 2.0 ALARA Princlples and 4.0 Radiation Safety Destgn. Comment: Need to address the use of a permanently installed glove bag or sleeving system to be used on the quick disconnects so that the potential for spillage of contaminated liquid is device has been successfully used to quickly seal/confine and separate contaminated hoses at ANLW for over twenty years. The radiological design concept for the building and the rooms (per the HSRMC) needs to be that the bay is a radiological buffer area when the RBA will be performed, generally using a PCM for personnel and an abbreviated (per documented survey plan) survey for equipment.

\section{Terry Merking}

SNF Salety eliminated. Heavy gauge plastic sleeving that can be heat sealed wth a hot wire sealing $M C O$ is in the bay. All other areas are clean, unrestricted areas. Surveys for items leaving a

HOLDPT RESPONSE
No Comment accepted. plastic bagging of the connections is proposed, the
details will be developed during definitlve design. As currently concleved, the bays provide the radiotogical buffer as described.
2751E/373-9412

HOLD PT RESPONSE 1.cont The radlological design concept for the building and the rooms (per the HSRCM) needs to be that the bay is a radiological buffer area when the MCO is in the bay. All other areas are clean; unrestricted areas. Surveys for ltems leaving a RBA will be performed; generally using a PCM for personnel and an abbreviated (per documented survey plan) survey for equipment. This is because the area is and remains free of removable contamination. This can be achieved through the use of engineered confinements such as sleeves/glovebags.
Comment accepted; plastic baging of the connections is proposed; the details will be developed during definitlve design. As currently concelved; the bays provide the radiologkal buffer as described.

\section{ITEM COMMENT}


Terry Merkling

SNF Safety

ITEM COMMENT

Section 3.0; 3.2.2.3; Decontamination Room and 3.2.2.4; Swipe Count Room. Comment:

Delete the words required from these two sections. The rooms are nice to have but not

required. The word required does not appear in the other CVD Bullding's room narratives.

ITEM COMMENT

4. Section 3.0; 3.2.2.3. Comment: Change drawing 80168 so that the decon room drain

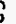

drains to the waste tank versus seantary tank.

Terry Merkiling

SNF Salety

\section{ITEM COMMENT}

$27516 / 373-9412$

Comment No:

HOLD PT RESPONSE

STATUS 


\section{Terry Merkling}

SNF Safely

ITEM COMMENT

6. Section 3.0. 3.2.3.4. Comment: Same comment as above for Counting room.
$2751 E / 373-9412$

Comment No:
STATUS

HOLDPT RESPONSE

Closed

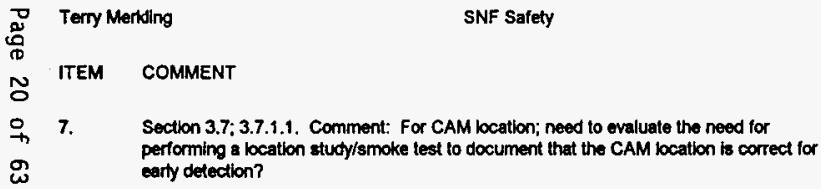

W performing a location study/smoke test to document that the CAM location is correct for early detection?

\section{E/ 373-9412}

HOLDPT RESPONSE

Comment No:

Comment accepted; the design will pick a location but it will be verifed by a smoke lest as proposed before turnover to operations. This comment pertains to an operations readiness plan to be written in the future.
STATUS

Closed

(1)

Terry Merking

SNF Safety

\section{ITEM COMMENT}

8. Section 3.7.1.2. Comment: Continuous monitoring is stated as being considered. 40 CFR 61 only requires sampling. Need to evaluate the need for alpha/beta-gamma moniloring in addition to sampling. Monitoring adds much complexity and maintenance difficulty to the process. Also; all radionuclide studies indicate that there will be no instance when you have alpha radioactivity without beta-gamma activity; thus the need for an alpha monitor should be studied if it is decided that an exhaust monitor is needed. See comment 17.
2751E/ 373-9412

Comment No:

\section{HOLD PT RESPONSE}

Comment accepted; the monitoring parameters will be further analyzed and established during definitive destgn. Agreed regarding alpha emilters. 40 CFR 61 is not necessarily the driving criteria. DOE rerquirements given in DOE $6430.1 \mathrm{~A} 1589.99 .0 .1$ must be considered as well.

\section{STATUS}


Terry Merking

SNF Salety

ITEM

COMMENT

Section 3.7.1.2. Comment: The location of the sampling probe is not stated. Need to state the location. I assume that the probe is downstream of the HEPA filters.
$2751 E / 373-9412$

Comment No:

HOLDPT RESPONSE

STATUS
Comment accepted; the location of the probe witl be downstream of HEPAs in a region of laminar flow to be selected in the detail design.

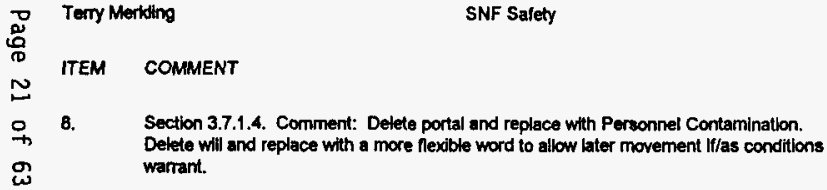

Terty Meriding

SNF Safety

ITEM COMMENT

9. Section 3.7.3.2 and 3.7.3.3. Comment: Need to address the opening of these doors so that there is sufficient interlocks so that they are not opened inadvertently while a Contamination or Off-Normal situation is occurring and the opening of the doors would/could violate confinement.

\section{HOLDPT RESPONSE}

STATUS
$27516 / 373-9412$

Comment No:
HOLDPT RESPONSE
Comment accepted; the interlocks will be addressed by the ladder logic diagrams that will be developed during definittve design. The programmable logic controllers will control door operation.
DD 
Terry Merking

SNF Safety

ITEM COMMENT

10. Appendix, Functions and Requirements. 4.0. Comment: Add 10 CFR 835; Occupational

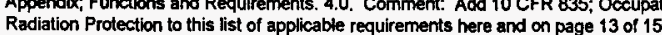
Change five to six. Delete reference to 10 CFR 835 on page 15 of 15 as a reference source.
2751E/ 373-9412

HOLD PT RESPONSE

Comment accepted, will be incorpotated
Comment No:

STATUS

Closed

$2751 \varepsilon / 373-9412$

Comment No:

HOLD PT RESPONSE

STATUS

No

Comment accepted, will be incorporated

Closed
11. Appendibc F\&R; page 9 of 15; A. OOE Regulations. Comment: Move this namative on 10 CFR 835 to Section 4.0 as discussed above.

Terry Merking

SNF Safety

ITEM COMMENT

12. Appendbr, ALARA plan. Third paragraph. Comment: Delete DOE Order 5480.11 and insert HSRCM in its place. Order. 11 has been discontinued.
2751E/373-9412

HOLDPT RESPONSE

Comment No:

No Comment accepted; revision will be made as suggested. To the best of our knowledge DOE 5480.11c has not been discontinued. It is analogous to 10 CFR 20. An Internet Site of active DOE Directives is maintained on the ANL server. DOE $5480.11 \mathrm{C}$ is still in this directory. 
5

喜

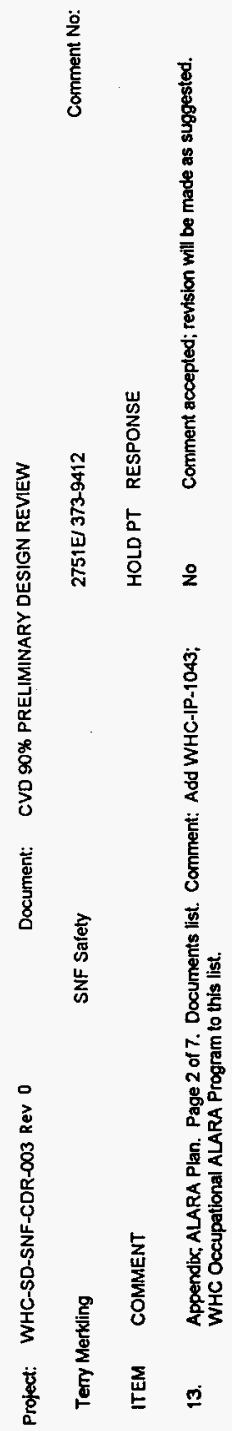

8

$\begin{array}{ll}\stackrel{5}{2} & 8 \\ 5 & 8 \\ 5 & 8\end{array}$

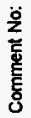
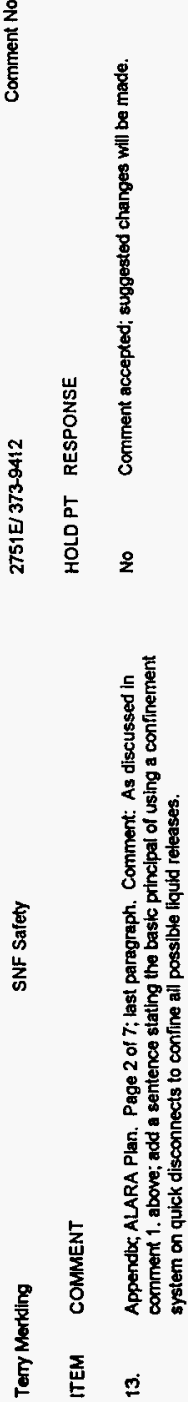

Page 23 of 63
8

営
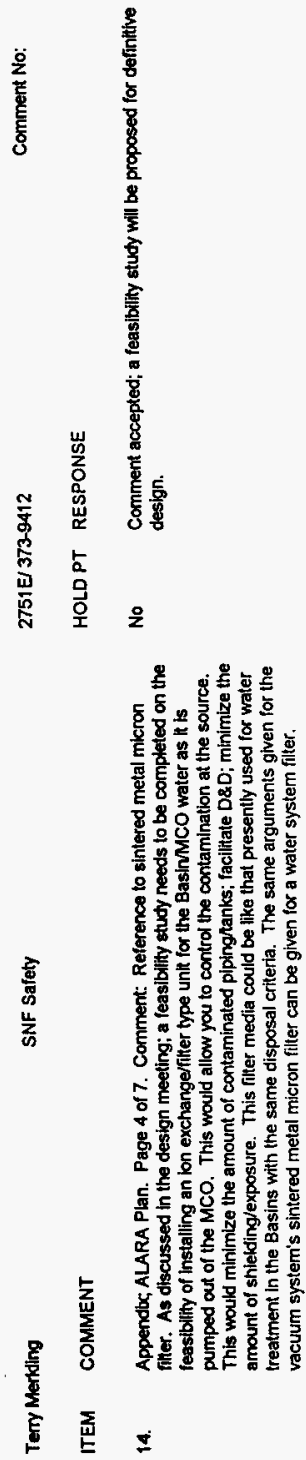
Project: WHC-SD-SNF-CDR-003 Rev 0

Terry Merkling

SNF Salety

Document: CVD 90\% PRELIMINARY DESIGN REVIEW
2751E/ 373-9412

Comment No:
ITEM COMMENT

15. Appendix, ALARA Plan. Radiation Satety Basis. Page 5 of 7. Comment: Delete relerence to DOE Order 5480.11 and replace with 10 CFR 835 and the HSRCM. 835 uses a design basis of 1000 mremiy or lower and the HSRCM uses 500 mremiyr. This CVD design document states that it uses 500 mrem/year which is perfectly OK and ALARA.

Terry Merking

SNF Safety

\section{ITEM COMMENT} 0.5 mrem/hr general areas except for continuous occupancy areas in 10 CFR 835 and the bay is not a continuous occupancy area; it is an administratively access controlled radiologlcal buffer area at best. Replace the sentence with the 500 mrem/y design gulde.
16. Appenchx, ALARA Pian. B. Comment: Deleto this sentence. There is no requirement for

HOLDPT RESPONSE

STATUS
No

Comment accepted, Need to study 10-CFR-835 to respond property.

However, DOE 5480.11 is analogous to 10 CFR 20 . Furthermore, DOE $5480.11 \mathrm{c}$ is stitl on the internet library of active DOE orders. Therefore, these orders should still apply until further evaluation of 10 CFR 835 can be completed.
HOLD PT RESPONSE

\section{ITEM COMMENT}

HOLDPT RESPONSE

17. Appendb, ALARA Plan. Page 6 of 7. Comment: Delete the reference to an alpha CAM. beta-gamma emitters. If you find beta-gamma; then you also count for alpha; but there will be no instance when you would only have alpha activity. Consider this also in the stated need for an alpha monitor in the exhaust stream. See comment 8 . 
Terry Merkling SNF Safety

ITEM COMMENT

18. Comment: Not to insult anyone; but a hard link between the casktransport people (height of the top of the cask on the transporter) and the beight of the roll-up doors needs to be established.
2751E/ 373-9412

HOLDPT RESPONSE

Comment accepted; the interface control mechanism provide this link.
STATUS

Closed

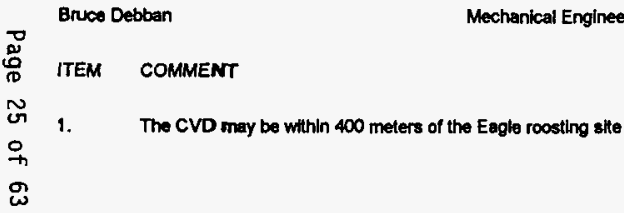

MO285/373-2168

HOLDPT RESPONSE
Comment No:

STATUS

Closed

\section{Bruce Debban}

Mechanical Engineer

\section{ITEM}

COMMENT

There needs to be a room In the CVD reserved for maintenance of equipment. Looking at drawings; noom 129 would be the most likely room to reserve for this purpose. (1st floor layout)
MO285/373-2168

Comment No:

HOLD PT RESPONSE

Agree, Room 129 shal be assigned equipment room. 


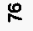

点

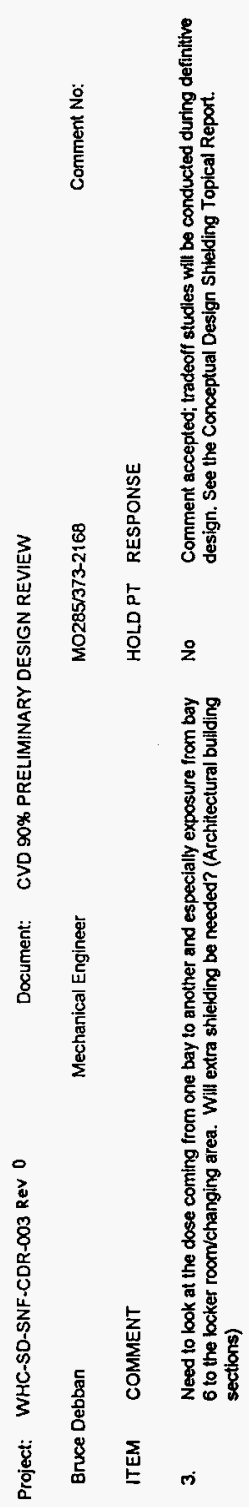

$E$

点
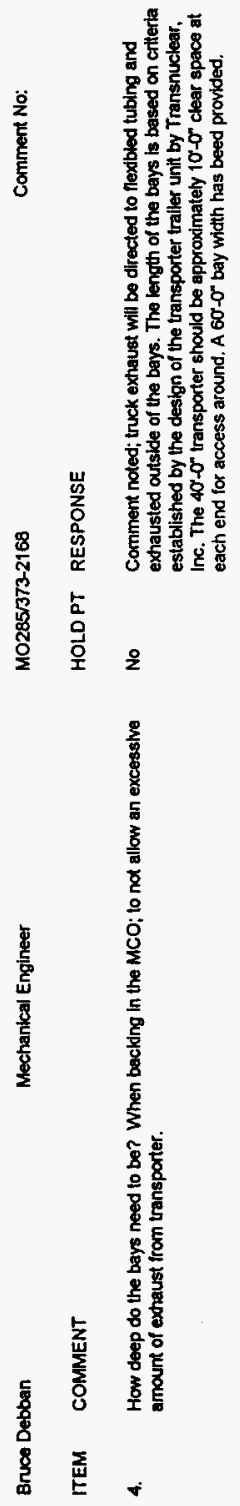

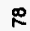

点

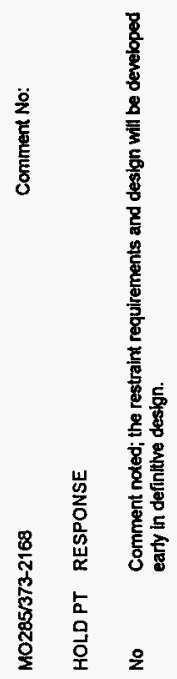

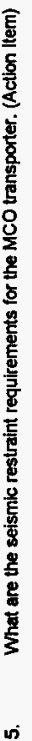

Page 26 of 63 
Project: WHC-SD-SNF.CDR-003 Rev 0

Kurt McCracken

ITEM COMMENT

1. 65\% ASHRAE Filters

Environmental Engineering

MO-293/373-6653

Comment No:

HOLD PT RESPONSE

STATUS

No 85\% ASHRAE preffters will be instalied ahead of the HEPA to minimize loading of HEPAs. The term refers to the fitter efflciency rating based on ASHRAE Standard 52.1 lest procedures.

Environmental Engineering

MO-293/373-6653

Comment No:

HOLDPT RESPONSE

STATUS

ITEM COMMENT

2. Primary Confinernent issues wisafety class. Solutions may be weld MCO prior to arrival at CVD then It can be considered primary

क)
Current prolect baseline is that the MCO is welded when recelved at the CVDS. Changes in this policy should consider this lssue.
Kurt MeCracken

Environmental Englneering

ITEM COMMENT

3. Gas purge P\&ID need now indicator and controller

HOLDPT RESPONSE 
Project: WHC-SD-SNF-COR-003 ReV 0

Kurt McCracken

ITEM COMMENT

4. Move RGA in front of condenser

Kurt MoCracken

ITEM COMMENT

5. Dual HEPA filter system

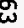

Document: CVD 90\% PRELIMINARY DESIGN REVIEW

Environmental Engineering

MO-293/373-6653

Comment No:

HOLD PT RESPONSE

No Comment accepted; RGA will be moved.
Envronmental Engineering

$M 0-293 / 373-6653$

HOLD PT RESPONSE
Comment accepted; dual HEPAs are provided to mantain isolation between the air streams of high contamination potential and lower contamination potential.
Comment No:

STATUS

Closed
Kurt McCracken

ITEM COMMENT

6. Dual exhaust Irom HEPA fitter room
Environmental Engineering

$M 0-293 / 373-6653$

Comment No:
STATUS
Comment accepted; The drawings are schematic in nature; exhaust ducts will be combined in the mechanical room with just one duct exiting the building. 
Project: WHC-SD-SNF-CDR-003 Rev 0

Kurt MeCracken

Environmental Engineering

\begin{abstract}
ITEM COMMENT
\end{abstract}
7. Outside air and recirc air do not add to $5400 \mathrm{CFM}$
Document: CVD 90\% PRELIMINARY DESIGN REVIEW

MO-293/373-6653

Comment No:
STATUS

Closed
Turt McCracken

ITEM COMMENT

8. What are Eddy effects around operator wth stot hood

学
Environmental Engineering

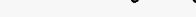

MO-293/373-6653

Comment No:
STATUS

No

Comment accepted; eddy effects have note been investigated at this

point. If efects are found to be a safely hazard; use of operalor safety equlpment such as half sults witl be addressed.

\section{Dean Smith}

SAR Engineering

\section{ITEM COMMENT}

1. The presentation stated that the safety class criteria is 25 rem offsite. This is not consistent with WHC-CM-4-46 which specifies 0.5 rem olfsilte threshold for safety class. Based on the draft PHA and the PSE potential accidents could result in offsite dose consequences greater that the safety class threshold of 0.5 rem release and the safety significant threshold of 5 rem for onsite releases.
2751E/372-3623

Comment No:
HOLD PT RESPONSE

No See criteria evaluation study. Also see $10 \mathrm{CFR} 840$ which applies to DOE. and which suggests 20 rem offisite to trigger emergency action.
STATUS 
Project: WHC-SD-SNF-CDR-003 Rev 0

Dean Smith

SAR Engineering

ITEM COMMENT

1.a It should also be noted that the MCO does not provide a safety class confinement barrier when the penetration covers are removed.

Dean Smith

SAR Engineering

\section{ITEM COMMENT}

2. The presentation noted that the faclity was to be deslgned to DOE 6430.1A; Division 1320 for the Spent Fuel Storage. The faclity does not provide a storage function. It should not be designated as such since this may invoke 10CFR 72

Dean Smith

SAR Engineering

\section{ITEM COMMENT}

3. Tornado criterka will apply to the facility design to meet NRC equivalency requirements.
$2751 E / 372-3623$

HOLDPT RESPONSE

STATUS

No

See criteria evaluation study for more discussion.

Closed
2751E/372-3623

Comment No:

HOLDPT RESPONSE

See crtterla evaluation study for more discussion we belleve Dlvision 1320 selection does not imply applicability of 10 CFR 72 .
STATUS

Closed
No
2751E/372-3623

Comment No:
STATUS
No The NRC equivalency criteria only Invokes the tornado criteria for safety class equipment; no safety class equipment has been ldentified for the CVDS. 
Dean Smith

SAR Engineering

ITEM COMMENT

4. The design should accommodale fuel particulate in the water removal from the MCO in the event of an upset condition which affects the MCO screening.

璦

Dean Smith

\section{ITEM COMMENT}

5. Design may have the potential to externally overpressurize MCO (i.e. for runaway heater). Design features to prevent overpressure need to be safety class.

\section{E $372-3623$}

HOLDPT RESPONSE

Comment No:
Comment accepted' a feasibility study will be proposed for definithe design to address this issue.
STATUS

DO

\section{$2751 E / 372-3623$}

Comment No:

\section{HOLDPT RESPONSE}

STATUS

The seal for the caskMMCO annulus will fail before the MCO. Being a cylinder; the MCO will have considerable resistence to external pressure.

\section{ITEM COMMENT}


Project: WHC-SD-SNF-CDR-0O3 Rev 0

Ronakd F. Hinz

Environmental

ITEM COMMENT

1 Will the increase in temperature cause any organics to be pulled through the pump? If so what effect will it have?
2440 STVCN/372-0850

HOLD PT RESPONSE

Comment No:

STATUS

No

The source of organics is unclear, but they would pass through the

Closed

in the refig without impacting its operation. They could either

exhausted to the atmosphere.

MO-285/372-3743

Comment No:

HOLD PT RESPONSE

STATUS

No

Comments accepted; will be incorporated.

Comments; a)Eliminate reference to Compressed Air System; b) Use common reference to the Cold Vacuum Drying System instead of Cold Vacuum Drying Module and Process Bay Instead of Vacuuming Bay or Drying Bay in all sectlons; c) perform check of text for reference to North; South; East and West direction references; d) reconcile all

equipment numbers between text and the drawings; e) the instrument; plping and

equipment numbering system needs to be defined ( $R$. Whitehurst of the SNFP has been

tasked to resolves this)' $f$ resolve issue of Metric/English units; g) a reference section and

an acronym section should be added.

\section{ITEM COMMENT}

HOLD PT RESPONSE

STATUS

2. The safety class; performance class; seismic response and tomado hardening requirements need to be clarified. The SNFP Salety Analysis Report subgroup has been tasked to resolve these issues. conceptual design report. 
ธิ

善

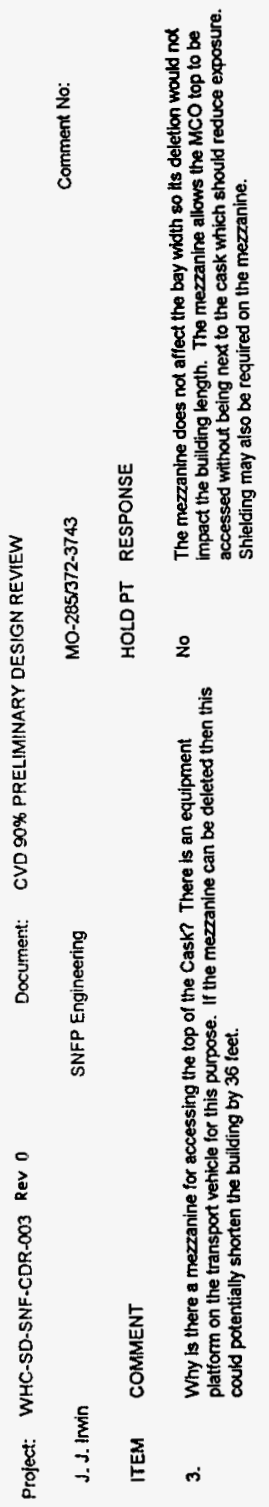

\&

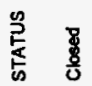
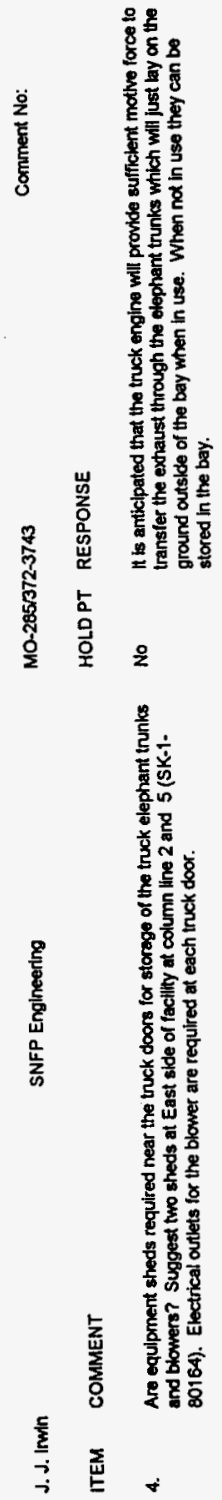

Page 32 of 63
8

蛋
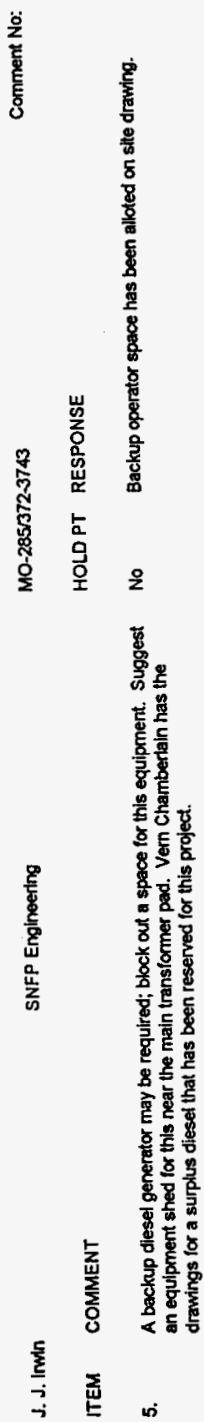
J. J. Irwin

SNFP Engineering

MO-285/372-3743

Comment No:

ITEM COMMENT

HOLDPT RESPONSE

STATUS

6. The text defines a requirement for six computer systems for the CVDS. There are five systems depicted in the control room layout (SK-1-B0162). Resolve discrepancy. The specification for the PC's should be revised to be the expected mainstream computer system at the time of their need; June 1997; (166 or $200 \mathrm{MHz}$ Pentium with 4 Gigabyte Fixed Disk). Also add a suitable backup device; eg. a $4 \mathrm{~Gb} M O$ drive. The computer system connection to the HLAN should be shown on SK-1-80170.

i 7. Section 2.1.1. Step 6; suggest Elephant trunk be attached to the truck prior to opening the tuck door, also remove trunk after truck is diven out and atter the door is closed; step 12 and 13. Step 28 and 29; the quick disconnects may be plnned to the MCO to prevent removal. Step 33; Add leak test of annular space seal system. Step 54; MCO temperature setpolnt should be determined by a temperature measurement; not a pressure

measurement Step 70; prio to this step: have CSB operations manager verity that the CSB is ready to accept a MCO/Cask. If not; maintain MCO cooling until CSB is ready.

\section{ITEM COMMENT}

8.

Section 2.2.2 Vacuum Modeling. The assumption for pump speed was not stated; a 1 line size is specified while the recommended pump has a $1-1 / 2$ iniet. The recommended pump has a catalog cut specifying a pump speed of $21 \mathrm{cfm}$; the stated requirement is $65 \mathrm{~cm}$. A report detailing the modelling methods and results will be required as part of definitive design.
HOLD PT RESPONSE 
J. J. Imin

SNFP Engineering

ITEM COMMENT

9. SK-1-80137. Should the RGA be placed belore the D-2012 dryer?
MO-285/372-3743

Comment No:

103
STATUS

Closed
10. SK-1-80138. Does the Inert Gas system need a fitter and dryer? The systern needs a low

o range gas metering system to control the injection of gas Into the MCO during vacuum drying.
Gas in tube trailers will be clean and dry. Low range gas metering system will be provided.

Closed

No $\quad$ Yes; revision will be made. 
Project: WHC-SD-SNF-CDR-003 Rev 0

J. J. Irwin

SNFP Engineering

ITEM COMMENT

12. Are P\&ID's required for HVAC; Central Low Level Waste; Fire Suppression;

Demineralized/De-ionized Water; Potable Water; Sanitary Waste systems?

\section{c. O'Neill}

ICF Kaiser

No

Section 1.2 - Third paragraph; top of page 3. The narative refers to Radiacthe liquid

avold any problems with regulators. Does using the term liquid waste cause any concerns?
$373-7642$

HOLDPT RESPONSE

MO-285/372-3743

HOLDPT RESPONSE

Comment No:

P\&IDs are not normally offered for facility audilary systems since there are so few controls. The schematic design documents only show the intent of the design. Final design should Include an overall facility P\&ID for any auxiliary system controls, the written description of each system In the preliminary report does not describe any necessary control features.

Comment accepted, will be incorporated

Comment No: waste; the term liquid waste was removed from the Performacnce Spec. and the F\&R's to

\section{ITEM COMMENT}

HOLDPT RESPONSE 


\section{ITEM COMMENT} Section 2.1.1; page 2; 75 . The paragraph says the MCO will be heated while it is full of water to increase heat transfer. Will this create a problem with hydrogen generation?

C. O'Nell

ICF Kaiser

ตั

\section{ITEM COMMENT}

4. Section $2.1 .1 ;$ page $4 ; 225$. The paragraph talks about item to be provided by the Transporter. There seem to be some confusion during the presentation about what the Cask/Transportation subproject will be providing with the trailer. Resolution: Contact Andy Kee and get the latest Information on the Transporter.

జ

\section{O'Neill}

ICF Kaiser

ITEM COMMENT

5. Section 211; page 4; $* 28$. The paragraph talks about removing the quick disconnect from the port. If we plan to remove the fitting and not use it then why put it on in the first place. Resolution: Decide if operations wants quick disconnects on the MCO and use them if they are installed.
HOLD PT RESPONSE

STATUS 
$\stackrel{2}{\frac{2}{5}}$

$\stackrel{9}{=} \underset{8}{\frac{2}{5}}$

$\begin{array}{lll} \pm & & \\ & 5 & 8 \\ & 5 & 8 \\ 0 & 8\end{array}$

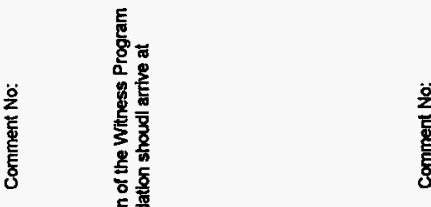

总

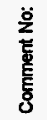
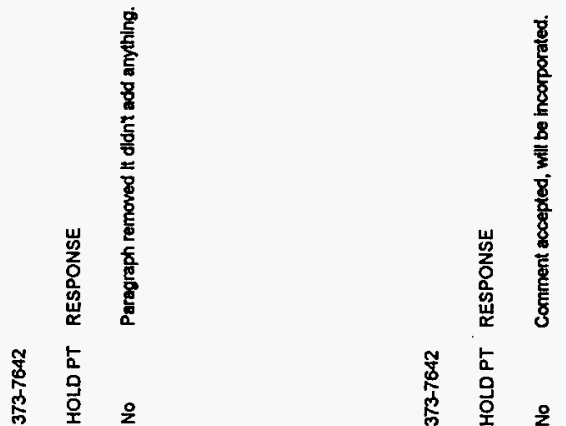

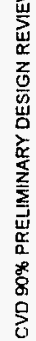

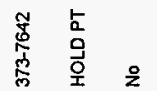
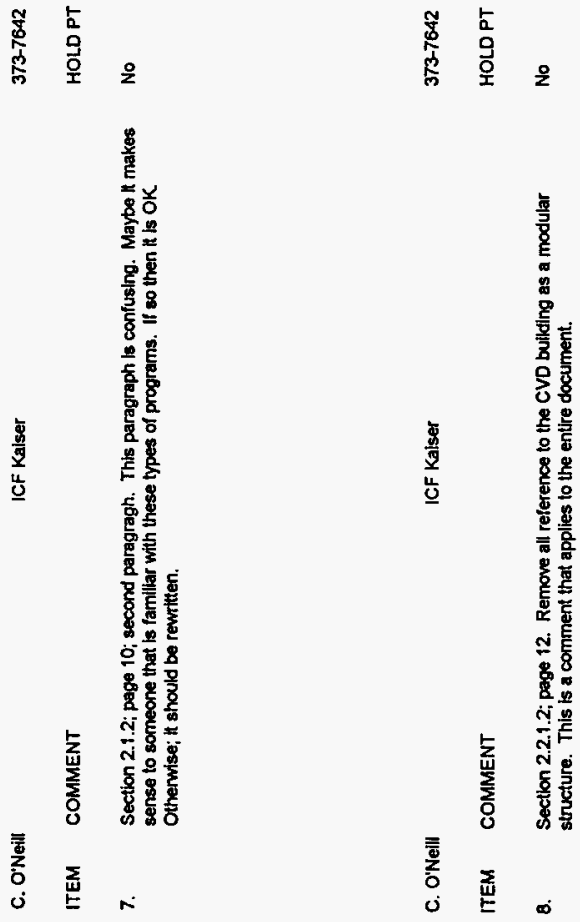

Page 37 of 63 
C. O'Neill ICF Kaiser

\section{ITEM COMMENT}

9. Section 2.2.1.4.2; page 15; second paragraph. In this discussion about how the

commercial nuclear industry dries fuel; Merrick describes welding the shield lid on afler fuel is baded into the canister and before drying. Welding with water in the canister has been a big concern on this project. If the commercial industry has a way of doing this; Merrick

should find out how it is done.

10. Section 2.2.2; page 24. Has the software used to model the vacuum system been verliried

\section{ITEM COMMENT}

11. Table 2.3.1. page 28. The table includes a parameter of External Design Pressure. The information in this table is taken from the Performance Spec. but it doesn't appear that they used the current Spec. This parameter was removed from the final version of the Spec. Resolution: Instruct Merrick to use the current Spec. for design input and WHC should monitor Merricks design effort more closely to make sure they are using the correct data.
HOLDPT RESPONSE

STATUS
The project team and Merrick wil ensure that current and correct input data Closed is in use.
Merrick does have the information from the commercial nuclear industry on Closed completed. 
Project: WHC-SD-SNF-COR-OO3 Rev 0

C. O'Neill

ICF Kaiser

Document:

CVD $90 \%$ PRELIMINARY DESIGN REVIEW

\section{ITEM COMMENT}

12. Section 2.4.2.4.1; page 34. This section says the MCO will be heated to 50 degrees $C$ Which will be estimated by measuring the ext temperature of the heating water. We

decided that measuring the temperature of the gas leaving the MCO was a better indication

of fuel temperature. Resoiution: Instruct Merrick that measurement of MCO/fuel

lemperature should be made using exit gas temperature. Also; anytime that the fuel is

being heated when the MCO is full of water there should be a purge gas flow through the

MCO to remove and dilute any hydrogen.

\section{c. O'Neill}

ICF Kaiser

0
苗
$\omega$
0
0
क
क

\section{ITEM COMMENT \\ 13. Section 2.5; page 35. Remove any reference to Llquild Waste. See comment \#1.}

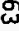

373.7642

Comment No:

HOLDPT RESPONSE

STATUS

No

Comment accepted, will be incorporated.

Closed

$373-7642$

Comment $\mathrm{No}$ :

HOLDPT RESPONSE

STATUS

No

Comment accepted, will be incorporated.

Closed
C. O'Nellt
ICF Kaiser

ITEM COMMENT

14. Section 2.9.4.1; page 45. This paragraph uses the initials HNL. What do these intials stand for?
$373-7642$

HOLDPT RESPONSE
Hanford National Laboratory, the correct accronim will be used and incorpotated.
Comment No: 
Project: WHC-SD-SNF-CDR-003 Rev 0

C. O'Neitl

\section{Document: CVD 90\% PRELIMINARY DESIGN REVIEW}

ICF Kaiser

$373-7642$

HOLD PT RESPONSE

Comment No:

\section{ITEM COMMENT}

15. Section $3.1,2.3$; page 2. Remove reference to Liquid Waste.
C. O'NeIll
ICF Kaiser

$373-7642$

Comment No:

HOLDPT RESPONSE

STATUS

No

Two exhaust fans, which normally run in parallet, are provlded for each exhaust system. Upon loss of one of the fans, the other will ramp up in speed by vitue of a variable speed ditve controller and continue to provide exhaust for the areas senviced. The exhaust provided by the single fan in operation will be approximately $80 \%$ of the design exhaust flow.
STATUS

Closed
STATUS

Closed
17. Section 3.4; page 13. Third paragraph. The air supply to the West Corridor should be HEPA fittered if it will be HEPA filtered on the exhaust ske.
Supply air to west corridor is $100 \%$ outside air, no contamination potential is foreseen. Dampers in exhaust system will prevent back flow in the event the exhaust fans shut down. Also fan system interlocks will be provided to prevent pressurization. 


\section{ITEM COMMENT}

18. Altachments; Last section of report that describes Merricks understanding of the

Performance Spec, and the F\&R's. This isn't quite what I expected for this deliverable. expected a more detailed explanation on how the the F\&R's and the Applicable documents applied to the design. I guess we shouldnt expect much more; we don't even know how al the F\&R's apply.

\section{General}

1. If cask is considered topless; unsealed MCO may not be considered primary containment. Cannot take credit for MCO safety class until it is sealed. What is a topless cask consist on

\section{HOLDPT RESPONSE}

This section was copied from a patten given by other subproject. Mertick doesn't like the form. But a lot of money can be wasted to do it right for little added value as is noted.
STATUS

Closed
Comment No:

HOLD PT RESPONSE

\section{ITEM COMMENT}

HOLDPT RESPONSE 
Project: WHC-SD-SNF-CDR-003 Rev 0

General

ITEM COMMENT

3. Interface needs to be changed regarding water removed from MCO

เั้

\section{$\stackrel{n}{+}$}

i 4. Impect limiter. Interface between cask and MCO people needs to be defined.

站

General

ITEM COMMENT

5. Seismic Criteria $/$ Tomado Criteria: If this applies; roof will need to be changed. If Tomado Criteria applies; specify Missile only or tornado. Does it state a specific target? This needs to be resolved. (Wind effect-Tornado loading)
Comment No:

HOLOPT RESPONSE

STATUS

Closed
Comment No:

HOLD PT RESPONSE

No

No Impact Limiter are required
128

STATUS

Closed 


\section{ITEM COMMENT}

6. Detailed design comments of valves. Vatve selection reliability in series manual redundancy. Depressurize valves for maintenance? (Process Piping and Instrument Diagrams)

\section{General}

ITEM

\section{COMMENT}

7. Add redundancy line In drawing P\&ID Chilled Water System.
No

Will address during the detailed design phase.
HOLDPT RESPONSE

STATUS

$\mathrm{DD}$

Comment No:

HOLD PT RESPONSE

No

Will address during the detalled design phase.
131

STATUS

DD 
HOLDPT RESPONSE

STATUS

No

DP

\section{ITEM COMMENT}

9.

P\&ID Llquid Mandling System 80141: Gravity feed water vs pumping water. What tank large enough to accommodate excess water? In line lon exchange to prevent contamination exposure for mainienance?

\section{General}

ITEM

\section{COMMENT}

10.

Mechanical Process Equipment Layout; Flexdble line; single lines; double lines. What if pump breaks? happens to the water if it is contaminated? In the event of a half filled MCO; Is the holding

\section{HOLDPT RESPONSE}

STATUS

HOLDPT RESPONSE

11. HVAC System: How often are HEPA fitters changed? Building power must be turned off to change HEPA fitters; Shutting down building to change fitters also shuts down Slot Hood. hence without shutting down the building system. In addition, the fitters will
The fitters can be change without shutting down the HVAC system and most tikely not clog during the entire lifetime of the facilty. 
ITEM COMMENT

12. Process Flow Diagram: Pressure of water too. Pressure vs restraint, Monitor water from cask for radiation.

$\rightarrow$ ITEM COMMENT

13. Purge- high rate or low Locetion of process flow filter; fitter in MCO.

g

Genera

ITEM COMMENT

14. Safety Class; distinguish between safety class and performance category
HOLD PT RESPONSE

STATUS durting the detailed design phase.

The performance category of SSC is determined by the safety classification of the SSC. 
Project: WHC-SD-SNF-CDR-003 Rev 0

General

ITEM COMMENT

15. Is there a need for back up power? is there a need for standby power source?

General

ITEM COMMENT

16.

Study to determine radiation dose effects of casks in neighboring bays

क)
Document: CVD $90 \%$ PRELIMINARY DESIGN REVIEW

Comment No:

HOLDPT RESPONSE

STATUS

No

There is no need for backup power or stand by power.

Closed

\section{ITEM COMMENT}


Project: WHC-SD-SNF-CDR-CO3 ReV 0

Kurt McCracken

Environmental Engineering

ITEM COMMENT

1. Can your organization provide a benefitcost analysis for HEPA fitter initial cost, and

ALARA considerations for a mulkiple system design compared to a single system design? Has this been factored into the choice?

Kurt McCracken

Environemental Engineering

\section{ITEM COMMENT}

2. What is the basis behind 6 alr changes per hour through the drying bays? is there a standard or DOE order that states this and can we defend it?

\section{MO-293/373-6653}

Comment No:

HOLDPT RESPONSE

STATUS

A multiple system design was chosen to prevent cross contamination of supply/retum air systems and ensure individual bays can operate when others are shitdown. A benelift/cost analysis has not been performed.

MO-293/737-6653

Comment No:

HOLDPT RESPONSE

STATUS

Sx air changes per hour is a general supply air motion gubdeline specified by ASHRAE. Mintmum outside air ventilation is based on ASHRAE Sid 62 1989

\section{Kurt McCracken}

Envronemental Engineering

ITEM COMMENT

3. What are the proposed exhaust stack heights? Will they conform to current standards such as ASKRAE accounting for stack position, air flow around the buildings, open doors, and outside air inlets?

MO-293/737-6653

Comment No:

HOLDPT RESPONSE

STATUS Stack height should be a minimum of 1.3 times the building height. Stack
location and air velocity will be determined to avold re-entry into the building according the ASHRAE. 
ITEM COMMENT

4. Are you ptanning to used a separate system for the office/change room space? I did not see its location during the Meier presentation.
HOLDPT RESPONSE

STATUS
MO-293/737-6653

HOLDPT RESPONSE \\ Kurt McCracken
} (1)

\section{Kurt McCracken}

Environemental Engineering

\section{ITEM COMMENT}

6. The preliminary hazard analysis (PHA) of the CVDF states that some of hge potential accidents will have potential for significant offsite consequences but with an estimated frequency from $1 \mathrm{E}-02$ per year to $1 \mathrm{E}-04$ per year. Do these, in anyway, conflict with the $6430.1 \mathrm{~A}$ interpretation or the HVAC design?
MO-293737-6653 Comment No: 
Project: WHC-SO-SNF-CDR+003 Rev 0

Kurt McCracken

ITEM COMMENT

Environemental Engineering

M-293/737-6653

HOLDPT RESPONSE

See Criteria Evaluation Report for further discussion of this point

7. What considerations were given to section 1550-1 of the order? These should be visited for design considerations. Will 1550-99.0.1 considerations cover enough for practices that "should" be followed or should 1550-99.0.2 be followed since the CVDF will be considered some type of confinement?

John Iowin

SNFP Engineering

MO-285/372-3743

Comment No:

HOLDPT RESPONSE

No

Comment accepted, will be incorporated.
148

STATUS

Closed

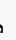

क

ITEM COMMENT

HOLDPT RESPONSE

STATUS 
Project: WHC-SD-SNF-CDR-003 ReV 0

John Irwin

ITEM COMMENT

3. P\&ID Comment: All piping, equipment, valves and instrumentation should be eventually numbered. Ths SNF Project should provide a number system.

HOLOPT RESPONSE

STATUS
5. P\&ID Comments: Drawing Coordinates should be added to Interface callouts.

$\boldsymbol{\omega}$

John Irwin

Envronemental Engineering

ITEM COMMENT

6. P\&ID Comments: Are HEPA fitters with inlet demisters required at all water tank vents? If demisters are required then are drains back to the tank required?
$M 0-2937737-6653$

Comment No: 
$\underline{\underline{B}}$

疍

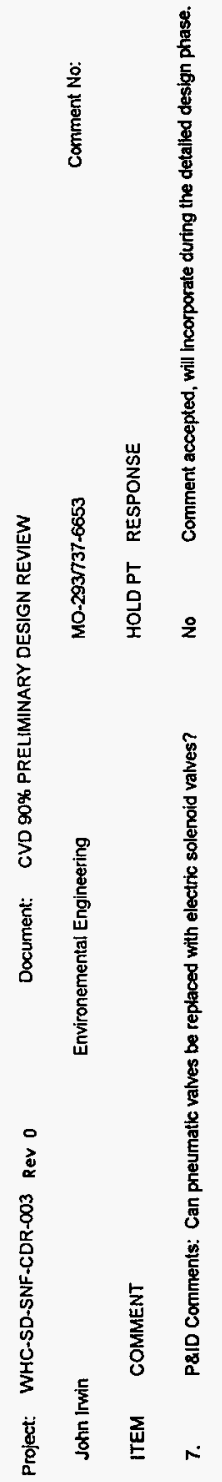

$\ddot{8}$

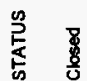

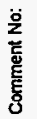
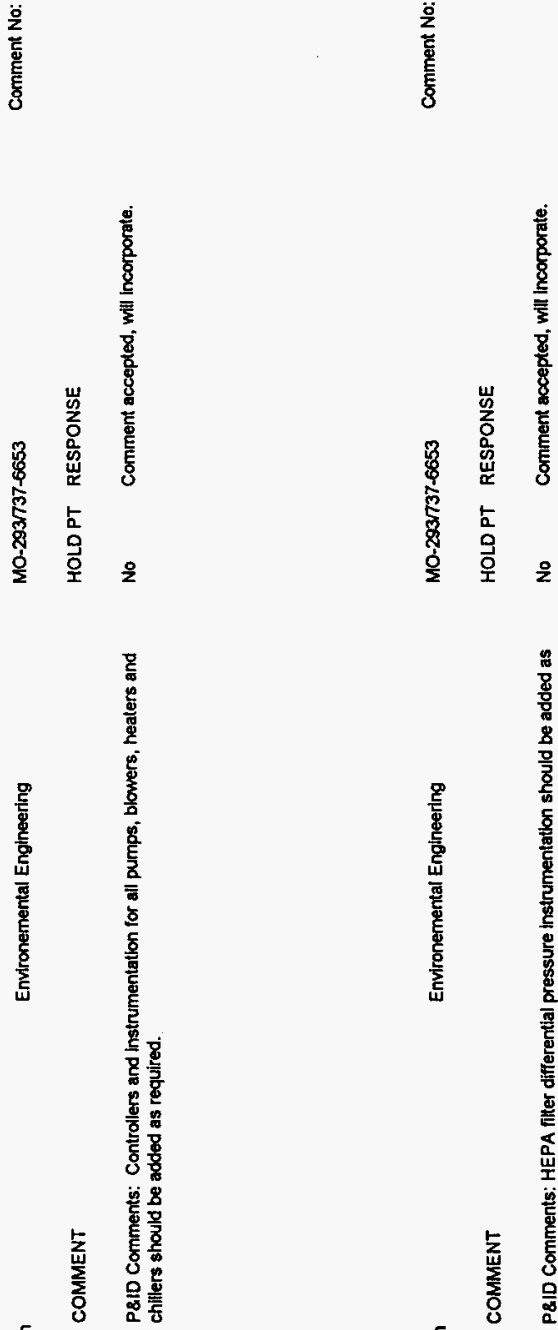

害总

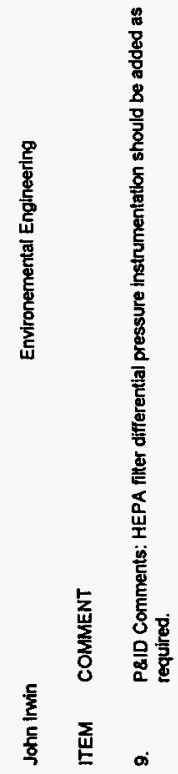

Page 51 of 63

5 蛋 
John Irwin

MO-2937737-6653

HOLDPT RESPONSE

Comment No:

ITEM COMMENT

10. SK-1-80136 There is only one penetration in the MCO, with quick disconnects, for the long downcomer pipe, the drawing shows three.

Comment accepted, will incorporate.
STATUS

Closed

\section{ITEM COMMENT}


$\Phi$

善高

究

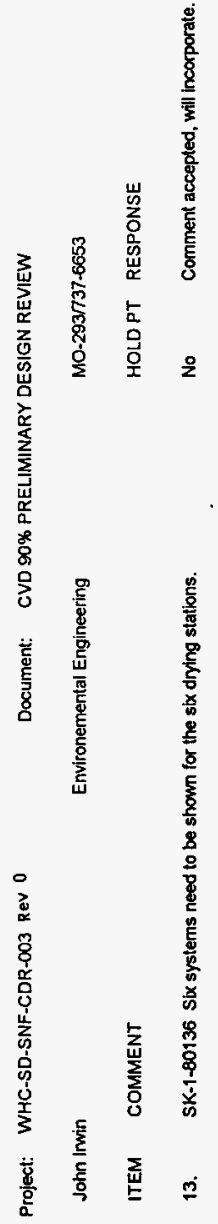

$\Phi$

$\sum_{\frac{5}{5}}^{\frac{5}{8}}$

ò
동
동

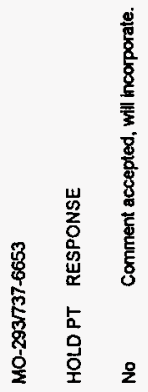

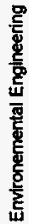

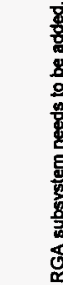

点 $\frac{5}{\overline{0}}$

寒 站
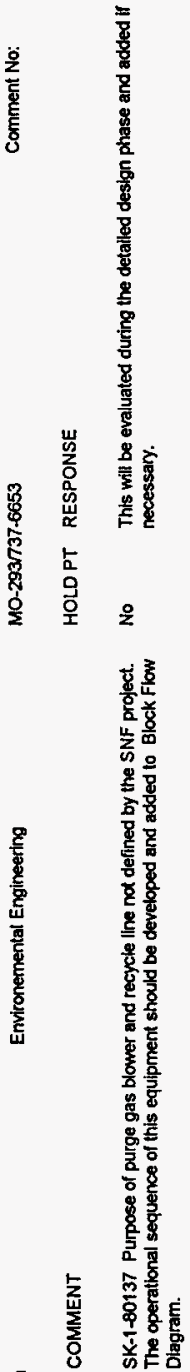

兵

Page 53 of 63 
Project: WHC-SO-SNF-CDR-003 ReV 0

John Irwin

Environemental Engineering

ITEM COMMENT

16. SK-1-60138 Filter and drier need to be added to inert gas system at a point prior to injecting the gas into the MCO (prior to pressure controller?).
John Irwin

ITEM COMMENT

17. SK-1-80139 Add demineralizer/Deionizer to water make up.

Document: CVD 90\% PRELIMINARY DESIGN REVIEW

MO-293/737-6653

HOLDPT RESPONSE

Comment accepted, will incorporate.
Comment No:

164

STATUS

Closed

\section{$M 0-2937737-6653$}

HOLDPT RESPONSE

\section{The Delonizer for the make up water system will be added during the} detalled design phase.

Comment No:

\section{ITEM COMMENT}

18. SK-1-80139 Add demister/HEPA filter to tank vent.

\section{HOLDPT RESPONSE}

STATUS 
Project: WHC-SD-SNF-COR-003 Rev 0

John Irwin

ITEM COMMENT

19. SK-1-80139 The drain from TK-4001 should interface with the grey water system or the LHS not to a foor drain.

John Irwin

Environemental Engineering

G ITEM COMMENT

in 20. SK-1-80139 Symbol at the tank outlet/inlet to the pump not defined (possibly a

$\boldsymbol{\omega}$

Document: CVD 9O\% PRELIMINARY DESIGN REVIEW

Environemental Engineering

MO-293737-6653

HOLDPT RESPONSE

Will be connected to grey (sanitary) line.

Comment No:

Closed

M0-293/737-6653

HOLDPT RESPONSE

The symbol is for a duplex strainer. The drawing will be labeled.
STATUS

Closed
John Irwin

ITEM

COMMENT

21. SK-1-80140 Should the make up water come from the demineralized water system
Environemental Engineering

MO-2937737-6653

HOLDPT RESPONSE
Comment No:
STATUS

Closed 
Project: WHC-SD-SNF-CDR-003 ReV O

John Irwin

ITEM COMMENT

22. SK-1-80140 Should there be a holding tank In the system with a vent, filter, and demister?
MO-293737-6653

Comment No:

HOLD PT RESPONSE

Yes the water heater tank also functions as a holding tank.

$0-293 / 737-6653$

Comment No:

HOLDPT RESPONSE

No

The water system should have a strainer. It wll be added.
$\$ 70$

STATUS

Closed

\section{John Irwin}

Environemental Engineering

ITEM COMMENT

24. SK-1-80140 Should the source of power for the water heater be designated, e.g. electric?
MO-293/737-6653

Comment No:
STATUS
The hot water heater is electric. The drawing wil be labeled to indicate the source of heating power. 
$\stackrel{8}{3}$

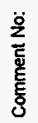

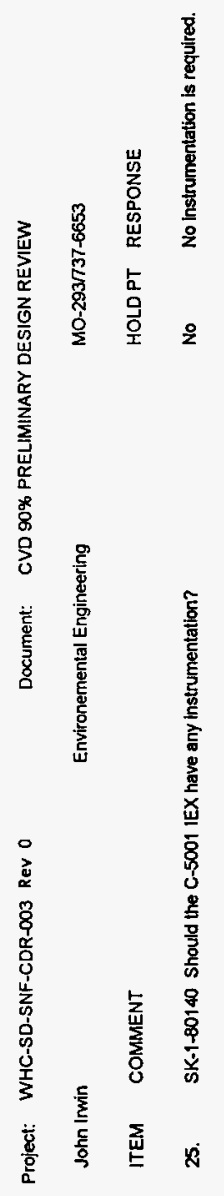

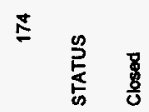

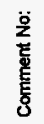

$\ddot{8}$
동
홍
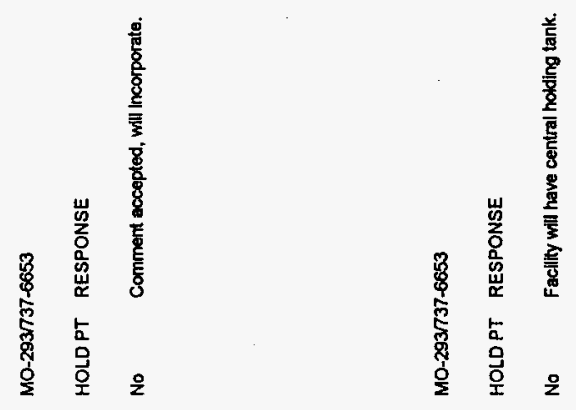

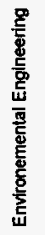
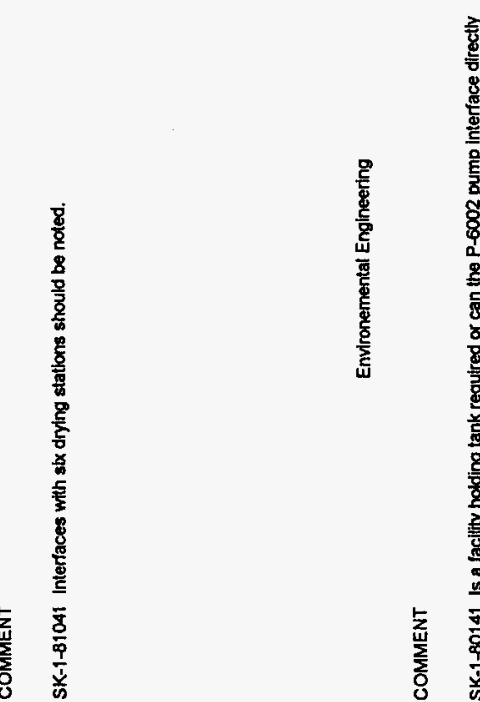

旁

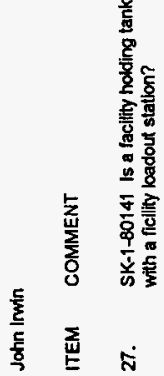

Page 57 of 63

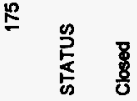
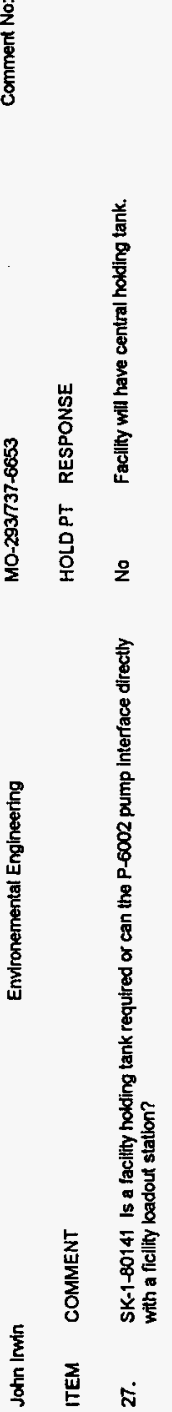
Project: WHC-SD-SNF-CDR-003 Rev 0

John Irwin

Environemental Engineering

ITEM COMMENT

28. SK-1-8014t Does the P-6002 pump need an isolation valve and an interface coupling with the loadout station?

\section{Glyn Trenchard}

\section{ITEM COMMENT}

\section{The introduction (4th para) states that preliminarily a Hazard Category 3 (HC-3)}

classification would be assigned to the facility. A hazards anatysis will be needed to support or

\section{ITEM COMMENT}

2.

The design parameters given for the Vacuum/Gas purge system in Tabie 2.3.1 for design maximum temperature (140F) and operating maximum temperature (120F) have no design margins. The process description indicates purge gas will be injected into the MCOs at $50 \mathrm{C}$ (122F) to $60 \mathrm{C}(140 \mathrm{~F}$ ). In addition, it should be noted the paragraph 2.4 .22 requires that the MCO/Cask temperature control system have the capability to heat the MCO/Cask to $75 \mathrm{C}$ (167F).
MO-293/737-6653

Comment No: make some assumption in order to proceed. see the criteria evaluation discussion. 
Project: WHC-SD-SNF-CDR-003 Rev 0

Glyn Trencharo

ITEM COMMENT

3.

Paragraphs 2.9.4.1 and 2.9.4.2 both refer 10 "HNL Management" Is this an incorrect reference to Hanford as the "Hanford National Laboratory" or what?
Comment No:
STATUS

Closed
Yes, One partner made this mistake in his writing. We thought we had caught all these errors. Will fix this one.

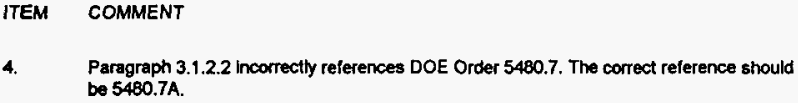

\section{Glyn Trenchard}

\section{ITEM COMMENT}

5. While I did not see it mentioned in the text. SK-1-80136 indicates that the Nitrogen purge gas and the Helium Inerting gas contain $2 \%$ Oxygen. Does this have any beneficlal affects at the cold vacuum diying stage?

\section{Comment No:}

\author{
HOLD PT RESPONSE
}

STATUS

Closed 
Giyn Trenchard

ITEM COMMENT

5.1. The design is well aiong in definition, despite a large number of TBDs. The design approach and rational for positioning and processing appear sound

in 5.2. The document makes a furdmental assertion, without detalled support in the document or

of by reference that the facility is a hazard category 3 (HC-3) even though the radiological inventory is much targer than $\mathrm{HC}-2$. The basis for this is stated to be that the Inventory in the MCOs is not avallable for release "should a credible accident scenarto be initiated". This determination leads to assignment of performance category 2 (PC-2) rating except for the building itself which is rated PC-3. I strongty recommend that the safety basis for the the building itself which is rated PC-3. I strongly recommend that the safety basis for the
facility be better established or displayed if already established. this should Include documentation of the $\mathrm{HC}-3$ determination justification of the $\mathrm{HC}-3$ determination v.s. the HC-2 inventory description of the conceptual design accidents which lead to conclusions that the MCO inventroy is not involved in accidents, etc. We don't want safety as an afterthought or add on.

Glyn Trenchard 
Project: WHC-SD-SNF-CDR-003 Rev 0

Glyn Trenchard
Document: CVD 90\% PRELIMINARY DESIGN REVIEW

Comment No:

HOLD PT RESPONSE

STATUS

Closed

HOLD PT RESPONSE

STATUS
Agree, will do earty in detall design. See Criteria Evalaution Report regarding NRC tornado applicabillty.
DD
5.5. The non-setsmic Natural Phenomena Hazards (NPH) used in the design should be indetified. This includes wind, tornadoes (if applicable), preclpitation, ash fall, snow load,

\section{No} etc. slightly smaller than the level od $0.24 \mathrm{~g}$ for the 200 East site, and should be checked to see that it conforms to the site specific assessment. 


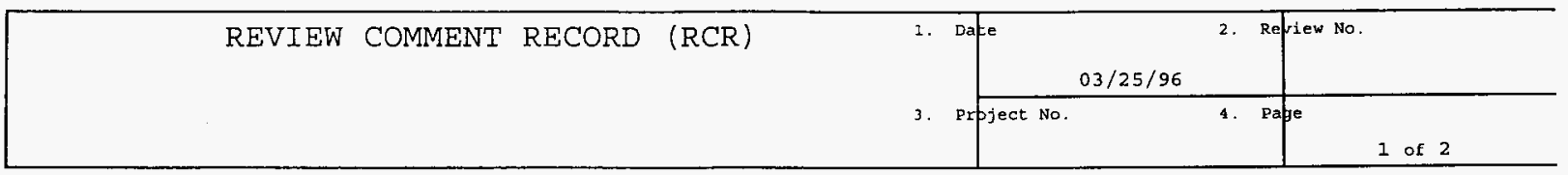

5. Document Number(s)/Title(s)
COLD VACUUM DRYING MODULE - 90\%
PRELIMINARY DESIGN REPORT

17. Comment Submittal Approval:

Organization Manager (Optional)

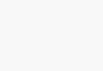

\begin{tabular}{|l|l}
\hline $\begin{array}{l}\text { 6. Program/Project/ } \\
\text { Building Number } \\
\text { CVD }\end{array}$ & 7. Reviewer \\
J. D. Mathews
\end{tabular}

10. Agreement with indicated comment disposition(s)

\section{Organization/Group \\ Fuel Handing Operations}

9. Location/Phone

$\mathrm{MO} 285 / 373-4598$

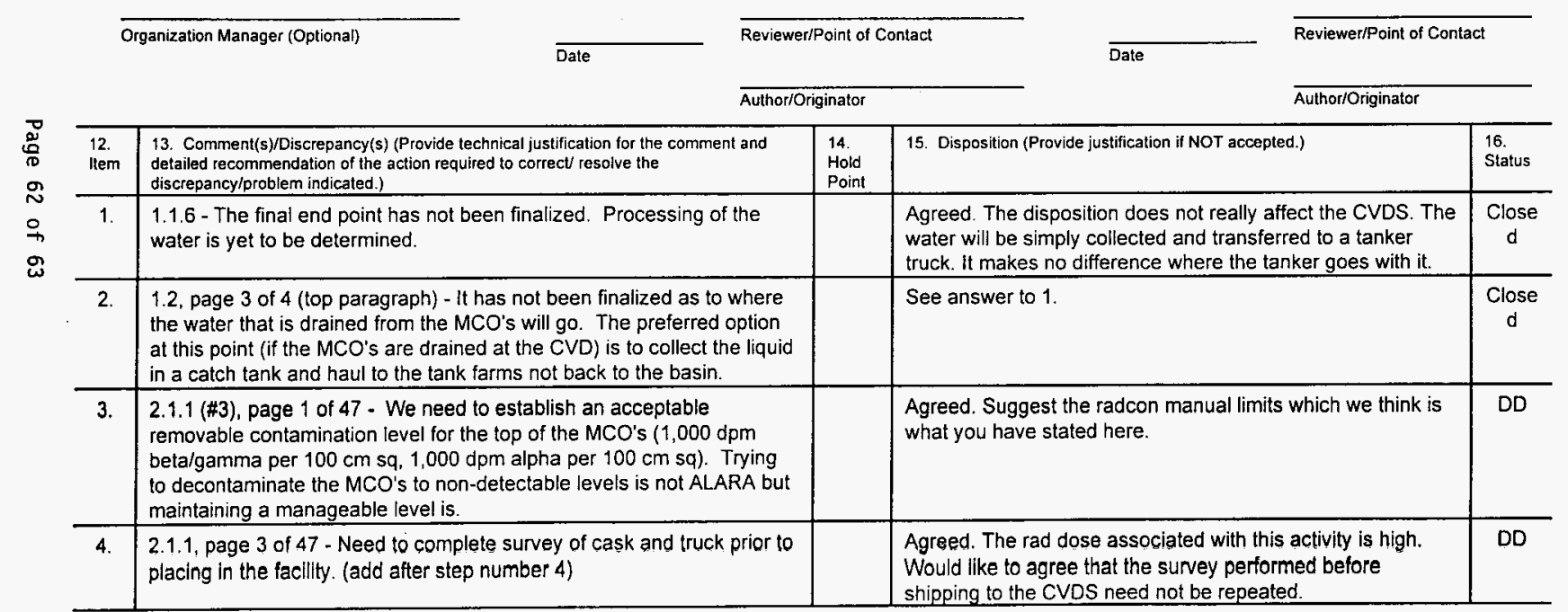




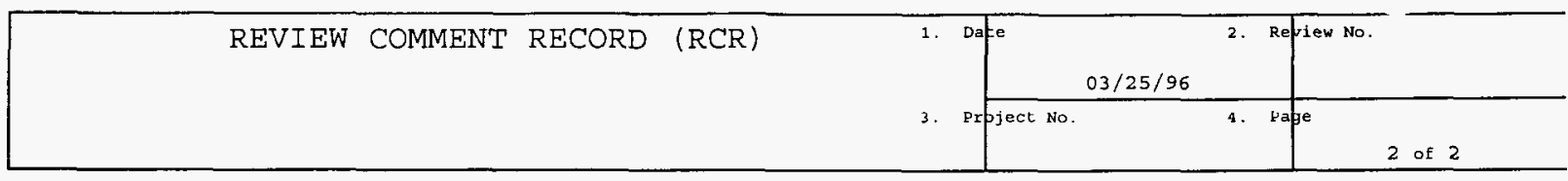

\begin{tabular}{|c|c|c|c|c|}
\hline $\begin{array}{l}12 . \\
\text { liem }\end{array}$ & $\begin{array}{l}\text { 13. Comment(s)/Discrepancy(s) (Provide technical justification for the comment and } \\
\text { detailed recommendation of the action required to correct/ resolve the } \\
\text { discrepancy/problem indicated.) }\end{array}$ & $\begin{array}{l}14 . \\
\text { Hold } \\
\text { Point }\end{array}$ & 15. Disposition (Provide justification if NOT accepted.) & $\begin{array}{l}16 . \\
\text { Status }\end{array}$ \\
\hline 5. & $\begin{array}{l}2.1 .1 \text { (\#15), page } 3 \text { of } 47 \text { - Change "Resolve Security Issues" to } \\
\text { "Resolve Accountability/Security Issues". }\end{array}$ & & $\begin{array}{l}\text { Agreed. Will change in early detail design since this } \\
\text { comment was received too late to incorporate in conceptual } \\
\text { design. }\end{array}$ & DD \\
\hline 6. & 2.1.1 ( $\$ 20)$, page 4 of 47 - See comment number 3 above. & & See answer to \#3. & $\mathrm{DD}$ \\
\hline 7. & $\begin{array}{l}\text { 2.1.1 (\#23), page } 4 \text { of } 47 \text { - Paperwork verification needs to be } \\
\text { completed prior to placing the cask into the facility (step \#4). }\end{array}$ & & $\begin{array}{l}\text { Prefer to perform receiving inspection activities out of the } \\
\text { weather. As long as truck is present and no connections } \\
\text { have been made to the transporter or MCO, it is a trivial } \\
\text { matter to refuse acceptance and remove the transporter from } \\
\text { the facility. }\end{array}$ & $\begin{array}{c}\text { Close } \\
d\end{array}$ \\
\hline 8. & $\begin{array}{l}\text { 2.1.1 (add after \#83) page } 8 \text { of } 47 \text { - Complete survey of cask and trailer } \\
\text { and complete the shipping paperwork. }\end{array}$ & & Comment noted. Received too late to incorporate. & $\begin{array}{c}\text { Close } \\
\mathrm{d}\end{array}$ \\
\hline 9. & $\begin{array}{l}\text { 2.2.1.4.2, page } 15 \text { of } 47 \text { (second paragraph) - Draining of the MCO, } \\
\text { See comment number } 2 \text { above. }\end{array}$ & & See answer to comment 1. & $\begin{array}{c}\text { Close } \\
\mathrm{d}\end{array}$ \\
\hline 10. & Appendix $B$ - Need to ensure that if oil is used that it is non-regulated. & & $\begin{array}{l}\text { An oiless pump has been selected specifically to avoid this } \\
\text { issue. }\end{array}$ & $\begin{array}{c}\text { Close } \\
d\end{array}$ \\
\hline 11. & $\begin{array}{l}2.9 .5 .3 \text { (\#6), page } 47 \text { of } 47 \text { - Are we really going to run step number } 5 \\
\text { for } 60 \text { days? If so is this in the schedule? }\end{array}$ & & $\begin{array}{l}\text { Yes - probably. This is a test to be run at the INEL during the } \\
\text { design phase to verify reliability of the pump. }\end{array}$ & $\begin{array}{c}\text { Close } \\
d\end{array}$ \\
\hline
\end{tabular}


The folling comments were responded to by John Inwin, Project Design Authority, Chris Thompson, Operations Manager, and Rick Bradshaw, Subproject Manager:

From: G. Trenchard

Subject: COMMENTS ON COLD VACUUM DRYING FACILITY 90\% PRELIMINARY DESIGN REPORT

\section{General Comments:}

The cold Vacuum Drying (CVD) facility described in the report is likely much larger and more complex than required. We have not had sufficient time to identify all of the reasons for this, and to evaluate the report in detail, but consider each of the following are contributors to the current facility complexity:

1. Based on the time and motion studies contained in the report, it appears that two bays rather than six bays would be sufficient. In particular, the study result is that a single bay can process 11 MCOs per month. For a facility with two bays, this corresponds to about 530 MCOs in a two year period, which exceeds the required process rate of 400 MCOs by over $30 \%$. We recognize that welding of the MCO closure head within the CVD may increase space requirements. This was not considered in the subject report, but is being evaluated separately.

The 11 MCO per month estimate is based on 11 average MCOs. It does not account for $\mathrm{MCOS}$ that $t$ ake significantly longer than the average, nor does it account for equipment repair. In addition, there will be a learning curve for the entire fuel removal process, requiring additional capacity to accommodate the high end of the curve and to achieve the scheduled milestones. A more detailed time motion study will be developed to further hone the design capacity requirements.

Particularly once the welding location has been finalized. However, at this point in the design we have captured the upper bound of the capacity required. This helps ensure that the technical, schedule and budget baselines can be maintained, and serves as the point from which scope (and potentially schedule and budget) can be cut, once more definitive information is developed.

2. Various process systems and equipments are provided which are not clearly needed. Examples include:

- Equipment for receipt inspection of the transport casks/Mcos, including swab tests, radiation level scans, etc. This is also done within the basin before release of the casks, and it is not clear another inspection is required.

Receipt surveys are required to identify contamination spread during transfer. 
- A chilled water system to cool down the cask after drying. The cask will be at $50^{\circ} \mathrm{C}\left(120^{\circ} \mathrm{F}\right)$ immediately after processing, but this is typical of the temperature for hands-on access to reactor vessel heads, so no cooling should be needed.

A chilled water system is absolutely required to achieve a safe shutdown condition for the fuel, not for personnel protection. In addition, the MCO will heatup during the transport to the CSB. The chilled water system will be used to lower the initial starting temperature prior to transport to ensure the $75 \mathrm{C}$ operation limit on the MCO is not exceeded at the CSB.

- A centralized control room is provided. Local control stations are employed for commercial drying units, and should be acceptable here.

Commercial drying units process 6 casks per year and not more than one at a time. On average, the CVD will process 5 casks per week, with the potential of having all five in some phase of the process at once. A central control room helps minimize crew size and places the crew in a zero dose zone. Overal7, the cost of a central control station is less than individual ones, it is more efficient and is ALARA.

3. Additional complexity results from the decision to employ a stand-alone facility instead of a facility adjacent to one of the basins. In particular:

- Various auxiliary systems are provided which would not be needed if the facility were located adjacent to the basin and could share auxiliaries. Examples include:

- A dedicated liquid radwaste system to collect and store water removed from the MCOs.

$-\quad$ HVAC

- Electrical

- Sanitary sewer

- Fire protection

- Various personnel support facilities are included which would not be needed if the equivalent basins facilities were employed. Examples include:

- A lunch room

- Central men's and women's change out rooms, as well as a separate change out room for each bay.

- Office space for the shift manager, and separate office space for QA personnel. 
- $\quad$ office/laboratory space for health physics personnel and radiation monitoring equipment.

- Men's rooms and women's rooms

Technical Issue Management Board Decision Memorandum \#4 - Cold Vacuum Drying Location - was concurred on by DOE and was issued on EDT NO. 612995 on January 29, 1996. This memorandum states "The Board's decision is to baseline (for Cold Vacuum Drying) a single stand-alone facility to be located within the 100K area." Details of that decision are included in the Decision Memorandum.

An additional issue resulting from our quick review is the radiation exposure of operations personnel. The transport casks are nominally designed for a dose rate of $100 \mathrm{mr} / \mathrm{hr}$ at 2 meters in order to minimize cask weight. Work activities around a transport cask can result in appreciable radiation dose. It is not clear how the designers will achieve ALARA objectives for workers within the bays of the facility.

The transport casks are nominally designed for a dose rate of $30 \mathrm{mr} / \mathrm{hr}$ with a maximum of $100 \mathrm{mr} / \mathrm{hr}$. This is one of the reasons a central control room is desirable. One of the methods of ALARA for this facility will be to design the system to minimize the time required to be spent inside the bay. In addition, the size and construction will be such as to minimize any exposure coming from one bay to the next. ALARA studies will commence as part of the next phase of design.

CVO was a simple and straightforward system consisting of a few stations located within or close to the basins. This approach should still be feasible.

There was never a baseline in which the CVD was simple, the proposed design is straight forward and represents the least costly method to meet the current requirements. 
WHC-SD-SNF-CDR-003, Revision 0

ATTACHMENT 9

CALCULATIONS

for the

COLD VACUUM DRYING SYSTEM

of the

K BASIN SPENT NUCLEAR FUEL PROJECT 
WHC-SD-SNF-CDR-003, Revision 0

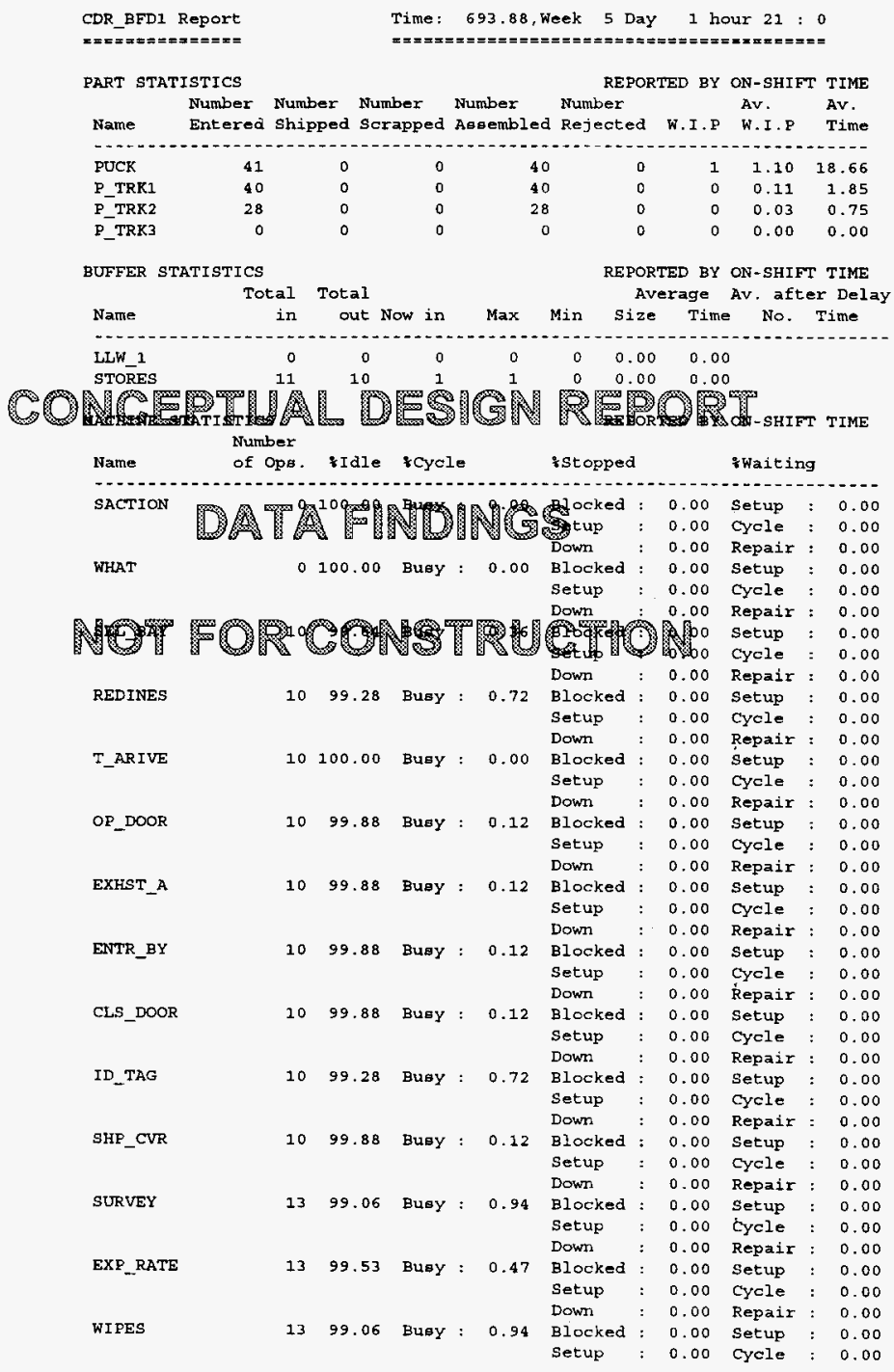

Page 1 of 54 


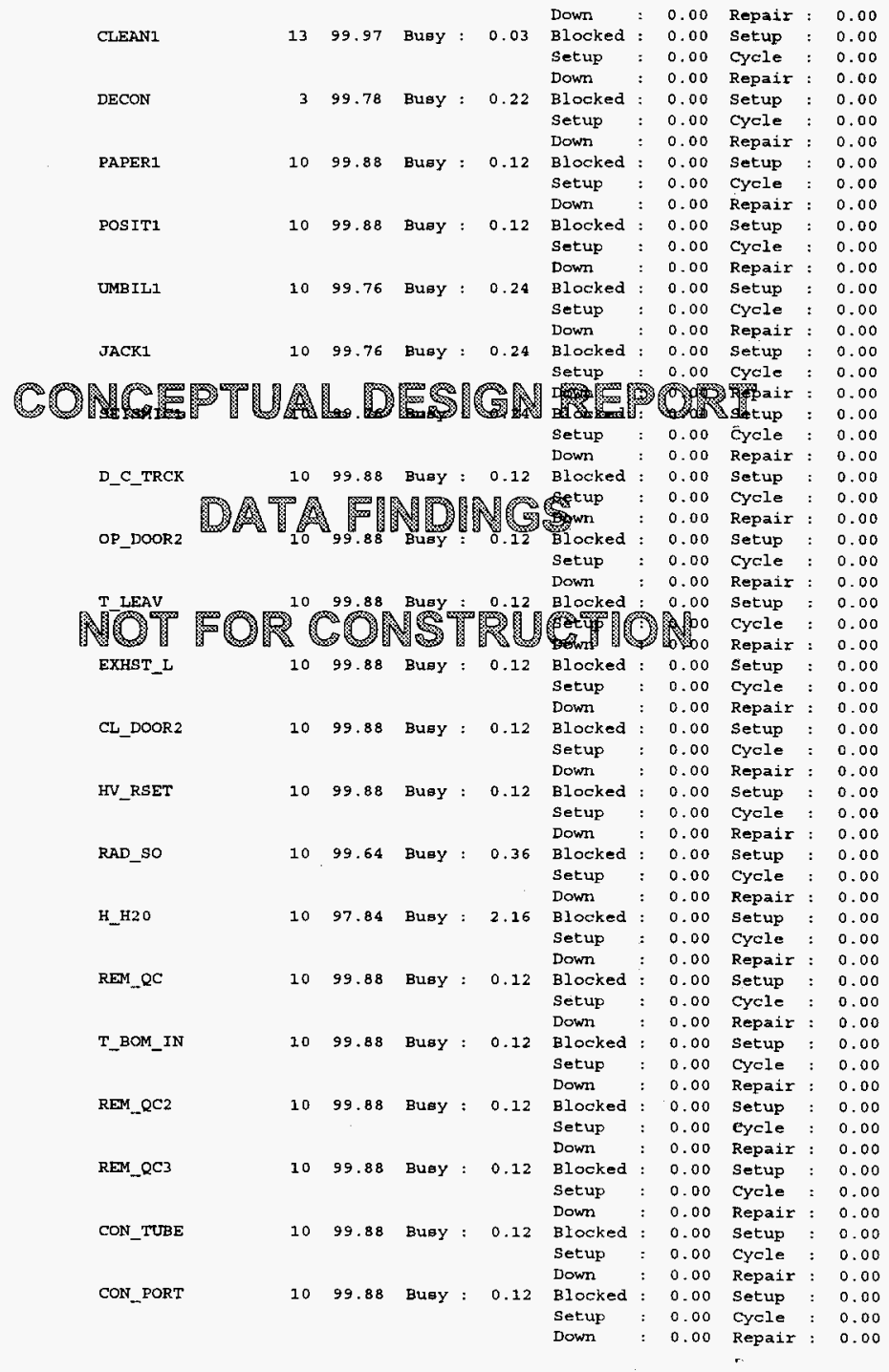

Page 2 of 54 


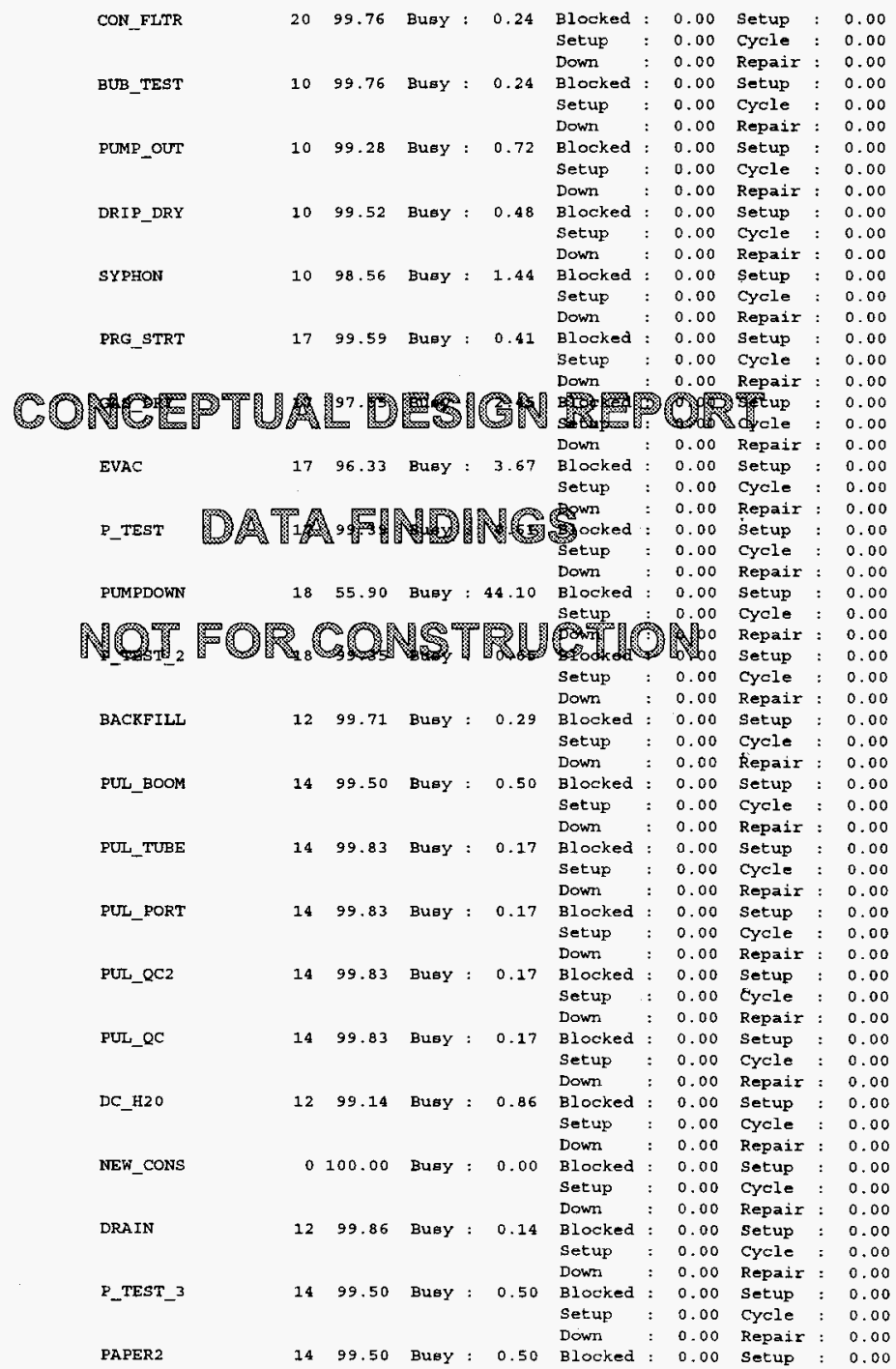


WHC-SD-SNF-CDR-003, Revision 0

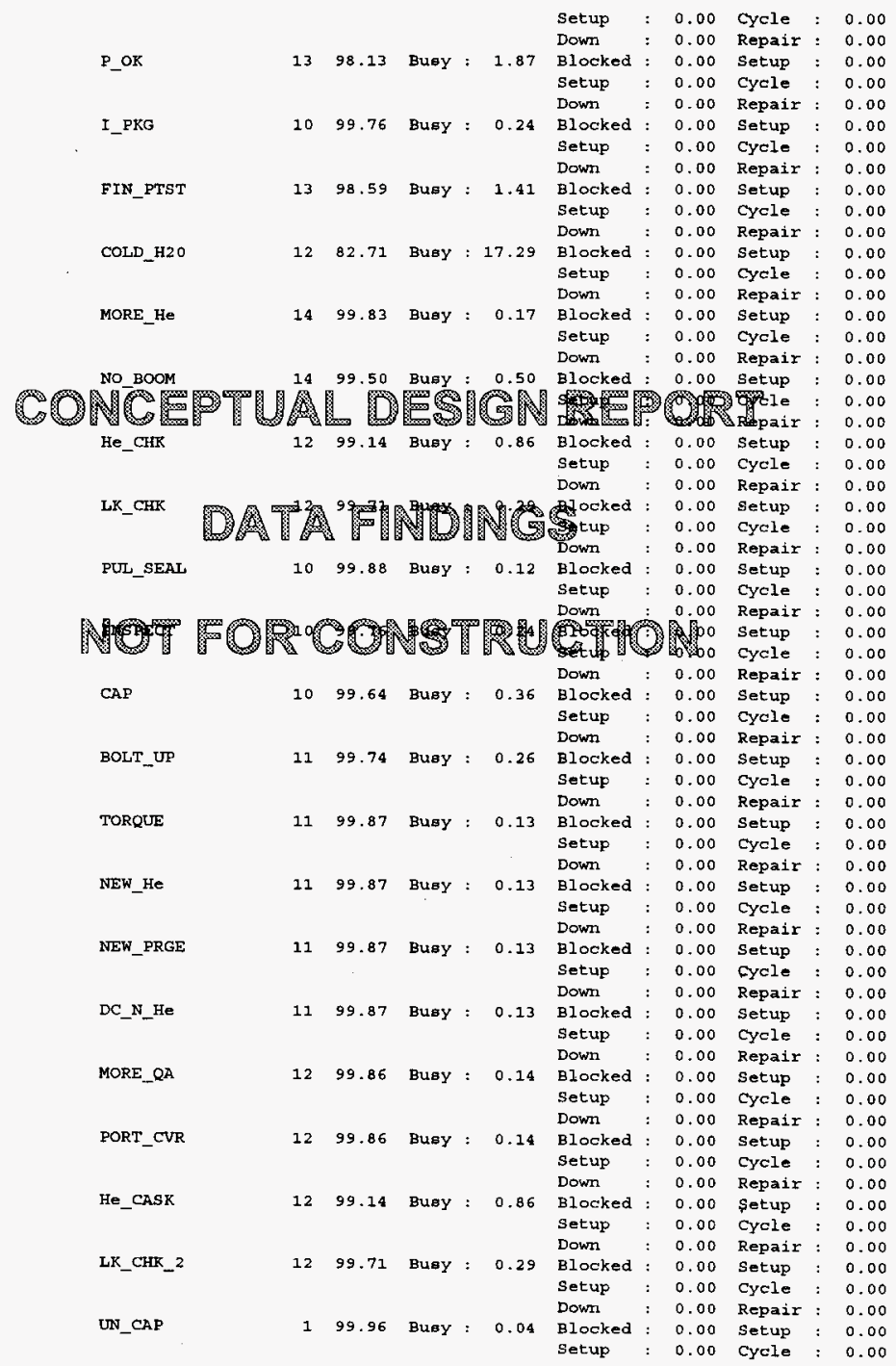

Page 4 of 54 


\begin{tabular}{|c|c|c|c|c|c|c|c|c|c|c|c|}
\hline & & & & & & Down & : & 0.00 & Repair & : & 0.00 \\
\hline \multirow[t]{3}{*}{ TRCK_CAL } & 10 & 99.76 & Busy & : & 0.24 & Blocked & $:$ & 0.00 & setup & : & 0.00 \\
\hline & & & & & & Setup & : & 0.00 & Cycle & : & 0.00 \\
\hline & & & & & & Down & : & 0.00 & Repair & : & 0.00 \\
\hline \multirow[t]{3}{*}{ OP_DOR_3 } & 10 & 99.88 & Busy & : & 0.12 & Blocked & : & 0.00 & Setup & : & 0.00 \\
\hline & & & & & & Setup & $=$ & 0.00 & Cycle & : & 0.00 \\
\hline & & & & & & Down & : & 0.00 & Repair & : & 0.00 \\
\hline \multirow[t]{3}{*}{ ENTR_BY2 } & 10 & 99.88 & Busy & : & 0.12 & Blocked & : & 0.00 & Setup & : & 0.00 \\
\hline & & & & & & Setup & : & 0.00 & Cycle & : & 0.00 \\
\hline & & & & & & Down & $:$ & 0.00 & Repair & : & 0.00 \\
\hline \multirow[t]{3}{*}{ EXHST_A2 } & 10 & 99.88 & Busy & : & 0.12 & Blocked & : & 0.00 & Setup & : & 0.00 \\
\hline & & & & & & setup & : & 0.00 & Cycle & : & 0.00 \\
\hline & & & & & & Down & : & 0.00 & Repair & : & 0.00 \\
\hline \multirow[t]{3}{*}{ CLS_DOR2 } & 10 & 99.88 & Busy & : & 0.12 & Blocked & : & 0.00 & setup & : & 0.00 \\
\hline & & & & & & Setup & : & 0.00 & Cycle & : & 0.00 \\
\hline & & & & & & Down & : & 0.00 & Repair & : & 0.00 \\
\hline \multirow[t]{6}{*}{ C_TRCK } & 10 & 99.88 & Busy & : & 0.12 & Blocked & : & 0.00 & Setup & : & 0.00 \\
\hline & & & & & & Setup & : & 0.00 & Cyele & : & 0.00 \\
\hline & & & & & & 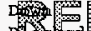 & 3. & 90 & pair & : & 0.00 \\
\hline & 20 & 99.8 & & & & EA & $:$ & 6020 & Astup & : & 0.00 \\
\hline & & & & & & Setup & : & 0.00 & cycle & : & 0.00 \\
\hline & & & & & & Down2 & : & 0.00 & Repair & : & 0.00 \\
\hline \multirow[t]{6}{*}{ JACK2 } & 10 & 99.76 & Busy & : & 0.24 & Blocked & : & 0.00 & Setup & : & 0.00 \\
\hline & & & & & & tup & : & 0.00 & Cycle & $=$ & 0.00 \\
\hline & & & & & & & : & 0.00 & Repair & : & 0.00 \\
\hline & 10 & 99.76 & Busy & $:$ & 0.24 & Blocked & : & 0.00 & Setup & : & 0.00 \\
\hline & & & & & & setup & : & 0.00 & Cycle & : & 0.00 \\
\hline & & & & & & Down & : & 0.00 & Repair & : & 0.00 \\
\hline \multirow{6}{*}{$\begin{array}{l}\text { I_PKG2 } \\
\text { FINAL_QC }\end{array}$} & & 99. & Busy & 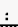 & 0.24 & Blocked & 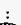 & 0.00 & Setup & : & 0.00 \\
\hline & & 9 & ${ }^{2}$ & & 27 & setus & 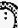 & 1) & Cycle & : & 0.00 \\
\hline & & & & & 8 & 5eturt & $\infty$ & bo & Repair & : & 0.00 \\
\hline & 10 & 99.28 & Busy & : & 0.72 & Blocked & $:$ & 0.00 & Setup & : & 0.00 \\
\hline & & & & & & Setup & : & 0.00 & Cycle & : & 0.00 \\
\hline & & & & & & Down & : & 0.00 & Repair & : & 0.00 \\
\hline \multirow[t]{3}{*}{ T_LEAV2 } & 10 & 99.88 & Busy & : & 0.12 & Blocked & : & 0.00 & Setup & : & 0.00 \\
\hline & & & & & & Setup & : & 0.00 & Cycle & : & 0.00 \\
\hline & & & & & & Down & $=$ & 0.00 & Repair & : & 0.00 \\
\hline \multirow[t]{3}{*}{ EXHST_L2 } & 10 & 99.88 & Busy & : & 0.12 & Blocked & : & 0.00 & setup & : & 0.00 \\
\hline & & & & & & Setup & : & 0.00 & Cycle & : & 0.00 \\
\hline & & & & & & Down & : & 0.00 & Repair & : & 0.00 \\
\hline \multirow[t]{3}{*}{ CL_DOOR3 } & 10 & 99.88 & Busy & : & 0.12 & Blocked & $:$ & 0.00 & setup & $:$ & 0.00 \\
\hline & & & & & & Setup & $=$ & 0.00 & Cycle & : & 0.00 \\
\hline & & & & & & Down & : & 0.00 & Repair & : & 0.00 \\
\hline \multirow[t]{3}{*}{ CLEANUP } & 20 & 97.12 & Busy & $:$ & 2.88 & Blocked & : & 0.00 & setup & : & 0.00 \\
\hline & & & & & & Setup & : & 0.00 & Cycle & : & 0.00 \\
\hline & & & & & & Down & : & 0.00 & Repair & : & 0.00 \\
\hline \multirow[t]{3}{*}{ SPOOLS } & 10 & 99.28 & Busy & : & 0.72 & Blocked & : & 0.00 & setup & : & 0.00 \\
\hline & & & & & & Setup & : & 0.00 & Cyole & : & 0.00 \\
\hline & & & & & & Down & $:$ & 0.00 & Repair & : & 0.00 \\
\hline \multirow[t]{3}{*}{ RESUP } & 10 & 99.28 & Busy & : & 0.72 & Blocked & : & 0.00 & Setup & : & 0.00 \\
\hline & & & & & & Setup & : & 0.00 & Cyole & : & 0.00 \\
\hline & & & & & & Down & : & 0.00 & Repair & : & 0.00 \\
\hline CALIB & 10 & 95.68 & Busy & : & 4.32 & Blocked & $:$ & 0.00 & Setup & : & 0.00 \\
\hline & & & & & & Setup & : & 0.00 & Cycle & $:$ & 0.00 \\
\hline & & & & & & Down & : & 0.00 & Repair & : & 0.00 \\
\hline RERUN & 10 & 99.98 & Busy & : & 0.02 & Blocked & 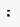 & 0.00 & setup & $:$ & 0.00 \\
\hline & & & & & & setup & : & 0.00 & Cycle & : & 0.00 \\
\hline & & & & & & Down & ; & 0.00 & Repair & : & 0.00 \\
\hline
\end{tabular}

VARIABLE STATISTICS

REFORTED BY ON-SHIFT TIME

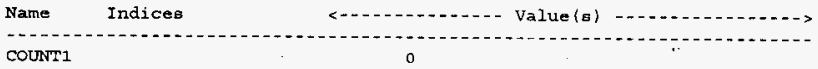

Page 5 of 54 


\section{WHC-SD-SNF-CDR-003, Revision 0}

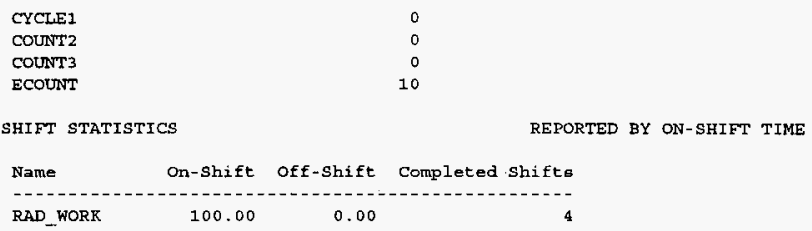

CONCEPTUAL DESIGN REPORT

DATA FINDINGS

NOT FOR CONSTRUCTION 


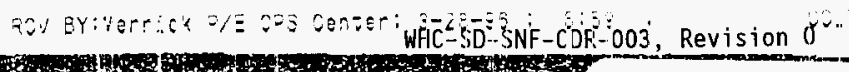

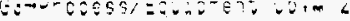

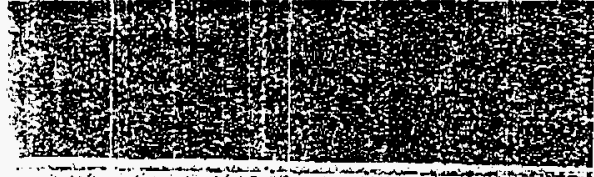

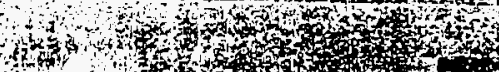

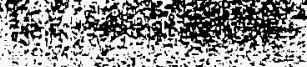

A.AILABLE COPY

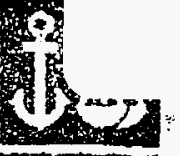

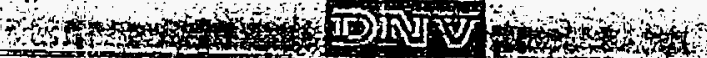

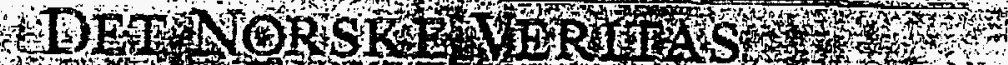

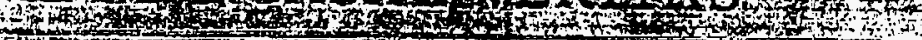

QUATTYSYSTEM GERTIGICATE

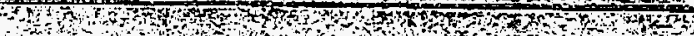

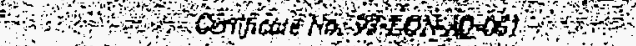

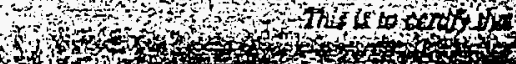

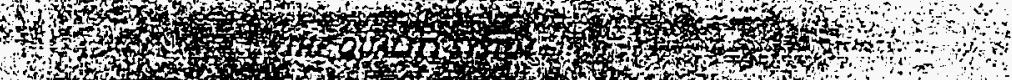

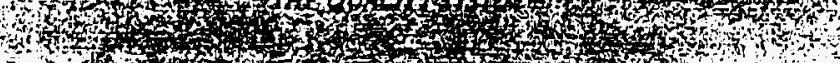

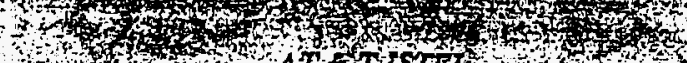

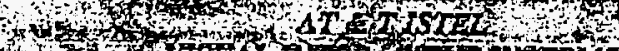

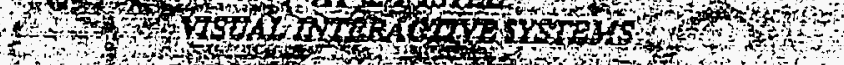

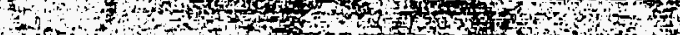

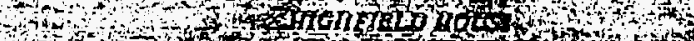

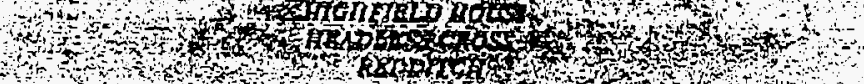

WORAS DT?

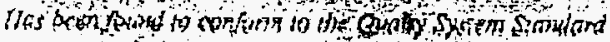

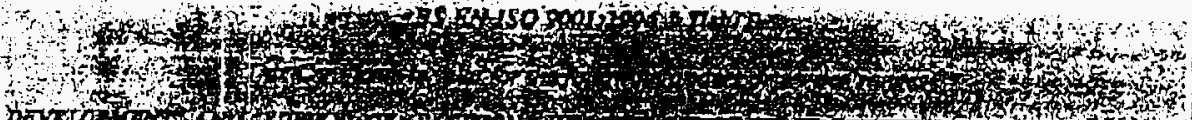

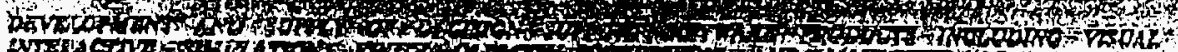

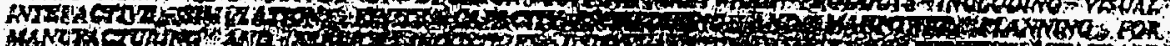

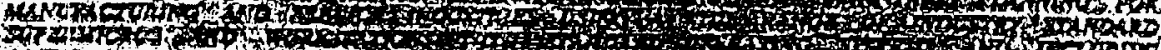

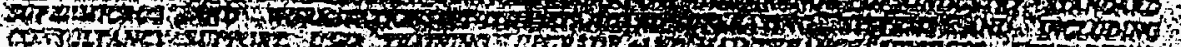

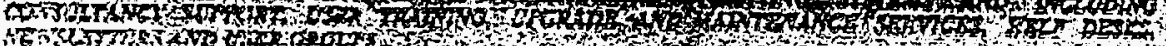
12.

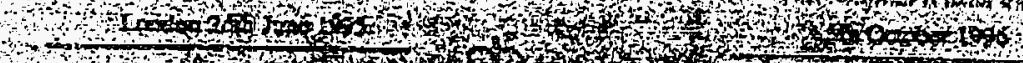

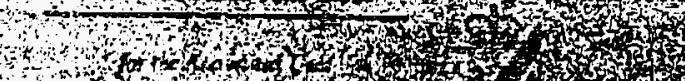

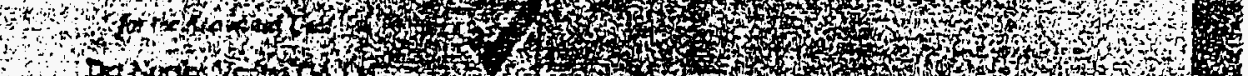

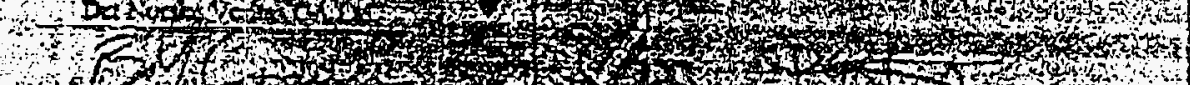

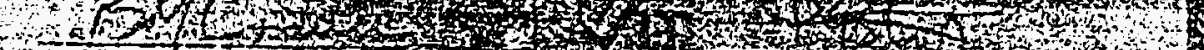




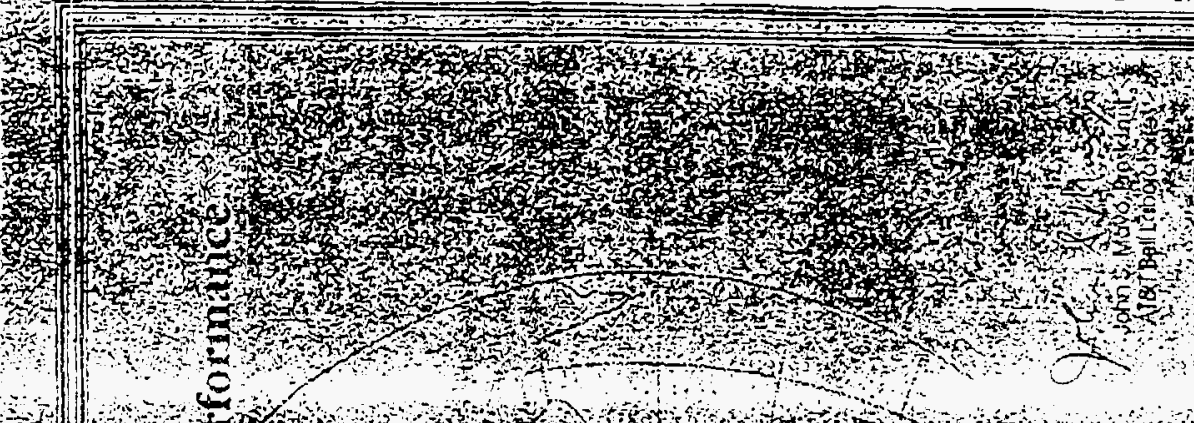

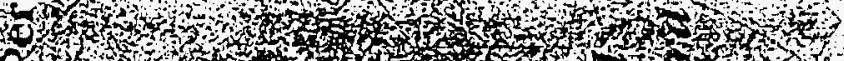

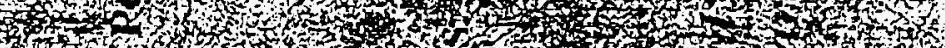

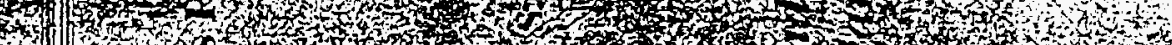

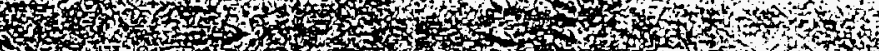


W'HC-SD-SNF-CDR-0J3, Revision 0

Engineering Calculation Sheet

MERRICK

Engineers 8 Architects
Date $3-2 c-9 \mathrm{C}$ Sheet of

Contract

By J mk Chk'd

\begin{tabular}{|l|l|l|}
\hline Revision & Date & By \\
\hline & & \\
\hline & & \\
\hline & & \\
\hline & & \\
\hline
\end{tabular}

)

Subject:

Ealc.No.VS-0o4

CUDS CONCEPTUAL DESIGN

HVAC CALCULATIONS

PROJECT NO 30012131

TABLE OF cONTENTS

$D E S C R I P T D N$

PASE

SUMMARY OF HEAL LOAD CALCULATIONS

1

$\mathrm{B}^{13}$

COMPUTER CALCULATION COVER SHEET

z

15 COMPUTER WAC LOAD CALCULATIONS

LOADS FOR A TYPICAL PROCESS BAY

ATTACHMENT A AND WEST LORKIOOR AREA

LOAD FOR MECHANICAL EQUPPENT ROOM $A T A C H M E N T$ B TOTAL LOAD SUMMARY FOR ALL PROCESS A TACH BENT C BAYS ANS WEST CORRIDOR AREA LOAD FOE AOMUISTRATION AREA ATACHMENT $D$

27
28
20
32
31

30

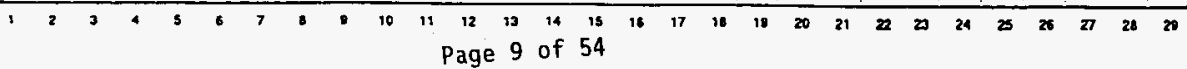


W'AC-SD-SNF-CDR-003, Revision 0

MERRICK

Engineers 6 Architects

Engineering Calculation Sheet

Date $3-26-96$ Sheet

Contract 3001213 .

By J mu Chin

Subject:

\begin{tabular}{|l|l|l|}
\hline Revision & Date & By \\
\hline & & \\
\hline & & \\
\hline & & \\
\hline & & \\
\hline
\end{tabular}

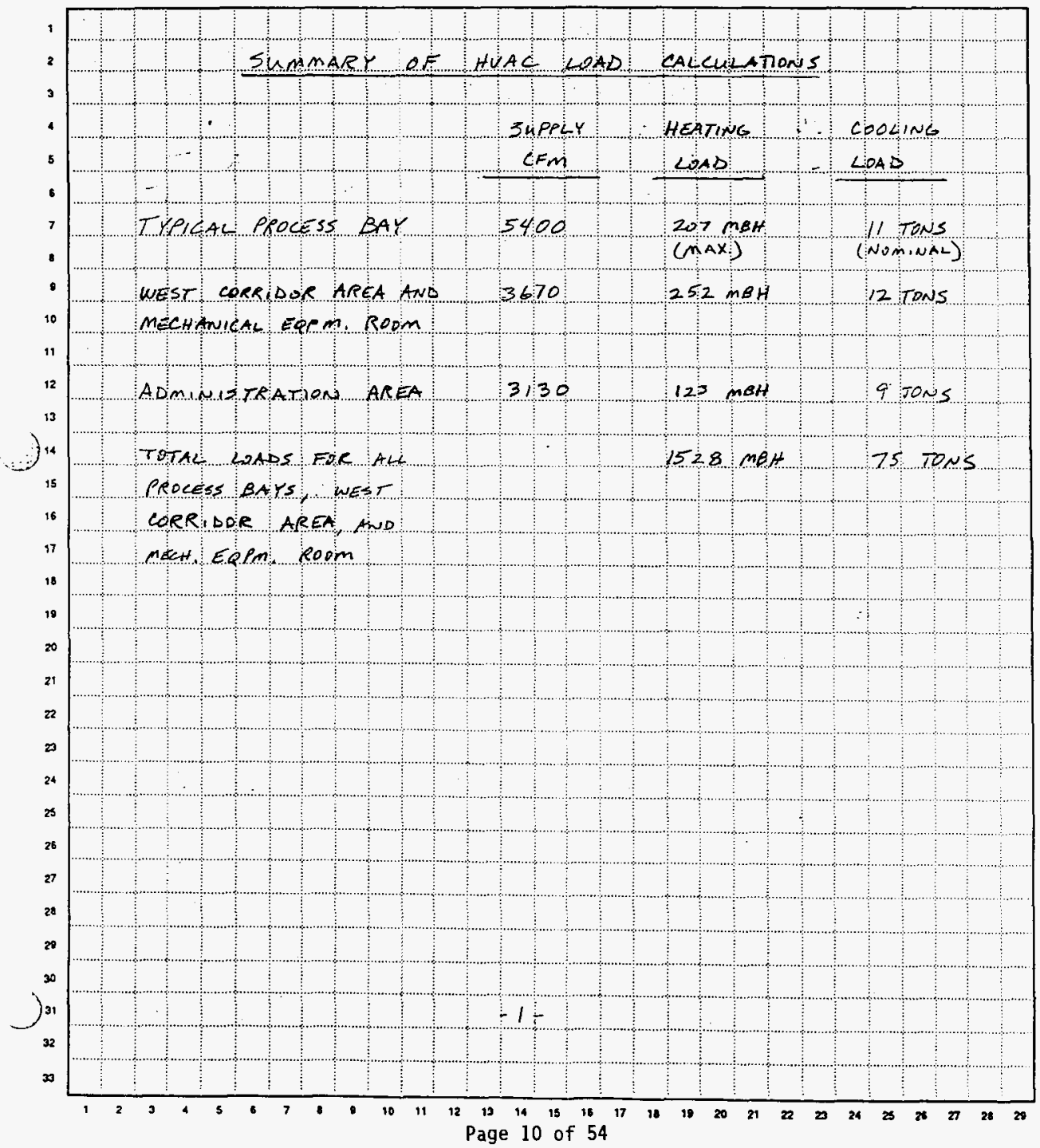


WHC-SD-SNF-CDR-003, Revision 0

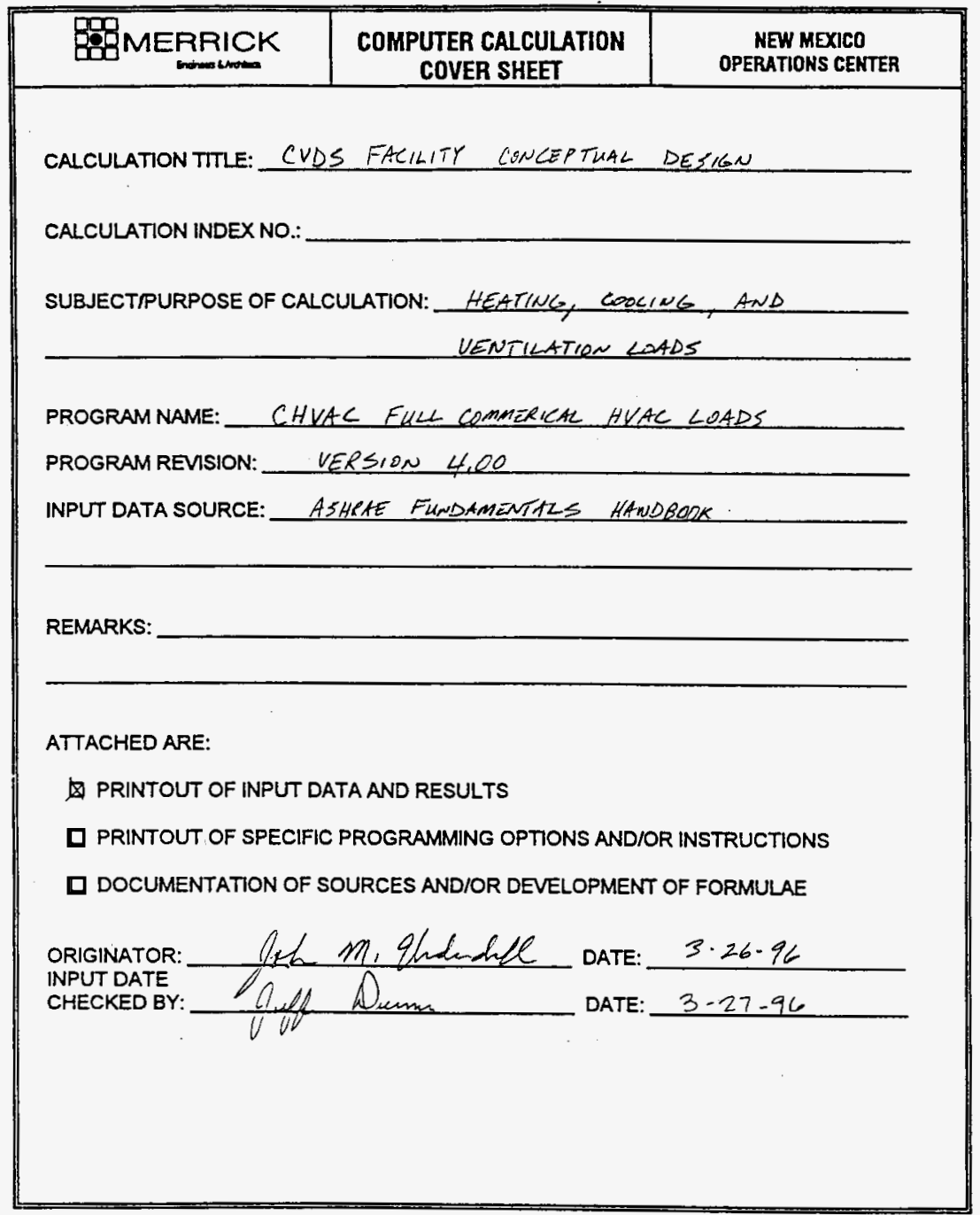

PDP-003.B 
WHC-SD-SNF-CDR-003, Revision 0 Engineering Calculation Sheet

Date $3-2 c-96$ Sheet
Contract $30012 / 3$, of
By Jmu Chkid

Subject:

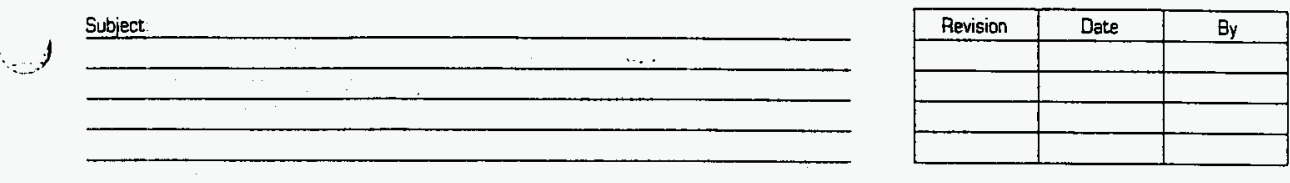

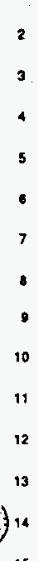

ATACH MENT A

LOADS FOC A TVPCAL PROCESS BAY AND WEST CURRIDOR AREA

17
18
10
20
21
22
23
24
25
26
27
26
20
30
31
32
33
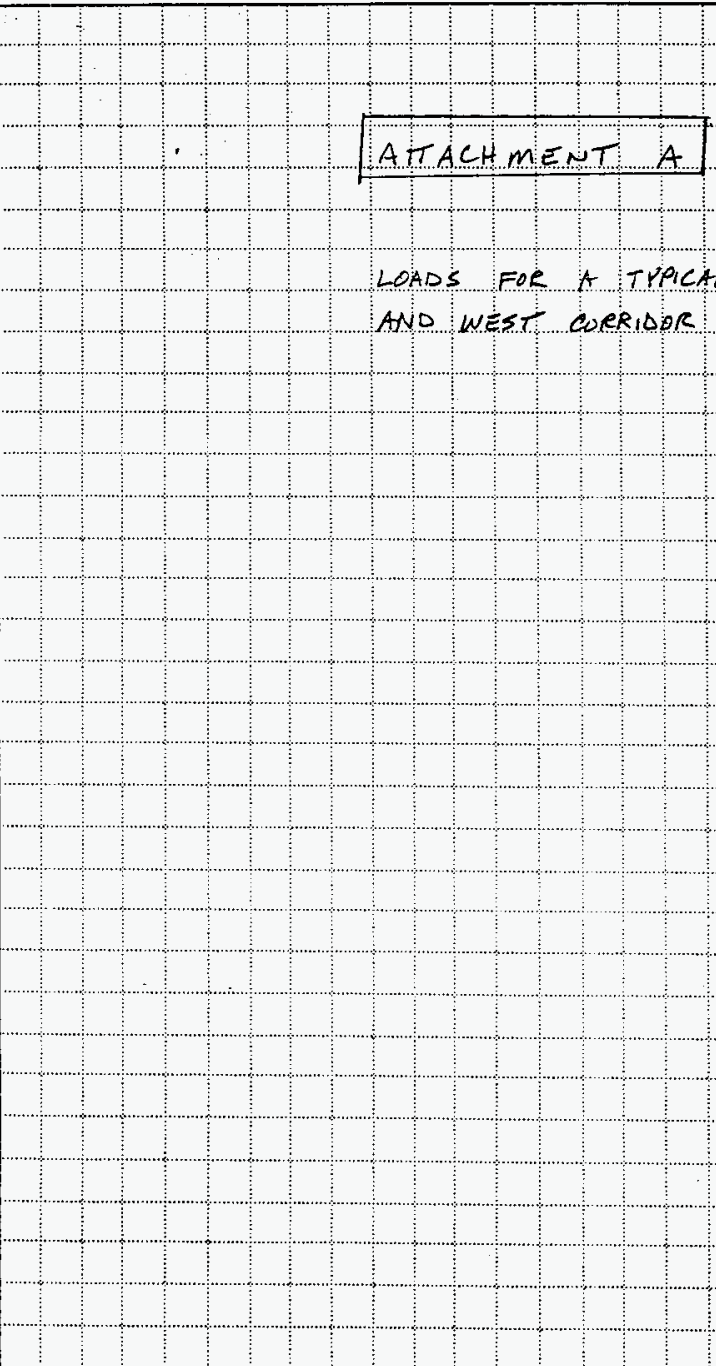
AND WERTDR

$3_{15}$ 
WHC-SD-SNF-CDR-003, Revision 0

\begin{tabular}{|c|c|c|c|c|c|c|c|c|c|c|}
\hline \multicolumn{2}{|c|}{ MERR1CK } & \multicolumn{2}{|l|}{8} & \multicolumn{3}{|l|}{ COMPANY } & \multirow{2}{*}{$\begin{array}{l}\text { PROJECT: } \\
\text { CLIENT: }\end{array}$} & \multicolumn{2}{|c|}{ CVDM-TYP.BAY/U. } & \multirow{2}{*}{$\begin{array}{r}\text { CORR. } \\
\text { DOE }\end{array}$} \\
\hline 600 & 6Тн. & \multicolumn{2}{|c|}{ STREET, } & & & \multirow{2}{*}{\multicolumn{2}{|c|}{$03-26-96$}} & \\
\hline $\operatorname{Los}$ & \multicolumn{2}{|c|}{ ALAMOS, } & NM & \multicolumn{3}{|l|}{$\begin{array}{r}\text { STE. } 103 \\
87544\end{array}$} & DATE: & & & $19: 15$ \\
\hline FULL & COMME & ERCIAL & L KVAC & LOADS PRC & OGRAM & & DESIGNER: & & & JMU \\
\hline \multicolumn{2}{|c|}{ BUILDING } & MASTE & R DATA & \multicolumn{3}{|c|}{ AND DESIGM PARAMETERS: } & & & & \\
\hline \multicolumn{2}{|c|}{ DESIGN } & \multicolumn{2}{|c|}{ OUTDOOR } & QUTDOOR & & INDOOR & INDOOR & GRAINS & \multirow{2}{*}{\multicolumn{2}{|c|}{ IH/OUTDOOR }} \\
\hline MONTK & & DRY & BULB & HET BU & & REL. HUM & DRY BULB & DIFF. & & ECTIION \\
\hline AUGUS & & & 98 & & 65 & $34 \%$ & 78 & -8.22 & & -2 \\
\hline JUNE & & & 94 & & 63 & $34 \%$ & 78 & -11.39 & & -6 \\
\hline JULY & & & 99 & & 66 & $34 \%$ & 78 & -4.89 & & -9 \\
\hline SEPTE & EMBER & & 89 & & 62 & $34 \%$ & 78 & -8.08 & & -11 \\
\hline JANUA & ARY & & 51 & & 46 & $34 \%$ & 78 & -90.48 & & -49 \\
\hline FEBRU & JARY & ' & 56 & & 49 & $34 \%$ & 78 & -8.05 & & -44 \\
\hline WINTE & & & 5 & & 0 & $50 \%$ & 72 & 0.00 & & \\
\hline ROOF & ASH & RAE & ROOF & RCOF & SUSP & & & & & \\
\hline TYPE & ROO & $F \#$ & $U-F A C$ & COLOR & CLG. & & & & & \\
\hline 1. & & 3 & 0.033 & DARK & NO & & & & & \\
\hline 2. & & 3 & 0.033 & DARK & YES & & & & & \\
\hline HALL & ASH & RAE & MALL & WALL & & & & & & \\
\hline TYPE & & Oup & U-FAC & COLOR & & & & & & \\
\hline 1. & & c & 0.048 & MED IUN & & & & & & \\
\hline 2. & & G & 0.091 & MEDIUM & & & & & & \\
\hline
\end{tabular}

GENERAL PROJECT INFORMATION:

PROJECT FILE NAME:

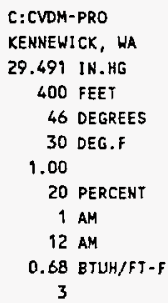


WHC-SD-SNF-CDR-003, Revision 0

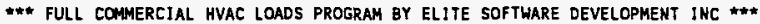
MERRICK \& COMPANY

CVDK-TYP.BAY/H. CORR.

03-26-96 19:15

LOS ALAMOS, NM 87544

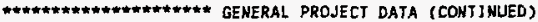

PAGE 2

BUILDING DEFAULT VALUES:

CALCULATIONS PERFORMED:

LIGHTING REQUIREMENTS:

BOTH HEATING AND COOLING LOADS

EQUIPMENT REQUIREMENIS:

PEOPLE SENSIBLE LOAD MULTIPLIER:

2.00 WATTS PER SQUARE FOOT

PEOPLE LATENT LOAD MULTIPLIER:

0.50 WATTS PER SQUARE FOOT

275 BTUHS PER PERSON

475 BTUHS PER PERSON

PEOPLE OCCUPANCY BASIS:

ZONE SENSIBLE SAFETY FACTOR:

ZONE LATENT SAFETY FACTOR:

1 PERSON PER 400 SO.FT

ZONE HEATING SAFETY FACTOR:

PEOPLE DIVER'SITY FACTOR:

LIGHTING PROFILE NUMBER:

EOUIPMENT PROFILE NUMBER:

PEOPLE PROFILE NUMBER:

BUILDING DEFAULT CLG. HEIGHT:

BUILDING DEFAULT HALL HEIGHT:

$10 \%$

Q\%

$10 \%$

$100 \%$

1

1

1

30.00 FEET

30.00 FEET

INTERNAL OPERATING LOAD PROFILES $(C=100)$ :

REF HR HR HR HR HR HR HR HR HR HR HR HR HR HR HR HR HR HR HR HR HR HR HR HR

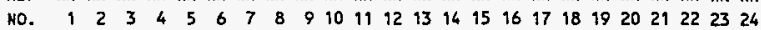

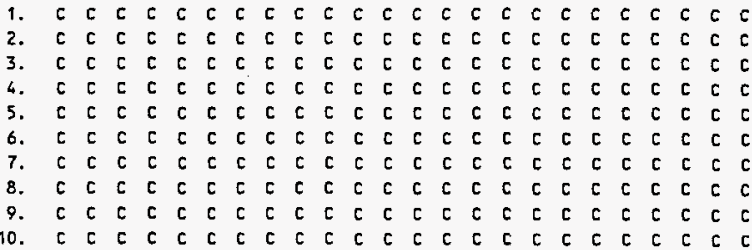

ALL DESIGN DATA TAKEN FROM THE 1989 ASHRAE HANDBOOK OF FUNDAMENTALS 


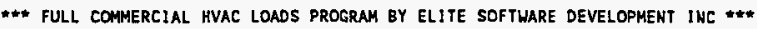
MERRICK \& COMPANY CVDH-TYP.BAY/H. CORR.

2ONE \# 1: TYPICAL BAY (1800 SF)

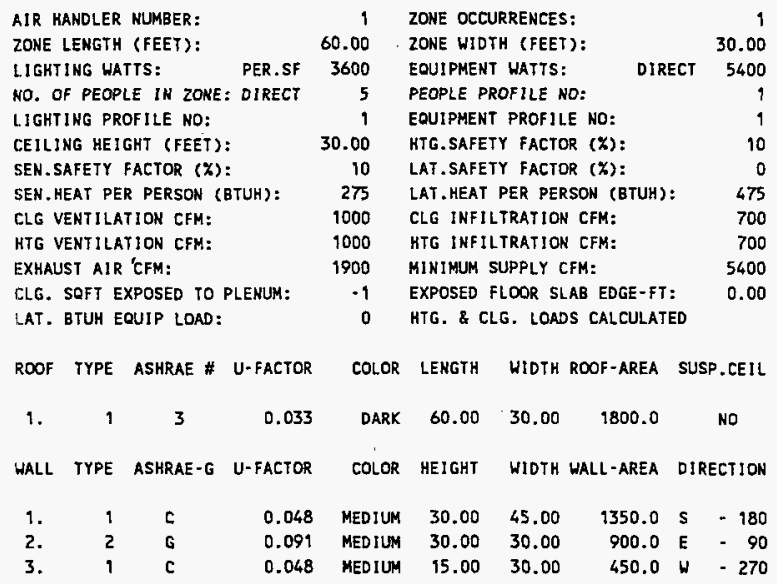


** full commercial hVAC loads program by elite software deVelopment INC ** MERRICK \& COMPANY

CVOM-TYP.BAY/W. CORR. 03-26-96 19:15 PAGE

ZONE \# 2: ACCESS CORR JDOR (1503 SF)

AIR HANDLER NUMBER:

ZONE LENGTH (FEET):

LIGHTING HATTS:

NO. OF PEOPLE IN ZONE: DIRECT

LIGHTIHG PROFILE NO:

CEILING HEIGHT (FEET):

SEN.SAFETY FACTOR $(X)$ :

SEN. HEAT PER PERSON (BTUH):

CLG VENTILATION CFM:

HTG VENTILATION CFM:

EXHAUST AIR TFM:

CLG. SEFT EXPOSED TO PLENUM:

LAT. BTUH EQUIP LOAD:

RDOF TYPE ASHRAE \# U-FACTOR
2

167.00

3006

4

1

14.00

10

275

700

700

700

$-1$

0
ZONE OCCURRENCES: ZONE WIDTH (FEET): $\quad 9.00$ EQUIPMENT WATTS: PER.SF 752 PEOPLE PROFILE NO: 3 EQUTPMENT PROF1LE NO: HTG.SAFETY FACTOR ( $\boldsymbol{x}):$ LAT.SAFETY FACTOR $(\boldsymbol{X}):$ : LAT. HEAT PER PERSON (BTUH): 275 CLG INFILTRATION CEM: HTG IHFILTRATION CFM: 75 MINIHUM SUPPLY CFM: $\quad 700$ EXPOSED FLOOR SLAB EDGE-FT: 0.00 HTG. \& CLG. LOADS CALCULATED

COLOR LENGTH WIDTH ROOF-AREA SUSP.CEIL

$\begin{array}{lllll}\text { DARK } & 167.00 & 9.00 \quad 1503.0 & \text { NO }\end{array}$

WALL TYPE ASHRAE-G U-FACTOR COLOR HEIGHT WIDTH HALL-AREA DIRECTION

1. $1 \quad 0 \quad 0.048$ MEDIUM $14.00 \quad 167.00 \quad 2338.0 \quad \mathrm{~W} \quad 270$


*** full commercial hVAC LOAdS program by ELITE SOFTWARE DEVELOPMENT INC *** MERRICK \& COMPANY CVDM-TYP.BAY $/$. CORR.

ZONE \# 3: CORRIDOR ROOMS (1980 SF)

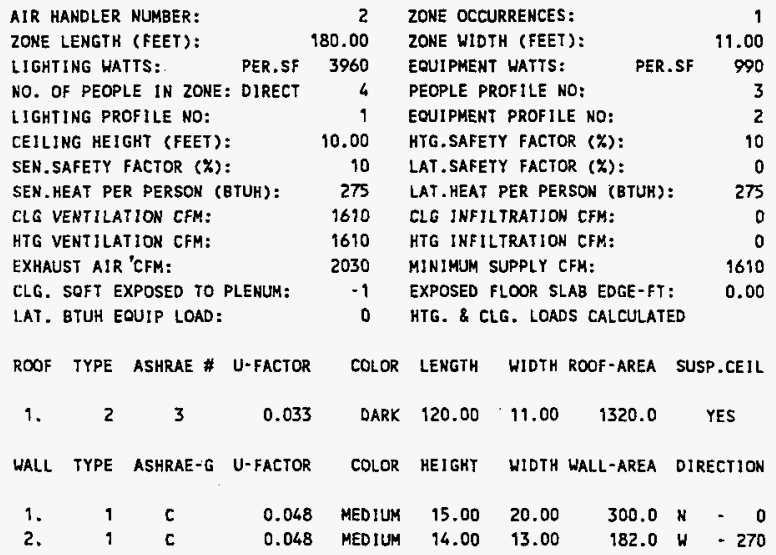


*** FULL COMMERCIAL hVAC LOADS PROGRAM BY ELITE SOFTUARE DEVELOPMENT INC *** MERRICK \& COMPANY

LOS ALAMOS, NM 87544 CVOM-TYP.BAY/L. CORR.

03-26-96 19:15

PAGE 6

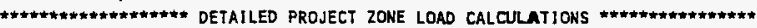

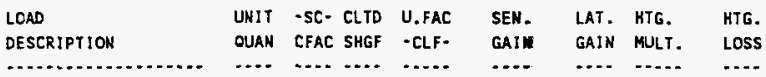

1. TYPICAL BAY SYS\# 1 PEAK TIME 3 PM JUL.

$(60 \times 30)=1800 \mathrm{sF}$

ROOF- $1-3-$ NO.CLG-D
S. WALL-1-C-M
E. WALL-2-G-M
W. WALL- $1-C-M$
LIGHTS-1
EQUIPMENT-1.
PEOPLE- 1
SUMMER INFL

HINTER INFL

IOTAL

2. ACCESS CORRIDOR SYSH 2 PEAK TIME 5 PM JUL.

ROOF-1-3-NO.CLG-D
H. WALL-1-C-M
LIGHTS-1
EQUIPMENT-2
PEOPLE-3
SUMMER INFL
HINTER INFL

TOTAL

$\begin{array}{rrrr}1503 & 1.000 & 70 & 0.033 \\ 2338 & 0.830 & 20 & 0.048 \\ 3006.00 & 1.000 & 100 \% & 3.410 \\ 752.00 & 1.000 & & 3.410 \\ 4.00 & 1.000 & 275 / 275 \\ 75 & & 19.515 \\ 75 & & & \end{array}$

700

22.768
$4099 \quad 2.211 \quad 3980$

$1014 \quad 3.216 \quad 4342$

$2025 \quad 6.097 \quad 5487$

$247 \quad 3.216 \quad 1447$

$3600.009 .000100 \% \quad 3.410 \quad 9276$

$\begin{array}{llll}5400.001 .000 & 3.410 \quad 18416\end{array}$

$5.001 .000 \quad 275 / 475 \quad 1375$

15938

0

2375

$-1607$

$71.320 \quad 49924$

\begin{tabular}{rrr}
55,385 & 768 & 65,180 \\
$\times 1.10$ & $\times 1.00$ & $\times 1.10$ \\
\hdashline 60,924 & 7.2. & $\ldots .2$. \\
\hline 688 & 71,698
\end{tabular}

$(967 \times 9)=1503 \mathrm{sF}$

\begin{tabular}{rrrr}
3472 & & 2.211 & 3323 \\
1846 & & 3.216 & 7519 \\
10250 & & & \\
2564 & 0 & & \\
1100 & 1100 & & \\
1464 & -6 & & \\
& & 71.320 & 5349 \\
& & & \\
20,696 & 1,094 & & 16,191 \\
$\times 1.10$ & $\times 1.00$ & & $\times 1.10$ \\
\hline 22,763 & 1,094 & & 17,810
\end{tabular}

$(180 \times 11)=1980 \mathrm{SF}$

3. CORRIDOR ROONS SYS\# 2 PEAK TIME 5 PM JUL.

$\begin{array}{rrrr}2788 & & 2.211 & 2919 \\ 141 & & 3.216 & 965 \\ 144 & & 3.216 & 585 \\ 13504 & & & \\ 3376 & 0 & & \\ 1100 & 1100 & & \\ & & & \\ 21,053 & 1,100 & & 4,469 \\ \times 1.10 & \times 1.00 & & \times 1.10 \\ \ldots . . & \ldots . . . & & \ldots . .2 \\ 23,158 & 1,100 & & 4,916\end{array}$




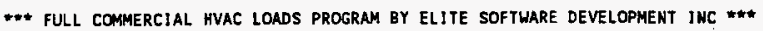
MERRICK \& COMPANY CVDM-TYP.BAY/H. CORR. LOS ALAMOS, NM 87544

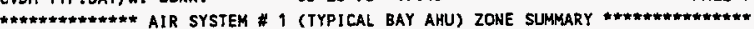

ZN. ZONE - DESCRIPTION FLOOR

NO. PEAK TIME \& MONTH AREA

... ....................

O.A. CFM

. GAIN

LAT.GAJN HTG.CFM CLG.CFN

1 TYPICAL BAY

1800

71,698

O.A. CFM

EXH. CFM

$\mathrm{CFM} / \mathrm{SF}$. CFM/SF.

3 PM JULY

1,000

60,924

-.......

2,928

$-\ldots$

ZONE PEAK TOTALS

1,800

71.698

1,000

TOTAL ZONES: 1

1,000

60,924

1,000

1,900

1.63

768

2,928

1,900

1.63

5,400

3.00 
*** fULl COMmercial hVAC LOADS PROgRAM by ELITE SOFTWARE DEVELOPMENT INC *** MERRICK \& COMPANY CVDM-TYP.BAY N. CORR.

03-26-96 19:15

LOS ALAMOS, NM 87544

PAGE 8

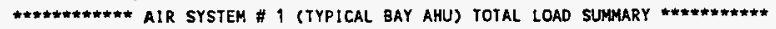

AIR HAKDLER DESC: TYPICAL BAY AHU WITH CV (PROPORTION) TERMINALS

SUPPLY AIR FAN: DRAW-THRU WITH PROGRAM ESTIMATED HORSEPONER OF 12.13 HP.

FAN INPUT: 70\% CONBINED FAN AND MOTOR EFF. WITH10.00 IN WATER ACROSS THE FAN SENSIBLE KEAT RATIO: $0.98 \ldots .$. . THIS SYSTEM OCCURS 1 TIME(S) IN THE BUILDING

AIR SYSTEM PEAK TIME: 4 PM IN JULY

OUTDOOR CONDITIONS: 98 DB, 66 WB, 45.80 GRAINS INSIDE: 78 DB, 33\% RH

BECAUSE OF THE DIVERSiTY IN ZONE, PLENUM, AND VENT, LOADS, THE ZONE SENSIBLE PEAK TIME IN JULY AT 3 PM IS DIFFERENT FROM THE TOTAL SYS. PEAK TIME HENCE, THE AIR SYSTEM CFM WAS COMPUIED USING A ZONE SEN. LOAD OF 60,924

SUMMER: EXH * CONTROLS OUTSIDE AIR -... HINTER: EXH CONTROLS OUTSIDE AIR

\begin{tabular}{|c|c|c|c|c|c|c|c|}
\hline ZONE & SPACE & SEN.LOSS: & 16,781 ВТИН & & & & \\
\hline INFILTI & IRATION & SEN.LOSS: & 54,917 вTUH & $c$ & 700 & (FN) & \\
\hline OUTSIDF & E AIR & SEN.LOSS: & 135,509 BTUH & 6 & 1,900 & (FM) & \\
\hline SUPPLY & Duct & SEN.LOSS: & O BTUH & & & & \\
\hline RETURN & DUCT & SEN.LOSS: & O BTUH & & & & \\
\hline TOTAL & SYSTEM & SEN.LOSS: & & & & & 207,207 ВТUН \\
\hline SUPPLY & AIR: 71 & $71.698 / 10.986 \times$ & $1.08 \times 231=$ & 6 & 2,928 & $(F M)$ & \\
\hline WINTER & VENT O & DUTSIDE AIR ( $64.9 \%$ & OF SUPPLY): & c & 1,900 & (FM) & \\
\hline ZONE & SPACE & SEN.GAIN: & 43,729 ВTUH & & & & \\
\hline INFILTH & FRATION & SEN.GAIN: & 16,697 ВTUН & $<$ & 700 & (FM) & \\
\hline DRAH-TH & THRU FAN & S SEN.GAIN: & 30,361 вTUH & & & & \\
\hline SUPPLY & Y DUCT & SEN.GAIN: & O BTUK & & & & \\
\hline TOTAL & SEN. GAIN & IN ON SUPPLY SIDE & OF COIL: & & & & 90,787 вTUH \\
\hline SUPPLY & AIR: 91 & $91,285 /<0.986 \times$ & $1.10 \times 16)=$ & 1 & 5,400 & (FM) & \\
\hline SUMMER & R VENT $\alpha$ & DUTSIDE AIR ( $35.2 \%$ & OF SUPP(Y): & 6 & 1,900 & (FM) & \\
\hline RETURN & N DUCT & SEN.GAIN: & O ВTUH & & & & \\
\hline RETURN & N PLENUM & 4 SEN.GAIN: & O BTUK & & & & \\
\hline OUTSIO & DE AIR & SEN.GAIN: & 41,199 BTUK & ( & 1,900 & (FM) & \\
\hline BLOW-T & THRU FAN & N SEN.GAIN: & O BTUH & & & & \\
\hline TOTAL & SEN.GAIN & IN ON RETURN SIDE & OF COIL: & & & & 41,199 BTUH \\
\hline TOTAL & SEN.GAIN & IN ON AIR HANDLING & G SYSTEM: & & & & 931,986 ВTUH \\
\hline ZONE & SPACE & LAT.GAJN: & 2,375 в UTH & & & & \\
\hline ¿NFILTH & TRATION & LAT.GAJN: & -861 вTUH & 6 & 700 & (FM) & \\
\hline OUTSIDE & DE AIR & LAT.GAIN: & $-2,337$ втUн & 6 & 1,900 & (FM) & \\
\hline TOTAL & LAT. GAII & IN ON AIR HANDLING & G SYSTEM: & & & & -823 BTUH \\
\hline TOTAL & SYSTEM & SENSIBLE AHD LATE & ENI GAIN: & & & & 131,163 BTUH \\
\hline & $\mathrm{E} E$ & WITH & AI & & & & 10.93 \\
\hline
\end{tabular}


*** FULl COMMERCIAL hVAC LOADS PROGRAM bY ELITE SOFTWARE DEVELOPMENT INC *** MERRICK \& COMPANY LOS ALAMOS, NM 87544 CVDM-TYP. BAY/H. CORR. $03-26-96 \quad 19: 15$ PAGE 9

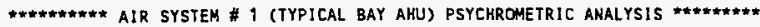

\begin{tabular}{|c|c|c|c|c|c|}
\hline SYSTEM LOAD ANALYSIS & LATENT & GRAINS & SENSI BLE & TEMP & CFM \\
\hline LEAVING COIL CONDITION & & 47.213 & & 62.408 & \\
\hline DRAH-THRU FAN & & & 30,361 & 5.186 & 711 \\
\hline MISC LOAD ON SUPPLY SIDE & & & 0 & 0.000 & 0 \\
\hline SIJPPLY AIR DUCT & & & 0 & 0.000 & 0 \\
\hline ZONE LOADS & 1,514 & 0.418 & 60,924 & 10.406 & 2,643 \\
\hline ZONE CONDITION & 1,514 & 47.631 & 91,285 & 78.000 & 5,400 \\
\hline RETURN AIR DUCT & & & 0 & 0.000 & \\
\hline RETURN AIR PLENUM & & & 0 & 0.000 & \\
\hline MISC LOAD ON RETURN SIDE & & & 0 & 0.000 & \\
\hline $1,900 \mathrm{CFM}$ & $-2,337$ & -0.646 & 41.199 & 7.037 & \\
\hline BLOW-THRU FAN & & & 0 & 0.000 & \\
\hline IS COIL COHOITION & 23 & 46.985 & 132,484 & 85.037 & $\because$ \\
\hline
\end{tabular}

GENERAL PSYCHROMETRIC EQUATIONS USED IN ANALYSIS:

PR = (BAROMEIRIC PRESSURE OF SITE / STANDARD ASHRAE PRESSURE OF 29.921)

$T S H=P R \times 1.10 \times$ CFM $\times$ (DB.ENTERING - DB.LEAVING)

$T L H=P R \times 0.68 \times$ CFM $\times$ (GRAINS.ENTERING - GRAINS.LEAVING)

GTH $=$ PR $\times 4.50 \times$ CFM $\times$ (ENTHALPY.ENTERING - ENTHALPY.LEAVING)

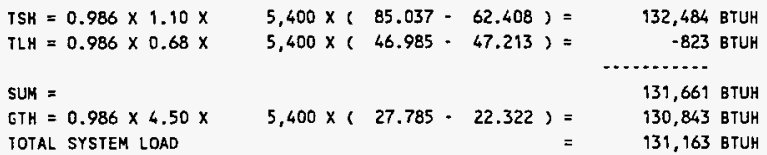

CHILLED-HOT WATER FLOW RATES:

COOLING GPM $=130,843 /(10.0 \times 500) \quad 26.2 \mathrm{GPM}$ HEATING GPM $=207,207 /(20.0 \times 500)=20.7 \mathrm{GPM}$

ENTERING COOLING COIL CONDITIONS:
DRY BULB TEMPERATURE:
85.04
WET BULB TEMPERATURE:
RELATIVE HUMIDITY(\%):
ENTHALPY:
27.79 BT
61.93
25.91
DRY BULB TEMPERATURE: $\quad 28.52$

LEAVING - COOLING COIL CONDITIONS:

DRY BULB TEMPERATURE: $\quad 62.41$

WET BULB TEMPERATURE: $\quad 53.42$

RELATIVE HUMIDITY(\%): $\quad 55.66$

ENTHALPY: $\quad 22.32$ BTU/LBM
ENTERING HEATING COIL CONOITIONS:

LEAVING HEATING COIL CONDITIONS:

ORY BULB TEMPERATURE: $\quad 95.00$ 
*** FULL COMMERCIAL hVAC LOADS PROGRAM by ELITE SOFTUARE DEVELOPMENT INC *** MERRICK \& COMPANY

LOS ALAMOS, NM 87544

CVOM-TYP.BAY/W. CORR

03-26-96 19:15

PAGE 10

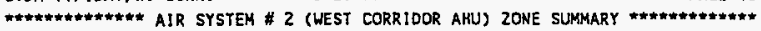

ZN. ZONE - DESCRJPIION FLOOR HTG.LOSS SEN.GAIN LAT.GAIM HTG.CFM CLG.CFM

NO. PEAK TIME \& MONTH AREA O.A. CFM O.A. CFM EXH. CFM CFM/SF. CFM/SF.

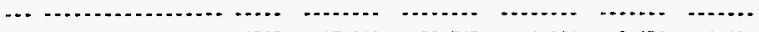

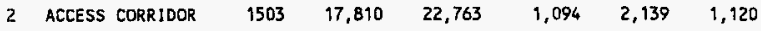

$\begin{array}{llllll}5 \text { PM JULY } & 700 & 700 & 700 & 1.42 & 0.75\end{array}$

$\begin{array}{llllllll}3 & \text { CORRIDOR ROONS } & 1980 & 4,916 & 23,158 & 1,100 & 591 & 1,610\end{array}$

$\begin{array}{lrrrrr}5 \text { PM JULY } & 1,610 & 1,610 & 2,030 & 0.30 & 0.81\end{array}$

$\begin{array}{lllllll}\text { ZONE PEAK TOTALS } & 3,483 & 22,726 & 45,921 & 2,194 & 2,730 & 2,730\end{array}$

$\begin{array}{llllll}\text { TOTAL ZONES: } 2 & 2,310 & 2,310 & 2,730 & 0.78 & 0.78\end{array}$ 
** FULL COMHERCIAL IVAC LOADS PROGRAM BY ELITE SOFTHARE DEVELOPMENT INC *** MERRICK \& CONPANY

LOS ALAMOS, NM B7544

CVDH-TYP.BAY/H. CORR.

03-26-96 19:15

PAGE 11

********** AIR SYSTEM \# 2 (WEST CORRIDOR AHU) TOTAL LOAD SUMMARY

AIR HANDLER DESC: WEST CORRIDOR AHU WITH CV (PROPORTION) TERMINALS

SUPPLY AIR FAN: DRAW-THRU WITH PROGRAM ESTIMATED HORSEPOWER OF $1.23 \mathrm{HP}$.

FAN INPUT: $70 \%$ COMBINED FAN AND MOTOR EFF. WITH 2.00 IN WATER ACROSS THE FAN SENSIBLE HEAT RATIO: $0.95 \ldots$.... THIS SYSTEM OCCURS 1 TIME(S) IN THE BUILDING

ALR SYSTEM PEAK TIME: 5 PM IN JULY

OUTDOOR CONDITIONS: 96 DB, 66 WB, 48.98 GRAINS INSIDE: 78 DB, $34 \%$ RH

SUMMER: EXY CONTROLS OUTSIDE AIR -.... WINTER: EXH CONTROLS OUTSIDE AIR

$\begin{array}{lrrr}\text { 2ONE SPACE } & \text { SEN.LOSS: } & 16,842 \text { BTUH } & \\ \text { INFILTRATION } & \text { SEN.LOSS: } & 5,884 \text { BTUH }( & 75 \text { CFM) } \\ \text { OUISIOE AIR' } & \text { SEN.LOSS: } & 194,704 \text { BTUH }( & 2,730 \text { (FM) } \\ \text { SUPPLY DUCT } & \text { SEN.LOSS: } & \text { O BTUH } & \\ \text { RETURN DUCT } & \text { SEN.LOSS: } & \text { O BTUH } & \end{array}$

TOTAL SYSTEM SEN.LOSS:

217,430 ВTUH

SUPPLY AIR: $22,726 /(0.986 \times 1.08 \times 8)=(2,730 \mathrm{CFM})$

WINTER VENT OUTSIDE AJR ( $100 \%$ OF SUPPLY): ( 2,730 CFM)

\begin{tabular}{|c|c|c|c|}
\hline SPACE & SEN,GAIN: & 44,311 в ТТН & \\
\hline INF ILTRATION & SER.GAIN: & 1,610 втUн \& & 75 (FM) \\
\hline DRAH-THRU FAN & SEN.GAIN: & 3,070 втUн & \\
\hline SUPPLY DUCT & SEN.GAIN: & О ВТUН & \\
\hline
\end{tabular}

48,999 ВTUH

SUPPLY AJR: $48,991 /(0.986 \times 1.10 \times 17)=$

2,730 (FM)

SUMMER VENT OUTSIDE AIR ( $100 \%$ OF SUPPLY): ( 2,730 CFM)

RETURN DUCT SEN.GAIN: 0 BTUH

RETURN PLENUM SER.GAIN: 0 BTUH

OUTSIDE AIR SEN.GAIN: $\quad 53,277$ BTUH ( 2,730 (FM)

BLON-THRU FAN SEN.GAIN: O BTUH

TOTAL SEN.GAIN ON RETURN SIDE OF COIL:

53,277 BTUK

TOTAL SEN.GAIN ON AIR HANDLING SYSTEM:

102,268 в тUн

ZONE SPACE LAT.GAIN: 2,200 BTUH

INFILTRATION LAT.GAIN: $\quad-6$ BTUH

-207 BTUH ( 2,73 CFM)

OUTSIDE AIR LAT.GAIN:
TOTAL LAT.GAIN ON AIR HANDLING SYSTEM:

1,987 втUн

TOTAL SYSTEM SENSIBLE AND LATENT GAIN:

104,256 ВTUH

TOTAL TONNAGE REQUIRED WITH OUTSIDE AIR:

8.69 TONS 
*** FULL COMHERCIAL HVAC LOADS PI3:II;RAM BY EIIITE SOFTWARE DEVELOPMENT INC \#\# MERRICK \& COMPANY CVM-TYP.BAY/W. CORR.

03-: $: i-96 \quad 19:-5$

LOS ALAMOS, NM 87544

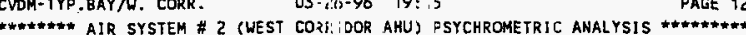

\begin{tabular}{lrrr}
\hline SYSTEM LOAD ANALYSIS & LATENT GRAINS & SENSIBLE & TEMP
\end{tabular}

GENERAL PSYCHROMETRIC EQURTIONS USED IN ANALYSIS:

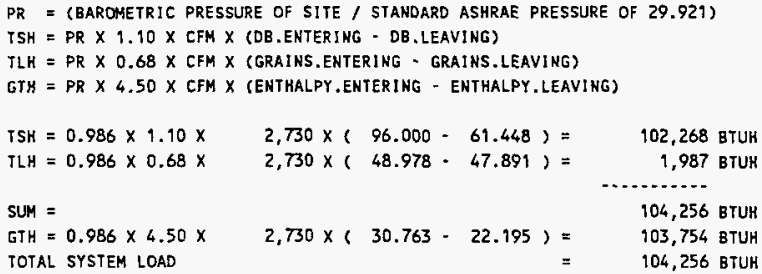

CHILLED-HOT WATER FLDW RATES:

$\begin{array}{llll}\text { COOLING GPM }= & 103,754 /(10.0 \times 500) & = & 20.8 \mathrm{GPM} \\ \text { HEATING GPM }= & 217,430 /(20.0 \times 500) & = & 21.7 \mathrm{GPM}\end{array}$

ENTERING COOLING COIL CONDITIONS:

ENTERING HEATING COIL CONOITIONS:

$\begin{array}{ll}\text { DRY BULB TEMPERATURE: } & 96.00 \\ \text { WET BULB TEMPERATURE: } & 66.00 \\ \text { RELATIVE HUMIDITY(\%): } & 19.15\end{array}$

ENTHALPY: $\quad 30.76$ BTU/LBM

LEAVING - COOLING.COIL CONDITIONS:

DRY BULB TEMPERATURE: $\quad 61.45$

HET BULB TEMPERATURE: $\quad \mathbf{5 3 . 1 9}$

RELATIVE HUMIDITY $(\%): \quad 58.39$

ENTKALPY: $\quad 22.19$ BTU/LBM
DRY BULB TEMPERATURE: $\quad 5.00$

LEAVING HEATING COIL CONDITIONS:

DRY BULB TEMPERATURE: $\quad 79.82$ 
$w^{\prime}-(-S)-S v^{\prime}=-2-023$, tev's on

ㅁㅁㅁㅁํㄹ

Engireering $C$ : : culiztion Sheret

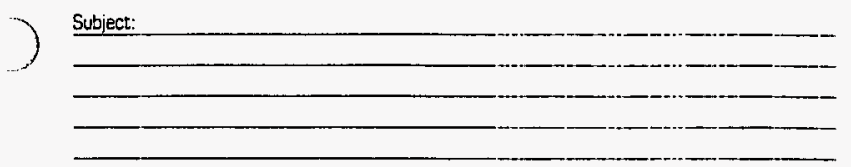

\begin{tabular}{|l|l|l|}
\hline Revision & Date & By \\
\hline & & \\
\hline & & \\
\hline & & \\
\hline & & \\
\hline
\end{tabular}

LOAD FOR MECHANICAL EQUIPAENT ROOM

(ROOM SERVED BT WEST LORRBOR AHU)

\section{$A \Pi A C H M E N T$ B}

Iete 3-26-96 Sheet

of

Oontract 30012131

Jy Jmu Chk'd 
WHC-SD-SNF-CDR-003, Revision 0

\begin{tabular}{|c|c|c|c|c|c|c|c|c|c|c|}
\hline \multicolumn{2}{|c|}{ MERRICK } & \multicolumn{2}{|l|}{ 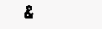 } & \multicolumn{3}{|l|}{ COMPANY } & \multirow{2}{*}{$\begin{array}{l}\text { PROJECT: } \\
\text { CLIENT: }\end{array}$} & \multicolumn{3}{|c|}{ CDS-MECH. RM. } \\
\hline 600 & GTH. & \multicolumn{2}{|c|}{ STREET, } & \multicolumn{3}{|l|}{ STE. 103} & & \multicolumn{3}{|c|}{ DOE } \\
\hline LOS & \multicolumn{2}{|c|}{ ALAMOS, } & NM & \multicolumn{3}{|l|}{87544} & DATE: & \multicolumn{2}{|c|}{$03-26 \cdot 96$} & $19: 30$ \\
\hline FULL & COMME & RIAL & 2 HVAC & LOADS PRC & ROGRAM & & DESIGNER: & & & JMU \\
\hline \multicolumn{2}{|c|}{ BUJLDING M } & ASTES & R DATA & \multicolumn{3}{|c|}{ AND DESIGN PARAMETERS: } & & & & \\
\hline \multicolumn{2}{|c|}{ DESIGW } & \multicolumn{2}{|c|}{ OUTDOOR } & \multicolumn{2}{|c|}{ OUTDOOR } & INDOOR & INDOOR & GRAINS & \multicolumn{2}{|c|}{ IN/OUTDOOR } \\
\hline MONTH & & DRY & BULB & WET BUL & JLB & REL. HUM & DRY BULB & DIFF. & CORRE & ECTION \\
\hline AUGUS & & & 98 & & 65 & $2 \pi 7$ & 85 & -8.07 & & -9 \\
\hline JUNE & & & 94 & & 63 & $27 x$ & 85 & -11.24 & & -13 \\
\hline JULY & & & 99 & & 66 & $27 \%$ & 85 & -4.74 & & -8 \\
\hline SEPIE & EMBER & & 89 & & 62 & $27 \%$ & 85 & $\cdot 7.92$ & & -18 \\
\hline JANUA & ARY & & 51 & & 46 & $27 x$ & 85 & -10.33 & & -56 \\
\hline FEBRU & JARY & 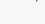 & 56 & & 49 & $27 \%$ & 85 & -7.90 & & -51 \\
\hline WINTE & & & 5 & & 0 & $50 \%$ & 50 & 0.00 & & \\
\hline RDOF & ASHR & & ROOF & ROOF & SUSP & & & & & \\
\hline TYPE & ROOF & $\#$ & $U \times F A C$ & COLOR & CLG. & & & & & \\
\hline 1. & & 3 & 0.033 & DARK & NO & & & & & \\
\hline HALL & ASHR & & WALL & WALL & & & & & & \\
\hline TYPE & GRO & & U-FAC & COLOR & & & & & & \\
\hline 1. & & c & 0.048 & MEDIUM & & & & & & \\
\hline
\end{tabular}

GENERAL PROJECT INFORMATION:

PROJECT FILE NAME:

$C:$ CVDM-MEC

PROJECT LOCATION:

KENNEUICK, HA

BAROMETRIC PRESSURE:

ALTITUDE :

29.491 IN. HG

400 FEET

46 DEGREES

NORTH LATITUDE

MEAN DAILY TEMPERATURE RANGE:

30 DEL.F

ATMOSPHERIC CLEARNESS FACTOR:

1.00

20 PERCENT

1 AM

$12 \mathrm{AM}$

STARTING TIME FOR HVAC LOAD CALCULATIONS:

FLOOR KEAT LOSS COEFFICIENT:

MUMBER OF UNIQUE ZONES IN THIS PROJECT:

0.68 BTUK/FT-F

\section{MECHANICAL ROOM SERVES BH WEST CORRIDOR AHU.}




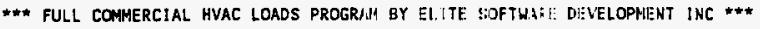
MERRICX \& COMPANY

LO: ALAMUS, NM 87544

CVDS-MECH. RM.

$03-26-! 9 \div 19: 30$

PAGE 2

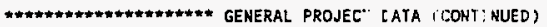

BUILDING DEFAULT VALUES:

CALCULATIONS PERFORMED:

L. IGKTING REQUIREMENTS:

EOUIPMENT REQUIREMENTS:

PEOPLE SENSIBLE LOAD MULTIPLIER:

PEOPLE LATENT LOAD MULTIPLIER:

ZONE SENSIBLE SAFETY FACTOR:

ZONE LATENT SAFETY FACTOR:

ZONE HEATING SAFETY FACTDR:

PEOPLE DIVERSITY FACTOR:

LIGHTING PROFILE NUMBER:

EOUIPMENT PROFILE NUMBER:

PEOPLE PROFILE NUMBER:

BUILDING DEFAULT CLG, HEIGHT:

BUILDING DEFAULT WALL HEIGHT:

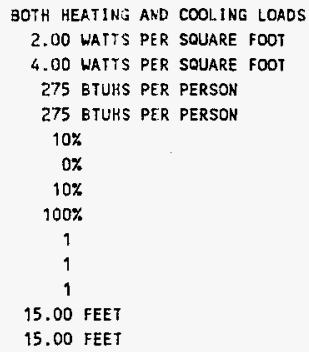

INTERNAL OPERATING LOAD PROFILES $(C=100)$ :

REF HR HR HR HR HR HR HR HR HR HR HR HR HR HR HR HR HR HR HR HR HR HR HR HR NO. $1 \begin{array}{llllllllllllllllllllllllll}1 & 2 & 3 & 4 & 5 & 6 & 7 & 8 & 9 & 10 & 11 & 12 & 13 & 14 & 15 & 16 & 17 & 18 & 19 & 20 & 21 & 22 & 23 & 24\end{array}$

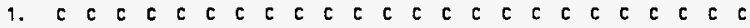

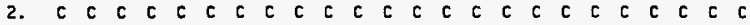

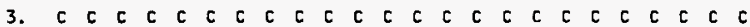

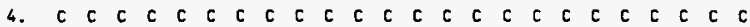

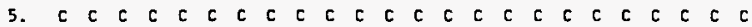

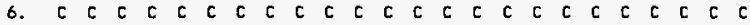

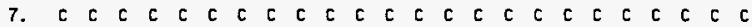

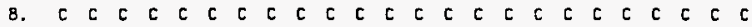

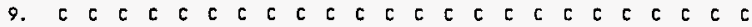

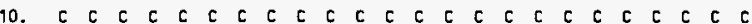

ALL DESIGN DATA TAKEN FROM THE 1989 ASHRAE HANDBOOK OF FUNDAMENTALS 
WHC-SD-SNF-CDR-003, Revision 0

** fUll commercial hVAC loads program by elite softhare DEVElopMENt INC *\#* MERRICK \& COMPANY

LOS ALAMOS, NM 87544

CVDS-MECH, RM.

03-26-96 19:30

PAGE 3

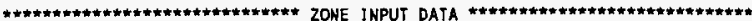

ZONE \# 1: MECH. RM. (1200 SF)

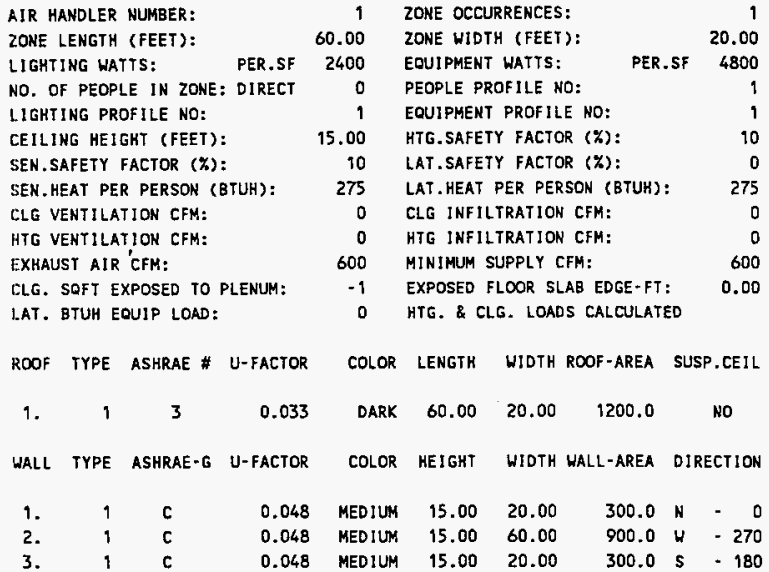


WHC-SD-SNF-CDR-003, Revision 0

\#\# FULL COMMERCIAL hVAC LOADS PROGRAM BY ELITE SOFTWARE DEVELOPMENT INC *** MERRICK \& COMPANY CVDS-MECH. RM.

$03 \cdot 26 \cdot 96 \quad 19: 30$

LOS ALAMOS, NM BTS44

CVDS

** DETAILED PROJECT ZONE LOAD

PAGE 4

$\begin{array}{llll}\text { LOAD UNIT } & \text {-SC- CLTD U.FAC } \\ \text { OESCRIPTION } & \text { QUAN } \\ \text { CFAC SHGE } & \text {-CLF- }\end{array}$

DESCRIPTION

Q...

SEN.

LAT. HTG. HTG.

GAIN GAIN MULT. LOSS

1. MECH. RM. SYS\# 1

PEAK TIME 5 PM JUL.

-...

....

ROOF-1-3-NO. CLG-D

$\begin{array}{llll}1200 & 1.000 & 63 & 0.033\end{array}$

$\begin{array}{llll}300 & 0.830 & 5 & 0.048\end{array}$

$\begin{array}{llll}900 & 0.830 & 13 & 0.048\end{array}$

N. WALL $-1-C-M$

$\begin{array}{llll}300 & 0.830 \quad 17 & 0.048\end{array}$

5. HALL- $1-C-M$

LIGHTS- 1

EQUIPMENT - 1 .

$2400.00 \quad 1.000100 \% \quad 3.410$

$4800.00 \quad 1.000$

3.410

$(60 \times 20)=1200 \mathrm{SF}$

TOTAL

$\begin{array}{rrr}27,678 & 0 & 5,022 \\ \times 1.10 & \times 1.00 & \times 1.10 \\ \ldots . .2 . & \ldots . . & \ldots . . . \\ 30,446 & 0 & 5,524\end{array}$


*** fUll commercial hVaC loads program by elite software deVElopment inc ** MERRICK \& COMPANY CVDS-MECH. RM. LOS ALAMOS, NM 87544

PAGE 5

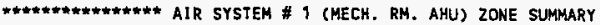

ZN. ZONE - DESCRIPTION FLOOR

HTG.LOSS SEN.GAIN

LAT.GAIN HTG.CFM CLG.CFM

NO. PEAK TIME \& MONTH AREA

O.A. CFM O.A. CFM

EXH. CFM

1 MECK. RM.

1200

……

5 PM JULY

5,524
600

ZONE PEAK TOTALS

1,200

5,524

600

30,446

0

$\mathrm{CFM} / \mathrm{SF}$.

$\mathrm{CFM} / \mathrm{SF}$.

TOTAL ZONES: ?

$\begin{array}{r}30,466 \\ -\quad 600 \\ \hline\end{array}$

600

600

-..-

30,446

600

0

0.50

936

$0.50 \quad 0.78$ 


\section{WHC-SD-SNF-CDR-003, Revision 0}

*** fULl COMMERCIAL hVAC LOADS PROGRAM BY ELITE SOFTHARE DEVELOPMENT IMC *** MERRICX \& COMPANY

CVDS-MECH. RH.

03-26-96 19:30

LOS ALAMOS, NM 87544

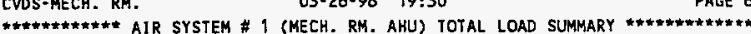

AIR HANDLER DESC: MECK. RM. AHU WITH CV (PROPORTION) TERMINALS

SENSIBLE HEAT RATIO: 1.00 ..... THIS SYSTEM OCCURS 1 TIME(S) IN THE BUILDING

AIR SYSTEM PEAK TIME: 5 PM IN JULY

DUTDOOR CONDITIONS: $96 \mathrm{DB}, 66 \mathrm{WB}, 48.98$ GRAINS INSIDE: 85 DB, $27 \%$ RH

SIMMER: EXH CONTROLS OUTSIDE AIR …. WINTER: EXH CONTROLS OUTSIDE AIR

$\begin{array}{lrrr}\text { ZONE SPACE } & \text { SEN.LOSS: } & 5,524 \text { BTUH } & \\ \text { INFILTRATION } & \text { SEN.LOSS: } & \text { O BTUH }( & \text { O (FM) } \\ \text { OUTSIDE AIR } & \text { SEN.LOSS: } & 28,741 \text { BTUH }( & 600 \text { (FM) } \\ \text { SUPPLY DUCT } & \text { SEN.LOSS: } & \text { O BTUH } & \\ \text { RETURN DUCT } & \text { SEN.LOSS: } & \text { O BTUH } & \end{array}$

TOTAL SYSTEM SEN.LOSS:

34,265 ВTUH

SUPPLY AIR: $5,524 /(0.986 \times 1.08 \times 9)=(600 \mathrm{CFM})$

WINTER VENT OUTSIDE AIR ( $100 \%$ OF SUPPLY): ( 600 CFM)

ZONE SPACE SEN.GAIN:

INFILTRATION SEN.GAIN:

30,446 втUH

O BTUH ( O CFM)

DRAW-THRU FAN SEN.GAIN: $\quad 0$ BTUH

SUPPLY DUCT SEN.GAIN: O BTUH

TOTAL SEN.GAIN ON SUPPLY SIDE OF COIL:

30,446 BTUH

SUPPLY AIR: $30,446 /(0.986 \times 1.10 \times 30)=(\quad 936$ [FM $)$

SUMMER VENT OUTSIDE AIR ( $64.1 \%$ OF SUPPLY): ( 600 CFM)

RETURN DUCT SEN.GAIN: 0 BTUH

RETURN PLENUM SEN.GAIN: 0 BTUH

OUTSIDE AIR SEN.GAIN: $\quad 7,156$ BTUH

BLOH-THRU FAN SEN.GAIN: 0 BTUH

TOTAL SEN.GAIN ON RETURN SIDE OF COIL:

7. 156 BTUK

TOTAL SEN.GAIN ON AIR HANOLING SYSTEM:

37,602 вTUH

ZONE SPACE LAT.GAIN: 0 BTUH

INFILTRATION LAT.GAIN: O BTUH :

OUTSIDE AIR LAT.GAIN: 15 BTUH (

0 (FM)

TOTAL LAT.GAIN ON AIR KANDLING SYSTEM:

600 (FM)

TOTAL SYSTEM SENSIBLE AND LATENT GAIN:

15 BTUH

37,617 BTUH

TOTAL TONNAGE REQUIRED WITH OUTSIDE AIR:

3.13 TONS 
*** FULL COMMERCIAL hVAC LOADS PROCBAM BY FLITE SOFTWARE DEVELOPMENT INC *** MERRICK \& COMPANY

LOS ALAMOS, NM 87344

CVDS-RECH. RM.

03-2t:-5o $19: 30$

PAGE 7

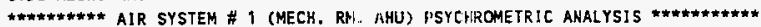

\begin{tabular}{|c|c|c|c|c|c|}
\hline SYSTEM LOAD ANALYSIS & LATEKT & GRA:NS & SENSIBLE & TEMP & CFM \\
\hline LEAVING COIL CONDITION & & 48.939 & & 55.000 & \\
\hline DRAW-THRU FAN & & & 0 & 0.000 & 0 \\
\hline MISC LOAD ON SUPPLY SIDE & & & 0 & 0.000 & 0 \\
\hline SUPPLY AIR DUCT & & & 0 & 0.000 & 0 \\
\hline ZONE LOADS & 0 & 0.000 & 30,446 & 30.002 & 936 \\
\hline ZONE CONDITION & 0 & 48.939 & 30,446 & 85.000 & 936 \\
\hline RETURN AIR DUCT & & & 0 & 0.000 & \\
\hline RETURN AIR PLENUM & & & 0 & 0.000 & \\
\hline MISC LOAD ONं RETURN SIDE & & & 0 & 0.000 & \\
\hline VENT AIR & 15 & 0.024 & 7,156 & 7.051 & \\
\hline BLOW-THRU FAN & & & 0 & 0.000 & \\
\hline ENTERING COIL CONDITION & 15 & 48.963 & 37,602 & 92.051 & 936 \\
\hline
\end{tabular}

GENERAL PSYCHROMETRIC EQUATIONS USED IN ANALYSIS:

PR = (BAROMETRIC PRESSURE OF SITE / STANDARD ASHRAE PRESSURE OF 29.921)

$T S H=P R \times 1.10 \times$ CFM $\times$ (DB.ENTERING - DB.LEAVING)

$T L H=P R \times 0.68 \times$ CFM $\times$ (GRAINS.ENTERING - GRAINS.LEAVING)

$G T H=P R \times 4.50 \times$ CFM $\times$ (ENTHALPY.ENTERING - ENTHALPY.LEAVING)

TSH $=0.986 \times 1.10 \times$

$T L H=0.986 \times 0.68 \times$

$936 \times(92.051-55.000)=$

37,600 BTUH

SUM $=$

$936 \times(48.963 \cdot 48.939)=$

15 BTUH

GTH $=0.986 \times 4.50 \times$

$936 \times(29.801-20.790)=$

37,615 BTUH

TOTAL SYSTEM LOAD

37,410 втUH

CHILLED-HOT WATER FLOW RATES :

$\begin{array}{llll}\text { COOLING GPM }= & 37,410 /(10.0 \times 500) & = & 7.5 \mathrm{GPM} \\ \text { HEATING GPM }= & 34,265 /(20.0 \times 500) & = & 3.4 \mathrm{GPH}\end{array}$

ENTERING COOLING COIL CONDITIONS:

ENTERING HEATING COIL CONDITIONS:

DRY BULB TEMPERATURE: 92.05

DRY BULB TEMPERATURE: $\quad 5.00$

WET BULB TEMPERATURE: $\quad 64.72$

RELATIVE HUMIDITY $(\%): \quad 29.63$

ENTHALPY: $\quad 29.80 \mathrm{BTU} / \mathrm{LBM}$

LEAVING - COOLING COIL CONDITIONS:

LEAVING HEATING COIL CONDITIONS:

DRY BULB TEMPERATURE: $\quad 55.00$

DRY BULB TEMPERATURE: $\quad 58.65$

WET BULB TEMPERATURE: $\quad 50.74$

RELATIVE HUMIDITY( $\%$ : $\quad 75.20$

ENTHALPY: $\quad 20.79$ BTU/LBM 
$-3,-3 i-63-0 / 13$, Revision 0

员口 NERFICK :̈ngineering De idtation Sheet

Date $3-26-96$ Sheet

of

By $\operatorname{Iin} u \quad$ Chk'd

Subject:

\begin{tabular}{|l|l|l|}
\hline Revision & Date & By \\
\hline & & \\
\hline & & \\
\hline & & \\
\hline & & \\
\hline
\end{tabular}

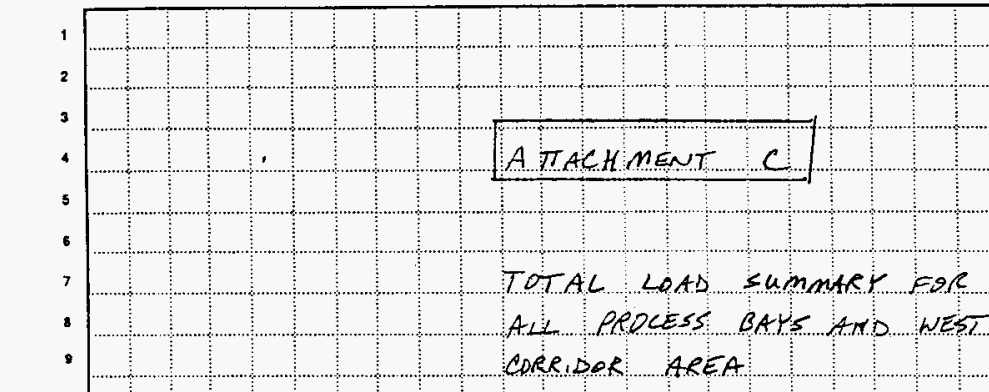

at 14

15

16

17

18

18

20

21

22

23

24

2

26

27

2

2

30

${ }_{31}^{30}$

3 


\begin{tabular}{|c|c|c|c|c|c|c|c|c|c|}
\hline \multicolumn{2}{|c|}{ MERRICK } & & \multicolumn{3}{|l|}{ COMPANY } & PROJECT: & \multicolumn{2}{|c|}{ CVDS-BAYS \& $\mathrm{H}$. } & \multirow{2}{*}{$\begin{array}{r}\text { CORR. } \\
\text { DOE }\end{array}$} \\
\hline 6006 & 6TH. STR & EET, & STE. 103 & & & CLIENT: & & & \\
\hline LOS & ALAMOS, & NM & 87544 & & & DATE: & $03-2$ & 8.96 & $20: 15$ \\
\hline FULL & COMMERCIA & L HVAC L & LOADS PRC & DGRAM & & DESIGNER: & & & JMU \\
\hline BUILDI & ING MASTE & R DATA A & AND DESIC & GN PAR & RAMETERS: & & & & \\
\hline DESIGI & OUT & DOOR & OUTDOOF & & INDOOR & INDOOR & GRAINS & IN/O & OUTDOOR \\
\hline MONTH & DRY & BULB & HET BUI & & REL. HUM & DRY BULB & DIFF. & CORR & RECTION \\
\hline AUGUS & & 98 & & 65 & $34 \%$ & 78 & -8.22 & & -2 \\
\hline JUNE & & 94 & & 63 & $34 \%$ & 78 & -11.39 & & -6 \\
\hline JULY & & 99 & & 66 & $34 \%$ & 78 & -4.89 & & -1 \\
\hline SEPTEI & MBER & 89 & & 62 & $34 \%$ & 78 & -8.08 & & -11 \\
\hline JANUA & & 51 & & 46 & $34 \%$ & 78 & -10.48 & & -49 \\
\hline FEBRU & ARY & 56 & & 49 & $34 \%$ & 78 & -8.05 & & -44 \\
\hline WINTE & & 5 & & 0 & $50 \%$ & 72 & 0.00 & & \\
\hline ROOF & ASHRAE & $800 F$ & ROOF & SUSP & & & & & \\
\hline TYPE & ROOF \# & $U-F A C$ & COLOR & CLG. & & & & & \\
\hline 1. & 3 & 0.033 & DARK & No & & & & & \\
\hline 2. & 3 & 0.033 & DARK & YES & ; & & & & \\
\hline WALL & ASHRAE & WALL & WALL & & & & & . & \\
\hline TYPE & GRDUP & $U-F A C$ & COLOR & & & & & & \\
\hline 1. & c & 0.048 & MEOIUM & & & & & & \\
\hline 2. & G & 0.091 & MEDIUM & & & & & & \\
\hline
\end{tabular}

GENERAL PROJECT INFORMATION:

PROJECT FILE NAME:

PROJECT LOCATION:

BAROMETRIC PRESSURE:

ALIITTUDE:

NORTH LATITUDE:

MEAN DAILY TEMPERATURE RANGE:

ATMOSPHERIC CLEARNESS FACTOR:

GROUND REFLECTANCE:

STARTING TIME FOR HVAC LOAD CALCULATIONS: ENDING TIME FOR HVAC LOAD CALCULATIONS: FLOOR HEAT LOSS COEFFICIENT:

NUMBER OF UNIQUE ZONES IN THIS PROJECT:

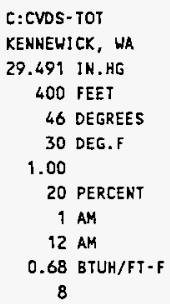




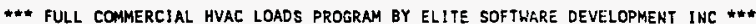
MERRJCK \& COMPANY

CVDS-BAYS \& $\mathrm{H}$. CORR.

BUILDING DEFAULT VALUES:

CALCULATIONS PERFORMED:

LIGHTING REOUIREMENTS:

EQUIPMENT REQUIREMENTS:

PEOPLE SENSIBLE LOAD MULTIPLIER:

PEOPLE LATENT LOAD MULTIPLIER:

PEOPLE OCCUPANCY BASIS:

ZONE SENSIBLE SAFETY FACTOR:

ZONE LATENT SAFETY FACTOR:

ZONE HEATING SAFETY FACTOR:

PEOPLE DIVER'SITY FACTOR:

LIGHTING PROFILE NUMBER:

EQUIPMENT PROFILE NUMBER:

PEOPLE PROFILE NUMBER:

BUILDING DEFAULT CLG. HEIGHT:

BUILDING DEFAULT WALL HEIGHT:

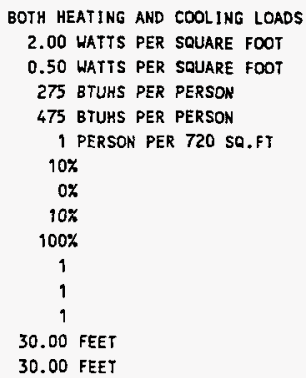

INTERNAL OPERATING LOAD PROFILES $(C=100)$ :

REF HR HR HR HR HR HR HR HR HR HR HR HR HR HR HR HR HR HR HR HR HR HR HR HR NO. $\quad \begin{array}{llllllllllllllllllllllll}2 & 3 & 4 & 5 & 6 & 7 & 8 & 9 & 10 & 11 & 12 & 13 & 14 & 15 & 16 & 17 & 18 & 19 & 20 & 29 & 22 & 23 & 24\end{array}$

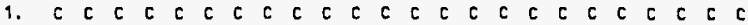

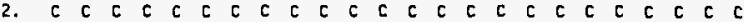

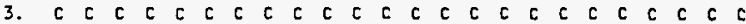

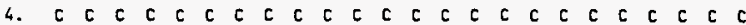

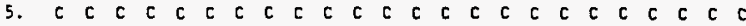

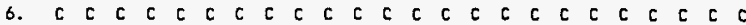

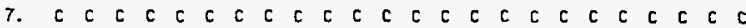

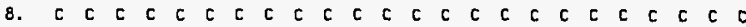

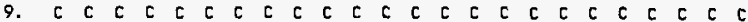

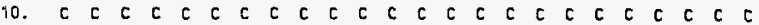

RLL DESIGN DATA TAKEN FROM THE 1989 ASHRAE HANDBOOK OF FUNDAMENTALS 
*** FULl COMMERCIAL HVAC LOADS PROGRAM BY ELITE SOFTWARE DEVELOPMENT INC *\#* MERRICK \& COMPANY

CVDS-BAYS \& W. CORR.

03-26-96 20:15

L.OS ALAMOS, NM 87546

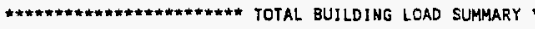

PAGE 3

BUILDING PEAKS IN JULY AT 4 PM

\begin{tabular}{|c|c|c|c|c|c|c|c|}
\hline $\begin{array}{l}\text { BLDG. LOAD } \\
\text { DESCRIPTIONS }\end{array}$ & $\begin{array}{l}\text { AREA } \\
\text { GUAN }\end{array}$ & $\begin{array}{l}\text { SEN. } \\
\text { LOSS }\end{array}$ & $\begin{array}{l}\text { ZTOT } \\
\text { LOSS }\end{array}$ & $\begin{array}{l}\text { LAT. } \\
\text { GAIN }\end{array}$ & $\begin{array}{l}+\quad \text { SEN. } \\
\text { GAIN }\end{array}$ & $\begin{array}{r}=\text { TOTAL } \\
\text { GAIN }\end{array}$ & $\begin{array}{l}\text { *TOT } \\
\text { GAIN }\end{array}$ \\
\hline & . & & & & & & \\
\hline ROOF & 13,623 & 33,134 & 2.30 & 0 & 35,081 & 35,081 & 4.05 \\
\hline WALL & 13,170 & 63,701 & 4.42 & 0 & 18,188 & 18,188 & 2.10 \\
\hline GLASS & 0 & 0 & 0.00 & 0 & 0 & 0 & 0.00 \\
\hline SKIN LORDS & 26,793 & 96,835 & 6.72 & 0 & 53,269 & 53,269 & 6.14 \\
\hline 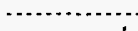 & & & 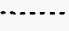 & & & & . \\
\hline LIGHTING & 28,566 & 0 & 0.00 & 0 & 107,153 & 107,153 & 12.36 \\
\hline EOUIPMENT & 34,142 & 0 & 0.00 & 0 & 128,064 & 128,064 & 14.77 \\
\hline PEOPLE & 23 & 0 & 0.00 & 8,458 & 6,005 & 14,463 & 1.67 \\
\hline PARTITION & 0 & 0 & 0.00 & 0 & 0 & 0 & 0.00 \\
\hline VENT 14,130 & 14,130 & $1,007,758$ & 69.98 & $-31,205$ & 306,393 & 275,988 & 31.73 \\
\hline :NFL $\quad 4,275$ & 4,275 & 335,386 & 23.29 & $-1,190$ & 103,460 & 102,270 & 11.79 \\
\hline DRAW-THRU FAN & & 0 & 0.00 & 0 & 186,771 & 186,771 & 21.54 \\
\hline BLOW-THRU FAN & & 0 & 0.00 & 0 & 0 & 0 & 0.00 \\
\hline SUPPLY DUCT & & 0 & 0.00 & 0 & 0 & 0 & 0.00 \\
\hline RETURN DUCT & & 0 & 0.00 & 0 & 0 & 0 & 0.00 \\
\hline UILDING TOTAL & & 1.439. & 00.00 & $-23,937$ & 891,115 & 867,178 & 100.00 \\
\hline
\end{tabular}

\begin{tabular}{|c|c|c|c|c|c|c|}
\hline $\begin{array}{l}\text { BUILDING SUMMARY } \\
\text { LOAD DESCRIPTIONS }\end{array}$ & $\begin{array}{l}\text { SEN. } \\
\text { LOSS }\end{array}$ & $\begin{array}{l}\text { xTOT } \\
\text { LOSS }\end{array}$ & $\begin{array}{l}\text { LAT. } \\
\text { GAIN }\end{array}$ & $\begin{array}{l}\text { SEN. } \\
\text { GAIN }\end{array}$ & $\begin{array}{r}=\text { TOTAL } \\
\text { GAIN }\end{array}$ & $\begin{array}{l}\text { BTOT } \\
\text { GAIN }\end{array}$ \\
\hline$+\ldots+\ldots$ & & & & & & \\
\hline VENTILATION & $1,007,758$ & 69.98 & $-31,205$ & 306,393 & 275,188 & 31.73 \\
\hline INFILTRATION & 335,386 & 23.29 & $-1,190$ & 103,460 & 102,270 & 11.79 \\
\hline ZONE LOADS & 96,835 & 6.72 & 8,458 & 294,491 & 302,949 & 34.94 \\
\hline PLENUM LOADS & 0 & 0.00 & 0 & 0 & 0 & 0.00 \\
\hline FAN \& DUCT LOADS & 0 & 0.00 & 0 & 186,771 & 186,771 & 21.54 \\
\hline & & & & & & . \\
\hline JILDING TOTALS & $1,439,979$ & 100.00 & $-23,937$ & 891,115 & 867,178 & 100.00 \\
\hline
\end{tabular}

TOTAL BUILDING SUPPLY AIR (BASED ON A 95 TD): TOTAL BUILOING VENT AIR ( $40.21 \mathrm{X}$ OF SUPPLY):

TOTAL CONDITIONED AIR SPACE:

SUPPLY AIR CFM/SO.FT. OF CONDITIONED SPACE:

SO.FT OF. CONDITIONED AIR SPACE PER TON:

IONNAGE PER SQ.FT OF CONDITIONED AIR SPACE:

TOTAL HEATING REQUIRED WITH OUTSIDE AIR: TOTAL TONNAGE REOUIREO WITH OUISIOE AIR:
$35,130 \mathrm{CFM}$

$94,130 \mathrm{CFM}$

94,283 SQ.FT

$2.4596 \mathrm{CFM} / \mathrm{SQ} . \mathrm{FT}$

197.6480 SO.FT/TON

0.0051 TONS/SO.FT

$1,439,98 \mathrm{MBH}$

72.26 IONS 


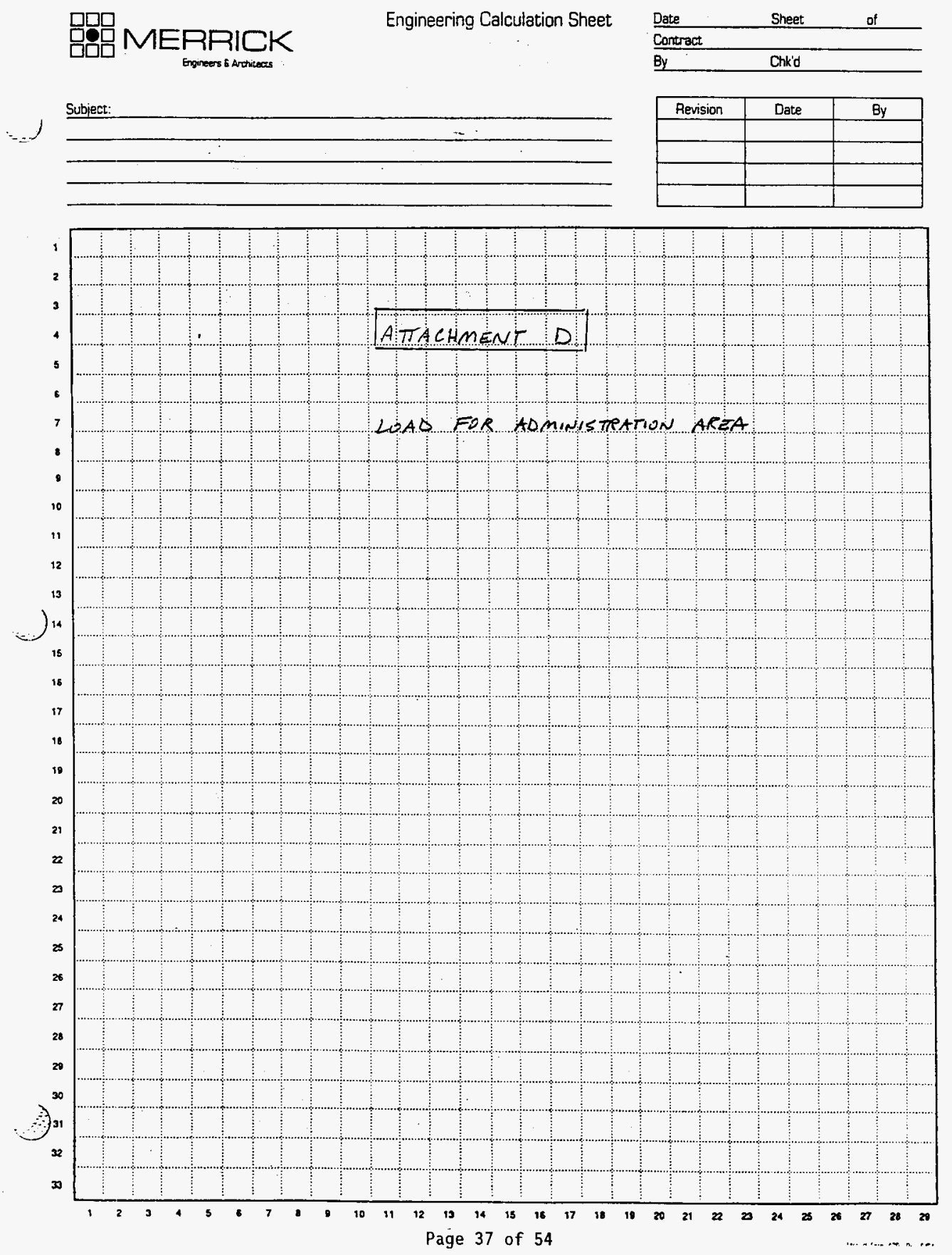


WHC-SD-SNF-CDR-0:3, Revision $C$

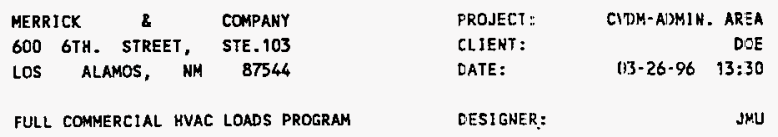

BUILDING MASTER DATA AND DESIGN PARAMETERS:

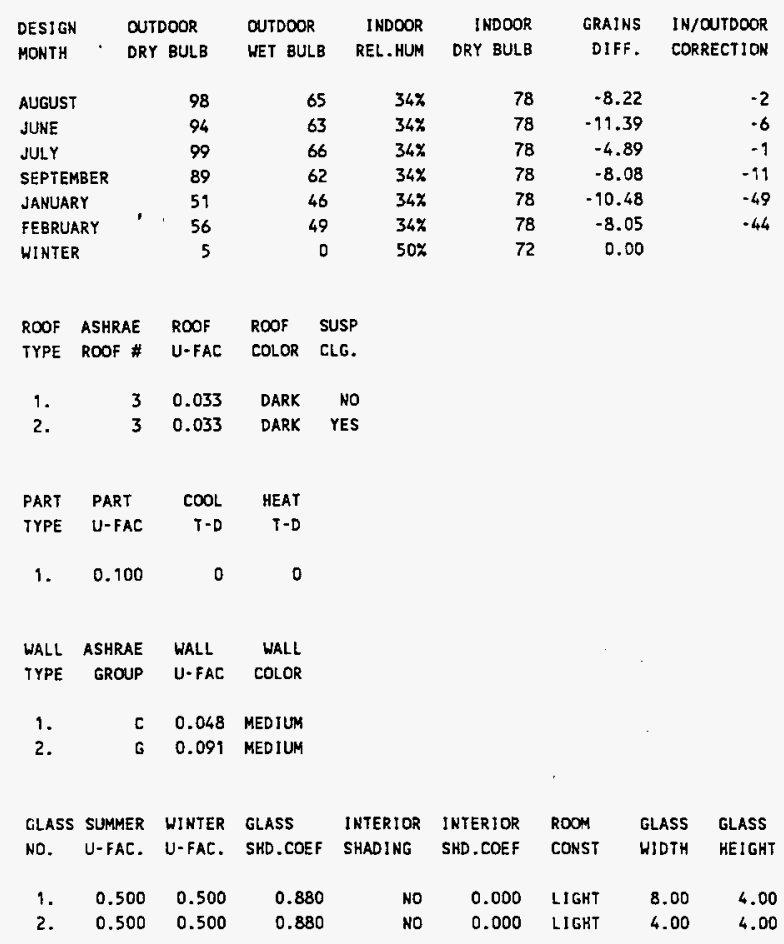


*** fUll commercial hVAC loads progran by elite softhare DeVelopment INC *** MERRICK \& COMPANY CVDM-ADMIN. AREA LOS ALAMOS, NM 87544 PAGE 3

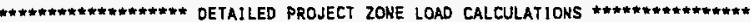

$\begin{array}{lllllll}\text { LOAD } & \text { UNIT } & \text {-SE- CLTD U.FAC } & \text { SEN. LAT. HTG. HTG. } \\ \text { DESCRIPTION } & \text { QUAN CFAC SHGF -CLF- } & \text { GAIN } & \text { GRIN MULT. LOSS }\end{array}$

1. LUNCH ROOM SYS\# I PEAK TIME 2 PM SEP.

$\begin{array}{lrrrr}\text { ROOF-2-3-SUSP.C-D } & 264 & 1.000 & 27 & 0.033 \\ \text { E. WALL-1-C-M } & 164 & 0.830 & 12 & 0.048 \\ \text { S. WALL- } 1-C-M & 298 & 0.830 & 14 & 0.048 \\ \text { S. GLS- } 1-90 \text {-TRANS } & 32 & 1.000 & 2 & 0.500 \\ \text { OKS- O- L- NS-SOLAR } & 32 & 0.880 & 216 & 0.650 \\ \text { E. GLS- 2- 90-TRANS } & 16 & 1.000 & 2 & 0.500 \\ \text { OXS- O- L- NS-SOLAR } & 16 & 0.880 & 195 & 0.320 \\ \text { LIGHTS-1 } & 528.00 & 1.000 & 100 \% & 3.410 \\ \text { EOUIPMENT-2 } & 132.00 & 1.000 & & 3.410 \\ \text { FEOPLE-3 } & 1.76 & 1.000 & 275 / 275 \\ \text { SUHMER INFL } & 13 & & 10.842 \\ \text { WINTER INFL } & 13 & & \end{array}$

TOTAL
GAIN GRIN MULT. LOSS

$(22 \times 12)=2645 F$

$2.211 \quad 584$

$3.296 \quad 527$

3.296958

$33.500 \quad 1072$

$33.500 \quad 536$

16

879

1800

$450 \quad 0$

$484 \quad 484$

$141-95$

\begin{tabular}{|c|c|c|}
\hline & & 927 \\
\hline 8,194 & 389 & 4,604 \\
\hline$\times 1.10$ & $\times 1.00$ & $\times 1.10$ \\
\hline$\cdots$ & ..... & $\cdots$ \\
\hline 9,013 & 389 & 5,0 \\
\hline
\end{tabular}

$(14 \times 12)=168 \mathrm{sF}$

\begin{tabular}{|c|c|c|c|c|c|c|c|c|}
\hline ROOF-2-3-\$USP.C-D & 168 & 1.000 & 27 & 0.033 & 150 & & 2.211 & 371 \\
\hline s. WALL-1-C-M & 164 & 0.830 & 14 & 0.048 & 7 & & 3.216 & 527 \\
\hline S. GLS- 2- 90-TRANS & 16 & 1.000 & 2 & 0.500 & 16 & & 33.500 & 536 \\
\hline OXS- O- L- NS-SOLAR & 16 & 0.880 & 216 & 0.650 & 1977 & & & \\
\hline LIGHTS-1 & 336.00 & 1.000 & $100 \%$ & 3.410 & 1146 & & & \\
\hline EQUI PNENT - 2 & 84.00 & 1.000 & & 3.410 & 286 & 0 & & \\
\hline PEOPLE - 3 & 1.12 & 1.000 & & $2 \pi / 275$ & 308 & 308 & & \\
\hline SUMMER INFL & 8 & & & 10.842 & 87 & -58 & & \\
\hline WINTER INFL & B & & & & & & 71.320 & 571 \\
\hline \multirow[t]{4}{*}{ TOTAL } & & & & & 4,047 & 250 & & 2,005 \\
\hline & & & & & $\times 1.10$ & $\times 1.00$ & & $\times 1.10$ \\
\hline & & & & & $\ldots .$. & $+\ldots$. & & $\cdots$ \\
\hline & & & & & 4,452 & 250 & & 2,206 \\
\hline
\end{tabular}


** FULL COMMERCIAL hVAC LOADS PROGRAM BY ELITE SOFTHAFE DEVELOPMENT INC \#* MERRICK \& COMPANY

CVDH-ADMIN. AREA

D3-26-96 $\quad 13: 30$

LOS ALAMOS, NM 87544

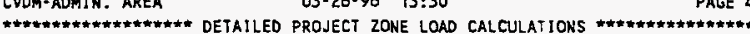

LOAD UNIT -SC- CLTD U.FAC SEN. LAT, HTG. HTG.

D..................

3. SHIFT MANAGER SYS\# 1 PEAK TIME 5 PM AUG. $\quad(13 \times 12)=156$ SF

\begin{tabular}{|c|c|c|c|c|c|c|c|c|}
\hline ROOF-2-3-SUSP. E-D & 156 & 1.000 & 58 & 0.033 & 299 & & 2.211 & 345 \\
\hline 5. HALL-1-C-M & 179 & 0.830 & 26 & 0.048 & 182 & & 3.216 & 576 \\
\hline H. WALL-1-C-M & 164 & 0.830 & 17 & 0.048 & 108 & & 3.216 & 527 \\
\hline S. GLS- 2- 90 -TRANS & 16 & 1.000 & 11 & 0.500 & 88 & & 33.500 & 536 \\
\hline O*S- O- L- NS-SOLAR & 16 & 0.880 & 173 & 0.430 & 1047 & & & \\
\hline w. GLS- 2- 90 -TRANS & 16 & 1.000 & 11 & 0.500 & 88 & & 33.500 & 536 \\
\hline OZS- 0- L: NS-SOLAR & 16 & 0.880 & 212 & 0.640 & 1910 & & & \\
\hline LIGHTS-1 & 312.00 & 1.000 & $100 \%$ & 3.410 & 1064 & & & \\
\hline EOUIPMENT - 2 & 78.00 & 1.000 & & 3.410 & 266 & 0 & & \\
\hline PEOPLE-3 & 1.04 & 1.000 & & $275 / 275$ & 286 & 286 & & \\
\hline SUMHER INFL & 8 & & & 18.431 & 147 & -42 & & \\
\hline HINTER INFL & 8 & & & & & & 71.320 & 571 \\
\hline \multirow[t]{4}{*}{ TOTAL } & & & & & 5,485 & 244 & & 3,091 \\
\hline & & & & & $\times 1.10$ & $\times 1.00$ & & $\times 1.10$ \\
\hline & & & & & 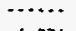 & 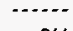 & & $\ldots$ \\
\hline & & & & & 6,034 & 244 & & 3,400 \\
\hline
\end{tabular}

4. EAST CORRIDOR SYS\# 1 PEAK TIME 5 PM JUL.

$(48 \times 6)=288 \mathrm{SF}$

ROOF-2-3-SUSP, C-D

$288 \quad 1.000 \quad 64 \quad 0.033$

E. HALL $+1-C-M$

LIGHTS+1

EQUI PMENT - 2

PEOPLE-3

SUMHER INFL

HINTER INFL

$\begin{array}{llll}720 & 0.830 & 30 & 0.048\end{array}$

$576.00 \quad 1.000 \quad 100 \% \quad 3.410$

144.001 .000 . $\quad 3.410$

$1.921 .000 \quad 275 / 275$

$14 \quad 19.515$

14

$2.211 \quad 637$

$3.216 \quad 2316$

855

1964

$491 \quad 0$

$528 \quad 528$

$273 \quad-42$

$79.320 \quad 998$

TOTAL

\begin{tabular}{rrr}
4,719 & 486 & 3,951 \\
$\times 1.10 \times 1.00$ & $\times 1.10$ \\
\hline 5,191 & 486 & $-\ldots .7$ \\
\hline
\end{tabular}


** FULL COMMERCIAL hVAC LOADS PROGRAM BY ELITE SOFTWARE DEVELOPMENT INC *** MERRICK \& COMPANY LOS ALAMOS, NH 87544

CVDN-ADMJN. AREA $03-26.96 \quad 13: 30$ PAGE 5

LOAD

UN1T -SC- CLTD U.FAC

DESCRIPTION

OUAN CFAC SHGF -CLF-

SEN.

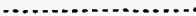

-..............

GAIN

GAIM MULT. LOSS

5. SQUTH CORRIDOR SYS\# 1 PEAK TIME 5 PM JUL.

$(44 \times 6)=264 \mathrm{SF}$

ROOF-2-3-SUSP.C-D $\quad 264 \quad 1.000 \quad 64 \quad 0.033$

W. WALL-1-C-M

$\begin{array}{llll}74 & 0.830 & 20 & 0.048\end{array}$

W. GLS- 2- 90-TRANS

$16 \quad 1.000 \quad 12 \quad 0.500$

OXS- O- L- NS-SOLAR

$\begin{array}{llll}16 & 0.880 & 215 & 0.640\end{array}$

LIGHTS- 1

$528.00 \quad 1.000 \quad 100 \% \quad 3.410$

EQUIPMENT - 2

132.001 .000

3.410

1.761 .000

$275 / 275$

SUMMER INFL

13

19.515

WINTER INFL

13

$2.219 \quad 584$

$3.216 \quad 238$

$33.500 \quad 536$

TOTAL

\begin{tabular}{|c|c|c|c|}
\hline 558 & & 2.211 & 584 \\
\hline 58 & & 3.216 & 238 \\
\hline 96 & & 33.500 & 536 \\
\hline \multicolumn{4}{|l|}{1937} \\
\hline \multicolumn{4}{|l|}{1800} \\
\hline 450 & 0 & & \\
\hline 484 & 484 & & \\
\hline \multirow[t]{2}{*}{254} & -39 & & \\
\hline & & 71.320 & 927 \\
\hline 5,637 & 445 & & 2,285 \\
\hline 1.10 & $\times 1.00$ & & $\times 1.10$ \\
\hline .... & ....... & & $\ldots . .$. \\
\hline 6,201 & 445 & & 2,594 \\
\hline
\end{tabular}

6. ELEC/CONM ROON SYS\# 1 PEAK TIME 4 PM JUL.

$(12 \times 12)=144 \mathrm{SF}$

ROOF-2-3-SUSP.C-D

$144 \quad 1.000 \quad 61 \quad 0.033$

290

$2.211 \quad 318$

LIGHTS-1

EQUIPMENT - 2

PEOPLE-3

$288.00 \quad 1.000100 \% \quad 3.410$

982

72.001 .000

3.410

0.961 .000

$275 / 275$

SUMAMER INFL

WINTER INFL

7

21.684

2460

$264 \quad 264$

$152-36$

$79.320 \quad 499$

TOTAL

\begin{tabular}{rrr}
1,934 & 228 & 817 \\
$\times 1.10 \times 1.00$ & $\times 1.10$ \\
\hline $2 . .2$ & $\times-2$. & $-\ldots$. \\
\hline 2,127 & 228 & 899
\end{tabular}

7. CONTROL ROOM SYS\# 1 PEAK TIME 4 PM JUL.

$(22 \times 12)=264 \mathrm{SF}$

ROOF-2-3-SUSP, C-D

$264 \quad 1.000 \quad 61 \quad 0.033$

531

$2.219 \quad 584$

LIGHTS- 1

EQU! PMENT - 2

PEOPLE-3

SUMMER INFL

WINTER INFI

$528.00 \quad 1.000100 \% \quad 3.410$

1800

$450 \quad 0$

$32.001 .000 \quad 3.410$

$1.761 .000 \quad 275 / 275$

$484 \quad 484$

$282-67$

13

21.684

$71.320 \quad 927$

TOTAL

\begin{tabular}{rrr}
3,547 & 417 & 1,511 \\
$\times 1.10 \times 1.00$ & $\times 1.10$ \\
\hline 2.2 & $\cdots .2$. & -1.2 \\
3,902 & 417 & 1,662
\end{tabular}


* FULL COMMERCIAL HVAC LOADS PROGRAM BY ELITE SOFTWARE DEVELOPMENT INC *** MERRITK \& COMPANY CVDM-ADMIN. AREA $03-26-96 \quad 13: 30$ LOS ALAMOS, NM 87544

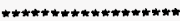
DETAILED PROJECT ZONE LOAD CALCULATIONS

PAGE 6

\begin{tabular}{|c|c|c|c|c|c|c|c|}
\hline LOAD & $\begin{array}{l}\text { UNIT } \\
\text { QUAN }\end{array}$ & $\begin{array}{l}\text {-SC- } \\
\text { CFAC }\end{array}$ & $\begin{array}{l}\text { CLTD } \\
\text { SHGF }\end{array}$ & $\begin{array}{l}\text { U.FAC } \\
\text {-CLF- }\end{array}$ & $\begin{array}{l}\text { SEN. } \\
\text { GAIN }\end{array}$ & $\begin{array}{l}\text { LAT. } \\
\text { GAIH }\end{array}$ & $\begin{array}{l}\text { KTG. } \\
\text { MULT. }\end{array}$ \\
\hline 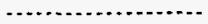 & & $\ldots$ & - & $\cdots$ & $\cdots$ & $\ldots$ & - \\
\hline
\end{tabular}

8. RAD MONITOR SYS\# 1 PEAK TIME 5 PM JUL.

$\{20 \times 10\rangle=200 \mathrm{SF}$

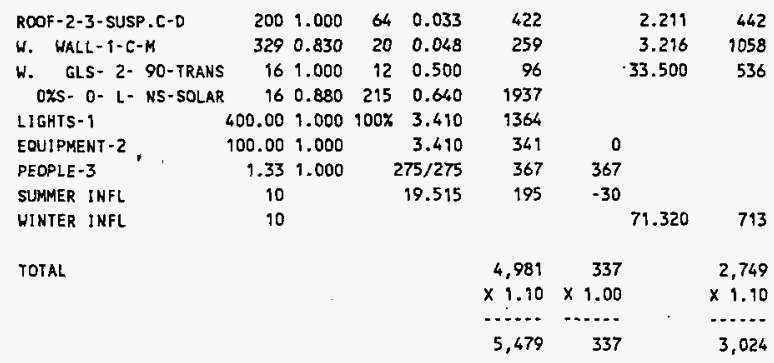

9. CONTROLLED AREA SYS\# 1 PEAX TIME 5 PM JUL.

$(23 \times 12)=276 \mathrm{SF}$

\begin{tabular}{|c|c|c|c|c|c|c|c|c|}
\hline ROOF-2-3-SUSP,C-D & 276 & 1.000 & 64 & 0.033 & 583 & & 2.211 & 610 \\
\hline W. WALL- $1-C-M$ & 285 & 0.830 & 20 & 0.048 & 225 & & 3.216 & 917 \\
\hline LIGHTS-1 & 552.00 & 1.000 & $100 \%$ & 3.490 & 1882 & & & \\
\hline EQUI PMENT - 2 & 138.00 & 1.000 & & 3.410 & 471 & 0 & 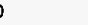 & \\
\hline PEOPLE-3 & 1.84 & 1.000 & & $275 / 275$ & 506 & \multicolumn{2}{|l|}{506} & \\
\hline SUMMER INFL & 14 & & & 99.515 & 273 & \multicolumn{2}{|l|}{.42} & \\
\hline WINTER INFL & 14 & & & & & \multicolumn{2}{|r|}{71.320} & 998 \\
\hline \multirow[t]{4}{*}{ TOTAL } & & & & & 3,940 & 464 & & 2,525 \\
\hline & & & & & $\times 1.10$ & $\times 1.00$ & & $\times 1.10$ \\
\hline & & & & & $\ldots \ldots$ & n.... & & $\cdots$ \\
\hline & & & & & 4,334 & 464 & & 2,778 \\
\hline 10. CHANOE ROOMS & SYS\# $1 P$ & EAK TIM & UE $4 P$ & PM JUL. & & \multicolumn{2}{|c|}{$(30 \times 30)=$} & $900 \mathrm{SF}$ \\
\hline ROOF-2-3-5USP.C-D & 900 & 1.000 & 61 & 0.033 & 1812 & \multicolumn{2}{|r|}{2.211} & 1990 \\
\hline LIGHTS - I & 1800.00 & 1.000 & $100 \%$ & 3.410 & 6138 & \multirow{2}{*}{\multicolumn{2}{|c|}{0}} & \\
\hline EOUIPMENT - 2 & 450.00 & 1.000 & & 3.410 & 1535 & & & \\
\hline PEOPLE-3 & 6.00 & 1.000 & & $275 / 275$ & 1650 & \multicolumn{2}{|l|}{1650} & \\
\hline SUMMER INFL & 45 & & & 21.684 & 976 & \multicolumn{2}{|l|}{-232} & \\
\hline WINTER INFL & 45 & & & & & \multicolumn{2}{|r|}{71.320} & 3209 \\
\hline \multirow[t]{4}{*}{ TOTAL } & & & & & 12,111 & 1,418 & - & 5,199 \\
\hline & & & & & $\times 1.10$ & $\times 1.00$ & & $\times 1.10$ \\
\hline & & & & & $\ldots .$. & ....... & & $\ldots$ \\
\hline & & & & & 13,322 & 1,418 & & 5,719 \\
\hline
\end{tabular}


WHC-SD-SNF-CDR-003, Revision 0

FULl COMMERCIAL hVAC LOADS PROGRAM BY ELITE SOFTWARE DEVELOPMENT INC \#\# MERRICK \& COMPANY

CVDN-ADMIN. AREA

$03-26.96 \quad 13: 30$

LOS ALAMOS, NM 87544

\begin{tabular}{|c|c|c|c|c|c|c|c|c|}
\hline ZN. & ZONE - DESCRIPTION & FLOOR & HTG.LOSS & SEN.GAIN & LAT.GAIN & HTG.CFH & CLG.CFM & \\
\hline NO. & PEAK TIME \& MONTH & AREA & O.A. CFM & $O . A$. CFM & EXH. CFM & $\mathrm{CFM} / \mathrm{SF}$. & $\mathrm{CFM} / \mathrm{SF}$. & \\
\hline .. & $\ldots+\ldots$ & $\ldots$ & $\ldots \ldots \ldots$ & $\ldots \ldots$ & $\ldots \ldots$ & $\ldots \ldots$ & $\ldots \ldots$ & \\
\hline \multirow[t]{2}{*}{$\mathfrak{t}$} & LUNCH ROOM & 264 & 5,064 & 9,013 & 389 & 207 & 361 & 360 \\
\hline & 2 PM SEPTEMBER & & 35 & 35 & 0 & 0.78 & 1.37 & \\
\hline \multirow[t]{2}{*}{2} & QUAL ASSURANCE & 968 & 2,206 & 4,452 & 250 & 90 & 179 & 180 \\
\hline & 2 PM SEPTEMBER & & 22 & 22 & 0 & 0.54 & 1.07 & \\
\hline \multirow[t]{2}{*}{3} & SHIFT MANAGER & 156 & 3,400 & 6,034 & 244 & 139 & 242 & 240 \\
\hline & 5 PM AUGUST & & 21 & 21 & 0 & 0.89 & 1.55 & \\
\hline \multirow[t]{2}{*}{4} & EAST COR'RIDOR & 288 & 4,346 & 5,191 & 486 & 178 & 288 & 290 \\
\hline & 5 PM JULY & & 38 & 38 & 0 & 0.62 & 1.00 & \\
\hline \multirow[t]{2}{*}{5} & SOUTH CORRIDOR & 264 & 2,514 & 6,201 & 445 & 103 & 264 & 26 \\
\hline & 5 PM JULY & & 35 & 35 & 0 & 0.39 & 1.00 & \\
\hline \multirow[t]{2}{*}{6} & ELEC/COMM ROON & 146 & 899 & 2,127 & 228 & 37 & 144 & 140 \\
\hline & 4 PH JULY & & 19 & 19 & 0 & 0.26 & 1.00 & \\
\hline \multirow[t]{2}{*}{7} & CONTROL ROOM & 264 & 1,662 & 3,902 & 417 & 68 & 264 & 260 \\
\hline & 4 PM JULY & & 35 & 35 & 0 & 0.26 & 1.00 & \\
\hline \multirow[t]{2}{*}{8} & RAD MONITOR & 200 & 3,024 & 5,479 & 337 & 124 & 220 & 220 \\
\hline & 5 PM JULY & & 27 & 27 & 200 & 0.62 & 1.10 & \\
\hline \multirow[t]{2}{*}{9} & CONTROLLED AREA & 276 & 2,778 & 4,334 & 464 & 113 & 276 & 280 \\
\hline & 5 PM JULY & & 37 & 37 & 276 & 0.41 & 1.00 & \\
\hline \multirow[t]{3}{*}{10} & CHANGE ROOMS & 900 & 5,719 & 13,322 & 1,418 & 234 & 900 & 400 \\
\hline & 4 PM JULY & & 120 & 120 & 800 & 0.26 & 1.00 & ـــ \\
\hline & & $\cdots$ & $\cdots$ & $\cdots$ & $\ldots$ & $\cdots$ & $\cdots$ & \\
\hline \multirow{2}{*}{\multicolumn{2}{|c|}{$\begin{array}{l}\text { ZONE PEAK TOTALS } \\
\text { TOTAL ZONES: } 10\end{array}$}} & 2,924 & 31,612 & 60,055 & 4,678 & 1,293 & 3,138 & 3130 \\
\hline & & & 389 & 389 & 1,276 & 0.44 & 1.07 & \\
\hline
\end{tabular}


*** full commercial hVac loads program gy elite software deVelopment inc *** MERRICK \& COMPANY

LOS ALAMOS, NM 87544

CVDM-ADMIN, AREA

$03-26-96 \quad 13: 30$

PAGE 8

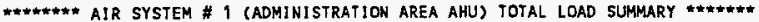

AIR HANDLER DESC: ADMINISTRATION AREA AHU WITH CV (SUM OF PEAKS) TERMINALS SENSIBLE HEAT RATIO: 0.94 -.... THIS SYSTEM OCCURS 1 TIME(S) IN THE BUILDING

AIR SYSTEM PEAK TIME: 5 PM IN JULY

OUTDODR CONDITIONS: 96 DB, 66 WB, 48.98 GRAINS INSIDE: 78 DB, $37 \%$ RH

SUMMER: EXH CONTROLS OUTSIDE AIR $\ldots$ WINTER: EXM CONTROLS OUTSIDE AIR

$\begin{array}{lrrr}\text { ZONE SPACE } & \text { SEN.LOSS: } & 20,236 \text { BTUH } & \\ \text { INFILTRATION } & \text { SEN.LOSS: } & 11,376 \text { BTUH }( & 145 \text { (FM) } \\ \text { OUTSIDE AIR } & \text { SEN.LOSS: } & 91,005 \text { BTUH }( & 1,276 \text { (FM) } \\ \text { SUPPLY DUCT } & \text { SEN.LOSS: } & 0 \text { BTUH } & \\ \text { RETURH DUCT } & \text { SEN.LOSS: } & 0 \text { BTUH } & \end{array}$

TOTAL SYSTEM SEN LOSS:

122,617 BTUH

SUPPLY AIR: $31,612 /(0.986 \times 1.08 \times 23)=(1,291 \mathrm{CFM})$

WINTER VENT OUTSIDE AIR ( $98.8 \%$ OF SUPPLY): ( 1,276 (FM)

\begin{tabular}{|c|c|c|c|}
\hline SPACE & SEN.GAIN: & 54,318 в & \\
\hline INFILTRATION & SEN.GAIN: & 3,914 STUH & 145 (FN) \\
\hline DRAW-THRU FAN & SEN.GAIN: & $O$ BTUH & \\
\hline SUPPLY DUCT & SEN.GAIN: & O BTUH & \\
\hline REHEAT & SEN.GAIN: & 20,830 BTUH & \\
\hline
\end{tabular}

TOTAL SEN.GAIN ON SUPPLY SIDE OF COIL:

78,262 ВTUH

SUPPLY AIR: $78,262 /(0.986 \times 1.10 \times 23)=(3,138 \mathrm{CFM})$

SUMMER VENT OUTSIDE AIR ( $40.7 \%$ OF SUPPLY): ( 1,276 CFM)

RETURN DUET SEN.GAIN: O BTUH

RETURN PLENUM SEN.GAIN: 0 BTUH

OUTSIDE AIR SEN.GAIN: 24,902 BTUH ( 1,276 (FM)

BLOW-THRU FAN SEN.GRIN: 0 BTUH

TOTAL SEN.GAIN ON RETURN SIDE OF COIL:

24,902 BTUH

TOTAL SEN.GAIN ON AIR HANDLING SYSTEM:

103,164 BTUH

ZONE SPACE LAT.GAIN: $\quad 5,361$ BTUH

INFILTRATION LAT.GAIN: $\quad .436$ BTUH ( 145 (FM)

OUTSIDE AIR LAT.GAIN: $\quad-3,847$ BTUK ( 1,276 CFM)

TOTAL LAT.GAIN ON AIR HARDLING SYSTEM:

1,078 BTUH

TOTAL SYSTEM SENSIBLE AND LATENT GAIN:

104,242 В

TOTAL TONNAGE REQUIRED WITH OUTSIOE AIR:

8.69 TONS 


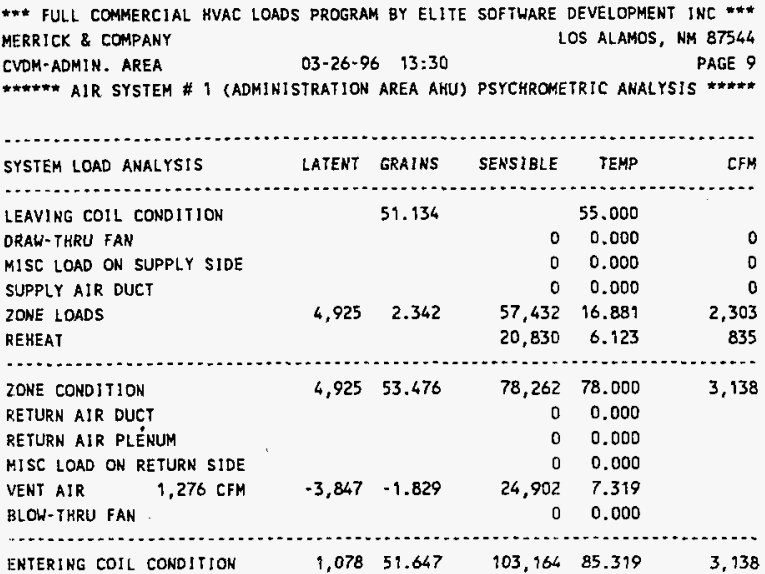

ENTERING COIL CONDITION $1,07851.647$ 3.138

GENERAL PSYCHROMETRIC EQUATIONS USED IN ANALYSIS:

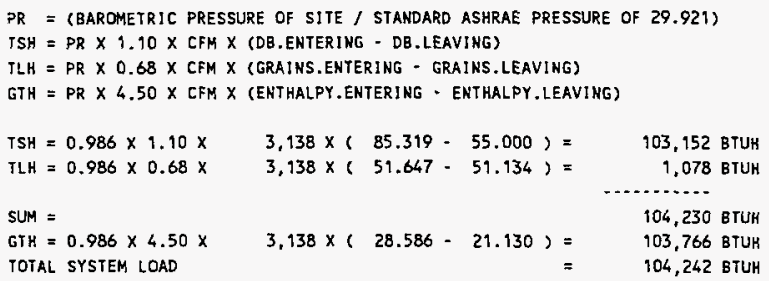

CHILLED-HOT WATER FLOW RATES:

$\begin{array}{llll}\text { COOLINE GPM }= & 103,766 /(90.0 \times 500) & = & 20.8 \mathrm{GPM} \\ \text { HEATING GPM }= & 122,617 /(20.0 \times 500) & = & 12.3 \mathrm{GPM}\end{array}$

ENTERING CDOLING COIL CONDITIONS:

ENTERING HEATING COIL CONDITIONS:

DRY BULB TEMPERATURE: $\quad 85.32$ WET BUL B TEMPERATURE: $\quad 63.03$

DRY BULB TEMPERATURE: $\quad 5.88$

RELATIVE HUMIDITY $(\%): \quad 28.18$

ENTHALPY: $\quad 28.59$ BTU/LBM

LEAVING COOLING COIL CONDITIONS: LEAVING HEATING COIL CONDITIONS:

DRY BULB TEMPERATURE: $\quad 55.00$ ORY BULB TEMPERATURE: 95.00

WET BULB TEMPERATURE: $\quad 51.33$

RELRTJVE HUMIDITY $(\%): \quad 78.53$

ENTHALPY: $\quad 21.13$ BTU/LBM 


\section{哭 MERRICK}

Subject: Cold Vacuum Drying Module - K Basins

Spent Nuclear Fuel Removal Project

Conceptual Design

Process Calculations

Engir 1s: ring 'alcula tion Shee:

\begin{tabular}{|c|c|c|}
\hline Date & $03 / 27 / 96$ & Sheet \\
\hline Contract & 30012131 & Task 14 \\
\hline 1̈y & & Chk'd \\
\hline Calcuiation & Number: & VS-001 thru VS-003 \\
\hline
\end{tabular}

\begin{tabular}{|c|c|c|}
\hline Revision & Date & By \\
\hline & & \\
\hline & & \\
\hline & & \\
\hline
\end{tabular}

Table Of Contents

\author{
Description \\ MCO Temperature Control System Heat Transfer \\ Initial Pumpdown - Water Removed \\ Initial Heat and Purge Cycle - Water Removal
}

$\begin{array}{lr}\text { Calc No. } & \text { Page } \\ \text { vs-001 } & 1 \\ \text { vS-002 } & 4 \\ \text { vs-003 } & 5\end{array}$


A- $-S-S-S 1-C J R-003$, Revision 0

MERRICK

Engineers \& Architects
E ginestricgl calculation Sheet

CALi: No. V.S-00)
Date $3 / 9 / 96$ Sheet $\mid$ of Contract 30012131

By mem Chad 015

Subject:, CVDM - Vacuum Sxticen

BACKUP to PFD SPREADSHEE

InITIAL Pump down-NATEF Removed

\begin{tabular}{|l|l|l|}
\hline Revision & Date & By \\
\hline & & \\
\hline & & \\
\hline & & \\
\hline & & \\
\hline
\end{tabular}

Assure Same for Second Pumpdown

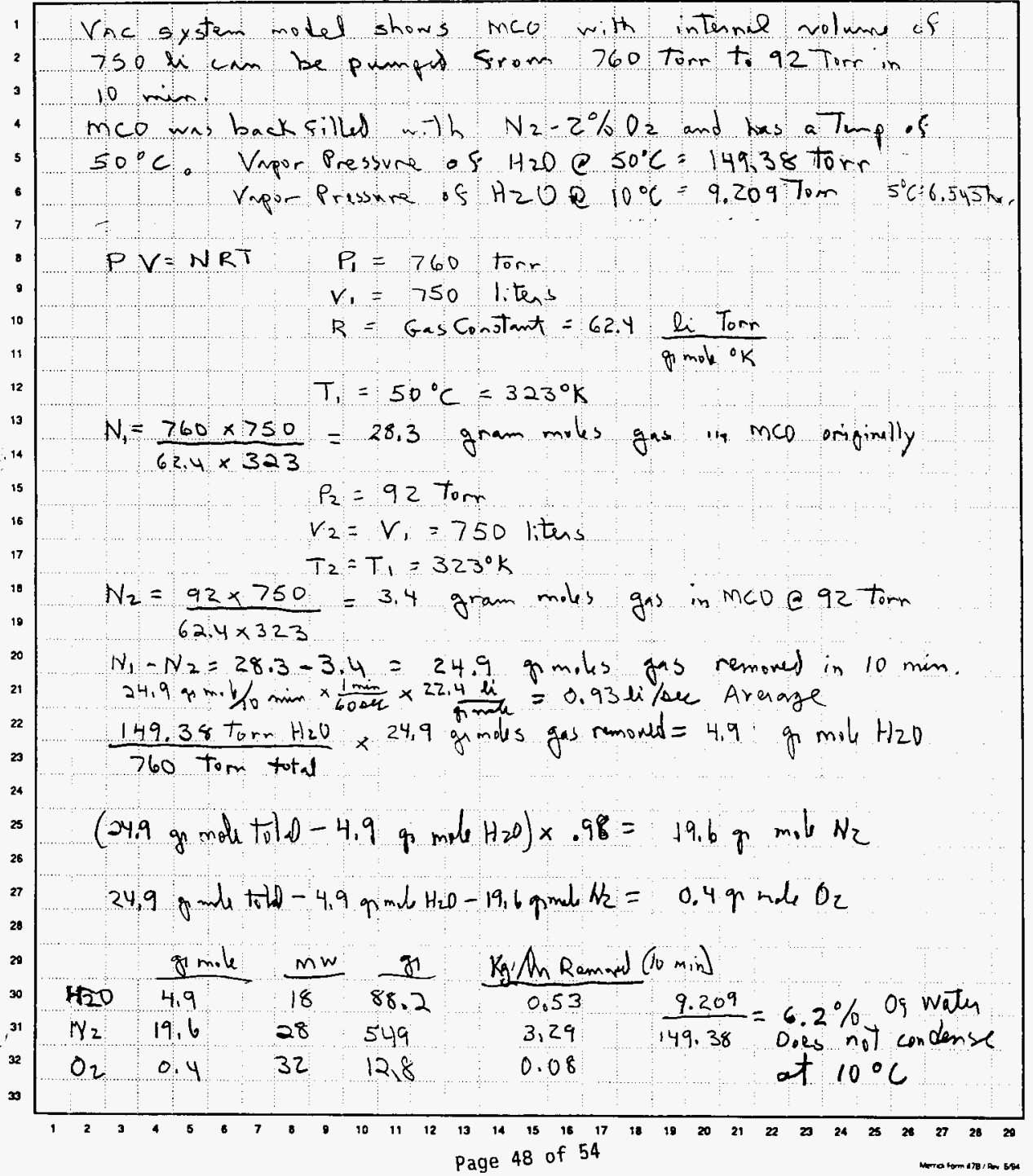


MERRICK

Engineers 6 Architects
Enginesring :aliulation She

CAss, Vio, Vio 2
Date $3 / 9 / 96$ Sheet 1 of 2 Contract 30012131 By msm Chid DAS

\begin{tabular}{|l|l|l|}
\hline Revision & Date & By \\
\hline & & \\
\hline & & \\
\hline & & \\
\hline & & \\
\hline
\end{tabular}

InItIAL Purge 3Heat Cyele - Water Bemoval

meo is backfilut with $N_{2}-2 \% O_{2}$, Temp is $50^{\circ} \mathrm{C}$, Pressurt is 760 Torr, gas is recyclet of 20 CFm nominil. Fon $55 \mathrm{~min}$ Vacurm systern model predicts 4 t/ $\mathrm{hn}$ wath remral rate.

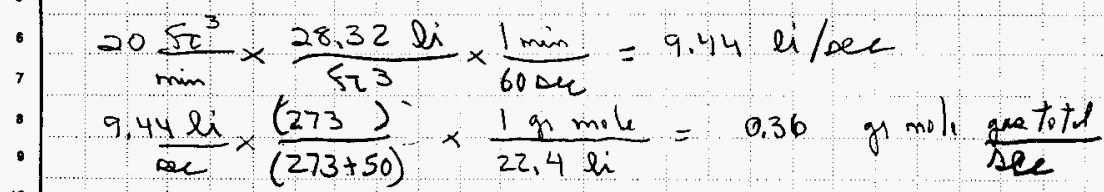

10

11

12
13

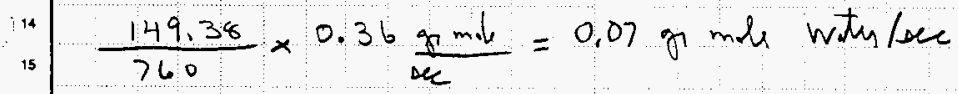

Wath Vupor Pressuree $50^{\circ} \mathrm{C}=149.38$ torn wath Vaph Pressuce $10^{\circ} \mathrm{C}=9.209$ Tour

$\left(0.36 \frac{\mathrm{gmol}}{22}\right.$ tolid $\left.-0.07 \mathrm{grmb} \mathrm{H}_{2} \mathrm{O}\right) .98=0.28 \mathrm{gpmlifec} \mathrm{H}_{2}$ $0.36-0.07-0.28=0.1 \mathrm{gma} / \mathrm{sec} \mathrm{O}_{2}$

2

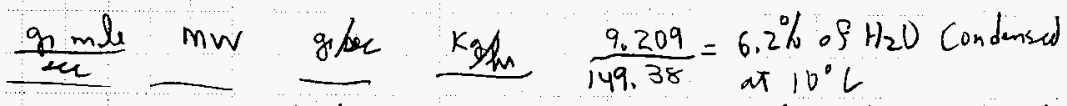

$\mathrm{H}_{2} \mathrm{O}$

$\mathrm{N}_{2}$ 18

$$
4.54 \frac{\mathrm{kg}}{\ln } \times(100-6.2)=4,3 \mathrm{~kg} / \mathrm{h}
$$

02 D. 01

$28 \quad 7,84 \quad 28,2$

$\begin{array}{lll}32 & 0,32 \quad 1,15\end{array}$

This indicates $4.3 \mathrm{~kg} / \mathrm{h}$ could be remored if the gas learing the cask were sturated, Tho model predict abut $1.8 \mathrm{Kg} / \mathrm{h}$.

$$
\frac{1.8}{4.3}=43 \% \text { sa Turation } \quad 1.8 \mathrm{~kg} / \mathrm{h} \times 1.062=1.91 \mathrm{~kg} / \mathrm{h} \text { * }\langle 9\rangle
$$

Page 49 of 54 


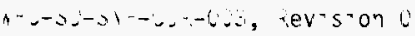

Eng nearing Calculation Sheet

[late $3 / 9 / 96$ sheet 2 of 2

MERRICK

CAL. N. N:S-0i2

Contract 300,2131

By mem Chad DS

Subject: CVDM-VACUUM SYstEm

BACKVP to PFD SPREKDSHEE?

INITIAL Purge 3 Heat Cycle - Water REMOVAE

\begin{tabular}{|l|l|l|}
\hline Revision & Date & By \\
\hline & & \\
\hline & & \\
\hline & & \\
\hline & & \\
\hline
\end{tabular}

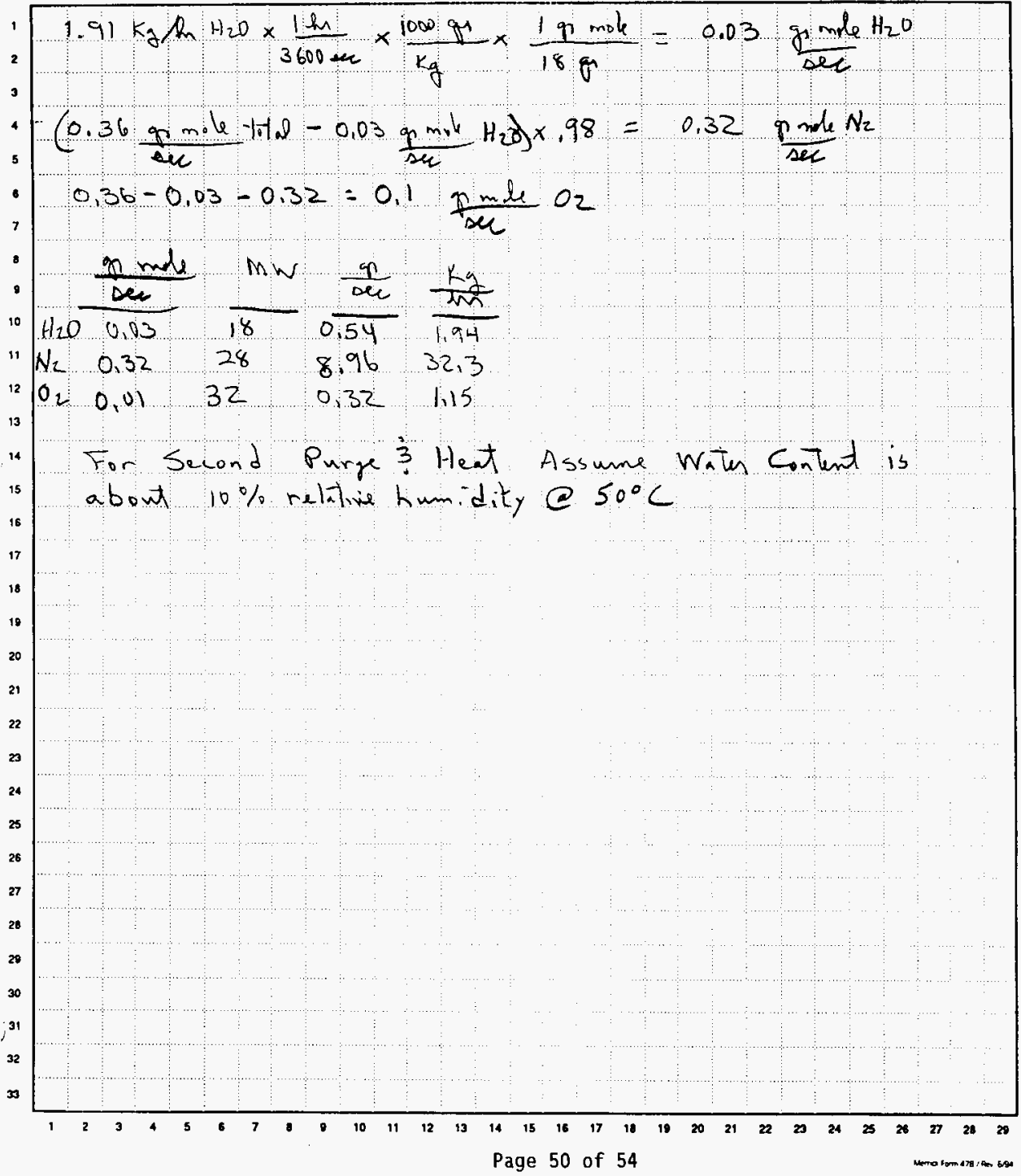




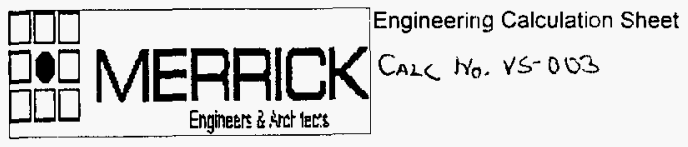

\begin{tabular}{ll} 
Date & $3 / 9 / 96$ Sheet 1 of 3 \\
\hline Contract & 30012131, Task 14 \\
\hline By MEM Chk'd M M \\
\hline
\end{tabular}

Subject: MCO Temperature Control System Heat Transfer Estimates

Cold Vacuum Drying Module - K Basins Spent Nuclear Fuel Removal Project - WHC

\begin{tabular}{|l|l|l|}
\hline Revision & Date & By \\
\hline & & \\
\hline & & \\
\hline & & \\
\hline & & \\
\hline
\end{tabular}

\section{Background}

Spent Nuclear Fuel from N-Reactor is stored in K-East and K-West basins in the 100 Area.

These elements will be cleaned and reracked into baskets that will then be loaded into a Multi Canister Overpack (MCO). The MCO will be in a shield cask and the assembly will be placed on a transporter and taken to the CVDM for vacuum drying. In the first step, the $\mathrm{MCO} /$ cask assembly will be heated by flowing hot water at $60 \mathrm{deg} \mathrm{C}$ into the annular space between the MCO and cask. The water flow rate will be $20 \mathrm{gpm}$.

Bart One - Calculate the amount of heat required to raise the cask, MCO, baskets, fuel elements, and remaining pool water to $50 \mathrm{deg} C$. Assume all components are at an initial temperatue of $20 \mathrm{deg} \mathrm{C}$. Information for cask, $\mathrm{MCO}$, baskets, fuel elements and water weights are taken from interface Control document for the MCO \& Cask/ransportation common information. This is also the source of surface area information.

\begin{tabular}{|c|c|c|c|c|}
\hline Delta $T=50$ & $\operatorname{deg} C-2$ & $\operatorname{deg} C=$ & $30 \operatorname{deg} C$ & $54 \operatorname{deg} F$ \\
\hline & & Weight & $\mathrm{SpHt}$ & Heat Rqd \\
\hline Componen & Material & lbs & $\mathrm{btu} / \mathrm{lb} F$ & btu \\
\hline Shield Plug & sst & 1,226 & 0.11 & 7,282 \\
\hline Baskets & sst & 750 & 0.11 & 4,455 \\
\hline Fuel Eleme & Uranium & 15,050 & 0.0279 & 22,674 \\
\hline Water & water & 1,112 & 1.00 & 60,048 \\
\hline $\mathrm{MCO}$ & sst & 1,954 & 0.11 & 11,607 \\
\hline Cask & sst & 37,750 & 0.11 & $\begin{array}{l}106,067 \text { btu to heat MCO \& contents } \\
224,235 \text { btu to heat cask }\end{array}$ \\
\hline
\end{tabular}

Part Two - Calculate the time required to heat the MCO/Cask assembly.

\section{Approach}

As a simplification of this complex heat transfer problem it will be assumed that heat is transferred from the water in the annulus to the cask at a rate of $300 \mathrm{btu} / \mathrm{hr}$ sq $\mathrm{ft}$ deg F. This is an engineering estimate based on turbulent flow in the annular area. The general formula is $Q=U A$ delta $T$. The cask temperature will be raised from 20 deg $C$ to nearly $60 \mathrm{deg} C$ so the average cask temperature is $40 \mathrm{deg} C$ which is $104 \mathrm{deg} F$. The average water temperature is assumed to be 50 deg $C$ which is $122 \mathrm{deg} F$. Thus the average delta $T$ is $18 \mathrm{deg} F$.

Cask length:

25.19 inches $=$

$2.10 \mathrm{ft}$

Cask Inner Dia: $\quad 160.5$ inches $=$

$13.38 \mathrm{ft}$

Surface Area $=$ length $X$ pi $X$ dia

$88.20 \mathrm{sq} f \mathrm{ft}$.

The heat flow to the cask will be the most rapid with the heat fiow to the MCO being much less. The heat flow to the MCO will be addressed first. 


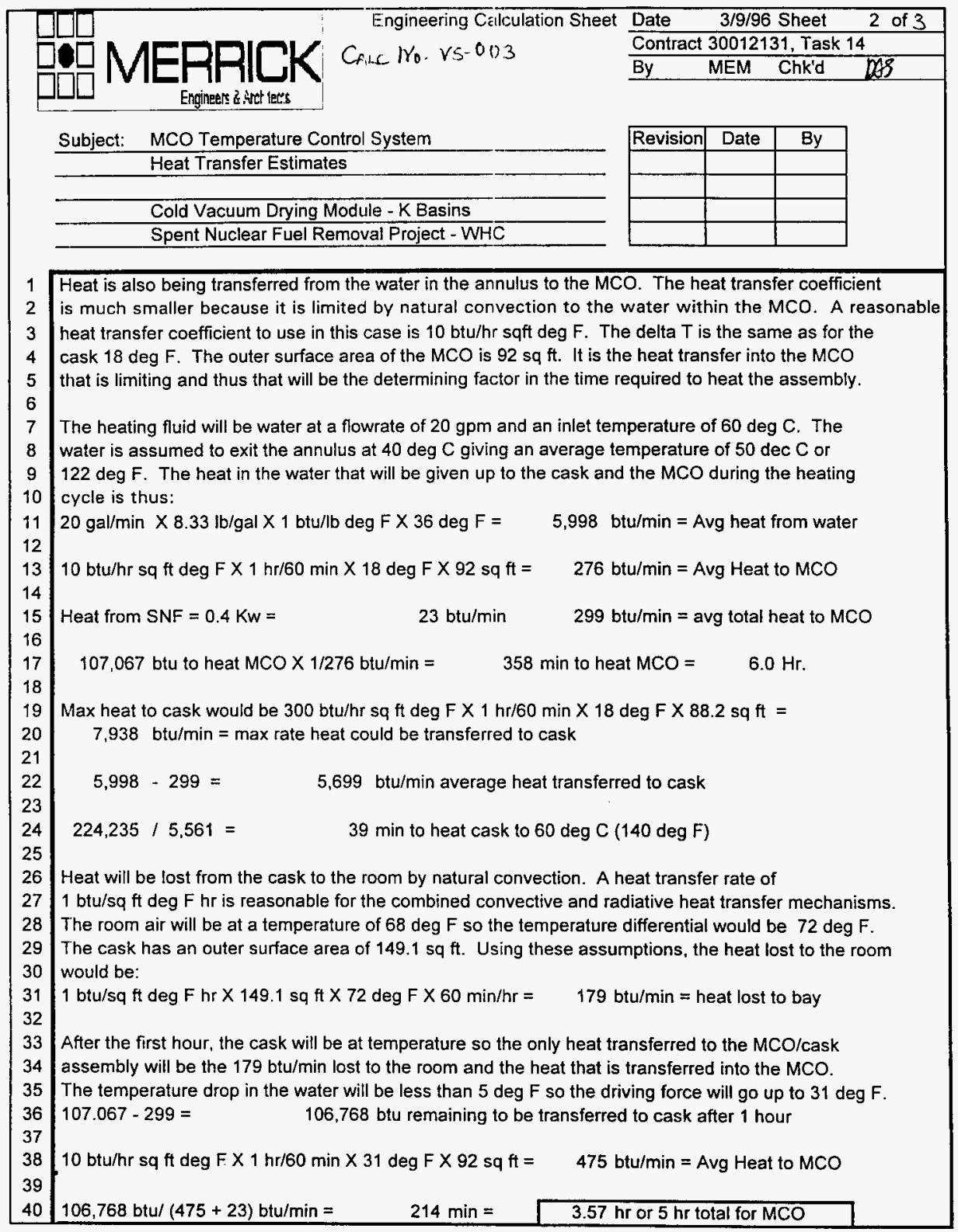




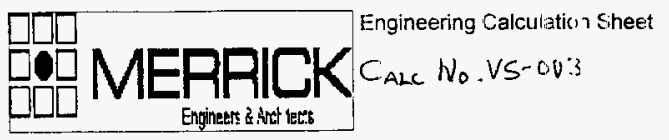

\begin{tabular}{ll} 
Date & $3 / 9 / 96$ Sheet 3 of 3 \\
\hline Contract & 30012131, Task 14 \\
\hline By & MEM Chk'd DS \\
\hline
\end{tabular}

Subject: MCO Temperature Control System Heat Transfer Estimates

Cold Vacuum Drying Module - K Basins Spent Nuclear Fuel Removal Project - WHC

\begin{tabular}{|l|l|l|}
\hline Revision & Date & By \\
\hline & & \\
\hline & & \\
\hline & & \\
\hline & & \\
\hline
\end{tabular}

Part Three - Calculate the amount of time it will take to cool the cask and MCO from its hot condition to room temperature. The cask will be at $60 \mathrm{deg} C$ while the MCO will be at $50 \mathrm{deg} C$. Once again the cask will cool down much more rapidly than the MCO. The heat transfer coefficient to the cask will be about $300 \mathrm{btu} / \mathrm{sq} \mathrm{ft} \mathrm{hr}$ deg $\mathrm{F}$. The overall heat transfer coefficient for the $\mathrm{MCO}$ will be about $4 \mathrm{btu} / \mathrm{sq} \mathrm{ft} \mathrm{hr} \operatorname{deg} \mathrm{F}$. After the cask has cooled down, the water temperature will . not rise appreciably as it cools the MCO so an average water temperature of $12 \mathrm{deg} C$ can be safely assumed. The cooling water flowrate will be $20 \mathrm{gpm}$.

Cask Weight: 37,750 lbs

Initial Temp: 140 deg $F$

Final Temp: $\quad 45 \operatorname{deg} \mathrm{F}$

Delta Temp: $\quad 95 \operatorname{deg} \mathbf{F}$

Sp Ht: $\quad 0.11$ btu/lb deg F

Heat Rem.: 394,488 btu

TWS Temp: $\quad 45 \mathrm{deg} F$

TWR Temp: $\quad 68 \operatorname{deg} F$

Delta Temp: $\quad 23 \operatorname{deg} F$

Flowrate: $\quad 20 \mathrm{gpm}$

Mass Flow: $\quad 167 \mathrm{lb} / \mathrm{min}$

Heat Tran: $3,832 \mathrm{btu} / \mathrm{min}$

103 min to cool cask

Heat transferred by cooling water in $6 \mathrm{hr}$ $3,832 \mathrm{btu} / \mathrm{min}$ $360 \mathrm{~min} / 6 \mathrm{hr}$ $1.38 \mathrm{E}+06 \mathrm{btu} / 6 \mathrm{hr}$

This is wels in excess of what is required to cool both the cask and the MCO to room temp.

$$
\begin{array}{rc}
\text { MCO Inital Temp: } & 122 \mathrm{deg} F \\
\text { MCO Final Temp: } & 68 \mathrm{deg} F \\
\text { Delta Temp: } & 54 \mathrm{deg} F \\
\text { Plug Wt: } & 1,226 \mathrm{lb} \\
\text { Basket W:: } & 750 \mathrm{lb} \\
\text { MCO Wt: } & 1,954 \mathrm{lb} \\
\text { Total SST WT: } & 3,930 \mathrm{lb} \\
\text { SST sp ht: } & 0.11 \mathrm{btu} / \mathrm{lb} \text { deg F } \\
\text { Heat to SST } & 23,344 \mathrm{btu} \\
\text { SNF Wt: } & 15,050 \mathrm{bb} \\
\text { SNF sp ht: } & 0,0279 \mathrm{btu} / \mathrm{lb} \mathrm{deg} \mathrm{F} \\
\text { Heat to SNF: } & 22,674 \mathrm{btu} \\
\text { Total Heat to MCO: } & 46,019 \mathrm{btu} \\
\text { Avg H2O Temp: } & 54 \mathrm{deg} F \\
\text { Driving Temp: } & 41 \mathrm{deg} \mathrm{F} \\
\text { Transfer Coefficient: } & 2 \mathrm{btu} / \mathrm{sq} \mathrm{ft} \mathrm{tb} \mathrm{deg} \mathrm{F} \\
\text { Area: } & 92 \mathrm{sq} \mathrm{ft} \\
\text { Heat Transferred: } & 7,544 \mathrm{btu} / \mathrm{hr} \\
\hline \text { Time to Cool MCO: } & 6 \mathrm{hr} \\
\hline
\end{array}
$$

$6 \mathrm{hr}$


WHC-SD-SNF-CDR-003, Revision 0:

Page 54 of 54 . 


\section{DISTRIBUTION SHEET}

\begin{tabular}{|c|c|c|c|c|c|}
\hline \multirow{2}{*}{$\begin{array}{l}\text { To } \\
\text { Distribution }\end{array}$} & \multirow{2}{*}{\multicolumn{3}{|c|}{$\begin{array}{l}\text { From } \\
\text { CVD Subproject }\end{array}$}} & \multicolumn{2}{|l|}{ Page 1 of 1} \\
\hline & & & & \multicolumn{2}{|c|}{ Date 5-02-96 } \\
\hline \multirow{2}{*}{\multicolumn{4}{|c|}{$\begin{array}{l}\text { Project Title/Work Order } \\
\text { Cold Vacuum Drying System Conceptual Design Report } \\
\text { WHC-SD-SNF-CDR-003 REV.0 }\end{array}$}} & \multirow{2}{*}{\multicolumn{2}{|c|}{$\begin{array}{ll}\text { EDT No. } & 607668 \\
\text { ECN No. } & \text { N/A }\end{array}$}} \\
\hline & & & & & \\
\hline Name & MSIN & $\begin{array}{l}\text { Text } \\
\text { With All } \\
\text { Attach. }\end{array}$ & Text Only & $\begin{array}{c}\text { Attach./ } \\
\text { Appendix } \\
\text { Only }\end{array}$ & $\begin{array}{c}\text { EDT/ECN } \\
\text { Only }\end{array}$ \\
\hline $\begin{array}{l}\text { JJ Irvin } \\
\text { WD Galio } \\
\text { BR Fillion } \\
\text { TD Merkling } \\
\text { JE Turnbaugh } \\
\text { CA Thompson } \\
\text { GD Trenchard } \\
\text { JR Frederickson } \\
\text { FW Bradshaw } \\
\text { CR Miska } \\
\text { AT Kee } \\
\text { LH Goldmann } \\
\text { EJ Shen } \\
\text { CVD Projects Files }\end{array}$ & $\begin{array}{l}\text { R3-86 } \\
\text { R3-85 } \\
\text { E6-03 } \\
\text { R3-09 } \\
\text { H6-21 } \\
\text { R3-85 } \\
\text { S7-41 } \\
\text { R3-86 } \\
\text { R3-85 } \\
\text { R3-86 } \\
\text { R3-86 } \\
\text { R3-86 } \\
\text { R3-86 } \\
\text { R3-11 }\end{array}$ & $\begin{array}{l}x \\
x \\
x \\
x \\
x \\
x \\
x \\
x \\
x \\
x \\
x \\
x \\
x \\
x\end{array}$ & & - & \\
\hline Central Files & A3-88 & 2 & & & \\
\hline
\end{tabular}

